US Army Corps of Engineers Engineer Research and Development Center

Strategic Environmental Research and Development Program

\title{
Effectiveness of Selected Native Plants as Competitors with Non-indigenous and Invasive Knapweed and Thistle Species
}

Thomas Smith and Ann L. Hild

September 2011

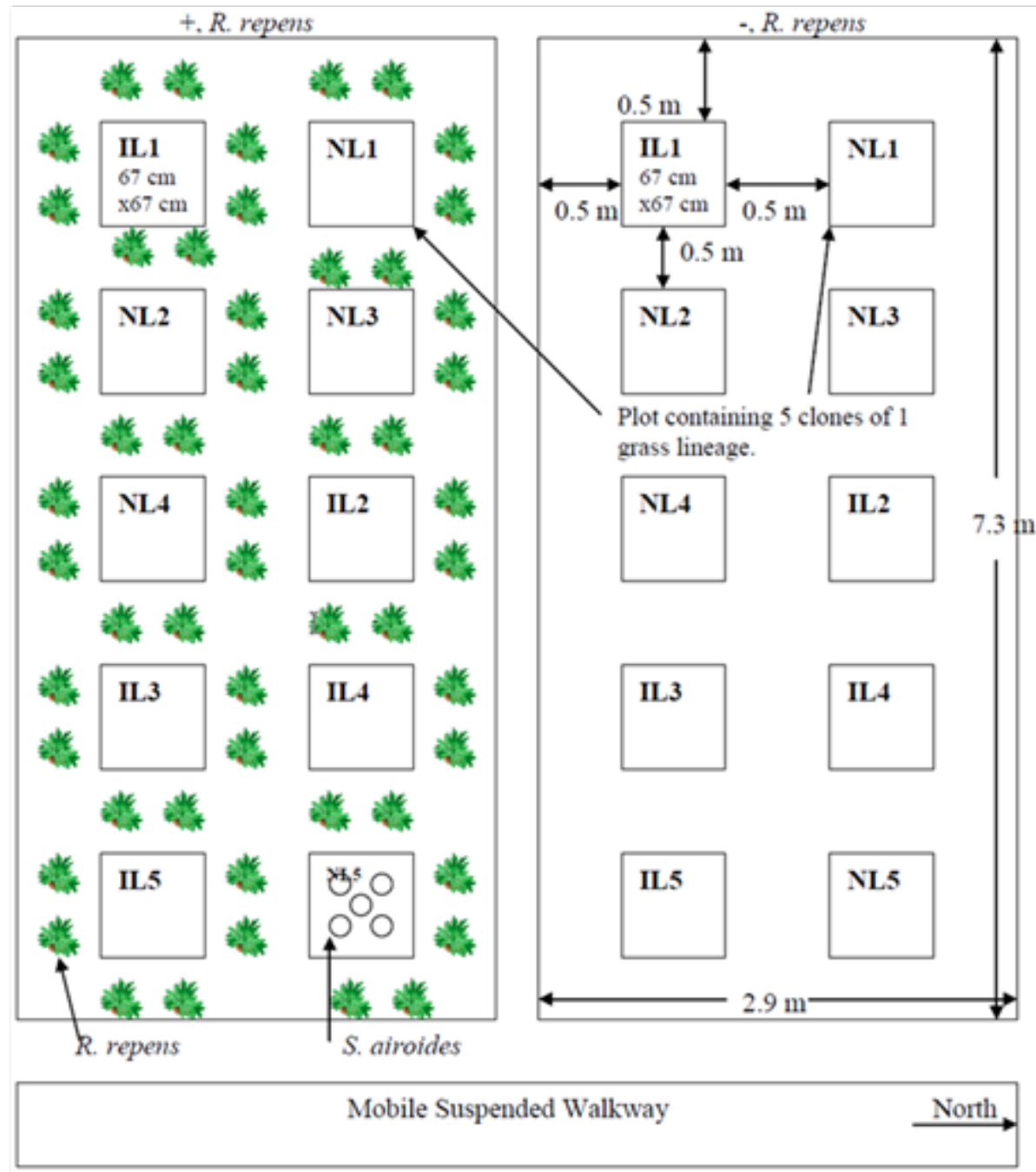

Layout of controlled experiment to test lineages of Sporobolus airoides with and without competition from Rhaponticum repens. 


\section{REPORT DOCUMENTATION PAGE}

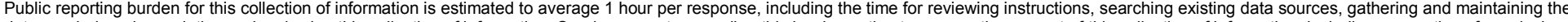

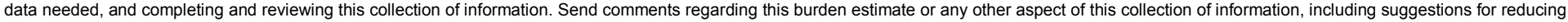

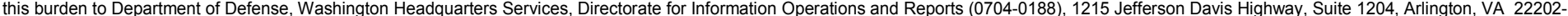

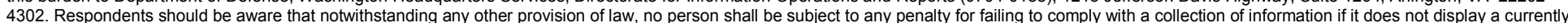
valid OMB control number. PLEASE DO NOT RETURN YOUR FORM TO THE ABOVE ADDRESS.

\begin{tabular}{l|l} 
valid OMB control number. PLEASE DO NOT RETURN YOUR FORM TO THE ABOVE ADDRESS. \\
\hline 1. REPORT DATE (DD-MM-YYYY)
\end{tabular}

\begin{tabular}{|c|c|}
\hline $\begin{array}{c}\text { 1. REPORT DATE (DD-MM-YYYY) } \\
26-09-2011\end{array}$ & 2. REPORT TYPE \\
Final
\end{tabular}

4. TITLE AND SUBTITLE

Final

Effectiveness of Selected Native Plants as Competitors with Non-indigenous and Invasive Knapweed and

Thistle Species

3. DATES COVERED (From - To)

5a. CONTRACT NUMBER

b. GRANT NUMBER

5c. PROGRAM ELEMENT

6. AUTHOR(S)

Thomas Smith and Ann L. Hild

5d. PROJECT NUMBER

5e. TASK NUMBER

5f. WORK UNIT NUMBER

7. PERFORMING ORGANIZATION NAME(S) AND ADDRESS(ES)

US Army Engineer Research and Development Center (ERDC)

Construction Engineering Research Laboratory (CERL)

PO Box 9005,

Champaign, IL 61826-9005

8. PERFORMING ORGANIZATION REPORT NUMBER

ERDC/CERL TR-11-28

9. SPONSORING / MONITORING AGENCY NAME(S) AND ADDRESS(ES)

10. SPONSOR/MONITOR'S ACRONYM(S)

Strategic Environmental Research and Development Program SERDP

901 North Stuart Street, Suite 303

Arlington, VA 22203

\section{SPONSOR/MONITOR'S REPORT} NUMBER(S)

Environmental Restoration Project RC 1389

\section{DISTRIBUTION / AVAILABILITY STATEMENT}

Approved for public release; distribution is unlimited.

\section{SUPPLEMENTARY NOTES}

\section{ABSTRACT}

This work examined the response of native grass populations to long-term presence of non-indigenous invasive plant species (NIPS). Two native grass species common to arid and semi-arid rangelands were identified (alkalai sacaton [Sporobolus airoides] and needle and thread grass [Hesperostipa comata]) as remnants of native communities subjected to NIPS Russian knapweed [Rhaponticum repens]). Maternal grass individuals were collected to examine the influence of the invasions on population genetics and phenology of the two grass species. In controlled greenhouse settings and field plantings, this work examined the growth, seed production, and germination of seedlings of the two grasses in competition with Russian knapweed and NIPS Canada thistle [Cirsium arvense]; and genetic variability of the two grasses via amplified fragment length polymorphism and Inter-Simple Sequence Repeat analyses. Results showed that maternal lines of the grasses demonstrate evidence of natural selection via the presence of the invaders. Continued work was recommended to obtain superior seed sources for native species to target the tradeoffs between phenotypic plasticity and increased vegetative growth, to develop wild seed collection protocols and production techniques so that native plants may be used to restore degraded areas and to reduce the chances of future exotic invasion.

\section{SUBJECT TERMS}

SERDP, plant communities, invasive plants, native grasses, indigenous plants

16. SECURITY CLASSIFICATION OF:

\section{a. REPORT}

Unclassified

\section{b. ABSTRACT}

Unclassified
17. LIMITATION

c. THIS PAGE

Unclassified
OF ABSTRACT

SAR
18. NUMBER OF PAGES

152 19a. NAME OF RESPONSIBLE PERSON

19b. TELEPHONE NUMBER (include area code) 


\section{Effectiveness of Selected Native Plants as Competitors with Non-indigenous and Invasive Knapweed and Thistle Species}

Thomas Smith

Construction Engineering Research Laboratory (CERL)

US Army Engineer Research and Development Center

2902 Newmark Dr.

Champaign, IL 61822-1076

Ann L. Hild

University of Wyoming

Final Report

Approved for public release; distribution is unlimited.

Prepared for Headquarters, US Army Corps of Engineers

Washington, DC 20314-1000 


\section{Abstract}

Objectives. This research is aimed at the problems of managing and controlling the spread of non-indigenous invasive plant species (NIPS) on DoD and other lands. This work examined the response of native grass populations to long-term presence of NIPS. As remnants of native communities subjected to the NIPS Russian knapweed (Rhaponticum repens), two native grass species common to western DoD lands were identified, alkalai sacaton and needle and thread grass. Specific objectives of this work were to: identify native grasses that may be more resilient to NIPS; to identify attributes of the experienced native plant populations that contribute to resilience and resistance to the competitive effects of NIPS; to identify genetic markers and phenotypic traits that confer superior competitive ability; and to determine if those phenotypic traits are transmitted to subsequent generations of the native grasses.

Technical Approach. This study was designed to test competitive abilities of native grass populations differing in NIPS invasion history (invaded and non-invaded). Maternal grass individuals were collected to examine the influence of the invasions on population genetics and phenology of the two species. In controlled laboratory and field settings, this research examined the growth, seed production, and germination of the two grasses in competition with Russian knapweed and the NIPS Canada thistle and genetic variability of the two grasses via amplified fragment length polymorphism and Inter-Simple Sequence Repeat analyses.

Results. The results of this research provides multiple lines of evidence that lineages of alkali sacaton, and to a lesser degree needle and thread, collected from within (IN) invaded sites of Russian knapweed, differ from lineages collected outside of (OUT) invaded sites. Indications are that these differences translate into differences in competitive ability. This research also provides evidence that differences in competitive ability toward the knapweed invader may also apply to other NIPS, in this instance Canada thistle. This research also provides evidence of differences in competitive performance of differing IN and OUT genotypes. Because needle and thread was not as competitive with Canada thistle, our results agree with other published research that warm-season plants have a competitive advantage over cool season species. 
We developed a Biological Screening Process to assist managers with selecting promising genotypes. This research developed an effective way to comparatively evaluate the performance of differing and disparate genotypes and to select for the most promising genotypes for further and expanded study evaluation.

Benefits. The impacts of NIPS on native plant populations and their potential use for restoration is poorly understood. However, native grasses that remain following long-term exposure to invading species may better tolerate weed presence than nonexposed natives. Such invasion experienced native plants can be more competitive with invaders but are often excluded as restoration materials. Planting native species with invasive history may augment biodiversity and in turn, increase native ecosystem resistance and resilience to invasion. Native seed collection may be enhanced by including invasion-experienced native plant populations. The native seed production industry can use this research to develop seed collection protocols to included remnant native populations and production techniques that ensure competitive traits are not being lost from native accessions.

DISCLAIMER: The contents of this report are not to be used for advertising, publication, or promotional purposes. Citation of trade names does not constitute an official endorsement or approval of the use of such commercial products. All product names and trademarks cited are the property of their respective owners. The findings of this report are not to be construed as an official Department of the Army position unless so designated by other authorized documents. 


\title{
Table of Contents
}

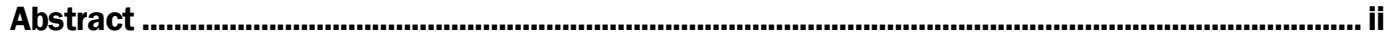

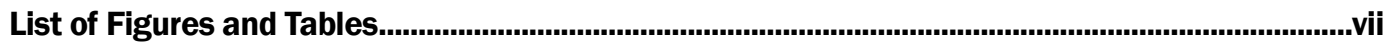

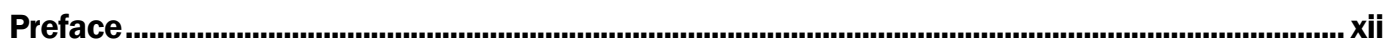

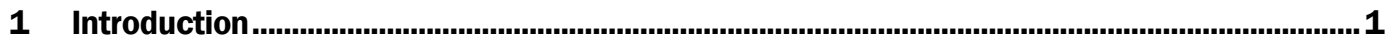

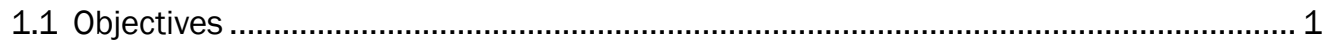

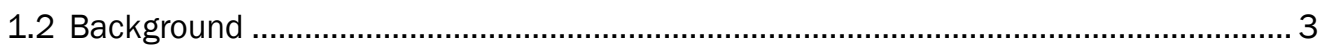

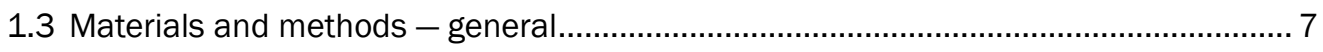

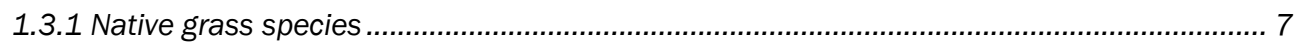

1.3.2 Invasive species and native species maternal site locations ............................................ 8

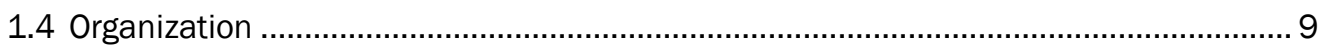

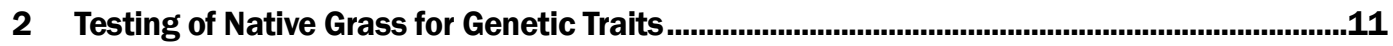

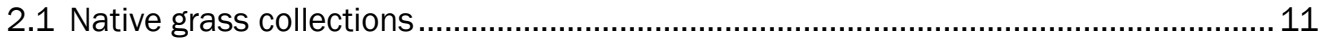

2.1.1 Experimental design ............................................................................................. 11

2.1.2 Experimental analysis ...................................................................................................... 12

2.2 Testing genetic variation of invaded and non-invaded Sporobolus airoides populations after two generations of greenhouse seed increase............................... 14

2.2.1 Experimental design ....................................................................................................... 14

2.2.2 Experimental analysis.......................................................................................... 15

\section{Greenhouse Testing of Native Grass Collections and Seedlings for Phenotypic and}

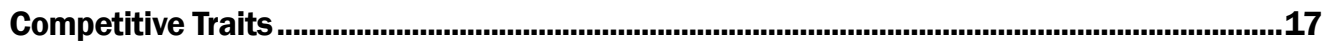

3.1 Testing for competition with Russian Knapweed .................................................. 17

3.1.1 Experimental design .................................................................................................. 17

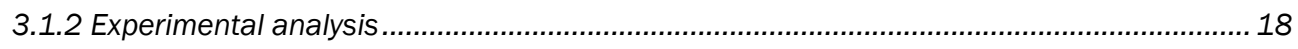

3.2 Testing for competition with Canada Thistle............................................................. 19

3.2.1 Experimental design .............................................................................................. 19

3.2.2 Experimental analysis........................................................................................... 19

3.3 Testing for native grass competition with Canada Thistle using the Relative

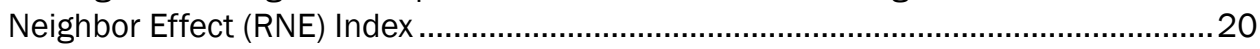

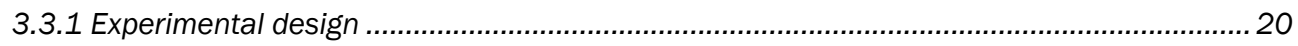

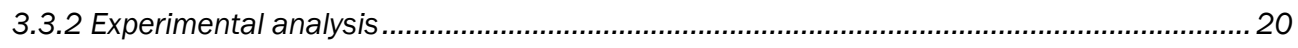

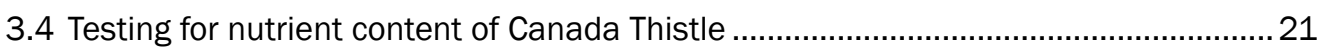

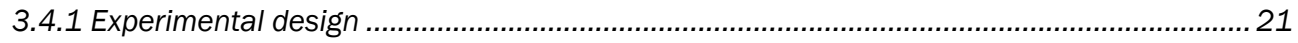

3.4.2 Experimental analysis............................................................................................. 22

3.5 Testing for competition with Canada Thistle under herbivory by Stem-Mining

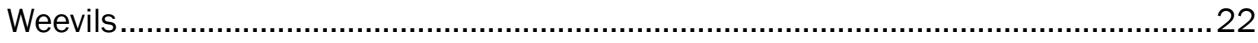

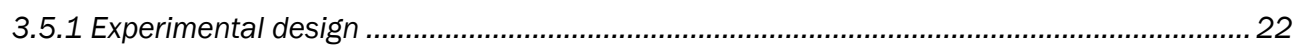

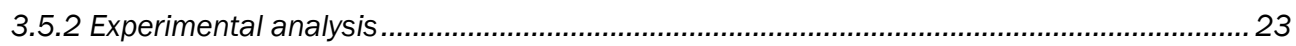

3.6 Testing for phenotype of first and second generation seedlings -- plant traits in response to long-term exposure to Rhaponticum repens 


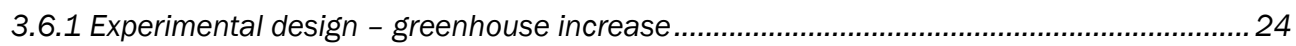

3.6.2 Experimental design - field increase ............................................................................. 25

3.6.3 Experimental Analysis - greenhouse increase .................................................................. 28

3.6.4 Experimental Analysis - germination and seedling root growth of maternal

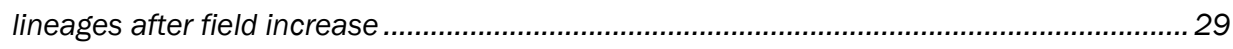

3.7 Environmental Simulation Laboratory (ESL) testing............................................... 31

3.7.1 Experimental design - environmental simulation laboratory............................................ 31

3.7.2 Experimental analysis - environmental simulation laboratory ........................................ 34

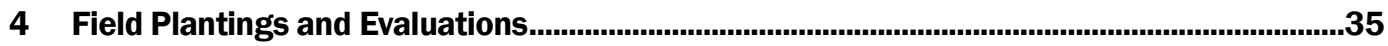

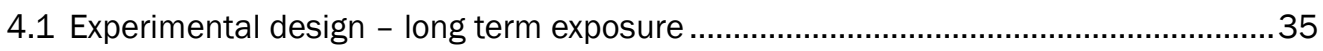

4.1.1 Collection of plant materials - long term exposure ............................................................. 35

4.1.2 Site description and field installation - long term exposure .............................................. 35

4.2 Experimental design - resistance and resilience ................................................. 37

4.2.1 Collection of plant materials - resistance and resilience ................................................... 37

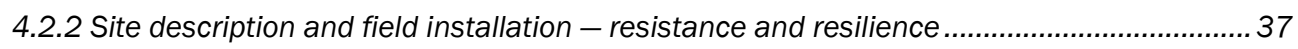

4.3 Experimental analysis - long term exposure...................................................... 41

4.3.1 Tiller production - genets................................................................................................. 41

4.3.2 Genotype and community of origin assessment ............................................................. 41

4.4 Experimental analysis - resistance and resilience.................................................42

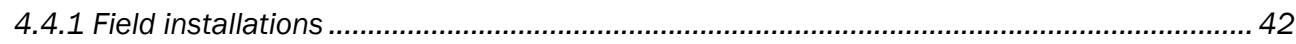

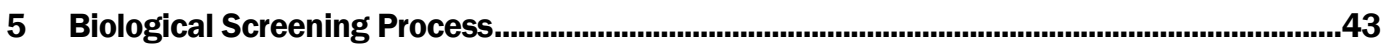

6 Results and Discussion ......................................................................................................4

6.1 Testing of native grass collections for genetic traits ...........................................44

6.1.1 Hesperostipa comata - maternal tissue ..........................................................................4

6.1.2 Sporobolus airoides - maternal tissue............................................................................. 44

6.1.3 Maternal plants genetic traits discussion........................................................................... 47

6.2 Results of testing genetic variation of invaded and non-invaded Sporobolus airoides populations after two generations of greenhouse seed increase ................48

6.3 greenhouse testing of native grass collections and seedlings for phenotypic

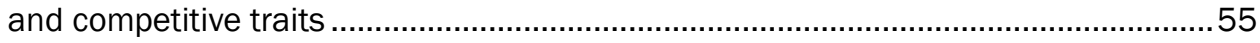

6.3.1 Results of testing of native collections and seedlings for phenotypic and competitive traits in response to Russian knapweed.

6.3.2 Results of testing of native collections and seedlings for phenotypic and competitive traits response in response to Canada thistle.

6.3.3 Results of testing for native grass competition with Canada thistle using the

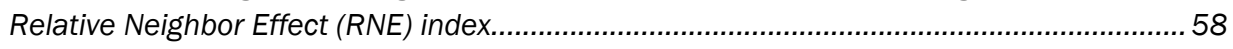

6.3.4 Results of testing for nutrient content of Canada thistle....................................................... 59

6.3.5 Results of testing for competition with Canada Thistle under herbivory by stemmining weevils.

6.3.6 Testing for phenotype of first and second generation seedlings - plant traits in response to long-term exposure to Rhaponticum repens ..................................................6 66

6.4 Environmental Simulation Laboratory .................................................................. 82

6.4.1 Above-ground production of Sporobolus airoides in the ESL ............................................ 82

6.4.2 Germination and seedling establishment of Sporobolus airoides in the ESL ..................... 84

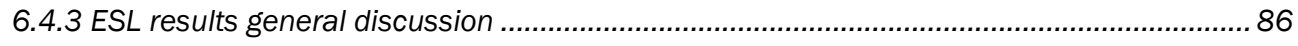


6.5 Field plantings - plant traits in response to long-term exposure to

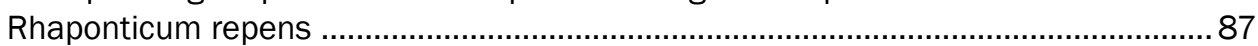

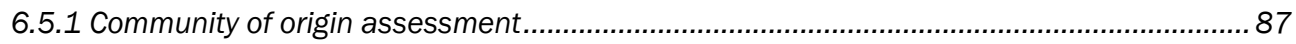

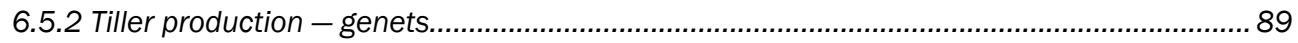

6.5.3 Results of testing the effect of long-term exposure to Rhaponticum repens on native populations - general discussion ........................................................................... 91

6.6 Field plantings - resistance and resilience............................................................. 91

6.6.1 Growth of Sporobolus airoides in field experiments ....................................................... 91

6.6.2 Establishment of Sporobolus airoides and invasive species in field experiments.............. 92

6.6.3 Field planting and ESL resistance and resilience results -- general discussion.................. 97

6.7 How to select candidate genotypes from the invaded and non-invaded sub-

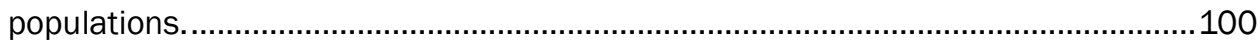

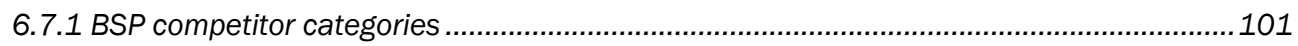

7 Conclusions and Implications for Future Research and Implementation..........................110

7.1 Summary of this research on native plant responses to invasions .........................110

7.2 Conclusions and research recommendations..................................................111

7.3 Implications for practice .............................................................................. 119

Literature Cited .................................................................................................................................120

Acronyms and Abbreviations ...............................................................................................................131

Appendix A: List of Scientific and Technical Publications...............................................................133

Appendix B: Other Supporting Materials: Patents, Protocols, Scientific Awards or Honors Graduate Students and Post-Doctoral Researchers Educated on this

Project .......................................................................................................................................... 137

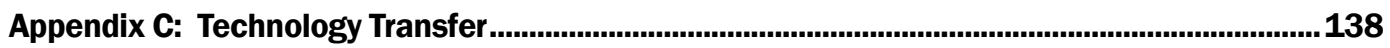

Report Documentation Page ..................................................................................................139 


\section{List of Figures and Tables}

\section{Figures}

1 Plant community and collection locations.

2 Layout of controlled experiment to test lineages of Sporobolus airoides with and without competition from Rhaponticum repens. Experiment was conducted in University of Wyoming Environmental Simulation Laboratory. Plots containing five identical clones of each invaded and non-invaded lineages were randomly placed into both weed treatments. Experimental design was a split plot arrangement. Plants represent R. repens planted around $\mathrm{S}$. airoides plots for one pit. Depth is $2.14 \mathrm{~m} /$ pit. $\mathrm{N}=$ non-invaded, I = invaded, Lines 1-5 = lineages. Identical lines were planted in the two sides of the ESL, i.e., IL3 is genetically identical in both weed treatments

3 Position of individual grass of Sporobolus airoides clones, seed bags, and seedling grid in plots. Each plot contains five transplanted clones, four seed bags, and a seedling establishment matrix.

4 Field plot layout at study site near Crowheart, WY with 20 transplant grids, 10 undisturbed plots and 10 disturbed plots spaced a minimum of $0.5 \mathrm{~m}$. Entire area is contained within invasion. Separate fence for disturbance plots were made due to lack of similar invasion area within main fence. Disturbance and main areas are equal density invasion of Rhaponticum repens. The same layout is also installed at FEWAFB, WY in an invasion of Cirsium arvense. $D=$ disturbed, $\mathrm{U}=$ undisturbed, $\mathrm{I}=$ invaded, and $\mathrm{N}=$ non-invaded.

5 Dendogram based on Reynold's genetic distances, constructed for invaded (IN) and non-invaded (OUT) Sporobolus airoides populations by maternal location (BGV, MONO, GB). The S. airoides cultivar obtained from Manderson, WY, and maternal locations are; Naturita, CO (BGV), Laramie, WY (MONO) and Greybull, WY (GB). Support values for each node are out of 1000 bootstraps

6 Number of tillers and number of leaves produced by Sporobolus airoides seedlings from communities invaded by Rhaponticum repens and non-invaded communities grown with and without $\mathrm{R}$. repens competition in a greenhouse experiment. Values are least squares means and SE.

7 Competitive response of Sporobolus airoides from three different locations and two communities when grown with Rhaponticum repens under greenhouse conditions. Values represent means $\pm 1 \mathrm{SE}$

8 Sporobolus airoides maternal genotype - Rhaponticum repens biomass production. Dark squares represent average production of S. airoides biomass relative to control plants (grown alone) of the same maternal genotype. Filled columns represent average biomass production of $R$. repens grown with the corresponding S. airoides maternal genotype. Black column is mean biomass of R. repens grown alone.

9 Growth (tiller number) of experienced and inexperienced grasses (Sporobolus airoides [a] and Hesperostipa comata [b]) with and without Cirsium arvense neighbors on eight sampling dates. Treatments are: experienced genets alone (squares), inexperienced genets alone (circles), experienced genets + C. arvense (triangles) and inexperienced genets $+\mathrm{C}$. arvense (diamonds). Within a date, treatments with the same letter do not differ $(p<0.05)$. 
10 Biomass of experienced and inexperienced Sporobolus airoides (a) and Hesperostipa comata (b) grass genets grown alone and with Cirsium arvense. Columns in the figures are grass biomass (solid columns) and biomass of $\mathrm{C}$. arvense (hatched columns). Means without the same letter differ (a. S. airoides $P=0.0002 ;$ b. H. comata $P=0.0161$; and C. arvense $P=0.0017$ ) ...

11 Relative Neighbor Effect (RNE) for interactions of Cirsium arvense (Ciar) with experienced (exp) and inexperienced (inexper) native grasses (Heco $=$ Hesperostipa comata, Spai $=$ Sporobolus airoides). Larger RNE values suggest greater impact of neighbors. Across all RNE values, means with the same letter do not differ $(P=0.03)$

12 Aboveground and belowground biomass of Cirsium arvense. $(p<0.01 ; d f=6)$ in competition and weevil herbivory treatments $(T=$ Canada thistle, N\&T = Needleand-thread grass, AS=Alkali sacaton (Sporobolus airoides) grass, $L=$ the weevil, Hadroplontus litura (syn. Ceutorhynchus litura).

13 Relative growth per week (mean \pm SE) for first (G1) and second (G2) generations of Sporobolus airoides populations from invaded (IN) and non-invaded (OUT) Rhaponticum repens areas. Probabilities (Proc GLM) for interactions (population*generation) are reported for each trait. Cultivar means provided for visual comparison (not included in GLM analysis). Within a population (IN or OUT), generation means with the same upper case letter do not differ. Within a generation (G1 or G2), population means with the same lower case letter do not differ.

14 Reproductive means ( $\pm \mathrm{SE}$ ) for first (G1) and second (G2) generations of Sporobolus airoides populations from invaded (IN) and non-invaded (OUT) Rhaponticum repens areas. Probabilities (Proc GLM) for interactions (population*generation) are reported for each trait. Germination rate is out of five seeds planted per pot. Within a population (IN or OUT), generation means with the same upper case letter do not differ. Within a generation (G1 or G2), population means with the same lower case letter do not differ

15 Germination (\%) of Sporobolus airoides by sample day profile plot for a) 2006 $(P=0.514)$ and b) $2007(p<0.001)$ seed. Significant differences exist on sample days two (Bonferonni $\mathrm{t}(66)=4.43, \mathrm{p}<0.001$ ), and four (Bonferonni t $(66)=4.70, p<0.001$ ). Solid line represents the commercial cultivar (included for comparison). Error bars represent \pm 1 standard error

16 IN and OUT Sporobolus airoides maternal lineage overlap between: (a) 2006 $(p=0.023)$ and (b) $2007(P=0.004)$ seed source years. Solid line represents the commercial cultivar (included for comparison). Error bars represent \pm 1 standard error...

17 Germination (\%) of Sporobolus airoides by sample day profile plot for a) 2006 seed with 18 months of after-ripening and b) 2006 seed with 26 months of after-ripening. Error bars represent \pm 1 standard error

18 Germination (\%) of Sporobolus airoides by sample day profile plot for a) 2007 seed with 6 months of after-ripening and b) 2007 seed with 14 months of afterripening. Error bars represent \pm 1 standard error

19 Profile plot for cumulative Sporobolus airoides root growth by IN and OUT positions for a) $2006(P=0.238)$ and $b) 2007$ seed $(P=0.380)$. Solid green line represents the commercial cultivar (included for comparison). Error bars represent \pm 1 standard error 
20 Length of longest leaf for Sporobolus airoides $(\mathrm{cm})$ within two weed treatments $(+,-)$ on 14 sampling dates grown within a controlled environment (University of Wyoming Environmental Simulation Laboratory). Means with the same letters do not differ, FLSD, 0.05.

21 Length of longest leaf for Sporobolus airoides $(\mathrm{cm})$ invaded and non-invaded lineages on 14 sampling dates grown within a controlled environment (University of Wyoming Environmental Simulation Laboratory). Means with the same letters do not differ, FLSD, 0.05

22 Inflorescence production of Sporobolus airoides with and without the presence of Raponticum repens competitors (+, -) on 14 sampling dates grown within a controlled environment (University of Wyoming Environmental Simulation Laboratory). Means with the same lowercase letters do not differ, FLSD, 0.05. Measurements between the dates of 21 January 2010 and 2 June 2010 are zero.

23 Sporobolus airoides germination (cumulative \%) from a) non-invaded lineage history and b) invaded lineage history grown with and without competition from Rhaponticum repens in controlled environment (University of Wyoming Environmental Simulation Laboratory). Three way interaction of weed $\mathrm{x}$ history $\mathrm{x}$ date $(p=0.0142)$. Within a date and lineage history, means with the same lowercase letters do not differ, FLSD, 0.05. Germination of non-invaded lines did not differ between weed treatments (part $a$, weed treatment $p=0.2847$ ).

24 Relative tiller production (a), change in basal area (b), and overall performance (c) of Hesperostipa comata and Sporobolus airoides populations from communities invaded by Rhaponticum repens and non-invaded communities when transplanted into two infestations of R. repens. Solid bars represent populations from invaded communities, open bars are populations from noninvaded communities. Asterisks denote significant differences $(p<0.01)$ between communities within a field site.

25 Relative tiller production at the Laramie field site for 20 Hesperostipa comata (a), and 30 Sporobolus airoides genotypes (b). Within a species, values with different letters are significantly different $(p<0.05, L S D)$.

26 Sporobolus airoides growth production at Crowheart, WY for two growing seasons (eight sampling dates); (a) longest leaf production, (b) tiller production, (c) basal circumference. In no case (a, b, or c) was interaction of history by date significant (a. $p=0.1866, b . p=0.8124, c . p=0.3912$ ).

27 Sporobolus airoides growth production at FEWAFB, WY for two growing seasons (eight sampling dates); (a) longest leaf production, (b) tiller production, (c) basal circumference. In no case (a, b, or $c)$ was interaction of history by date significant (a. $p=0.9230$, b. $p=0.9879$, c. $p=0.499$ )

28 Mean inflorescence production per plant at FEWAFB, WY. Means with the same lowercase letters do not differ, FLSD, 0.05

29 Biological Screening Process to assess and select competitive Sporobolus airoides maternal lineages based on past competition experiments. Location of maternal plant collections were Naturita, CO (bgv), Greybull, WY (gb), and Laramie, WY (mono) 103

30 Predicted probabilities by position for Competitor Category $=$ Competitive

31 Predicted probabilities for Competitor category = Competitive by position and location

32 Conceptualized process of native plant response to exotic invasives 


\section{Tables}

1 SERDP SI 1389 Objectives, tasks and experimental comparisons and outcomes. 4

2 Descriptive characteristics of six Rhaponticum repens invaded rangeland sites ...............10

3 Levels of polymorphism of scored amplified fragment length polymporphism (AFLP) loci. A locus was considered polymorphic if at least one individual demonstrated a variant pattern .

4 Loci potentially linked to genes under selection (SL) in two native grass species at three locations.

5 Genetic diversity statistics from AFLP analysis of Hesperostipa comata and Sporobolus airoides from two community types (invaded by Rhaponticum repens and non-invaded). Loci examined are all polymorphic loci, loci not linked to selection (NSL), and loci potentially linked to selection (SL).

6 Chi-square analysis of parallel trends in divergence in two grasses. Tests compare observed number of parallel trends to the number expected under neutrality for NSL and SL in two community types: invaded by Rhaponticum repens, non-invaded

7 Expected heterozygosity ( $\mathrm{He}$ ), total loci, and percentage of polymorphic loci (P) for successfully genotyped plants of invaded (IN) and non-invaded (OUT) Sporobolus airoides populations. Individuals were analyzed separately by first (G1) and second (G2) generations of original sampling location (BGV, MONO, GB). Original sampling locations were: Naturita, CO (BGV), Laramie, WY (MONO) and Greybull, WY (GB). The commercial cultivar was obtained from Manderson, WY.

8 Analysis of molecular variance (AMOVA) of Sporobolus airoides from invaded (IN) and non-invaded (OUT) areas of exotic invasion. Populations (IN, OUT) and generations (G1, G2) were analyzed by maternal locations (BGV, MONO, GB). Original sampling locations were: Naturita, CO (BGV), Laramie, WY (MONO) and Greybull, WY (GB).

9 Measures of genetic variation for comparing sources of variation in the first (G1) and second (G2) generations of invaded (IN) and non-invaded (OUT) Sporobolus airoides populations. Individuals were analyzed as an entire group, by populations within a location, and then generations of a population for a location. The cultivar was obtained from Manderson, WY and maternal collection locations were: Naturita, CO (BGV), Laramie, WY (MONO) and Greybull, WY (GB).

10 Nitrogen and carbon content ( $\mathrm{mg} / \mathrm{mg}$ tissue) in Cirsium arvense grown alone and with grass competitors (Sporobolus airoides) from populations exposed to Russian knapweed invasions (experienced) and from outside the invasion (inexperienced). Mean separation was completed using Tukey's HSD

11 Mean $( \pm S E)$ values of phenotypic traits for cultivar and native Sporobolus airoides populations

12 Summary of total Sporobolus airoides seedlings used in the study and reproductive outputs. Original maternal plants were collected from invaded (IN) and non-invaded (OUT) areas of long-term Rhaponticum repens invasion (Mealor and Hild 2006). Each population consisted of maternal lineages that were increased for two generations (G1 and G2) in the greenhouse

13 S. airoides growth production Analysis of Variance F-test probabilities for data collected in Environmental Simulation Laboratory

14 Seedling germination Analysis of Variance F-test probabilities (Environmental Simulation Laboratory) 
15 Invasive encroachment Analysis of Variance F-test probabilities for Environmental Simulation Laboratory study. Source DF R. repens.

16 Invasive species encroachment (stems per $1.0 \mathrm{~m} 2$ ) within plots at FEWAFB and Crowheart, WY. Invaded, non-invaded, disturbed, and undisturbed means with the same letter do not differ for a location ( $p>0.05$, LSD)

17 Total plant cover (\%) within plots at FEWAFB and Crowheart, WY

18 Growth and reproduction of Soporobolus airoides at Crowheart, WY when transplanted into Rhaponticum repens invasion. Within a growth trait (i.e., longest leaf), invaded and non-invaded means with the same letter do not differ $(p>0.05, L S D)$. Inflorescence production is not presented because of insufficient results

19 Sporobolus airoides growth trait Analysis of Variance F-test probabilities for data collected at Crowheart and FEWAFB, WY transplant field sites. .94

20 Growth and reproduction of Sporobolus airoides at FEWAFB, WY when transplanted into Cirsium arvense invasion. Within a growth trait (i.e., longest leaf), invaded and non-invaded means with the same letter do not differ ( $p$ > 0.05, LSD). Inflorescence production is not presented because of insufficient results

21 Sporobolus airoides seedling germination Analysis of Variance F-test probabilities at Crowheart and FEWAFB, WY

22 Sporobolus airoides seedling establishment Analysis of Variance F-test probabilities at Crowheart and FEWAFB, WY

23 Invasive species encroachment within plots Analysis of Variance F-test probabilities at Crowheart and FEWAFB, WY

24 Maternal lineages corresponding with the BSP, their code, and their final competitor category ranking.

25 Maternal lineages, their associated seed weights (per seed in grams) and the rank the maternal lineage received (based on 45 maternal lineages examined) ........... 105

26 Number of Sporobolus airoides maternal lineages falling into three competitive categories as determined by the BSP. 106

27 Number of Sporobolus airoides maternal lineages falling into two competitive categories as determined by the BSP. 


\section{Preface}

This study was conducted for the Strategic Environmental Research and Development Program (SERDP) under Resource Conservation and Climate Change Project RC-1389, "Effectiveness of Selected Native Plants as Competitors with Non-Indigenous and Invasive Knapweed and Thistle Species.” The SERDP technical monitor was Pedro Morales.

The work was completed by the Ecological Process Branch (CN-N) of the Installations Division (CN), Construction Engineering Research Laboratory (CERL). The CERL Principal Investigator was Thomas Smith, CN-N. William D. Meyer is Chief, CN-N, and Dr. John Bandy is Chief, CEERDCN. The associated Technical Director was Alan Anderson, CEERD-CV-T. The Director of ERDC-CERL is Dr. Ilker R. Adiguzel.

CERL is an element of the US Army Engineer Research and Development Center (ERDC), US Army Corps of Engineers. The Commander and Executive Director of ERDC is COL Kevin J. Wilson, and the Director of ERDC is Dr. Jeffery P. Holland. 


\section{Introduction}

\subsection{Objectives}

This research was proposed and conducted to respond to the Strategic Environmental Research Development Program (SERDP) Statement of Need (SON) entitled "Control of Non-indigenous Invasive Plant Species Affecting Military Training and Testing Activities" (CSSON-04-01), which specifically identified the need to develop new methods or improve existing methods for the control, reduction, and elimination of non-indigenous invasive plant species (NIPS) while effectively protecting native species and their habitats on Department of Defense (DoD) installations.

This study hypothesizes that, as a consequence of the presence of NIPS, remaining native plants are subjected to natural selection, resulting in genetic shifts within native populations. Subsequent native populations should then become increasingly resilient following their "experience" with NIPS invasions. If so, experienced native populations should differ from conspecifics with no previous non-indigenous invasive species exposure (inexperienced natives) and should demonstrate both phenologic and genetic differences. Such phonologic and genetic shifts should also contribute to increased competitive ability against the NIPS. Thus, this work focused on the concept that native plant populations with a history of competition from invasive species may differ in their resistance and resilience traits from grass populations lacking history of exposure to invaders. This work tested these ideas using two common dry land native grasses (alkalai sacaton, Sporobolus airoides [Torr.,] and needle and thread grass, Hesperostipa comata [Trin. \& Rupr.] Barkworth), both of which were exposed to the NIPS Russian knapweed (Rhaponticum repens [L.] Hidalgo; Synonyms: Centaurea repens [L.], Acroptilon repens [L.]) and a novel NIPS, Canada thistle (Cirsium arvense[ L.] Scop.)

Most research studies on the ecology of invasive plant species, which are mostly of exotic or non-indigenous origin, have focused on the response and effects, particularly toward native plants, of the invasive in a new environment. In contrast, this research examines the competitive responses of native species to the exotic invasive. Furthermore, this research focuses on underlying mechanisms and expressions of inherent abilities of native plant resistance to invasion by non-indigenous exotics and on their con- 
tinuing resilience in the face of continuing non-native invasive species competition.

In that context, the objectives of the research were:

1. To identify native grasses that may be more resilient to NIPS, to manage and control the spread of non-indigenous invasive species on DoD and other lands.

2. To identify attributes of the experienced native plant populations that contribute to resilience and resistance to the competitive effects of NIPS.

3. To identify genetic markers and phenotypic traits that confer superior competitive ability, and to determine if those phenotypic traits are transmitted to subsequent generations of the native grasses.

Eleven tasks were developed to accomplish the objectives of this research effort (Table 1). Tasks were further divided into subtasks for organizational and reporting purposes, into roughly four categories: (1) site location, and plant collection and propagation (Tasks 1-3), (2) testing of the native collections and their seedlings for genetic, phenotypic and competitive traits to identify promising versus less promising genotypes (Tasks 4-7), (3) controlled (laboratory) and field plantings and evaluations (Tasks 8 and 9), and (4) technology transfer (Tasks 10 and 11).

While the identified tasks are fairly discrete and generally follow in sequence, there was by necessity some overlap between them. For example, genetic analysis as identified in Task 4 for maternal or parent stock germplasm was also conducted on subsequently derived plant propagules and plants, and the results were used as part of selection processes to identify promising genotypes (Task 7). Also, technology transfer (in particular Task 10) occurred throughout the study.

At the time this work was initiated, native plant responses to nonindigenous invasive plant species (NIPS) (aka exotics) invasions had not been well documented (Grant et al. 2003). Subsequently, and including the results of work conducted as part of this effort, we now have a better understanding of the influence and effects of NIPS invasions on native species populations (Mealor et al. 2004, Callaway 2005, Lau 2006, Mealor and Hild 2006, Strauss et al. 2006, Mealor and Hild 2007, Leger 2008, Ferrero-Serrano et al. 2009, Bergum et al. 2010, Sebade 2011). 


\subsection{Background}

There is a well documented association between anthropogenic disturbance and non-indigenous plant invasions (Larson et al. 2001). Many US Army and other DoD lands have been subjected to varying degrees of disturbance. NIPS are recognized as a widespread problem on DoD and other Federal lands, as well as on state and private lands. Non-indigenous invasive plants dominate millions of acres throughout the country, but particularly in the west (Whitson et al. 1992). These invasions have had many effects including reduced (and sometimes eliminated) native plant and animal diversity, decreased community productivity, altered fire regimes, altered nutrient cycling, and altered community structure and function. Additionally, non-indigenous, invasive, exotic, and noxious plants degrade native habitats, alter ecosystems and ecological processes, and result in large agricultural economic losses.

In an ecological context, invasive species are second only to habitat destruction in potentially causing other species to become at risk and (ultimately) endangered. On military installations, invasive plant species can present serious problems that impact military mission requirements. Nonindigenous invasive species negatively affect military training and other activities largely, but not exclusively, through the alteration of military training and testing conditions. For example, in addition to habitat alterations, NIPS can have physical characteristics that can severely limit training activities. Moreover, the negative impacts of NIPS extend far beyond immediate and direct effects on military training and other activities. These impacts and effects include those related to siphoning and diverting of valuable and scarce economic and other resources from military training activities for NIPS control. The alteration of ecosystems and ecological processes can have further secondary negative effects and impacts on military training by detracting and degrading the quality and the realism of military training lands. A more insidious effect of NIPS is that containing them can require the use of environmental toxicants, which can further negatively affect the environment and non-target organisms, including sensitive, rare, and threatened and endangered species. 
Table 1. SERDP SI 1389 Objectives, tasks and experimental comparisons and outcomes.

\begin{tabular}{|c|c|c|c|c|}
\hline Objectives & SERDP Tasks & Experimental Comparisons Examined & Knowledge Gained & Figures/Tables \\
\hline $\begin{array}{l}\text { Find, collect \& propagate native species } \\
\text { found to occur with NIS }\end{array}$ & $\begin{array}{l}\text { Pre-proposal re- } \\
\text { search }\end{array}$ & $\begin{array}{l}\text { Compare invaded and non-invaded communities for } \\
\text { presence and abundance of native species }\end{array}$ & $\begin{array}{l}\text { Native grasses survive within invasions of NIPS more than } 80 \text { years } \\
\text { old, although in lower abundance }\end{array}$ & $\begin{array}{l}\text { Prior research; } \\
\text { Fig } 1 \text { ( p 10); } \\
\text { Tab } 2 \text { (p 10) }\end{array}$ \\
\hline $\begin{array}{l}\text { Test maternal native grass collections for } \\
\text { competitive ability with original NIS }\end{array}$ & Tasks $1 \& 2$ & $\begin{array}{l}\text { Growth of native grass subpopulations In vs. Out* } \\
\text { grown with \& without Russian knapweed (NIPS) }\end{array}$ & $\begin{array}{l}\text { Native grass from some invasions of NIPS out-compete native grass } \\
\text { from the adjacent non-invaded area when in greenhouse setting }\end{array}$ & $\begin{array}{l}\text { Fig. } 3 \text { ( } p 39) \\
\text { Fig. } 4 \text { ( } p 40)\end{array}$ \\
\hline $\begin{array}{l}\text { Propagate seed and seedlings from mater- } \\
\text { nal plant collections }\end{array}$ & Task 3 & In vs. Out* flowering and seed production & $\begin{array}{l}\text { Seed from this effort used in subsequent comparisons of phenology, } \\
\text { genetics, competition. }\end{array}$ & Tab 14 (p 84) \\
\hline $\begin{array}{l}\text { Examine genetics of maternal collections } \\
\text { for evidence of selection by NIS }\end{array}$ & Task 4 & $\begin{array}{l}\text { In vs. Out* sub-population genetic indicators of } \\
\text { selection }\end{array}$ & $\begin{array}{l}\text { Native grass IN subpopulation suggests genetic makeup under selec- } \\
\text { tion via NIS stress }\end{array}$ & $\begin{array}{l}\text { Tab } 2 \text { ( p 10); } \\
\text { Tab } 4 \text { (p 46); } \\
\text { Tab } 5 \text { (p 46); } \\
\text { Tab } 6 \text { (p 47) }\end{array}$ \\
\hline $\begin{array}{l}\text { Examine genetic profiles of native seedlings } \\
\text { of two generations }\end{array}$ & $\begin{array}{l}\text { Task 4, added } \\
\text { component }\end{array}$ & $\begin{array}{l}\text { In vs. Out* seedling genetics from two generations } \\
\text { compared }\end{array}$ & $\begin{array}{l}\text { Seedling populations from In vs. Out subpopulations diverge in genetic } \\
\text { profiles especially in G1, but genetic traits can be lost in subsequent } \\
\text { generations of In sub-populations }\end{array}$ & $\begin{array}{l}\text { Tab } 9 \text { (p 52); } \\
\text { Tab } 10 \text { (p 62); } \\
\text { Tab } 11 \text { (p 68); } \\
\text { Tab } 12 \text { (p 70); } \\
\text { Fig. } 18 \text { (p 78) }\end{array}$ \\
\hline $\begin{array}{l}\text { Test native competitive ability with a new } \\
\text { NIS with and without herbivory. }\end{array}$ & $\begin{array}{l}\text { Tasks } 5 \& 6 \text {, with } \\
\text { added components }\end{array}$ & $\begin{array}{l}\text { In vs. Out* clones \& seedlings with \& without com- } \\
\text { petition from NIPS Russian knapweed and novel } \\
\text { NIPS Canada thistle (added component = herbivory) }\end{array}$ & $\begin{array}{l}\text { IN vs. Out differ in ability to limit growth of NIS } \\
\text { Herbivory altered this outcome }\end{array}$ & $\begin{array}{l}\text { Tab } 7 \text { ( } p 49) ; \\
\text { Fig. } 5 \text { (p 50); } \\
\text { Fig. } 6 \text { (p 55) } \\
\text { Fig. } 7 \text { ( } p 57) ; \\
\text { Fig. } 8 \text { ( } p 57)\end{array}$ \\
\hline $\begin{array}{l}\text { Overall evaluation of the potential of native } \\
\text { genotypes in revegetation }\end{array}$ & Task 7 & $\begin{array}{l}\text { Evaluate individual genotype performance in all } \\
\text { experiments. Categories= strong, moderate or un- } \\
\text { likely competitors. }\end{array}$ & $\begin{array}{l}\text { Using the Biological Screening Process (BSP) Matrix of promising geno- } \\
\text { types, IN genotypes were not clearly superior across all experiments. } \\
\text { Consequently, subsequent field experiments included all categories of } \\
\text { genotypes. }\end{array}$ & $\begin{array}{l}\text { Tab } 13 \text { ( p 70); } \\
\text { Tab } 14 \text { (p 84); } \\
\text { Tab } 15 \text { (p 86); } \\
\text { Fig. } 19 \text { (p 78) }\end{array}$ \\
\hline $\begin{array}{l}\text { Test seedling plantings in competition with } \\
\text { NIS in controlled setting. }\end{array}$ & Tasks $8 \& 9$ & $\begin{array}{l}\text { IN vs. Out* genotypes planted with Russian knap- } \\
\text { weed in University of Wyoming ESL. }\end{array}$ & ESL plantings provide comparison to field results. & $\begin{array}{l}\text { Fig. } 9 \text { (p 60) } \\
\text { Fig. } 10 \text { (p 61) }\end{array}$ \\
\hline $\begin{array}{l}\text { Test native grass competition in field set- } \\
\text { tings. }\end{array}$ & Tasks 8 \& 9 & $\begin{array}{l}\text { Field plantings of identical native grass genotypes in } \\
\text { field invasion of Russian knapweed, Canada thistle }\end{array}$ & $\begin{array}{l}\text { Field plantings differ by associated NIPS. } \\
\text { To be evaluated for long-term success, and provide demonstration } \\
\text { sites to The Nature Conservancy, WY, F.E. Warren Air Force Base, } \\
\text { Cheyenne, WY, and others. }\end{array}$ & $\begin{array}{l}\text { Fig.24 (p 88) } \\
\text { Fig. } 25 \text { ( } p 90) \\
\text { Fig. } 26 \text { (p 93) } \\
\text { Fig. } 27 \text { (p 95) }\end{array}$ \\
\hline Tech transfer & Tasks $10 \& 11$ & $\begin{array}{l}\text { Professional meetings, demonstration plantings, } \\
\text { popular and peer-reviewed publications }\end{array}$ & $\begin{array}{l}\text { Publications and professional meetings, and demonstration sites are } \\
\text { ongoing. }\end{array}$ & $\begin{array}{l}\text { App A-C } \\
(\text { pp 133-138) }\end{array}$ \\
\hline
\end{tabular}


Federal agencies are required and authorized, under several authorities (e.g., Federal Noxious Weed Act, 7 USC 2814; Executive Order 13112), to conduct research on invasive species and develop technologies for control and prevention of further invasive species introduction and establishment. Furthermore, the Sikes Act (16 USC 670 et seq.) requires integrated natural resources management plans for all DoD lands; these management plans can allow for non-indigenous invasive species related research.

The research reported on here builds on the preliminary work that had already tested, verified, and provided a "proof of concept." Previously, with a Seed Grant from the National Research Initiative (NRI-CGP Agreement 2001-35311-09846) Biology of Weedy and Invasive Plants program, we began evaluating native species' response to exotic invasions. This research continued and expanded that research to a wider geographic area and to more native plant species and invasive weeds. Previously, we had learned that native plant individuals often remain as remnant individuals within very old ( $>25$ years) invasions of $R$. repens (and other species) and that the phenotypic and genotypic traits of remnant natives differ from their conspecifics derived from outside invasions (Mealor et al. 2004). These results suggested that natural selection of native species, as a result of exotic invasions, may improve native plants' competitive ability (we call these plants "experienced" natives).

Prior to our studies, little research had been conducted to evaluate the response of native species to long-term associations with exotic species. Most research has concentrated on non-indigenous invasive species in their new range. At onset, we know of only two studies that considered variation in a native population as a response to the presence of an exotic (Callaway and Aschehoug 2000, Goodwin et al. 1999). Callaway and Aschehoug (2000) found that diffuse knapweed (Centaurea diffusa Lam), a Eurasian NIPS like $R$. repens, has much stronger negative effects on grass species from North America than on closely related grass species from communities to which it is native. Goodwin et al. 1999 found that germination and growth of Bluebunch wheatgrass (Agropyron spicatum [Pursh] Scribn. \& Smith) seedlings differed when seed was derived from native area versus areas invaded with downy brome (Bromus tectorum $\mathrm{L}$ ). More recent literature on intra-population variability relative to exotics has focused on the invasive and not on native populations (Blossey and Notzold 1995, Hanfling and Kollmann 2002, Mooney and Cleland 2001, Mack 1985, Thompson 1995). 
Most genotypic and other research in invasion ecology examines the changes in non-indigenous invasive species in a new environment, rather than the genetic flexibility of native species to respond to new exotic neighbors. Consequently, the research reported on here offers an innovative approach to discerning inherent genotypic resistance mechanisms in native plant populations. As such, our studies provide a critical turning point in our ability to strategically intervene and respond to the threat of invasive species in North American natural areas. This approach has not been conducted by other researchers in invasive ecology.

This research is novel in its application of theoretic notions of intrapopulation variability to the common problem of NIPS monocultures that limit productivity of natural areas. By taking advantage of natural selection to maintain the genetic diversity of native plant species, we can acquire important accessions and seed sources that are often neglected by native seed collectors.

Our earlier studies suggested that remaining isolated native plants within exotic invasions do offer more successful (competitive with invaders) individuals than do native plants in adjacent undisturbed sites. This research adds to our knowledge of the relationship of native plant genotypic variability and their parallel competitive ability, and of whether inherent native genotypes can be managed to produce natives for revegetation that more successfully compete with weedy invaders.

Our results are important because they offer a new approach to exotic invasions and promise a potential to realize management opportunities not previously recognized. The approach and results of the NIPS research reported on here will serve to:

1. Enhance and improve US Army and DoD training (and other) lands;

2. Result in long term cost and other savings to US Army and other DoD training and operations;

3. Provide a means to limit future NIPS invasions on DoD and other lands; and,

4. Alter the way NIPS invasions are perceived and dealt with by military and other land managers and ecologists.

The research and approach implemented here are consistent and in step with current scientific thinking and direction with invasive species control. The thrust of this research is in concert with integrated pest management 
principles and focuses on biological aspects of non-indigenous invasive species control as advocated by the Armed Forces Pest Management Board and other Federal government agencies. In addition, the results of this research will complement and integrate with other SERDP projects.

\subsection{Materials and methods - general}

\subsubsection{Native grass species}

Two native grass species were selected for study because they are commonly found in invasions of $R$. repens in the Intermountain West (Mealor et al 2004). Sporobolus airoides is a native warm season $\left(\mathrm{C}_{4}\right.$ photosynthetic pathway) perennial bunchgrass widely distributed throughout western North America. This grass is useful for restoration practices because of its ability to tolerate saline soils (Aldon 1981) and its ability to accumulate potentially toxic compounds in soils (Retana et al. 1993). After establishment, $S$. airoides is tolerant of both drought and inundation by water (Johnson 2000). In productive environments, S. airoides is more competitive than other arid rangeland grasses (Novoplansky and Goldberg 2001). Sporobolus airoides is predominantly a self-pollinator (Fryxell 1957) and therefore may be affected by localized selection with little impact from gene flow via pollen (Grant 1971).

Hesperostipa comata is a native cool season $\left(\mathrm{C}_{3}\right.$ photosynthetic pathway) perennial bunchgrass useful for stabilizing degraded or eroded rangeland sites (Zlatnik 1999). Hesperostipa comata tolerates drought (Mueller and Weaver 1942) and distributes most of its roots in the upper $0.2 \mathrm{~m}$ of soil (Melgoza and Nowak 1991). Although Freeman and Emlen (1995) assert that $H$. comata is a weak competitor with several rangeland species, it is found persisting in old $R$. repens invasions (Mealor et al. 2004), and has been observed to apparently resists invasion by other non-indigenous grass species (Belnap et al. 2004). Hesperostipa comata is capable of either self or cross pollination (Fryxell 1957), suggesting that genetic divergence may be observed only under very strong selection conditions (Grant 1971).

Both grass species are potentially long-lived and exhibit a high degree of clonality. Although both species are used in restoration efforts, there was no evidence that the rangeland locations in this study had undergone restoration plantings in the past. 


\subsubsection{Invasive species and native species maternal site locations}

Rhaponticum repens and $C$. arvense and are cool season perennial forbs (members of the Asteraceae family (USDA 2011)). These species are respectively the sixth and first most common problematic weeds for the US and six Canadian Provinces (Skinner et al. 2000). Rhaponticum repens and $C$. arvense are problematic because of their competitive abilities (i.e., sexual reproduction, vegetative reproduction, and rapid growth). These exotics, among over 5000 others, limit ecological function (hydrologic, nutrient cycling, and plant competiveness functions) in many communities, especially the variability of native populations (Mack et al. 2000, Skinner et al. 2000). Cirsium arvense and $R$. repens affect both range and agricultural lands where monocultures and dense stands can be found. Dense invasive species stands often replace other native plant species and therefore lead to decreased native species richness (Watson 1986, Mack et al. 2000). Ecosystem effects of invading species are well studied, whereas much less research focuses on responses of native plant populations (Levine 2000, MacDougall and Turkington 2005, Messing and Wright 2006).

After extensive searches in Wyoming, Idaho, and Colorado, three R. repens invasion locations were identified where each native grass species cooccurred on the $R$. repens invaded site (Figure 1, Mealor et al. 2004). Sites were selected for three criteria: (1) evidence of knapweed infestation for at least 25 years, (2) clearly visible boundary between invaded and noninvaded communities, and (3) comparable soil textures between community types. Collection sites varied in age, elevation, and weed density (Table 2). Determination of invasion age was based on herbarium records, publications of knapweed locations, and on incidences of drastic disturbance that may have contributed to knapweed invasion. For example, Rogers (1928) reported infestations of knapweed in southern Montrose County, CO as early as 1928 near the collection site near Naturita. The Naturita collection site is located near the Montrose and San Miguel County, CO border, and is tentatively aged at approximately 75 years. The earliest

herbarium record of $R$. repens in Jefferson County, ID (near Mud Lake) is from 1934 (Invaders database). Rhaponticum repens was reported in irrigated and occasionally in non-irrigated areas throughout Wyoming as early as 1935 (Sabin 1935), and was considered the most serious weed pest in Wyoming by 1940 (Boyd and Corkins 1940). The first herbarium record for northern Albany County, WY is dated 1950, and in Big Horn County, 1981. Rhaponticum repens occurred near the Wyoming collection sites in Fremont, Big Horn, and Albany Counties by 1962 (Mitich et al. 1962). Re- 
cognizing that herbarium or other published records are often obtained later than the first occurrence of plants, these may not be the actual ages of $R$. repens infestations at the subject sites, but are the best available estimates. Geographic distances between locations ranged from $723 \mathrm{~km}$ (Greybull [Big Horn County] to Naturita [Montrose County]) to $291 \mathrm{~km}$ (Laramie [Albany County] to Riverton [Fremont County]). More detailed characterization of field collection sites is available in Mealor and Hild (2006).

For experiments that test native grass for phenotypic and competitive traits (Section 3, p 17), roots of $R$. repens were collected from an approximately 40-year old invasion site near Laramie, WY. A novel NIPS (C. arvense) was used to also evaluate competitive ability of the native grasses against a related competitor. Roots of $C$. arvense were collected at Francis E. Warren Air Force Base (FEWAFB), near Cheyenne, WY, and were propagated in University of Wyoming at Laramie, WY, greenhouses for competition studies. Also, R. repens and C. arvense-invaded sites at Crowheart, WY and FEWAFB, respectively, were used in field planting experiments.

\subsection{Organization}

This report is generally organized in the sequence that the various experiments and tasks identified to complete the effort (Table 1) were performed. This was done in large part to facilitate both reporting of results and minimization of complexity and redundancy that would result if methods, materials, and results for all experiments were categorized together. It is the intent that the approach used herein will present a clearer and more comprehensive picture of the results of this research effort. 


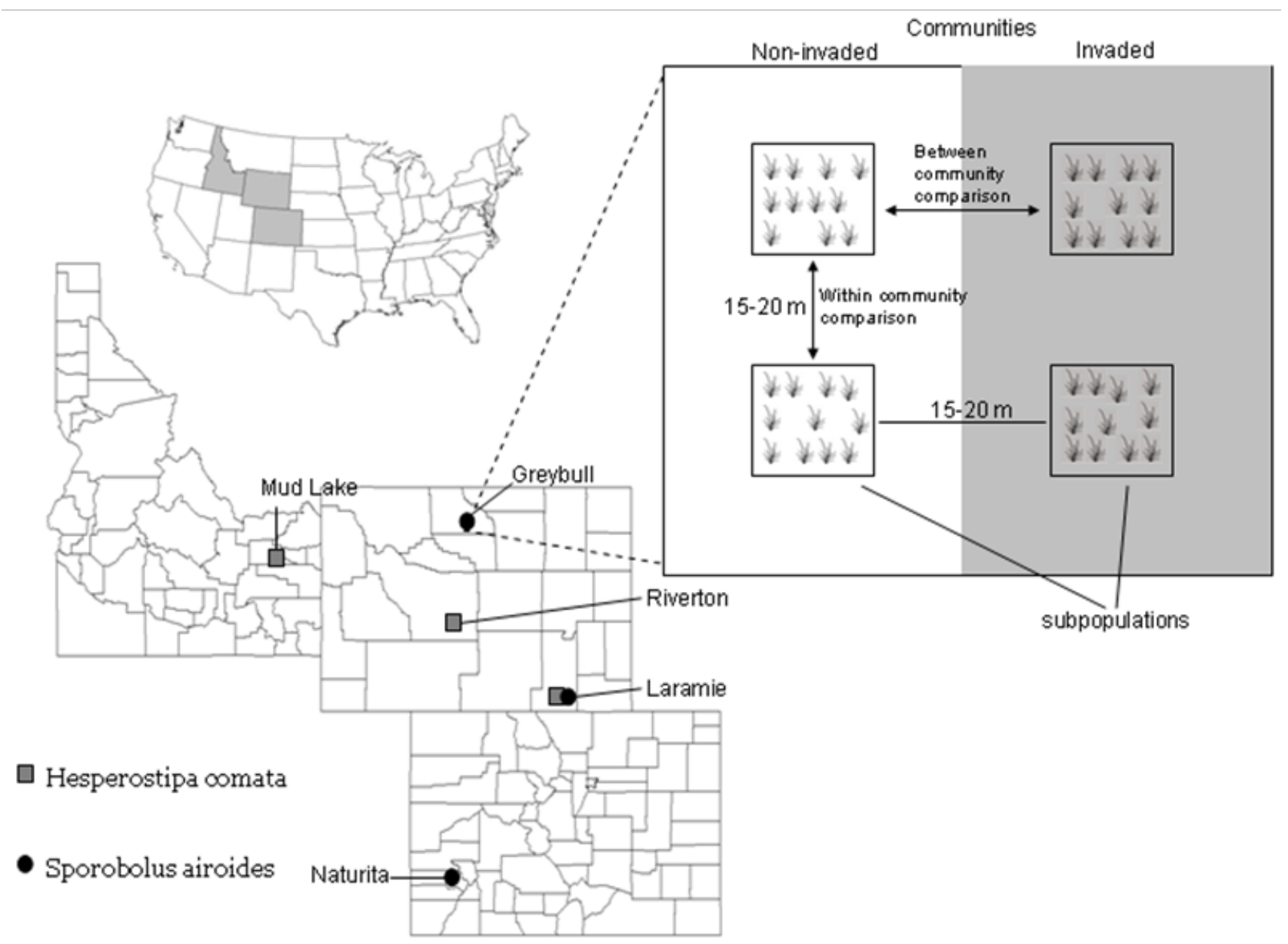

Figure 1. Plant community and collection locations.

Table 2. Descriptive characteristics of six Rhaponticum repens invaded rangeland sites.

\begin{tabular}{|l|l|c|c|c|l|}
\hline \multirow{2}{*}{ Grass species } & Location & $\begin{array}{c}\text { Elevation } \\
(\mathrm{m})\end{array}$ & $\begin{array}{c}\text { R. repens } \\
\text { density } \\
\left(\text { stems } \mathrm{m}^{2}\right)\end{array}$ & $\begin{array}{c}\text { Invasion } \\
\text { Age }(\mathrm{y})^{*}\end{array}$ & $\begin{array}{c}\text { Soil } \\
\text { (texture } \\
\text { class })\end{array}$ \\
\hline \multirow{3}{*}{ Hesperostipa comata } & Laramie, WY & 2194 & 7 & 40 & sandy loam \\
\cline { 2 - 7 } & Mud Lake, ID & 1460 & 80 & 70 & loamy sand \\
\cline { 2 - 7 } & Riverton, WY & 524 & 30 & 35 & sandy loam \\
\hline \multirow{3}{*}{ Sporobolus airoides } & Greybull, WY & 1190 & 57 & 40 & silty clay \\
\cline { 2 - 7 } & Laramie, WY & 2189 & 14 & 40 & silty clay loam \\
\cline { 2 - 7 } & Naturita, CO & 1621 & 17 & 75 & loamy sand \\
\hline$*$
\end{tabular}

Invasion years are based on literature citations and herbarium specimens for each locale. 


\section{Testing of Native Grass for Genetic Traits}

\subsection{Native grass collections}

\subsubsection{Experimental design}

\subsubsection{Sample collection - native grass}

Previously identified $R$. repens-invaded and non-invaded sites were sampled hierarchically for each grass species at three levels: (1) geographic location, (2) community within location, and (3) subpopulation within community. At each location, community types were categorized as invaded or non-invaded by the density of fresh green $R$. repens stems. Invaded communities contained high densities of $R$. repens (7-80 stems $\mathrm{m}^{2}$ ) and the species was absent from non-invaded communities. Within each community type, actively photosynthesizing leaf tissue was collected from 10-15 individual grasses in each of two subpopulations ( $\sim 30$ individuals per community type per location). Community types and subpopulations within communities were separated by no less than $15 \mathrm{~m}$ and no more than $20 \mathrm{~m}$. Sampling mature plants rather than seed better enabled researchers to describe those individuals able to persist inside invasions; however, such sampling does not address current levels of gene flow between communities. Leaves were immediately placed in silica gel and stored in an ice-filled cooler for transportation. Samples were kept in a freezer at $-20^{\circ} \mathrm{C}\left(-4.00{ }^{\circ} \mathrm{F}\right)$ at the University of Wyoming until deoxyribonucleic acid (DNA) extraction could be done using the standard 2X CTAB protocol (Doyle and Doyle 1987).

\subsubsection{Molecular analyses of maternal plant tissue}

Using samples of $S$. airoides and $H$. comata collected at R. repens-invaded and non-invaded sites, amplified fragment length polymorphisms (AFLPs) were performed as described by Vos et al. (1995) except that EcoRI selective amplification primers included a fluorescent 6-FAM (6-carboxy fluorescein) label on the 5 -ft nucleotide. Over 40 selective primer combinations were screened for the ability to consistently produce more than 40 bands per native species. Of those screened, five EcoRI/MseI primer pairs (ACG.CAC, ACG.CTA, ACG.CTC, ACGT.CTTC, AGT.CTT) were chosen to be used in selective amplifications as performed by Larson et al. (2004). Amplified DNA fragments were size fractionated using an ABI310o in- 
strument with 50-cm capillaries, POP-6 Polymer, GeneScan 400HD ROX (rhodamine X) internal size standards, and GeneScan software (PE Applied Biosystems, Foster City, CA). The GeneScan sample files were visually analyzed for presence or absence of DNA fragments between 50 and 400 base pairs using Genographer version 1.5 (Benham et al. 1999), which reduced subjective scoring of profiles. A locus was considered polymorphic if at least one individual showed a variant pattern.

\subsubsection{Inference of loci under selection}

To identify loci that may have been influenced by selection, this work followed the approach developed by Bowcock et al. (1991) (Beaumont and Nichols 1996). The program DFdist, provided by Dr. Mark Beaumont (Beaumont and Balding 2004), was used to simulate the distribution of differentiation across loci under neutral expectations. DFdist differs from the distributed Fdist (Beaumont and Nichols 1996) and Fdist2 (Beaumont and Balding 2004) in that DFdist uses Zhivotovsky's approach (Zhivotovsky 1999) to calculate the simulated values for heterozygosity and Fst, and DFdist uses the overall heterozygosity of the pooled sample. This approach provides a more accurate simulation for biallelic markers in a small number of populations (Beaumont, personal communication). For each grass species, individuals were grouped according to community type and simulations were run to generate expected distributions of heterozygosity and Fst for each location separately. Loci with Fst values above the upper 95 percent quantile for this simulation were inferred as being influenced by selection in accordance with community differences (hereafter selected loci, $\mathrm{S}_{\mathrm{L}}$ ). The 95 percent quantile represents a one-tailed hypothesis of linkage to selection (see Beaumont and Nichols 1996). Loci with Fst estimates within the expected boundaries were labeled as not linked to genes under selection $\left(\mathrm{NS}_{\mathrm{L}}\right)$.

\subsubsection{Experimental analysis}

\subsubsection{Parallel patterns of divergence in maternal plants}

Parallel trends in divergence indicate that observed divergence was affected by selection (Gavrilets 1997, Campbell and Bernatchez 2004). Within each grass species, trends in the divergence of $S_{L}$ markers among the three locations were described to reveal parallel selection (Campbell and Bernatchez 2004). A locus was designated as having a parallel trend in divergence if its frequency of band presence in one community type was at 
least 5 percent greater than in the other community type at all three locations. For instance, if locus $x$ had a higher frequency of band presence for the invaded community type in all three locations, then it would be determined that locus $\mathrm{x}$ exhibits a parallel trend in divergence.

A chi-square test was used to compare observed and expected proportions of $\mathrm{NS}_{\mathrm{L}}$ and $\mathrm{S}_{\mathrm{L}}$ loci showing parallel trends in divergence. To calculate expected proportions of loci exhibiting parallel trends, the product of the proportions of $\mathrm{NS}_{\mathrm{L}}$ loci was used with parallel trends for both invaded and non-invaded community types over all three locations for each species (Campbell and Bernatchez 2004). This expected proportion was multiplied by the absolute number of loci in each category $\left(\mathrm{NS}_{\mathrm{L}}, \mathrm{S}_{\mathrm{L}}\right)$ to assign expected values to be used in the chi-square test. For example, if locations A, $\mathrm{B}$, and $\mathrm{C}$ had proportions of $\mathrm{NS}_{\mathrm{L}}$ with parallel trends of $0.4,0.3$, and 0.5 , respectively, then the product of those proportions would be 0.06. Thus, the expected proportion of loci to exhibit parallel trends in divergence would be 0.06. If selection is occurring between the two community types, one would expect to see an excess of observed parallel trends in $\mathrm{S}_{\mathrm{L}}$ relative to $\mathrm{NS}_{\mathrm{L}}$ loci.

\subsubsection{Genetic distances among maternal plant sub-populations}

This work used subpopulations to address whether observed patterns of divergence are greater between community types within a location than within community types, and $\mathrm{S}_{\mathrm{L}}$ loci were analyzed separately from $\mathrm{NS}_{\mathrm{L}}$ loci. At each location, divergence (Nei 1978) was compared between subpopulations within a community (invaded vs. invaded) to that of subpopulations between communities (invaded vs. non-invaded). The software Popgene (Yeh et al. 1997) was used to calculate genetic distances and gene diversity (Nei 1973) for all comparisons. When using dominant markers (like AFLPs), Hardy-Weinberg equilibrium is assumed for all calculations. Student's t-tests, with locations as replicates, were used to test the null hypothesis that divergence between subpopulations will be equal when compared within or between community types. If selective pressures were driving divergence between community types, then one would expect to see greater genetic distance between community types in $\mathrm{S}_{\mathrm{L}}$ than within community types in $\mathrm{S}_{\mathrm{L}}$. This work also predicted that genetic distance would be similar within and between community types in selectively neutral loci, $\mathrm{NS}_{\mathrm{L}}$. For all tests, differences were considered significant at $\alpha=$ 0.1 , and $\mathrm{p}<$ values are reported in the text. 


\subsection{Testing genetic variation of invaded and non-invaded Sporobolus airoides populations after two generations of greenhouse seed increase}

\subsubsection{Experimental design}

The original collection of Sporobolus airoides plants were hand dug in 2004 from three grassland locations near Greybull (GB), WY, Laramie (Mono), WY, and Naturita (BGV), CO (Figure 1). At each site was an area dominated by long-term (25-70 years) $R$. repens invasions (Mealor et al. 2004). Ten $S$. airoides plants were collected from within invaded areas (IN) and ten plants were collected from noninvaded areas (OUT) and brought to the University of Wyoming greenhouses in Laramie, WY. Plants were held in identical growth environments to minimize maternal effects and cross-pollination of the two populations was avoided by growing the populations in separate greenhouses. However, within a population plants from different geographic locations were held together in one greenhouse.

Maternal plants produced first generation seed in 2005 which was sown in the greenhouse in 2006 and 2007. Second generation seed was then collected from first generation plants. The first generation $(\mathrm{G} 1)$ is the offspring from the maternal field plants and the second generation (G2) is the offspring of G1. Each population (IN, OUT) originally consisted of 30 maternal lineages (10 plants from each of the three locations). In this study, we used 16 IN and 20 OUT maternal lineages that successfully produced seed from G1 and G2. A commercially available cultivar of $S$. airoides, from a 2007 seed stock grown in Manderson, WY, was obtained to provide a standard for comparison to the native populations (IN and OUT combined).

Greenhouses were divided into 10 blocks. In each block, five seeds from each $S$. airoides maternal line and generation (2006 and 2007, based on seed available) were sown into a plastic cylindrical container $(39.4 \mathrm{~cm}$ deep x $22.7 \mathrm{~cm}$ wide) filled with a standard potting mix (1:1 mixture of washed sand and growing mix [equal mix of peat moss, vermiculite, and perlite]) on 10-12 March 2008. After 1 week, seedlings were thinned to one seedling per pot. Maternal lineages with poor germination results were supplemented with seedlings started in a growth chamber to ensure enough plant material for analysis, and were labeled as supplemented plants throughout the study. Greenhouse temperatures were maintained at $26^{\circ} \mathrm{C}\left(79^{\circ} \mathrm{F}\right)$ for $12 \mathrm{hrs}$ and $20^{\circ} \mathrm{C}\left(68^{\circ} \mathrm{F}\right)$ for $12 \mathrm{hrs}$. Plants were wa- 
tered twice a week using timed drip irrigation at 6-minute intervals equaling $600 \mathrm{ml}$ of water per plant per week.

Leaf tissue was collected when seedlings had at least five tillers with fully expanded leaves. Collections occurred on 11 July, 3 August, 11 September, and 10 October 2008. Three leaves, about $10 \mathrm{~cm}$ long (approximately 20 $\mathrm{mg}$ of tissue), were sampled from each plant and placed in a plastic bag with $2.5 \mathrm{~g}$ of grade 12 silica desiccant. Bagged samples were refrigerated. Dried leaf samples (10 to $20 \mathrm{mg}$ ) were cut into small pieces ( 1 to $5 \mathrm{~mm}$ lengths) before being transferred to a tissue DNA extraction and purification kit cartridge (Promega Corp. 2007). Extraction results were checked on a spectrophotometer before storing at $4-6{ }^{\circ} \mathrm{C}\left(39-43^{\circ} \mathrm{F}\right)$.

\subsubsection{Experimental analysis}

AFLP (amplified fragment length polymorphism) genetic marker techniques were used for their high reproducibility, and cost and time efficiency for generating DNA fingerprints regardless of origin or complexity (Mueller and Wolfenbarger 1999). AFLP markers have effectively been used for several North American native grasses such as slender wheatgrass (Elymus trachycaulus) (Ferdinandez et al. 2005), blue gramma (Bouteloua gracilis) (Fu et al. 2004), purple needlegrass (Nassella pulchra) (Larson et al. 2001), Sandberg bluegrass (Poa secunda) (Larson et al. 2001b), and S. airoides (Mealor and Hild 2006). All DNA extraction and AFLP lab work was conducted at the University of Wyoming's Nucleic Acid Exploration Facility.

Adaptor pairs (MseI and EcoRI) were annealed before use by heating to $95{ }^{\circ} \mathrm{C}\left(203{ }^{\circ} \mathrm{F}\right)$ for 5 minutes in a thermal cycler with no heated lid. A plant mapping kit and protocol was used for AFLP reactions (Applied Biosystems 2007). The protocol was modified by diluting only $10.0 \mu \mathrm{L}$ of preselective product with $190.0 \mu \mathrm{L}$ of TE buffer. The following primer combinations were used in selective amplification: ACG-CAC, ACG-CTA, and ACGCTC. Denaturing occurred in a 96-well microamp plate using $0.5 \mu \mathrm{L}$ of Rox 500 size standards, 8.5 $\mu \mathrm{L}$ of $\mathrm{HiDi}$, and $1.0 \mu \mathrm{L}$ of selective amplification product in each well. Plates were run on a thermal cycler at $95{ }^{\circ} \mathrm{C}$ $\left(203{ }^{\circ} \mathrm{F}\right)$ for 3 minutes, followed by a quick cool in an ice plate for $3 \mathrm{mi}-$ nutes. Denatured amplification products were run on a capillary electrophoresis system for fragment analysis and sequencing. 
Raw AFLP data were analyzed using GeneMapper ${ }^{\circledR}$ software to create tables of fragment sizes for each individual seedling and each primer combination. Tables were then converted to a binary matrix that scored fragments as present (1) or absent (o). Statistics of genetic diversity within and among populations (IN and OUT), generations (G1 and G2), and maternal locations (BGV, MONO, and GB) were computed using the software AFLPSURV v1.o. (Vekemans 2002). The values for polymorphic loci are reported at the 5 percent level. Population expected heterozygosity $\left(\mathrm{H}_{\mathrm{e}}\right)$, gene diversity within $\left(\mathrm{H}_{\mathrm{s}}\right)$, total gene diversity $\left(\mathrm{H}_{\mathrm{t}}\right)$, and gene diversity among populations $\left(\mathrm{G}_{\mathrm{st}}\right)$ were all calculated (Lynch and Milligan 1994). Genetic distances calculated in AFLP-SURV (Reynolds et al.1983) were used to construct an unrooted, neighbor-joining tree in PHYLIP (Felsenstein 1989). A thousand bootstraps were performed over the AFLP loci for node support. The portioning of genetic variation within and among populations (IN, OUT), maternal locations (BGV, MONO, GB), and generations (G1, G2) were calculated using the analysis of molecular variance (AMOVA) technique in ARLEQUIN (Excoffier et al. 2005).

A polymorphic locus occurs when allelic variation occurs at frequencies that are too high to be accounted for by selection or mutation (Nei 1987). Expected heterozygosity $\left(\mathrm{H}_{\mathrm{e}}\right)$ is the estimated fraction of all individuals who would be heterozygous for any randomly chosen locus; values range from zero (no heterozygosity) to nearly one (a large number of frequent alleles) (Nei 1987). Total genetic diversity $\left(\mathrm{H}_{\mathrm{t}}\right)$ can be broken down to determine the proportion of genetic diversity present within $\left(\mathrm{H}_{\mathrm{s}}\right)$ populations and between populations ( $D_{s t} ;$ Nei 1987). $\mathrm{H}_{t}$ and $\mathrm{H}_{\mathrm{s}}$ values range from zero (o) to 1, but minimum and maximum values vary based on the number of alleles present at a locus, or on the amount of polymorphic loci. Nei's coefficient of gene differentiation $\left(\mathrm{G}_{\mathrm{st}}\right)$ (Nei 1987) and Wright's fixation index $\left(\mathrm{F}_{\mathrm{st}}\right)$ (Wright 1943) are used to quantify the amount of genetic variation among individuals within and among populations. The values for $\mathrm{G}_{\text {st }}$ and $\mathrm{F}_{\text {st }}$ range between zero (o) (allele frequencies are identical across all populations; $\mathrm{H}_{\mathrm{t}}$ and $\mathrm{H}_{\mathrm{s}}$ are equal) and 1 (no variation within populations and all variation is portioned among populations). 


\section{Greenhouse Testing of Native Grass Collections and Seedlings for Phenotypic and Competitive Traits}

\subsection{Testing for competition with Russian Knapweed}

\subsubsection{Experimental design}

Roots of $R$. repens (8-10 mm diameter) were collected from a dense invasion near Laramie, WY, washed, and cut into approximately $6 \mathrm{~cm}$ sections. Root sections were planted into flats and watered daily. After shoot emergence, the root and shoot units were again washed and each individual weighted before planting them into plastic lined, $15 \times 45 \mathrm{~cm}$ polyvinyl chloride (PVC) pots. Potting media was a 50 percent sand and 50 percent commercial growing soil mix (equal mix of peat moss, vermiculite, and perlite) to facilitate root penetration and extraction via washing. After shoots emerged from the cuttings, the roots were again washed and each individual weighed before planting into experimental plots.

Sporobolus airoides collections for this experiment were obtained from grass populations previously analyzed using amplified fragment length polymorphism (AFLPs), which revealed evidence of divergent selection between two community types (those exposed to $R$. repens invasion and those not (Mealor and Hild 2006, Figure 1).

In 75 pots, randomly planted $R$. repens plants were started in flats. One week after planting $R$. repens into the experimental pots, seven $S$. airoides seeds from 24 maternal genotypes were planted into two pots with $R$. repens and two pots without $R$. repens. Twelve genotypes were from invaded (i.e., experienced; IN) and 12 from non-invaded (i.e., inexperienced; OUT) communities (Mealor and Hild 2006), which resulted in two copies of each maternal genotype with $R$. repens and two copies without $R$. repens. Maternal genotypes were assigned randomly to $R$. repens pots as well as to 50 pots not containing $R$. repens. Twenty five pots contained only $R$. repens plants alone. Plants were grown under natural lighting, watered three times weekly, and pots were re-randomized periodically to reduce influence of greenhouse bench position. 
Emergence of $S$. airoides were monitored daily for a 2-week period following planting, as were plants thinned to one plant per pot following the initial 2 weeks. For each $S$. airoides plant, number of tillers, number of leaves, and length of longest leaf were measured every 2 weeks for the duration of the experiment. Also measured were the height, number of shoots, width of canopy and number of leaves for $R$. repens throughout the experiment. After 150 days, $R$. repens plants showed evidence of senescence, so plant biomass was harvested. A moderate pressure hose above two layers of hardwire cloth was used to remove soil and particulate matter from roots before separating $R$. repens from $S$. airoides roots. All biomass was oven dried at $60^{\circ} \mathrm{C}\left(140^{\circ} \mathrm{F}\right)$ for 3 days before weighing.

\subsubsection{Experimental analysis}

Each grass genet (genetically distinct individuals as determined from collection) was divided into multiple clones (ramets) and maintained under irrigation to maximize seed production. Ramets from invaded communities were separated from non-invaded ramets to prevent cross-pollination between the two different community types. Seeds used in this experiment were produced and collected under the same greenhouse conditions for all ramets, thereby reducing potential maternal effects. Seeds produced may have been cross-fertilized between genets within a community type (i.e., invaded $\times$ invaded), but not across community types. Because of the potential for cross pollination, seeds were identified as from a particular maternal genet rather than identical genotypes.

To analyze nondestructive monitoring data for $S$. airoides, a completely randomized two-factor factorial set in a split plot in time with knapweed competition and community of origin was used as treatment factors. A two-factor factorial design was also used to test for differences among the growth of 24 individual maternal genotypes with and without knapweed. The same factorial design was used to assess the effects of each maternal genotype on $R$. repens growth. For $R$. repens biomass data, analysis of covariance (ANCOVA) was used, with neighbor (S. airoides from invaded and non-invaded communities and no neighbor) as the treatment and initial dry $R$. repens biomass (estimated) as a covariate. 


\subsection{Testing for competition with Canada Thistle}

\subsubsection{Experimental design}

These experiments used two grass species (S. airoides and $H$. comata) commonly found in invasions of $R$. repens (Mealor et al. 2004). Collections for these experiments were obtained from grass populations previously analyzed using AFLPs, which revealed evidence of divergent selection between the two community types (Mealor and Hild 2006, Figure 1). The grasses were collected from invasions of $R$. repens and had not experienced competition from the related NIPS, $C$. arvense. Native grasses were sampled randomly within each community (invaded, noninvaded; IN, OUT) at each location. We excavated large genets (approximately 25 $\mathrm{cm}$ diameter) of each native grass species and transported them to greenhouse facilities at the University of Wyoming, Laramie, WY. Once all plants were in the greenhouse, each genet was divided into multiple clones (ramets). A subset of these clones was used for this study. On 1 April 2005, C. arvense roots were collected at FEWAFB and transported to the University of Wyoming greenhouses. C. arvense plants were grown from 10 $\mathrm{cm}$ root cuttings in flats containing a $50 \%$ sand, $50 \%$ peat soil mix.

On 24 and 25 April 2005, we randomly assigned nine treatments to two pots within five blocks. Treatments were $C$. arvense grown 1) alone, 2) with experienced $H$. comata, 3 ) with inexperienced $H$. comata, 4) with experienced $S$. airoides, 5) with inexperienced $S$. airoides, and each grass grown alone (treatments 6-9). Grasses and thistles were planted into 15 $\mathrm{cm} \times 45 \mathrm{~cm}$ columnar PVC pots in a 50\% sand and $50 \%$ peat soil media (by volume). Plants were grown under $30{ }^{\circ} \mathrm{C}$ day and $20{ }^{\circ} \mathrm{C}$ night. Plants were watered once a week and day length varied from 15 hours in May to 12 hours in December.

\subsubsection{Experimental analysis}

This study used C. arvense to assess establishment, survival, and reproduction of the two native grasses. This allowed documentation of the competitive ability of native grasses against a novel (but related) NIPS, thus broadening the assessment of the competitive traits of the grasses.

To determine if either experienced or inexperienced native grasses grew larger in competition with $C$. arvense, grasses that grew as well with the exotic neighbor were considered more tolerant to $C$. arvense presence. To 
provide a measurement of grass growth during the study, we documented number of tillers. Monitoring was initiated on 11 May 2005 and was repeated every 2 weeks for a total of 16 weeks ( 8 observations). Each block was harvested at 2-week intervals from the 15 October 2005 to 10 December 2005 .

The experiment was analyzed as a completely randomized block design (CRBD). Biomass data were analyzed using ANOVA appropriate to a CRBD. Following ANOVA. Means were compared using LSD (at the $\alpha=$ 0.05 level (SAS 2003).

The number of tillers over time was analyzed using a split plot arrangement of CRBD in time and means were separated with LSD $(\alpha=0.05)$.

\subsection{Testing for native grass competition with Canada Thistle using the Relative Neighbor Effect (RNE) Index}

\subsubsection{Experimental design}

Nine treatments were randomly assigned to two pots (samples) of randomly selected genets from all locations, within five replicate blocks, resulting in 10 pots for each treatment, a total of 90 pots. Two pots were treated identically in each of the five blocks to allow for better estimates and incidental mortality. Treatments were C. arvense grown: (1) alone, (2) with experienced $H$. comata, (3) with inexperienced $H$. comata, (4) with experienced $S$. airoides, (5) with inexperienced S. airoides, and each grass and experience combination grown alone (treatments 6-9). Grasses and thistles were planted into $15 \mathrm{~cm} \mathrm{x} 45 \mathrm{~cm}$ columnar PVC pots in a 50 percent sand and 50 percent peat soil media (by volume). Plants were grown under $30^{\circ} \mathrm{C}\left(86^{\circ} \mathrm{F}\right)$ day and $20^{\circ} \mathrm{C}\left(68^{\circ} \mathrm{F}\right)$ night. Plants were watered once a week and day length varied from $15 \mathrm{hrs}$ in May 2005 to $12 \mathrm{hrs}$ in December 2005.

\subsubsection{Experimental analysis}

Competition between grasses and thistles was quantified using the Relative Neighbor Effect (RNE) index (Markham and Chanway 1996, Huckle et al. 2000). The index is based on target plant growth (in this study, biomass) in the presence of a neighbor, relative to growth alone, such that $\mathrm{RNE}=\left(P_{-\mathrm{N}}-P_{+\mathrm{N}}\right) / x$, where $\mathrm{P}$ is the performance of plants in the presence $(+\mathrm{N})$ and absence $(-\mathrm{N})$ of neighbors. 
The term "x" was regarded as $P_{-\mathrm{N}}$ when $P_{-\mathrm{N}}$ was greater than $P_{+\mathrm{N}}$, and "x" was regarded as $P_{+\mathrm{N}}$ when $P_{+\mathrm{N}}$ was greater than $P_{-\mathrm{N}}$. RNE is a modified version of the Relative Competitive Intensity (RCI) index (Belcher et al. 1995, Goldberg et al. 1999, Weigelt and Jolliffe 2003). To account for differences between very high competition intensity or facilitation, the arc sin transformation of RNE (Huckle et al. 2000), also called Corrected Relative Competition Index (CRCI) (Oksanen et al. 2006) was used. Competitiveness of experienced and inexperienced grasses using RNE as a standardized means to compare each grass's competitive growth with, and influence on C. arvense (calculated as the RNE for C. arvense in competition with each grass) was assessed.

RNE measures of $C$. arvense biomass were analyzed for five treatments (thistle grown alone, and with experienced and inexperienced genets of the two grasses) and grass biomass was analyzed separately for each species (four treatments: with and without thistle neighbors and both inexperienced and experienced grass conspecifics). RNE values (differences in biomass between plants grown with a neighbor and grown alone) were analyzed across all species for differences among neighbor effects (RNE values for $C$. arvense combined with each of four grass treatments and the corresponding grass RNE values).

Experienced or inexperienced native grasses that grew larger in competition with the exotic neighbor were considered more tolerant to $C$. arvense presence. Grass growth was documented during the study via number of tillers and final biomass. Monitoring was initiated in May and was repeated every 2 weeks for a total of 16 weeks (eight observations) after which plant harvest was begun. Each block was harvested at 2-week intervals from 15 October to 10 December 2005. Beginning in October harvests, if a pot lost a portion of its treatment due to mortality (i.e., a neighboring grass or thistle died), the remaining plants were harvested for biomass, but were not included in analyses of leaf nutrient content.

\subsection{Testing for nutrient content of Canada Thistle}

\subsubsection{Experimental design}

Five replicate pots were randomly selected from the $S$. airoides competition treatments (C. arvense with experienced $S$. airoides, $C$. arvense with inexperienced $S$. airoides, and three pots containing $C$. arvense grown alone. cf. Section 3.2, p 19), to assess nitrogen content in C. arvense. Each 
pot was injected with $15 \mathrm{~N}$ as solution $\left(20 \%{ }^{15 \mathrm{~N}}\right)$ containing $0.5 \mathrm{~g}$ of ammonium nitrate over a 2-hr period at $15 \mathrm{~cm}$ soil depth. Watering was suspended following injection until the plants were harvested ( $48 \mathrm{hrs}$ later) to avoid ${ }^{15 \mathrm{~N}}$ leaching (McKane et al. 1990). Following harvest, all leaf material was oven-dried at $60^{\circ} \mathrm{C}\left(140^{\circ} \mathrm{F}\right)$ and ground until samples would pass through a $0.5 \mathrm{~mm}$ mesh (McKane et al. 1990) to obtain a minimum of 3 $\mathrm{mg}$ of dry plant tissue. Once samples were homogenized, they were analyzed using an isotopic mass spectrometer to obtain leaf nitrogen and carbon concentrations. One pot containing an inexperienced $S$. airoides grown with $C$. arvense was inadvertently over-injected and in one other pot the experienced $S$. airoides died; both were removed from analysis leaving four replicate pots of each competition treatment and three pots containing $C$. arvense grown alone for comparison.

\subsubsection{Experimental analysis}

Once samples were homogenized, they were analyzed using an isotopic mass spectrometer to obtain leaf nitrogen and carbon concentrations. After homogenization Cirsium arvense leaf tissue nutrient content was analyzed for differences among three treatments (grown alone, or with either experienced or inexperienced $S$. airoides) using an isotopic spectrometer. Where ANOVA revealed significant F-tests, means were compared using Tukey's Honestly Significant Difference (HSD) at the $\alpha=0.05$ level.

\subsection{Testing for competition with Canada Thistle under herbivory by Stem-Mining Weevils}

\subsubsection{Experimental design}

The potential was evaluated for combining a stem boring weevil (Hadroplontus litura) (formerly, Ceutorhynchus litura; Coleoptera) with competition from the two native bunchgrass species, $H$. comata and $S$. airoides. As indicated, these grasses have demonstrated the ability to grow within very old invasions (30 to 80 years) of $R$. repens (Mealor et al. 2004). Hadroplontus litura is of special interest for biological control of $C$. arvense because the insect thrives in cultivated land and attacks in early spring before the thistle has become troublesome. This introduced stem boring weevil has been employed as a biological control agent on C. arvense in the United States and Canada for several decades (see Zwölfer and Harris 1966). 
In a greenhouse experiment, we compared the impacts of seven treatment combinations of thistle plants exposed to grass competition and weevil herbivory alone or in concert. In the fall of 2004, we collected $S$. airoides near Greybull and Laramie, WY, and Naturita, CO, and H. comata near Riverton and Laramie, WY, and Mud Lake, ID (Figure 1). We excavated large individuals (approximately $25 \mathrm{~cm}$ diameter) of each native grass species and transported them to and maintained them in greenhouse facilities at the University of Wyoming, Laramie, WY. Once all plants were in the greenhouse, each genet was divided into multiple clones and repotted to allow recovery following division. Cirsium arvense roots were collected at FEWAFB. On 1 April 2005 C. arvense roots were grown in flats from selected $10 \mathrm{~cm}$ root cuttings of similar diameters.

On 24 and 25 April 2005 grasses and thistles were randomly assigned for planting into $15 \mathrm{~cm} \mathrm{x} 45 \mathrm{~cm}$ columnar pots in a media of $50 \%$ sand and 50 $\%$ peat soil (by volume). Treatments were: $C$. arvense 1) grown alone, 2) subjected to herbivory by $H$. litura, 3 ) in competition with $H$. comata only, 4) in competition with $S$. airoides only, 5) in competition with $H$. comata and subjected to $H$. litura, 6 ) in competition with $S$. airoides and subjected to $H$. litura, and 7) C. arvense competing with both grasses. To avoid losing data for a treatment due to mortality, each treatment was randomly assigned to two duplicate pots within each of five replicate blocks. Five $H$. litura individuals obtained from a commercial source (Integrated Control of Weeds, Bozeman, MT) were placed on thistles into herbivory treatments on 12 May 2005 and the pots were covered with polyester netting until the 20 May 2005, when the adult insects were removed from the plants. Plants were grown under $30^{\circ} \mathrm{C}\left(86^{\circ} \mathrm{F}\right)$ day and $20^{\circ} \mathrm{C}\left(68^{\circ} \mathrm{F}\right)$ night temperatures. Plants were watered once a week and day length varied from 15 hours in May to 12 hours in December.

\subsubsection{Experimental analysis}

Each block was harvested at 2-week intervals from October 2005 to December 2005. Plants were assessed for mortality at the time of harvesting. Plants were removed from pots and washed in a sieve to retain roots. Washed plants were divided into roots and shoots. Leaves were removed and leaf area was measured with a leaf area meter LI-3100 (LI-Cor, Lincoln, NE). All plant material was dried at $65{ }^{\circ} \mathrm{C}\left(149^{\circ} \mathrm{F}\right)$ for $36 \mathrm{hrs}$ and weighed. Specific Leaf Area (SLA) from the coefficient between the leaf area and leaf biomass was calculated. Root and shoot biomass were summed to obtain total biomass. 
To provide a non-destructive estimate of shoot biomass during the study, biomass estimates were derived from a series of stem volume measures on C. arvense individuals following procedures of Montagu et al. (2005) and Segura and Kanninen (2005). Cirsium arvense was monitored by measuring height and diameter of each thistle stem, to calculate stem volume. Aboveground biomass of $C$. arvense was inferred from stem volume calculated as the volume in a column and aboveground biomass measures of 60 harvested C. arvense individuals. This allometric relationship provided an equation to estimate aboveground biomass $\left(\mathrm{p}<0.01, \mathrm{R}^{2}=0.8135\right)$, where aboveground biomass $(\mathrm{g})=0.0339 \times$ stem volume $\left(\mathrm{cm}^{3}\right)+0.0705$. These estimates allowed the examination of aboveground biomass during the study, before harvest, giving an assessment of insect impacts before harvest.

Treatment effects on thistle growth were analyzed using ANOVA for a randomized complete block experimental design (CRBD). Five replicate blocks containing two pots (subsamples) of each treatment were used to control variation due to bench position and to stagger harvest dates. Above and belowground biomass at harvest were analyzed using ANOVA (SAS 2003). We conducted a relative efficiency test to evaluate the impact of blocking in the design. In the case of non-significance for the blocking factor at $\mathrm{p}=0.05$, data was re-analyzed removing blocks for the model. Shoot biomass estimates over the time of the study were analyzed using a split plot design to incorporate repeated measures. Where F-tests were significant at $\alpha=0.05$, mean comparisons between treatments within a sampling date were made using an LSD mean separation test at the $\alpha=0.05$ level. Mortality was evaluated using a Chi-square analysis.

\subsection{Testing for phenotype of first and second generation seedlings -- plant traits in response to long-term exposure to Rhaponticum repens}

\subsubsection{Experimental design - greenhouse increase}

\subsubsection{Maternal lineages material collection}

Maternal S. airoides plants were hand dug in 2004 from grassland locations: Greybull (GB) and Laramie, WY (Mono), and Naturita, CO (BGV) (Figure 1). Ten S. airoides plants collected from within R. repens invaded areas (IN) and 10 plants collected from adjacent non-invaded areas (OUT) were brought to the University of Wyoming greenhouses in Laramie, WY, 
and held in identical growth environments to minimize maternal effects. Cross pollination of the two populations was avoided by growing the populations in separate greenhouses. Seed was collected from original maternal plants in 2005 and first generation offspring was sown from seed in the greenhouse from 2006 to 2007. First generation (G1) plants are the offspring from the maternal field collections and second generation (G2) is the offspring of G1. Each population (IN, OUT) originally consisted of 30 maternal lineages (10 plants from each of the three locations). This study used 16 IN and 20 OUT maternal lineages that successfully produced seed from G1 and G2. A commercially available cultivar of $S$. airoides from a 2007 seed stock grown in Manderson, WY was obtained to provide a standard for comparison to the native populations.

\subsubsection{3.6.1.2 Germination of maternal lineages derived from greenhouse increase}

These experiments were conducted in two separate greenhouses, one containing the IN population and one held the OUT population. Each greenhouse was divided into 10 blocks and each block consisted of one plant from each generation (G1, G2) and each maternal lineage. In March 2008, 50 randomly selected seeds (five seeds per block) were sown into 10 plastic cylindrical containers (39.4 cm deep x $22.7 \mathrm{~cm}$ wide) filled with a standard potting mix (1:1 mixture of washed sand and growing mix [equal mix of peat moss, vermiculite, and perlite]).Seedlings were thinned to one seedling per pot after 1 week. Maternal lineages with poor germination results were supplemented with seedlings started in a growth chamber to ensure enough plant material for the study and labeled as supplemented plants throughout the study. Greenhouse temperatures were maintained at $26^{\circ} \mathrm{C}$ $\left(78^{\circ} \mathrm{F}\right)$ for $12 \mathrm{hrs}$ and $2 \mathrm{O}^{\circ} \mathrm{C}\left(68^{\circ} \mathrm{F}\right)$ for $12 \mathrm{hrs}$. Plants were watered twice a week using timed drip irrigation at 6-minute intervals equaling $600 \mathrm{ml}$ of water per plant per week.

\subsubsection{Experimental design - field increase}

\subsubsection{Maternal lineages material collection}

Maternal plants were collected from three locations (Greybull and Laramie, WY, and Naturita, CO; Figure 1, Mealor and Hild 2006), were kept in field plots since 2006 (see Section 4.1.2, p 35), and were subjected to temperature and moisture regimes typical of Laramie, WY. IN genotypes were distanced from OUT genotypes to eliminate out crossing. Sporobolus airoides seeds used in the germination and root growth experiments were 
hand-collected from maternal plants in either 2006 or 2007. Seeds were allowed to fully ripen, and the inflorescences were clipped, bagged, and then stored at room temperature. Seed cleaning consisted of removing the glumes, lemma, and palea. Seeds were then counted, placed in paper envelopes, and stored at room temperature. The commercial cultivar grown in Manderson, WY and harvested in 2006 was obtained from a commercial grower and was cleaned in the same fashion.

\subsubsection{Germination of maternal lineages derived from field increase}

Eighteen genotypes from the 2006 seed source, twenty-four genotypes from the 2007 seed source, and one commercial cultivar from the 2006 seed source were germinated for 21 days (4 - 24 March 2008) under controlled conditions. Each genotype was assigned three replicate Petri dishes (experimental unit) each containing 50 seeds. Seed orientation was kept uniform in the Petri dishes. Fully developed seeds were selected at random, disregarding seed size and color (Knipe 1967). The study consisted of a total of 129 Petri dishes. Each experimental unit was placed on one of two shelves within each growth chamber. Three growth chambers were tested and calibrated prior to the experiment to assure temperatures met accuracy standards (+ or $-0.1^{\circ} \mathrm{C}$ ). Each chamber was thoroughly cleaned and disinfected prior to use.

We placed two layers of ( $90 \mathrm{~mm}$ diameter, number 2) filter papers in the bottom of plastic Petri dishes (90 mm dia.) and placed 50 seeds on top of the filter papers. Dishes were watered with $10 \mathrm{~mL}$ of distilled water, lids placed on top of the dishes, and the dishes placed into the growth chambers. Petri dishes were re-moistened with distilled water once daily to ensure moist conditions.

Each of the 43 maternal lineages represented a combination of position (IN, OUT), and seed source $(2006,2007)$. Seed of each maternal lineage (replicated 10 times) was germinated in growth chambers and followed to record root growth. Radicle length was measured for 10 days following germination. Eighteen maternal lineages from a 2006 seed source, 24 maternal lineages from a 2007 seed source, and one commercial cultivar from a 2006 seed source were germinated in one growth chamber, which was calibrated according to industry standards $\left( \pm 0.1^{\circ} \mathrm{C}\left[ \pm 0.06^{\circ} \mathrm{F}\right]\right)$. The growth chamber was thoroughly cleaned and disinfected before use. Ten seeds per maternal lineage were placed in paper germination sleeves $(15 \mathrm{x}$ $22 \mathrm{~cm}$ ), which helps to facilitate directional growth and measurement of 
seed radicles and to ensure proper moisture around the seed by wicking water upwards to the seed trough. Germination sleeves were moistened with distilled water and placed in the growth chamber under alternating temperatures of 33 to $26^{\circ} \mathrm{C}$ ( 91.4 to $78.8^{\circ} \mathrm{F}$ ) in $12 \mathrm{hr}$ intervals. Germination sleeves were positioned vertically during germination. Due to $S$. airoides being negatively photoblastic (Knipe 1970), growth chamber lights were kept off for the duration of the experiment.

S. airoides germinates best at a constant temperature of $32.2^{\circ} \mathrm{C}\left(90^{\circ} \mathrm{F}\right)$ and at alternating temperatures ranging from 26.1 to $32.2^{\circ} \mathrm{C}\left(79-90^{\circ} \mathrm{F}\right.$, Knipe 1967), and so chamber temperatures were kept at $26.0^{\circ} \mathrm{C}\left(78.8^{\circ} \mathrm{F}\right)$ for 12 hours at $70 \% \mathrm{RH}$ and $33.0^{\circ} \mathrm{C}\left(89.6^{\circ} \mathrm{F}\right)$ for 12 hours at $80 \% \mathrm{RH}$. Lights remained off for the duration of the experiment. Genotypes and seed lot (2006 and 2007) were rotated on shelves every other day. Seed germination was recorded every 2 days starting on 6 March 2008. The commercial cultivar (150 seeds, three dishes) was included for comparison. Results from the commercial cultivar were used in figures but were not statistically compared to our genotypes.

We conducted our experiment for 22 days to document seed germination and possible effects of $R$. repens on maternal plant offspring germination. Sporobolus airoides seeds were considered germinated when both the radicle and plumule had broken through the seed coat (Knipe 1970).

Seed viability was determined for remaining non-germinated seeds in each Petri dish using a 1.0\% Tetrazolium staining (TZ) solution (derivative 2, 3 , 5 -triphenyl tetrazolium chloride TTC) mixed with distilled water (AOSA Tetrazolium Testing Handbook 2000). Seeds were bisected through the embryo, placed into the TZ solution to imbibe for 24 hours and then viewed under a microscope. Seed embryos that were stained fully red were deemed viable and embryos that were stained only partially red were deemed not viable. Seed viability results were used to adjust the starting numbers of seeds for each genotype to only account for non-dormant seed (i.e., if ten seeds were deemed not viable, then germination percent was calculated using only 40 seeds instead of the original starting number of 50). Taking seed viability into account helps to minimize confounding effects in statistical analyses (Scott et al. 1984). 


\subsubsection{Experimental Analysis - greenhouse increase}

\subsubsection{Phenotypic observations - greenhouse increase}

Plant measurements were taken bi-weekly for 26 weeks (starting on 26 March 2008 and ending 24 September 2008) or until inflorescences were harvested or plants displayed signs of senescence. Dates of germination, inflorescence emergence, pollen shed, and inflorescence harvest were documented as they occurred. Plant measurements included: tiller number, length and width of three leaves, plant height, basal diameter, inflorescence height, and inflorescence number. Tiller and inflorescence production were counted on all seedlings. Leaf length, plant height, basal diameter, and inflorescence height were measured in centimeters and leaf width was measured in millimeters. Three leaves of each plant were measured for length and width and values averaged for analysis. Plant height was measured from the base of the plant up to the highest point. Basal diameter was measured in a cross section from the outermost tillers on opposite sides of the plant. Three inflorescences were measured from the base of the plant to the tip of the inflorescence and the values averaged for inflorescence height analysis. When seeds reached maturation (dark in color and hard to the touch) inflorescences were collected and air dried in paper bags. After 1 month, seeds were hand cleaned, counted, and weighed to the nearest milligram. For purposes of discussion, we divided phenotypic traits into vegetative and reproductive traits. Vegetative growth traits include tiller production, plant height, leaf length, and basal diameter. Reproductive traits include inflorescence height, seed production, inflorescence production, seed weight, and germination.

\subsubsection{Data analysis - greenhouse increase}

Phenotypic traits were measured to determine 1) which population had the greatest tiller production, plant height, basal diameter, leaf elongation, and leaf width and 2) which population had greatest sexual reproduction effort (inflorescence production, inflorescence height, seed production, and seed weight). Bi-weekly phenotypic data were summarized and analyzed using a functional data analysis approach. Plants varied for germination, sexual maturation, and senescence timing, so not all plants were measured at each sampling date. Individual plant measurements for a trait were summarize by dividing total growth by the number of weeks it took to achieve maximum growth for that trait: total growth = maximum growth $\mathrm{o} /$ number of weeks. This approach eliminates the variation in number of 
weeks required for individuals to reach maximum for each trait. Final measurements were not used because they did not always reflect maximum growth because of senescence and the switching of resources from vegetative to sexual reproductive growth.

A general linear model ANOVA was used to examine growth differences between populations and generations. When interactions between population and generation occurred, a difference of means within a population or generation was calculated with a Bonferroni adjusted $p$-value. The native populations (IN and OUT) were averaged and compared to the cultivar using a two sample $t$-test (95\% CI).

Traits displaying unequal variance, outliers toward the high end, and right-skewed data were logten-transformed to conform to assumed normality. Those traits for which data were log-transformed included: inflorescence height, seed production, inflorescence number, seeds per inflorescence, and weight per 100 seeds. Traits not log transformed were tiller production, plant height, basal diameter, leaf length and leaf width.

Regressions were run to determine which generation within each population had the fastest growth rate. For this analysis, data from weeks 2-14 were averaged across all individuals within each sampling date for each trait. Regressions determined how long (in weeks) a population took to reach the study average for each vegetative growth trait.

\subsubsection{Experimental Analysis - germination and seedling root growth of maternal lineages after field increase}

Seeds collected in different years from the same species may differ greatly in germination and root growth due to highly variable environmental conditions from year to year (Baskin and Baskin 2001). Seeds used in these experiments were collected from field plots but were grown in a common environment. Seed collections from the 2 years were not pooled or combined into one analysis to examine any differences between years. Genotypes exhibiting similar germination traits or primary root growth from collection year to collection year will provide even stronger evidence of any differences among IN and OUT genotypes than if only one collection year was examined. S. airoides seeds require after-ripening before notable germination can be expected (Knipe 1968). Seed lots underwent afterripening periods of at least 17 months (2006 seed), five months (2007 seed), and at least 16 months (commercial cultivar). Although larger $S$. 
airoides seeds tend to germinate more quickly than smaller seeds (Knipe 1970), we examined germination among genotypes regardless of seed size.

Since $S$. airoides seeds were collected in two different years $(2006,2007)$, differences in germination or root growth results may be due to differences in after-ripening periods. For example, the 2007 seed source year should exhibit greater variability in cumulative germination than the 2006 seed source year due to after-ripening differences between source years.

Cumulative and daily germination results and cumulative root growth results were analyzed for each seed source year using trend analysis (MANOVA) and the multivariate procedure hierarchical cluster analysis (Ward's linkage and squared Euclidian distances). Very similar to repeated measures (time measured on an ordinal scale), time is measured in trend analysis on a ratio scale. We used trend analysis instead of repeated measures because we were concerned with trends in germination and root growth over time. Additionally, determining polynomial effects (trends tests) are not possible in repeated measures which provide specific information about each dependent variable (explained in greater detail later in this chapter). In trend analysis there are normally two or more nominal level independent variables and only one dependent variable. In this thesis, the independent variable was either position (IN, OUT) or competitor category (strong, moderate, unlikely) and the dependent variable was time (sample days). The position by time (parallelism) interaction was analyzed first. If significant, each level of the independent variable (main effects) was analyzed separately and then trends tests (polynomial levels) were conducted to see which level of polynomial (linear, quadratic, cubic, etc.) best fit the data. If the interactions were not significant, then time (within) and group (between) main effects are discussed. For significant interactions, Bonferonni post hoc procedures were used to determine differences between IN and OUT positions within sample days. In instances where trend analysis gave $\mathrm{P}$ values that were approaching our alpha, univariate (ANOVA) $F$ statistics and P values were used instead (SPSS output yields output for both MANOVA and ANOVA procedures).

Cluster analysis of cases contains no "a-priori" information in regards to the position (IN, OUT) or the competitive categories (strong, moderate, unlikely) generated by the BSP. Cluster analysis was used to cluster $S$. airoides genotypes (cases) based on the germination data. To reduce the subjectivity inherent in cluster analysis, we conducted normal cluster analys- 
es, and then conducted discriminant analyses using the clustered variables as grouping variables and sample days as the independent variables. Discriminant analyses yields structure loadings and centroids which result in more objective interpretation of the clusters.

Daily germination and root growth results were analyzed for each seed source year with trend analysis (MANOVA) using Statistical Package for the Social Sciences (SPSS) (version 15). Very similar to repeated measures (ANOVA; time measured on an ordinal scale), time is measured in trend analysis on a ratio scale. Trend analysis was used instead of repeated measures because the study had focused on trends in germination and root growth over time. Additionally, determining polynomial effects (trends tests) are not possible in repeated measures that provide specific information about each dependent variable. In trend analysis, there are normally two or more nominal level independent variables and only one dependent variable. In this analysis, the independent variable was position (IN, OUT) and the dependent variable was time (sample days). The position by time (parallelism) interaction was analyzed first. If significant, each level of the independent variable (main effects) was analyzed separately and then trends tests (polynomial levels) were conducted to see which level of polynomial (linear, quadratic, cubic, etc.) best fit the data. If the interactions were not significant, then time (within) and group (between) main effects are discussed. For significant interactions, Bonferonni post hoc procedures were used to determine differences between IN and OUT positions within sample days. In instances where trend analysis gave $P$ values that were approaching this study's alpha, univariate (ANOVA) $F$ statistics and P values were used instead (SPSS output yields output for both MANOVA and ANOVA procedures).

\subsection{Environmental Simulation Laboratory (ESL) testing}

\subsubsection{Experimental design - environmental simulation laboratory}

We used the Environmental Simulation Laboratory (ESL) at the University of Wyoming to directly test competition between $S$. airoides and $\underline{R}$. repens. The ESL was divided into two adjacent pits that are $7.3 \mathrm{~m} \mathrm{x} 2.9 \mathrm{~m} \mathrm{x}$ $2.3 \mathrm{~m}$ (length $\mathrm{x}$ width $\mathrm{x}$ depth) (Figure 2). Total potential maximum volume of substrate for both pits is $48.7 \mathrm{~m}^{3}$ (we filled the ESL to a depth of $2.14 \mathrm{~m}, 45.3 \mathrm{~m}^{3}$ ). Two layers of substrate were used to fill the ESL, a bottom layer of washed masonry sand and a top soil layer (sandy clay loam). The bulk density of the top soil was $3.3 \mathrm{~g} / \mathrm{cm}^{3}$ and the washed masonry 
sand was $1.8 \mathrm{~g} / \mathrm{cm}^{3}$. A geotextile layer was installed on top of the sand to prior to adding top soil. Minirhizotron observation tubes were placed horizontally (slope of 3.5\%) across the length of each plot in the sand layer approximately $1.1 \mathrm{~m}$ from the bottom of each pit. These were designed to view plant roots that might penetrate the geotextile, but no plant roots reached the tubes during the 9-month study. Twelve Time Domain Reflectometry (TDR) probes were installed in the topsoil, yet were not used in the study.

The ESL allowed control of temperature, humidity, precipitation, and light regimes. Temperatures were maintained at $27^{\circ} \mathrm{C}$ during 9 hours of light and $16{ }^{\circ} \mathrm{C}$ during darkness. Daily precipitation averaged $3 \mathrm{~cm}$ depth for a 10 minute period using a ground sprinkler system. The relative humidity was kept near $20 \%$, yet varied slightly throughout the day as temperatures and moisture fluctuated. Light regimes were achieved using 1000 watt metal halide lamps during the entire experiment. Light regimes were achieved using 1000 watt metal halide lamps during the entire experiment. On 15 April 2010, new 1000 watt metal halide light bulbs were installed to increase light intensity as the experiment progressed. Irradiation levels at $15 \mathrm{~cm}$ above the soil surface for 9 hours a day were $194 \mu \mathrm{mol}$ $\mathrm{m}^{-2} \mathrm{~s}^{-1}$ from January to April and $308 \mu \mathrm{mol}^{\circ} \mathrm{m}^{-2} \mathrm{~s}^{-1}$ from April to September.

On 11 and 12 January 2010, clones of $S$. airoides from the original collections of invaded and non-invaded populations from Mealor and Hild (2006) were planted into the ESL. Clones were planted in a matrix of five clones per $0.45 \mathrm{~m}^{2}$ plot with a minimum distance of $0.5 \mathrm{~m}$ between plots and sides of the pit (Figure 2). Plots of invaded and non-invaded transplant clones were arranged at random within the first planted pit and then placed in identical positions in the second pit. One pit was randomly selected to contain the invader and the other did not (Figure 2). On 15 January 2010, $54 R$. repens plants were planted into one randomly selected pit. Two $R$. repens were planted on all sides of all grass plots. Rhaponticum repens plants were started from $8-10 \mathrm{~cm}$ long root cuttings and were 4 months old when planted into the ESL. On 25 August 2010, four seed bags containing 100 seedlings of each lineage were planted into plots. Seed bags contained $100 S$. airoides seedlings. On 14 July 2010, S. airoides seeds were directly planted into soil within an 11 by $12 \mathrm{~cm}$ grid located within each clone matrix to document establishment. Seed bags were collected at timed intervals (every 2 days) to estimate seed germination. 


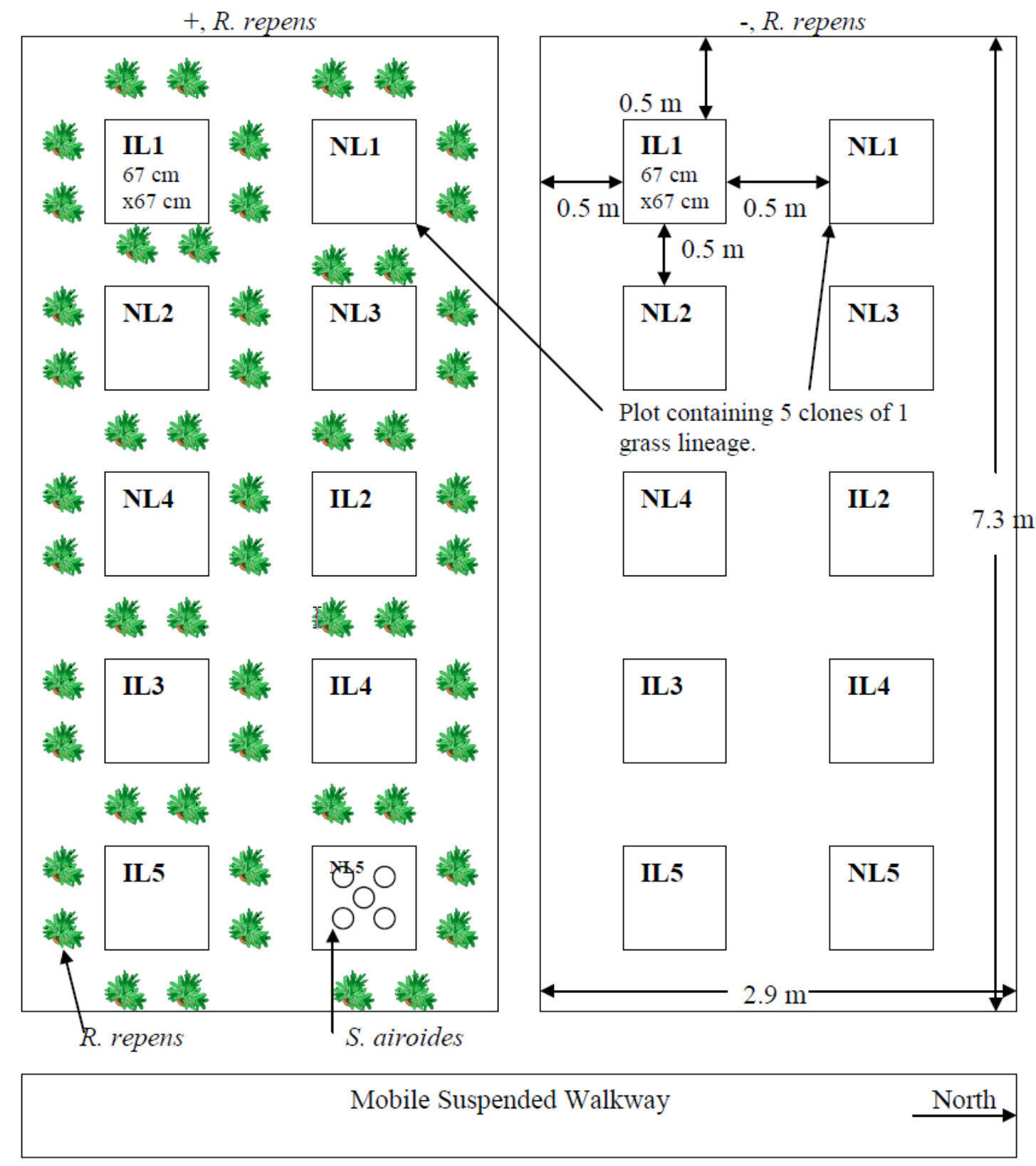

Figure 2. Layout of controlled experiment to test lineages of Sporobolus airoides with and without competition from Rhaponticum repens. Experiment was conducted in University of Wyoming Environmental Simulation Laboratory. Plots containing five identical clones of each invaded and non-invaded lineages were randomly placed into both weed treatments. Experimental design was a split plot arrangement. Plants represent $R$. repens planted around $\mathrm{S}$. airoides plots for one pit. Depth is $2.14 \mathrm{~m} /$ pit. $\mathrm{N}=$ non-invaded, $\mathrm{I}=$ invaded, Lines $1-5=$ lineages. Identical lines were planted in the two sides of the ESL, i.e., IL3 is genetically identical in both weed treatments. 
Seed bags were collected on $8,10,12$, and 14 September 2010, 10 days after planting. Seeds used for germination and establishment were collected from the same mature maternal lineages as transplant clones. Seed and seed bags were placed later in the study to allow $R$. repens to mature and provide a competitive environment for seedling tests.

Monitoring occurred once every 4 weeks starting initially on 15 January and ending on 5 May 2010.Transplanted clones were measured every 2 weeks until 8 September 2010 resulting in a total of 14 sampling dates. Above-ground vegetative production was measured on clones using longest leaf $(\mathrm{cm})$, number of tillers, basal circumference $(\mathrm{cm})$, and number of inflorescences produced. The number of established seedlings and number of invasive species within each plot were counted on each sampling date. Rhaponticum repens transplants were monitored for number of leaves and stems on each date.

\subsubsection{Experimental analysis - environmental simulation laboratory}

The ESL experiment was analyzed as a split plot in time arrangement of completely randomized block design (CRBD) using $R$. repens presence $(+,-$ ) as the main plot treatment (randomly assigned to one pit) and invasion history of $S$. airoides lineages as sub-plot treatments assigned within each main plot (Figure 2). Germination was analyzed as cumulative values over four dates where F-tests were significant at 0.05. Mean separation was conducted using the LSD mean separation test at the $\alpha=0.05$ level. As with the field experiments, statistical analysis was completed using JMP, Version 7. SAS Institute Inc., Cary, NC, 1989-2007. 


\section{Field Plantings and Evaluations}

\subsection{Experimental design - long term exposure}

\subsubsection{Collection of plant materials - long term exposure}

To assess the effect of long-term exposure to $R$. repens on native populations, two native grass species from two communities of origin (R. repens dominated community and native, non-invaded rangeland) were sampled at three different locations. Sporobolus airoides was collected near Greybull and Laramie, WY and Naturita, CO, and H. comata was collected near Riverton and Laramie, WY and Mud Lake, ID at the same time that plant materials were collected for the molecular studies presented in Mealor and Hild (Mealor and Hild 2006) (Figure 1). All locations were estimated to have contained $R$. repens infestations for more than 30 years, possibly up to 80 years (Mealor and Hild 2006). The two native grass species, S. airoides and $H$. comata, were selected based on their presence and apparent resistance to $R$. repens in old $R$. repens invasions (Mealor et al. 2004). Collecting native grasses included random sampling within each community (invaded, non-invaded) at each location. Collections were separated by more than $1 \mathrm{~m}$ to reduce chance re-sampling of individuals. Invaded and non-invaded communities were less than $20 \mathrm{~m}$ apart at each location. Ten large genets (approximately $25 \mathrm{~cm}$ diameter) of each native grass species were excavated from each collection location and transported to greenhouse facilities at the University of Wyoming in Laramie, WY.

Each grass genet was divided into multiple clones and transplanted into pots in the greenhouse. Individual ramet groups to be used as transplants were maintained under greenhouse conditions with drip irrigation and supplemental lighting until 2 weeks before field planting ( $\sim 10 \mathrm{mo})$. The prolonged hold-over time in the greenhouse was used in hope of decreasing maternal effects on the performance of the transplants, but the potential impacts of maternal effects cannot be completely ruled out. Ramet groups were then moved out of the greenhouses into a sheltered area for a 2-week hardening-off period before field planting.

\subsubsection{Site description and field installation - long term exposure}

Fifty genets of the two native grass species were obtained from communities long-invaded (25-70 years) by $R$. repens and from adjacent, non- 
invaded areas. Collections for this experiment were obtained from populations previously analyzed using AFLPs, which suggested evidence of divergent selection between communities invaded and free of $R$. repens (Mealor and Hild 2006).

Five transplants of each genet were planted into two $R$. repens infestations (Laramie and Fort Steele, WY) to document their growth and survival. The common characteristic shared by the study sites was the presence of large infestations of $R$. repens. The Laramie study site $\left(41.31^{\circ} \mathrm{N}, 105.66^{\circ} \mathrm{W}\right)$ is situated at $2215 \mathrm{~m}$ and receives an average of $284 \mathrm{~mm}$ of precipitation annually, whereas the Fort Steele site $\left(41.77^{\circ} \mathrm{N}, 106.93^{\circ} \mathrm{W}\right)$ lies at $1978 \mathrm{~m}$ and averages $247 \mathrm{~mm}$ of precipitation annually. There was an abundance of standing dead and fallen $R$. repens litter at the Laramie site ( $\left.9000 \mathrm{~kg} \cdot \mathrm{ha}^{-1}\right)$, but the Fort Steele site had no R. repens litter accumulation (potentially because of herbivory). The upland Laramie transplant site originally contained $H$. comata, and may be more environmentally suited to the cool-season $R$. repens. The Fort Steele site is at lower elevation than the Laramie site and is characterized by a different set of plant species, including $S$. airoides. To facilitate planting of native grasses, standing dead biomass was mowed and nearly all $R$. repens litter was raked from the planting plots at the Laramie site before beginning the experiment. Rhaponticum repens live stem density was less at the Fort Steele site (24.8 \pm 0.50 stems per $\left.\mathrm{m}^{2}\right)$ than at Laramie $\left(34.7 \pm 0.79\right.$ stems $\cdot$ per $\left.\mathrm{m}^{2}\right)$.

In May (Laramie) and June (Fort Steele), transplants of each grass genotype were placed into the two sites in the following manner. At each site, five experimental planting grids were created within the $R$. repens invasion. Within each grid, 90 holes were dug for transplanting including extra holes around the grid perimeter to limit boundary effects on transplants. Perimeter holes were refilled after digging. One of five transplants of each grass ( $H$. comata or $S$. airoides) representing each community of origin (invaded, non-invaded) and collection location (Laramie, Greybull, Naturita, Mud Lake, Riverton; community $\times$ location $\times$ individual combination = genotype) were randomly assigned to one of five grids. Within each grid, transplants were separated by $50 \mathrm{~cm}$. Each grid contained all genotypes (10 H. comata invaded, $10 \mathrm{H}$. comata non-invaded, $15 \mathrm{~S}$. airoides invaded, $15 \mathrm{~S}$. airoides non-invaded), resulting in 250 transplants at each site (50 transplants in each grid $\mathrm{x} 5$ grids per site). Transplants were watered after installation and weekly for the first month; they received only natural precipitation for the remainder of the experiment. 
Transplanted grasses were monitored every 2 weeks during the growing season, and measured height (length of longest leaf), two measures of basal diameter, number of green tillers and survival. The two measures of basal diameter were used to calculate bunchgrass basal area. Monitoring continued for two growing seasons. At the onset of the experiment, transplants were variable in size. Grass growth was calculated as change relative to initial size, as has been used previously for bunchgrass transplant studies (Smith 1998, Callaway et al. 2005, Page and Bork 2005). Seeds were also collected from any transplants that produced seeds.

\subsection{Experimental design - resistance and resilience}

\subsubsection{Collection of plant materials - resistance and resilience}

To assess the effect of exposure to $R$. repens on resistance and resilience of native grass populations, $S$. airoides from two Russain knapweed communities of origin ( $R$. repens dominated community and native, noninvaded rangeland) were sampled at three different and previously identified locations (Mealor and Hild 2006, Figure 1). All locations were estimated to have contained $R$. repens infestations for more than 30 years, possibly up to 80 years (Mealor and Hild 2006). Sporobolus airoides was selected based on its presence and apparent resistance to $R$. repens in old $R$. repens invasions (Mealor et al. 2004), and on the species response to NIPS exposure (Mealor and Hild 2007, Ferrano-Serrano et al. 2008). We use two distinct communities of origin, invaded plants formerly grown in invasions for 25-70 years, and non-invaded, lacking a history of competition with invasives. We transplanted both lineage histories into invaded field sites dominated by $R$. repens and $C$. arvense. In addition to the two field sites, for comparison we also and a controlled environment, (the University of Wyoming Environmental Simulation Lab, (ESL)). In the ESL we transplanted both lineages into plots with and without $R$. repens.

\subsubsection{Site description and field installation - resistance and resilience}

Field sites were established near Crowheart, WY and Cheyenne, WY. The Crowheart, WY site is located adjacent to the Wind River in a cottonwood gallery forest system that contains a large dense $\left(18 \mathrm{stems} / \mathrm{m}^{2}\right)$ stand of $R$. repens. Soil at the site is sandy loam, $\mathrm{pH}$ of 8.5 , and an electrical conductivity of $1.98 \mathrm{DS} / \mathrm{M}$. The site lies at an elevation of $1709 \mathrm{~m}$ and receives on average $235 \mathrm{~mm}$ of precipitation annually (NCDC 2010). The Cheyenne, WY study site is located in the north east corner of FEWAFB between the 
North and South Pearson Lakes within a dense (61 stems $\left./ \mathrm{m}^{2}\right)$ stand of $C$. arvense. Soil texture is clay, $\mathrm{pH}$ of 8.1, and electrical conductivity of 1.14 $\mathrm{DS} / \mathrm{M}$. Annual precipitation is $394 \mathrm{~mm}$ and the site lies at an elevation of 1888 m (NCDC 2010).

Invaded and non-invaded sub-populations of $S$. airoides were collected from three field sites, Laramie and Greybull, WY and Naturita, CO (Mealor and Hild 2006, Figure 1). Populations were marked with location of excavation and placed in separate greenhouses to prevent cross-pollination between populations (invaded greenhouse and non-invaded greenhouse). Forty experimental plots $(67 \mathrm{~cm} \mathrm{x} 67 \mathrm{~cm})$ were established at each field site. Ten invaded and ten non-invaded maternal lineages were randomly assigned to twenty of the experimental plots. Into each of the 20 plots were transplanted five identical grass clones arranged in a matrix formation. Transplants were installed on 8 November 2008 at Crowheart and 1 May 2009 at FEWAFB. Individual lineages were used from all three collection sites (3 Laramie, WY, 7 Greybull, WY, and 10 Naturita, CO). Four seed bags (100 seeds per bag) and one direct seeded establishment grid (100 seeds planted into soil) were also included in the experimental plots (Figure 3). Seeds for the seed bags and the establishment grids were collected from the same lineage as the transplants in each plot. Soil in each plot was removed 15 to $24 \mathrm{~cm}$ deep (depending on top soil depth), placed on a large screen and sifted over a tarp to remove all $R$. repens and $C$. arvense tap roots and other large root and woody material. The soil was returned to each grid after sifting. Soils were sifted to give the transplanted grasses an opportunity to establish before encountering direct competition from $R$. repens and $C$. arvense. Although the soil was sifted, $R$. repens and $C$. arvense tap roots still remained intact below the removed soil depth. The additional 20 plots at each site consisted of 10 undisturbed "reference" plots and 10 disturbed, but unplanted plots. Plots were separated by at least $0.5 \mathrm{~m}$. Fences were constructed around all plots to prevent herbivory from wildlife (Figure 4). Undisturbed plots were mixed with the invaded and non-invaded plots. Disturbed plots were located nearby (within $3 \mathrm{~m}$ ) in an area with comparable density of $R$. repens (18 stems/ $1.0 \mathrm{~m}^{2}$; Figure 4). Several plots at Crowheart were disturbed by small burrowing rodents despite the fences. Undisturbed plots were mixed with the invaded and non-invaded plots. Disturbed plots were located nearby (within $3 \mathrm{~m}$ ) in an area with comparable density of $R$. repens ( $18 \mathrm{stems} / 1.0 \mathrm{~m}^{2}$; Figure 4). 


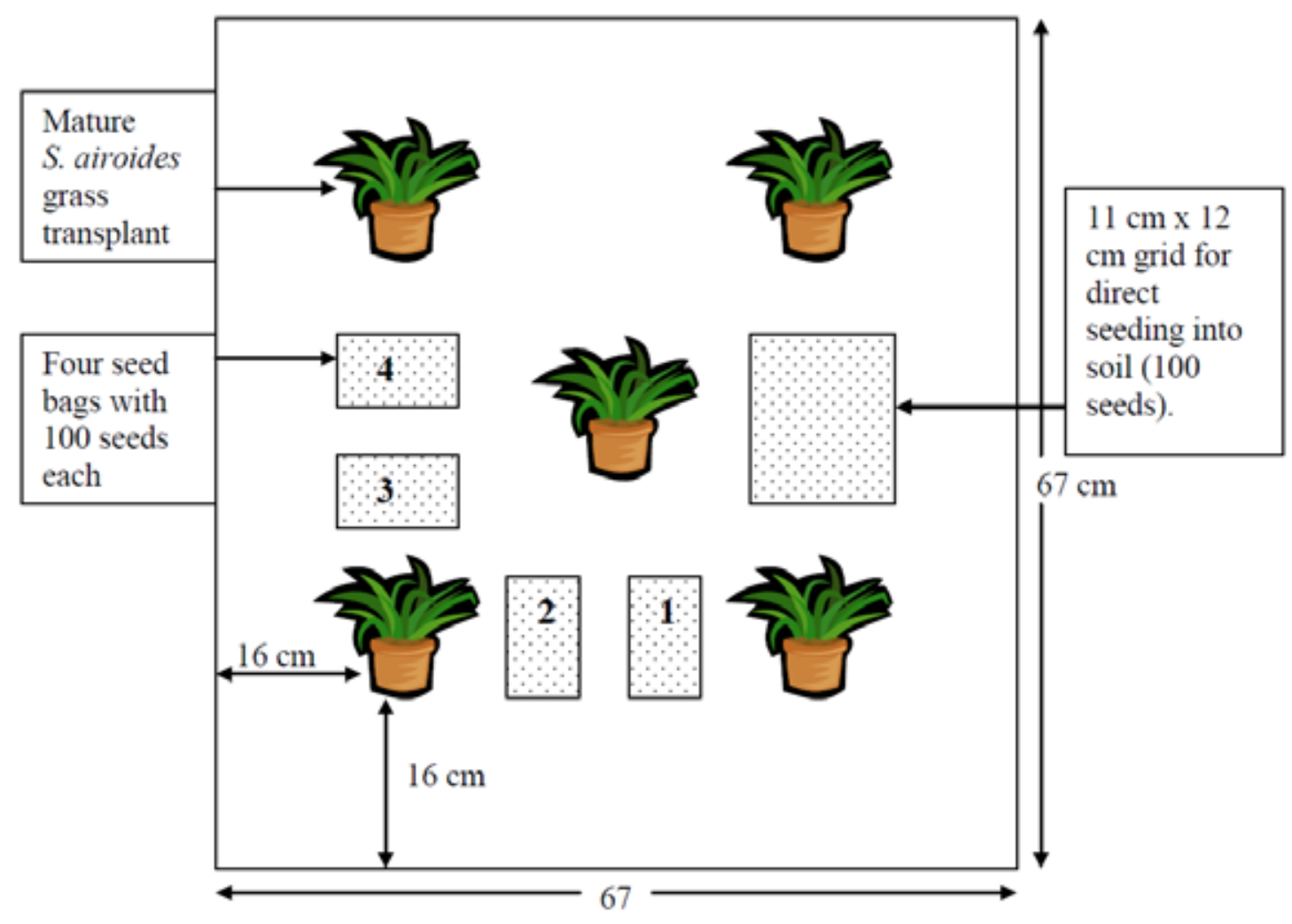

Figure 3. Position of individual grass of Sporobolus airoides clones, seed bags, and seedling grid in plots. Each plot contains five transplanted clones, four seed bags, and a seedling establishment matrix. 


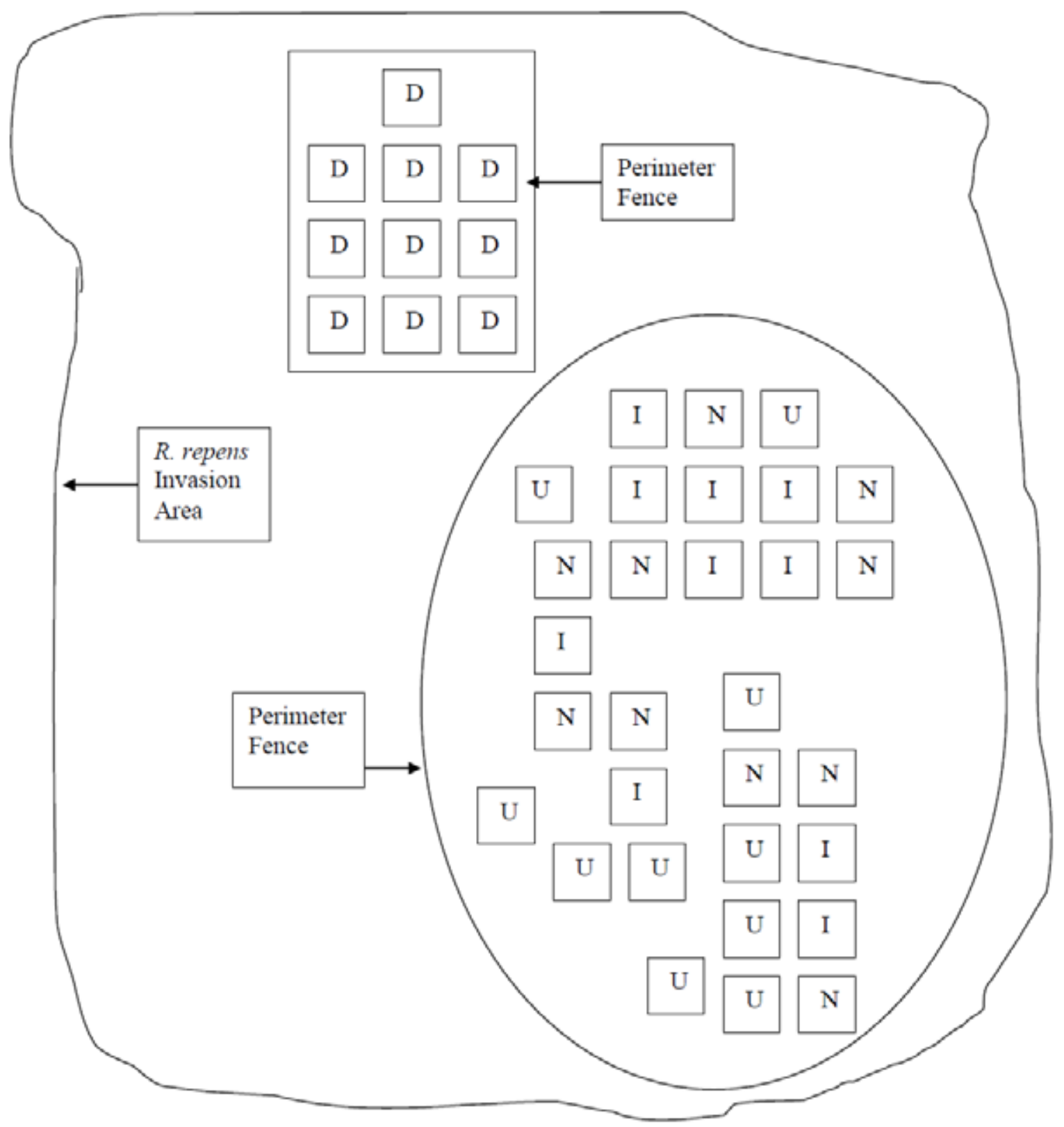

Figure 4. Field plot layout at study site near Crowheart, WY with 20 transplant grids, 10 undisturbed plots and 10 disturbed plots spaced a minimum of $0.5 \mathrm{~m}$. Entire area is contained within invasion. Separate fence for disturbance plots were made due to lack of similar invasion area within main fence. Disturbance and main areas are equal density invasion of Rhaponticum repens. The same layout is also installed at FEWAFB, WY in an invasion of Cirsium arvense. $\mathrm{D}=$ disturbed, $\mathrm{U}=$ undisturbed, $\mathrm{I}=$ invaded, and $\mathrm{N}=$ noninvaded. 


\subsection{Experimental analysis - long term exposure}

\subsubsection{Tiller production - genets}

Tiller production was calculated by dividing the maximum number of green tillers by the number of green tillers at the initiation of the experiment. Basal area changes were calculated as the final basal area divided by initial basal area. Tiller production and change in basal area were calculated for surviving ramets only. Percent survival of a genotype was expressed as the proportion of cloned transplants surviving throughout the experiment (number of transplants surviving / number of transplants established for each genotype). Individual transplants were considered established if they were alive 1 week following planting. A performance value was calculated for each genotype as the product of maximum tiller production, change in basal area, and survival. Similar measures combining survival and growth have been used to assess performance in other work (Blair and Wolfe 2004). The integration of survival in this calculation weights each genotype for survival. For example, a genet with no transplants surviving the duration of the experiment would have an overall performance of zero, regardless of how great its tiller production or basal area change.

\subsubsection{Genotype and community of origin assessment}

To screen genotypes for differential performance within a knapweed invasion, ANOVA was used with field site and genotype as treatments and the five clonal transplants of each genotype as replicates. In genotype-level analyses, dead individuals were included as zero values. All statistical analyses were conducted using SAS. Significance for all analyses was declared at $\alpha=0.05$ level and mean separation was accomplished using least significant difference (LSD) with error terms appropriate to each comparison.

Data were assessed and conformed to assumptions of normality.

Native grass growth data (tiller production, change in basal diameter, survival, and performance) were analyzed using ANOVA to partition sources of variation due to field site, community of origin, and collection location with each factor considered fixed. Each grass species was analyzed separately. Data conformed to the assumptions of ANOVA.

To compare populations from invaded to non-invaded communities, data from the five clonal transplants were averaged together and genotypes 
served as replicates. Transplants from non-invaded communities were larger than those from invaded communities at the onset of the experiment (Mealor 2006). To account for this initial variation, the study focused on measures of proportional change in size. A combined measure of plant performance was also calculated as (basal area change $\times$ tiller production $\times \%$ survival) for each genet. Plant performance, survival, and proportional growth (tiller production and basal area change) were assessed by implementing an ANOVA design using field site, location, and community of origin as treatment factors.

\subsection{Experimental analysis - resistance and resilience}

\subsubsection{Field installations}

Sporobolus airoides clones and seedling establishment were evaluated on eight dates over two field seasons (11-12 June 2009, 9-10 July 2009, 6-7 August 2009, and 3-4 September 2009, 10-11 June 2010, 8-9 July 2010, 56 August 2010, and 2-3 September 2010). Clones were measured for longest leaf $(\mathrm{cm})$, number of tillers, basal circumference $(\mathrm{cm})$, and number of inflorescences produced. Established seedling (number) and encroachment of invasive species within each plot $(67 \mathrm{~cm} \times 67 \mathrm{~cm})$ were counted on each date. Seed bags for germination were collected on four dates in the spring of $2009(9,11,13,15$ June at Crowheart and 7, 9, 11, 13 June at FEWAFB). Seed bags were collected every 2 days after initial germination was observed in test seed bags (test bags not measured for analysis).

The field experiments were analyzed as a completely randomized design (CRD) with analysis of variance (ANOVA) for each site individually. Field sites were analyzed separately because they differed in the dominant invasive species. Datasets (cumulative germination, growth of clones, and seedling establishment) were analyzed as a two factor factorial treatment using position and date (Figures 3 and 4). Germination (\%) was analyzed using cumulative values over the four sampling dates. Where F-tests were significant at the $\alpha=0.05$ level, mean separation was conducted using LSD at the $\alpha=0.05$ level. Statistical analysis was completed using JMP, Version 7. SAS Institute Inc., Cary, NC, 1989-2007. 


\section{Biological Screening Process}

Developing and constructing a Biological Screening Process (BSP) to assist in the identification and selection of promising genotypes began with a pool of 50 maternal lineages, most of which had been used in previous experiments. Prior experiments examined: (1) competition of $S$. airoides against $C$. arvense in greenhouse plantings (measured as above- and below-ground growth (Ferrero-Serrano et al. 2006, Ferrero-Serrano et al. 2008)), (2) competition of $S$. airoides combined with a stem mining weevil against $C$. arvense in greenhouse plantings (Ferrero-Serrano et al. 2006, Ferrero-Serrano et al. 2008), (3) competition of S. airoides and R. repens in field and greenhouse plantings (Mealor and Hild 2007), and (4) unpublished fecundity data on seeds collected from maternal and first generation S. airoides plants. Additionally, experiments used in the BSP analyzed between 17 and $48 \mathrm{~S}$. airoides maternal lineages (the number varied for each experiment). An initial ranking scale of 1 to 20 was used to determine and place $S$. airoides maternal lineages within a successful or unsuccessful category. Each maternal lineage received a rank number ranging from 1 to 20 for each experiment. The top 10 maternal lineages were designated successful and remaining maternal lineages were designated unsuccessful. In experiments that assessed fewer, or more than 20 maternal lineages, weighted values were calculated to adjust to a 1 to 20 scale. In some cases, particular maternal lineages were included in more experiments than other maternal lineages. 


\section{Results and Discussion}

\subsection{Testing of native grass collections for genetic traits}

\subsubsection{Hesperostipa comata - maternal tissue}

Five AFLP primer combinations produced 454 loci (84.6 percent polymorphic). A range of 47 to 124 bands were observed per primer pair in 139 individual $H$. comata plants (Table 3). There were no fragments exclusive to either invaded or non-invaded communities at any of the three locations. When observed Fst values were compared to simulated Fst values for polymorphic loci in $H$. comata separately for each location, 10 loci (2.6 percent) fell above the upper 95 percent quantile indicating potential linkage to genes under selection (Table 4). Number of $S_{L}$ loci varied by location and by primer combination (Table 4). Nei's gene diversity (1973) did not differ between community types for $\mathrm{NS}_{\mathrm{L}}, \mathrm{S}_{\mathrm{L}}$, or all loci combined.

Twenty four loci (6.3 percent) exhibited parallel trends in divergence, 22 among $\mathrm{NS}_{\mathrm{L}}$ and 2 among $\mathrm{S}_{\mathrm{L}}$ loci. The proportions of greatest band presence in the invaded community were: Laramie (o.353), Mud Lake (o.310), and Riverton (0.283) (product $=0.031)$. The proportions of greatest band presence in the non-invaded communities were $0.294,0.308$, and 0.252 (product $=0.024$ ), respectively. The proportion of loci expected to exhibit parallel trends in divergence, therefore was calculated as the sum of the products for each community type $(0.030+0.024=0.054$, or 5.4 percent). No excess of parallel trends were observed in $\mathrm{NS}_{\mathrm{L}}$ loci $\left(\mathrm{X}^{2}=0.189\right.$, $\mathrm{p}=0.664)$ whereas $\mathrm{S}_{\mathrm{L}}$ loci showed a significant excess of parallel trends in divergence $\left(X^{2}=4.20, p=0.040\right.$ (Tables 5 and 6). On a more local scale, the study tested for differences in genetic distances (Nei 1978) between subpopulations within a community and between communities at each location. When using $\mathrm{S}_{\mathrm{L}}$ loci, the distance between communities was larger than the distance within communities $(\mathrm{p}=0.090)$ whereas distance within and between communities did not differ $(\mathrm{p}=0.260)$ when using $\mathrm{NS}_{\mathrm{L}}$ loci.

\subsubsection{Sporobolus airoides - maternal tissue}

AFLP analysis produced 553 loci (92.6 percent polymorphic) in 162 individual $S$. airoides plants. The number of bands produced per primer pair ranged from 76 to 153 (Table 2). When observed Fst values were compared to simulated Fst values for polymorphic loci in $S$. airoides separately for 
each location, 45 loci (8.7 percent) fell above the upper 95 percent quantile indicating selection. The proportion of $\mathrm{S}_{\mathrm{L}}$ loci varied by location and by primer pair. Community gene diversity (Nei 1973) did not differ between $\mathrm{S}_{\mathrm{L}}$ loci, $\mathrm{NS}_{\mathrm{L}}$ loci, or all loci combined (Table 4).

Forty eight loci (9.4 percent) exhibited parallel trends in divergence, 42 among $\mathrm{NS}_{\mathrm{L}}$ and six among $\mathrm{S}_{\mathrm{L}}$ loci. At Greybull, Laramie, and Naturita, the proportions of greatest band presence in the invaded community were $0.372,0.359$, and 0.353 (product $=0.047$ ). The proportions of greatest band presence in the non-invaded communities were $0.320,0.329$, and 0.269 (product $=0.027$ ). The proportion of loci expected to exhibit parallel trends in divergence, therefore was calculated as the sum of the products for each community type $(0.047+0.027=0.074$, or 7.4 percent $)$. No excess of parallel trends were observed in $\mathrm{NS}_{\mathrm{L}}$ loci $\left(\mathrm{X}^{2}=1.67, \mathrm{p}=0.196\right)$ or in $S_{L}$ loci $\left(X^{2}=2.25, p=0.133\right)$ although there were nearly twice more than expected in $\mathrm{S}_{\mathrm{L}}$ loci (Tables 5 and 6).

Differences in genetic distances (Nei 1978) between subpopulations within a community and between communities at each location were similar to $H$. comata. That is, when using $\mathrm{S}_{\mathrm{L}}$ loci, the distance between communities was larger than the distance within communities $(p=0.077)$ whereas there was no difference $(\mathrm{p}=0.625)$ when using $\mathrm{NS}_{\mathrm{L}}$ loci suggesting greater differentiation between communities than within a community.

Table 3. Levels of polymorphism of scored amplified fragment length polymporphism (AFLP) loci. A locus was considered polymorphic if at least one individual demonstrated a variant pattern.

\begin{tabular}{|l|r|r|r|r|r|r|}
\hline \multirow{2}{*}{ Species } & \multicolumn{6}{|c|}{ Primer Combination } \\
\cline { 2 - 7 } & ACG.CAC & ACG.CTA & ACG.CTC & ACGT.CTTC & AGT.CTT & Total \\
\hline H. comata & \multicolumn{7}{|c|}{ Number of bands } \\
\hline Variable bands & 41 & 99 & 55 & 97 & 92 & 384 \\
\hline Fixed bands & 6 & 3 & 6 & 23 & 32 & 70 \\
\hline Total & 47 & 102 & 61 & 120 & 124 & 454 \\
\hline S. airoides & 74 & 120 & 78 & 107 & 123 & 512 \\
\hline Variable bands & 2 & 6 & 6 & 7 & 20 & 41 \\
\hline Fixed bands & 76 & 126 & 84 & 114 & 153 & 553 \\
\hline Total & 74 & & & & \\
\hline
\end{tabular}


Table 4. Loci potentially linked to genes under selection $\left(\mathrm{S}_{\mathrm{L}}\right)$ in two native grass species at three locations.

\begin{tabular}{|l|l|l|l|l|l|l|}
\hline Species & Primer Combination \\
\hline Location & Number S $\mathrm{L}$ & ACG.CAC & ACG.CTA & ACG.CTC & ACGT.CTC & AGT.CTT \\
\hline H. comata \\
\hline Laramie & 4.0 & 1.0 & 0.0 & 0.0 & 3.0 & 0.0 \\
\hline Mud Lake & 0.0 & 0.0 & 0.0 & 0.0 & 0.0 & 0.0 \\
\hline Riverton & 6.0 & 0.0 & 3.0 & 2.0 & 0.0 & 1.0 \\
\hline Mean & 3.0 & 0.3 & 1.0 & 0.7 & 1.0 & 0.3 \\
\hline S. airoides & \multicolumn{7}{|l|}{} & \\
\hline Greybull & 4.0 & 2.0 & 3.0 & 2.0 & 0.0 & 7.0 \\
\hline Laramie & 11.0 & 1.0 & 3.0 & 1.0 & 2.0 & 4.0 \\
\hline Naturita & 21.0 & 2.0 & 5.0 & 4.0 & 6.0 & 4.0 \\
\hline Mean & 5.3 & 1.7 & 3.7 & 2.3 & 2.7 & 5.0 \\
\hline
\end{tabular}

Table 5. Genetic diversity statistics from AFLP analysis of Hesperostipa comata and Sporobolus airoides from two community types (invaded by Rhaponticum repens and noninvaded). Loci examined are all polymorphic loci, loci not linked to selection (NSL), and loci potentially linked to selection $\left(\mathrm{S}_{\mathrm{L}}\right)$.

\begin{tabular}{|c|c|c|c|c|c|}
\hline \multirow[b]{2}{*}{ Location } & \multirow[b]{2}{*}{ Community } & \multirow[b]{2}{*}{$\mathrm{N}^{1}$} & \multirow{2}{*}{\begin{tabular}{|l|} 
All \\
$h^{2}$
\end{tabular}} & \multirow{2}{*}{$\frac{\mathrm{NS}}{\mathrm{h}}$} & \multirow{2}{*}{$\frac{S_{L}}{h}$} \\
\hline & & & & & \\
\hline \multicolumn{3}{|c|}{ H. comata (no. loci examined) } & $(384)$ & $(374)$ & (10) \\
\hline Mud Lake, ID & $\mathrm{IN}^{3}$ & 29 & 0.120 & 0.150 & 0.266 \\
\hline (ML) & OUT & 28 & 0.146 & 0.176 & 0.2 .86 \\
\hline Laramie, WY & IN & 13 & 0.183 & 0.218 & 0.331 \\
\hline (LA) & OUT & 15 & 0.162 & 0.193 & 0.304 \\
\hline Riverton, WY & IN & 27 & 0.145 & 0.179 & 0.278 \\
\hline$(\mathrm{RV})$ & OUT & 27 & 0.147 & 0.182 & 0.256 \\
\hline \multirow[t]{2}{*}{ Mean } & IN & 69 & 0.149 & 0.182 & 0.292 \\
\hline & OUT & 70 & 0.151 & 0.184 & 0.282 \\
\hline \multicolumn{3}{|c|}{ S. airoides (no. loci examined) } & $(512)$ & $(465)$ & $(45)$ \\
\hline Greybull, WY & IN & 26 & 0.186 & 0.204 & 0.254 \\
\hline (GB) & OUT & 24 & 0.183 & 0.201 & 0.252 \\
\hline Laramie, WY & IN & 29 & 0.184 & 0.200 & 0.244 \\
\hline (LA) & OUT & 26 & 0.194 & 0.212 & 0.2722 \\
\hline Naturita, CO & IN & 29 & 0.172 & 0.185 & 0.257 \\
\hline (NA) & OUT & 28 & 0.178 & 0.190 & 0.275 \\
\hline \multirow[t]{2}{*}{ Mean } & & 84 & 0.181 & 0.196 & 0.252 \\
\hline & & 78 & 0.185 & 0.201 & 0.266 \\
\hline $\begin{array}{ll}1 & n=\text { numb } \\
2 & h=\text { Nei's } \\
3 & \text { 'in' denote }\end{array}$ & $\begin{array}{l}\text { viduals sampl } \\
\text { rsity (Nei } 197 \\
\text { d communitie }\end{array}$ & “out" d & otes adjac & t, non-inv & ommunities. \\
\hline
\end{tabular}


Table 6. Chi-square analysis of parallel trends in divergence in two grasses. Tests compare observed number of parallel trends to the number expected under neutrality for $N S_{L}$ and $S\llcorner$ in two community types: invaded by Rhaponticum repens, non-invaded.

\begin{tabular}{|c|c|c|c|c|c|}
\hline & & Observed & Expected & $\mathrm{X}^{2}$-value & P-value \\
\hline \multicolumn{6}{|c|}{ Hesperostipa comata } \\
\hline \multirow{2}{*}{$N S_{L}$} & Parallel trend & 22 & 20.1 & 0.2 & \\
\hline & No parallel trend & 352 & 353.9 & 0.01 & 0.664 \\
\hline \multirow{2}{*}{$S_{\llcorner}$} & Parallel trend & 2 & 0.5 & 4.0 & \\
\hline & No parallel trend & 8 & 9.5 & 0.2 & 0.040 \\
\hline \multicolumn{6}{|c|}{ Sporobolus airoides } \\
\hline \multirow{2}{*}{$N S_{L}$} & Parallel trend & 42 & 34.7 & 1.6 & \\
\hline & No parallel trend & 423 & 430.3 & 0.1 & 0.196 \\
\hline \multirow{2}{*}{$S\llcorner$} & Parallel trend & 6 & 3.4 & 2.1 & \\
\hline & No parallel trend & 39 & 41.6 & 0.2 & 0.133 \\
\hline
\end{tabular}

\subsubsection{Maternal plants genetic traits discussion}

The proportion of loci designated as $\mathrm{S}_{\mathrm{L}}$ is perhaps smaller than one would have expected from self-fertilizing plants. However, the high levels of polymorphism observed are not expected for principally self-pollinating species (Ferdinandez et al. 2005). This study's reports of mating systems were based on a historical paper (Fryxell 1957), which, together with other research, has also shown a discrepancy (Ferdinandez et al. 2005). Levels of polymorphism in these two grasses may reflect a higher level of outcrossing than originally suspected, but this explanation would have to be further assessed.

The observed patterns of parallel divergence of $\mathrm{S}_{\mathrm{L}}$ and $\mathrm{NS}_{\mathrm{L}}$ loci seem to be consistent with an expectation that parallel selection is occurring on $\mathrm{S}_{\mathrm{L}}$ across locations. Overall, few loci exhibited parallel trends in divergence for either grass species. This study's observations of parallel divergence are comparable to observations in lake whitefish (Coregonus clupeaformis), which occur in two distinct morphotypes (dwarf, normal) where around 12 percent (Campbell and Bernatchez 2004) of polymorphic loci (8 and 10 percent were observed in this work) showed parallel trends. Despite the many differences between fish and perennial grasses, it is interesting to note the similarity of the observations. The grasses used in this work have only been subject to altered environmental conditions for a short time, but exhibit nearly as many parallel trends as the whitefish. That these grasses may be capable of self-fertilization might contribute to the rapidity of selection, as differentiation is highly likely in taxa with high levels of self- 
fertilization (Linhart and Grant 1996). Currently, there are no easily observable morphological differences between these grasses in the different communities. Because some are present in knapweed invasions while others are in areas free of knapweed, there may be physiological differences that allow persistence and require further study.

Note that, with the methodology used, outliers are expected simply by chance, and results must be interpreted with caution. Before SL loci identified in this study can be confidently regarded as under the effect of directional selection, concordant results from an independent source (e.g., Quantitative Trait Locus [QTL] mapping) should be considered (Campbell and Bernatchez 2004).

\subsection{Results of testing genetic variation of invaded and non-invaded Sporobolus airoides populations after two generations of greenhouse seed increase}

Three AFLP primer combinations amplified a total of 250 unique fragments (Table 7). The most and least fragments were recorded within the OUT population; MONO G2 at 188 fragments and BGV G1 with 147 fragments. Within the IN population, more fragments were recorded for the first generation than the second generation for MONO and GB. Within the OUT population, more fragments were recorded for the second generation than the first for BGV and MONO, while GB was opposite this trend.

Most genetic variation was attributed to differences among individuals within a population (95.0 percent; Table 8 ) or location (93.7 percent) rather than between populations (5.0 percent) or locations (6.3 percent; AMOVA Table 8). Expected heterozygosity $\left(\mathrm{H}_{\mathrm{e}}\right)$, total loci, and percentage of polymorphic loci $(P)$ for successfully genotyped plants of invaded (IN) and non-invaded (OUT) Sporobolus airoides populations. Individuals were analyzed separately by first (G1) and second (G2) generations of original sampling location (BGV, MONO, GB). Original sampling locations were: Naturita, CO (BGV), Laramie, WY (MONO) and Greybull, WY (GB). The commercial cultivar was obtained from Manderson, WY.

Within a location (BGV, MONO, and GB) differences between IN and OUT populations accounted for 5.9 to 8 percent of the genetic variation. Wright's fixation index $\left(\mathrm{F}_{\mathrm{st}}\right)$ for genetic differentiation was 0.08 for BGV and GB locations and 0.103 for the MONO location. Differences between generations (G1 and G2) accounted for 4.1 percent of the genetic variation for the IN population of the BGV and MONO location. 
Table 7. Expected heterozygosity $\left(\mathrm{H}_{\mathrm{e}}\right)$, total loci, and percentage of polymorphic loci $(P)$ for successfully genotyped plants of invaded (IN) and non-invaded (OUT) Sporobolus airoides populations. Individuals were analyzed separately by first (G1) and second (G2) generations of original sampling location (BGV, MONO, GB). Original sampling locations were: Naturita, CO (BGV), Laramie, WY (MONO) and Greybull, WY (GB). The commercial cultivar was obtained from Manderson, WY.

\begin{tabular}{|l|c|l|l|l|}
\hline & \multirow{2}{*}{$\begin{array}{l}\text { Genotyped } \\
\text { Population }\end{array}$} & Loci & \multicolumn{2}{l}{} \\
\cline { 3 - 4 } in (no.) & Total & \multicolumn{2}{l|}{ P } & \multicolumn{1}{l}{ le } \\
\hline BGV G1 & 260 & 183 & 72.4 & 0.219 \\
\hline BGV G2 & 48 & 155 & 62.0 & 0.208 \\
\hline MONO G1 & 22 & 183 & 73.2 & 0.241 \\
\hline MONO G2 & 26 & 165 & 66.0 & 0.232 \\
\hline GB G1 & 62 & 180 & 72.0 & 0.222 \\
\hline GB G2 & 56 & 171 & 68.4 & 0.217 \\
\hline OUT & 303 & 188 & 69.6 & 0.198 \\
\hline BGV G1 & 63 & 147 & 58.8 & 0.178 \\
\hline BGV G2 & 58 & 151 & 60.4 & 0.186 \\
\hline MONO G1 & 35 & 165 & 66.0 & 0.215 \\
\hline MONO G2 & 32 & 188 & 75.2 & 0.220 \\
\hline GB G1 & 63 & 179 & 71.6 & 0.207 \\
\hline GB G2 & 52 & 169 & 67.6 & 0.205 \\
\hline Cultivar & 16 & 174 & 69.6 & 0.239 \\
\hline
\end{tabular}

Generational differences in the OUT population for BGV and MONO locations were considerably smaller (1 percent). This trend was opposite for both IN and OUT populations of the GB location (0.7 percent, 2.2 percent respectively). Generational genetic differentiation $\left(F_{\mathrm{st}}\right)$ for both populations at the MONO location were similar even though the OUT population displayed less genetic variation between generations than the IN population. Analysis of 1000 bootstraps for genetic distance revealed a strong influence of sampling location, even after two generations removed from their original sampling location (Figure 5). 
Table 8. Analysis of molecular variance (AMOVA) of Sporobolus airoides from invaded (IN) and non-invaded (OUT) areas of exotic invasion. Populations (IN, OUT) and generations (G1, G2) were analyzed by maternal locations (BGV, MONO, GB). Original sampling locations were: Naturita, CO (BGV), Laramie, WY (MONO) and Greybull, WY (GB).

\begin{tabular}{|l|c|c|c|}
\hline Group & Source of Variance & Variation $\%$ & Fst \\
\hline All individuals & IN, OUT & 5.0 & $0.050^{* *}$ \\
\hline All individuals & BGV, MONO, GB & 6.3 & $0.063^{* *}$ \\
\hline BGV & IN, OUT & 5.9 & $0.082^{* *}$ \\
\hline MONO & IN, OUT & 8.0 & $0.103 * *$ \\
\hline GB & IN, OUT & 6.7 & $0.080^{* *}$ \\
\hline BGV IN & G1, G2 & 4.1 & $0.041 * *$ \\
\hline BGV OUT & G1, G2 & 1.0 & $0.010^{*}$ \\
\hline MONO IN & G1, G2 & 4.1 & $0.041 * *$ \\
\hline MONO OUT & G1, G2 & 1.3 & $0.032 *$ \\
\hline GB IN & G1, G2 & 0.7 & $0.007 *$ \\
\hline GBO UT & G1, G2 & 2.2 & $0.022^{* *}$ \\
\hline
\end{tabular}

Variation \% is the proportion of variation between sub-groups for a specific row; $F_{\text {st }}$ is the proportion of total genetic variance found in the subgroups relative to the total genetic variance.

* $p<$ value $<0.05$

$* * p<$ value $<0.001$

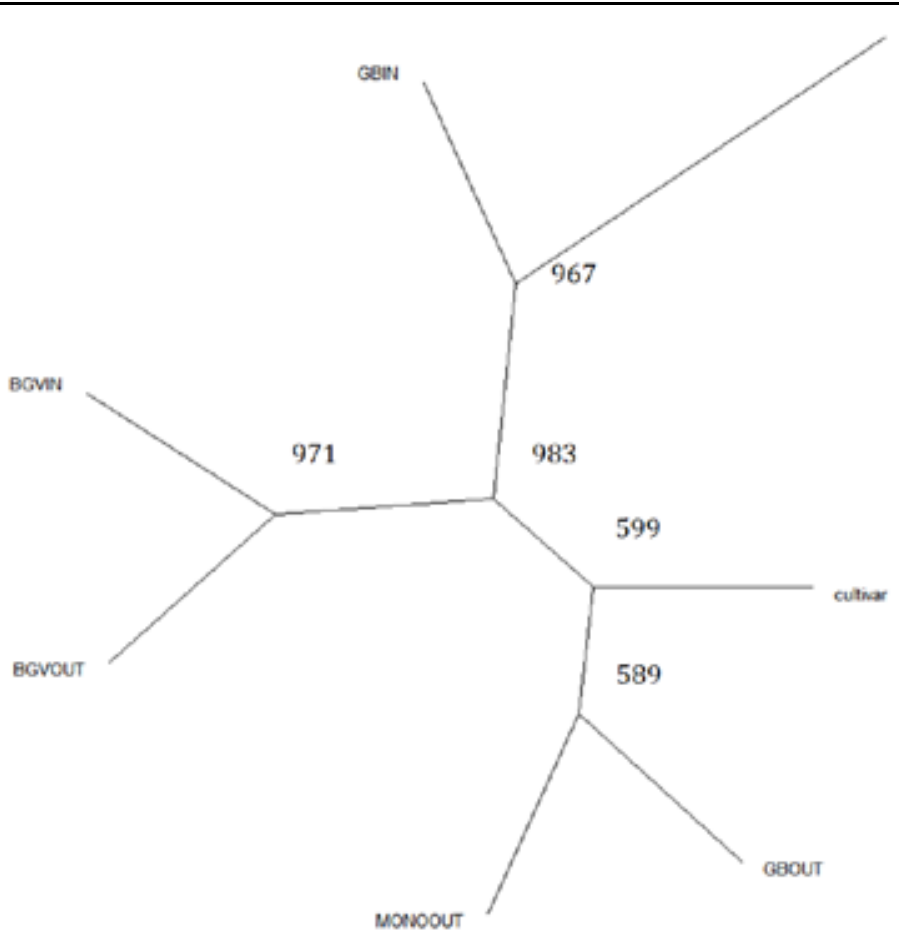

Figure 5. Dendogram based on Reynold's genetic distances, constructed for invaded (IN) and non-invaded (OUT) Sporobolus airoides populations by maternal location (BGV, MONO, GB). The $S$. airoides cultivar obtained from Manderson, WY, and maternal locations are; Naturita, CO (BGV), Laramie, WY (MONO) and Greybull, WY (GB). Support values for each node are out of 1000 bootstraps. 
Populations formed three distinct groups by location. A common node united the IN and OUT populations of BGV, both IN populations from GB and MONO, and the third node joins GB and MONO from the OUT population with the cultivar. There was strong support (minimum 500 of 1000 bootstraps) for all five nodes.

Percent polymorphism was higher in the MONO IN population (72 percent) than the OUT or cultivar populations (both 70 percent; Table 7). Analyzing the IN population by generations within a location, MONO G1 had the highest (73 percent) and BGV had the lowest percent polymorphism (62 percent for both G1 and G2). Examining the OUT population by generations within a location, MONO G2 had the highest percent polymorphism (75 percent) and BGV G1 had the lowest (59 percent).

Expected heterozygosity $\left(\mathrm{H}_{\mathrm{e}}\right)$ was highest in the cultivar (0.239) and lowest in the OUT population (0.198; Table 7). The highest $\mathrm{H}_{\mathrm{e}}$ was in the IN population, MONO G1 at 0.241 , and lowest in the OUT population, BGV $\mathrm{G} 1$ at 0.178 . Within the IN population, $\mathrm{H}_{\mathrm{e}}$ was higher in the first generation (G1) than the second generation (G2) for MONO and GB locations, but not for BGV, which was similar for both generations. This trend was opposite in the OUT population; increased $\mathrm{H}_{\mathrm{e}}$ was exhibited in $\mathrm{G} 2$ compared to $\mathrm{G} 1$ for all locations, except for GB, which was similar for both generations.

Intra-population genetic diversity $\left(\mathrm{H}_{\mathrm{S}}\right)$ for populations (IN, OUT) was 0.211 and 0.209 for locations (BGV, MONO, and GB; Table 9). Individuals from MONO had the highest $\mathrm{H}_{\mathrm{S}}(0.222)$ and individuals from BGV had the lowest $\mathrm{H}_{\mathrm{s}}(\mathrm{0.192})$ for populations (IN, OUT). Generational $\mathrm{H}_{\mathrm{s}}$ was highest for the IN population of the MONO location (0.237) and lowest for the OUT population of the BGV location (0.182).

Total genetic diversity $\left(\mathrm{H}_{\mathrm{t}}\right)$ for all individuals of both populations was 0.216 and 0.217 for all locations (Table 9). Analyzing locations separately, $\mathrm{H}_{\mathrm{t}}$ for all populations ranged from 0.201 for BGV to 0.234 for MONO. Generational $\mathrm{H}_{\mathrm{t}}$ in the IN population of the MONO location was highest (0.241) and lowest for OUT population of the BGV location (0.183).

Genetic differentiation $\left(\mathrm{G}_{\mathrm{st}}\right)$ was highest among locations (3.8 percent) and lowest between populations (2.4 percent; Table 9). Higher levels of genetic differentiation between populations were found in the location MONO (4.9 percent) than in the locations of BGV (4.5 percent) and GB (4.o percent). Generational genetic differentiation was low for both populations within all locations (0.4 to 1.9 percent). 
Table 9. Measures of genetic variation for comparing sources of variation in the first (G1) and second (G2) generations of invaded (IN) and non-invaded (OUT) Sporobolus airoides populations. Individuals were analyzed as an entire group, by populations within a location, and then generations of a population for a location. The cultivar was obtained from Manderson, WY and maternal collection locations were: Naturita, CO (BGV), Laramie, WY (MONO) and Greybull, WY (GB).

\begin{tabular}{|c|c|c|c|c|}
\hline Group & Source of Variance & $\mathrm{H}_{\mathrm{s}}$ & $\mathrm{H}_{\mathrm{t}}$ & $\mathrm{G}_{\text {st }}$ \\
\hline All individuals & IN, OUT, Cultivar & 0.219 & 0.225 & $0.030^{* *}$ \\
\hline All individuals & IN, OUT & 0.211 & 0.216 & $0.024^{* *}$ \\
\hline All individuals & BGV, MONO, GB & 0.209 & 0.217 & $0.038^{* *}$ \\
\hline BGV & IN, OUT & 0.192 & 0.201 & $0.045^{* *}$ \\
\hline MONO & IN, OUT & 0.222 & 0.234 & $0.049^{* *}$ \\
\hline GB & IN, OUT & 0.210 & 0.219 & $0.040^{* *}$ \\
\hline BGV IN & G1, G2 & 0.207 & 0.210 & $0.019 * *$ \\
\hline BGV OUT & G1, G2 & 0.182 & 0.183 & $0.004^{*}$ \\
\hline MONO IN & G1, G2 & 0.237 & 0.241 & $0.018^{* *}$ \\
\hline MONO OUT & G1, G2 & 0.218 & 0.219 & $0.004^{*}$ \\
\hline GB IN & G1, G2 & 0.219 & 0.220 & $0.004^{*}$ \\
\hline GB OUT & G1, G2 & 0.206 & 0.208 & $0.011^{* *}$ \\
\hline \multicolumn{5}{|c|}{$\begin{array}{l}\mathrm{H}_{\mathrm{s}} \text {, mean gene diversity within sampling group; } \mathrm{H}_{\mathrm{t}} \text {, total genetic diversity; } \\
\mathrm{G}_{\mathrm{st}} \text {, the proportion of gene diversity that occurs among as opposed to within populations. } \\
{ }^{*} p<\text { value }<0.05 \\
{ }_{* *} p<\text { value }<0.001\end{array}$} \\
\hline
\end{tabular}

Self-pollinating species typically demonstrate reduced heterozygosity, low intra-population genetic diversity, and substantial genetic differentiation among populations, but $S$. airoides populations had notably lower interpopulation genetic variation and the genetic structure of the populations did not differ (Yan et al. 2010). The expected heterozygosity values for the IN and OUT populations were higher than expected, but are supported by the higher levels of variation attributed to individuals of a population based on AMOVA. Both IN and OUT populations partitioned their total genetic diversity within $\left(\mathrm{H}_{\mathrm{s}}\right)$ individuals rather than among $\left(\mathrm{G}_{\mathrm{st}}\right)$ locations or populations.

These results for intra-population genetic diversity were similar to those of previous research on $S$. airoides from invaded areas $\left(\mathrm{H}_{\mathrm{s}}, 0.203\right)$, but interpopulation estimations differed ( $\mathrm{G}_{\mathrm{st}}, 0.121$; Mealor et al. 2004). The present study included 579 plants genotyped rather than 12 plants analyzed in Mealor et al. (2004) and 162 plants analyzed in Mealor et al. (2006), so the robustness of this current study may be more compelling than earlier work. 
Greater intra-population genetic diversity suggests individuals within a population display a large proportion of genetic loci with much allelic variation, characteristic of widespread, out-crossing, long-lived perennial plant species (Hamrick and Godt 1996, Odat et al. 2004). These are traits of $S$. airoides except that $S$. airoides is thought to be predominately selfpollinated (Fryxell 1957). The results of this work could imply that $S$. airoides has a mixed mating system (both self- and cross-pollinating) especially since florets are open during anthesis (personal observation). Pollen transfer is more likely in an enclosed greenhouse environment. Having multiple breeding strategies, such as clonal reproduction and seed production from self- and cross- pollination, may favor persistence even within a small or fragmented populations such as those coexisting with exotic invaders (Gustafson et al. 1999). Some species (e.g., Canada wild rye, Elymus canadensis) are known to have varying out-crossing rates and these rates differ from population to population (Sanders and Hamrick 1980). Rare out-crossing events are also thought to contribute to the genetic variation found within Illinois bundle flower (Desmanthus illinoensis) populations (DeHaan et al. 2003). Increased gene flow among individuals may have increased the genetic variation within invaded populations of $S$. airoides and could be a factor in their persistence within invasions.

Moderate levels of gene flow among self-pollinating individuals can occur especially if populations have a wide distribution over a broader range of growing conditions (Lesica and Allendorf 1999). Seed-mediated gene flow is important to genetic structure and gravity dispersed populations (as is S. airoides) should cause genetic differences between populations. This study's $S$. airoides populations and locations do not demonstrate this trend, perhaps because of their multiple breeding strategies. Invasive species are thought to fragment native populations, but when brought to a common greenhouse, $S$. airoides appears to have rather open gene flow. $S$. airoides is capable of polyploidy, which also provides a means to increase intra-population diversity from gene duplication leading to fixed heterozygosity (Díaz et al. 1999).

Geographic location of original maternal plants was expected to play a significant role in the amount of genetic diversity found in IN and OUT populations of $S$. airoides. A relationship between maternal plant collection location and genetic variation appeared when individuals were analyzed by populations from their location (BGV, MONO, and GB). The IN population of both MONO and BGV locations derived 4 percent of their genetic variation from generational differences, indicating the potential for a shift in 
gene flow during a seed increase or more open pollination occurring within a greenhouse.

Dendogram analysis supports the divergence between Wyoming (MONO, GB) and Colorado (BGV) locations (Figure 5). Interestingly, MONO and GB had the highest inter-population genetic diversity and were separated into two different nodes for IN and OUT populations. Greater invasion pressures at the GB location (much higher density of $R$. repens) could mean the location faced stronger selection pressures for plants able to coexist within the invasion. Although GB had a higher density of invasive plants, the location BGV had the longest period of exotic invasion (35 years longer than either MONO or GB). The IN population at BGV had higher genetic diversity than the OUT population, which could be evidence for the longer time under exotic pressures selected for plants with increased cross-pollination.

The cultivar used in this study demonstrated itself as a genetically diverse candidate for restoration, and the amount of genetic variation was higher than the IN and OUT populations. A reason for the increase in variation is that the cultivar population was derived from more individuals than the IN and OUT lineages. It is reassuring that the cultivar population was placed near GB populations in the endogamy since the cultivar was developed geographically nearest to the GB site.

It is often suggested that new seed sources should be collected every few years for agronomic production (Knapp and Rice 1994). Generational differences in genetic diversity were low for the OUT population meaning genetic diversity could be maintained within a greenhouse seed increase for several generations. Significant generational differences in genetic diversity of the IN population could become more pronounced in future generations, so IN populations may be best used for short-term seed increases within a production environment or collected as seed from the wild and planted directly into a restored area.

Exotic invasion may influence native populations beyond competition for nutrients and space, but could affect how genetic traits are passed on to subsequent generations. This research demonstrated that as few as two generations of seed increase in a greenhouse environment can influence gene flow of native species. Future research should detail influences of newly created greenhouse populations on the genetic diversity of restoration plantings and surrounding wild populations. 


\section{3 greenhouse testing of native grass collections and seedlings for phenotypic and competitive traits}

\subsubsection{Results of testing of native collections and seedlings for phenotypic and competitive traits in response to Russian knapweed}

Sporobolus airoides emergence did not differ according to presence of $R$. repens or community of origin ( $\mathrm{p}>0.05)$. Presence of $R$. repens reduced the growth of $S$. airoides irrespective of community of origin or genotype (Figure 6). There was a significant interaction between $R$. repens competition and $S$. airoides community of origin for number of tillers $\left(\mathrm{F}_{1,191}=\right.$ 10.27, $p=0.002)$ and number of leaves $\left(F_{1,214}=7.63, p=0.006\right.$; Figure 6$)$.

As a group, plants from invaded communities were smaller $\left(F_{1,24}=4.69\right.$, $\mathrm{p}=0.041$ ) than those from non-invaded communities. Both aboveground $\left(\mathrm{F}_{24,50}=2.14, \mathrm{p}=0.012\right)$ and belowground $\left(\mathrm{F}_{24,50}=1.91, \mathrm{p}=0.027\right) S$. airoides biomass production differed among maternal genotypes with and without competition.

Patterns of competitive response varied according to scale of investigation. Although varied, there was a significant location by community interaction for the competitive response of $S$. airoides $\left(\mathrm{F}_{2,86}=8.83, \mathrm{p}=0.003\right.$; Figure 7). Rhaponticum repens grown with grasses from invaded areas had a lower competitive response (mean $\mathrm{CR}=0.932 \pm 0.064$ ) than those grown with grasses from non-invaded communities (mean $\mathrm{CR}=1.047 \pm 0.057 ; \mathrm{F}_{2,86}=$ 4.74, $\mathrm{p}=0.032)$.
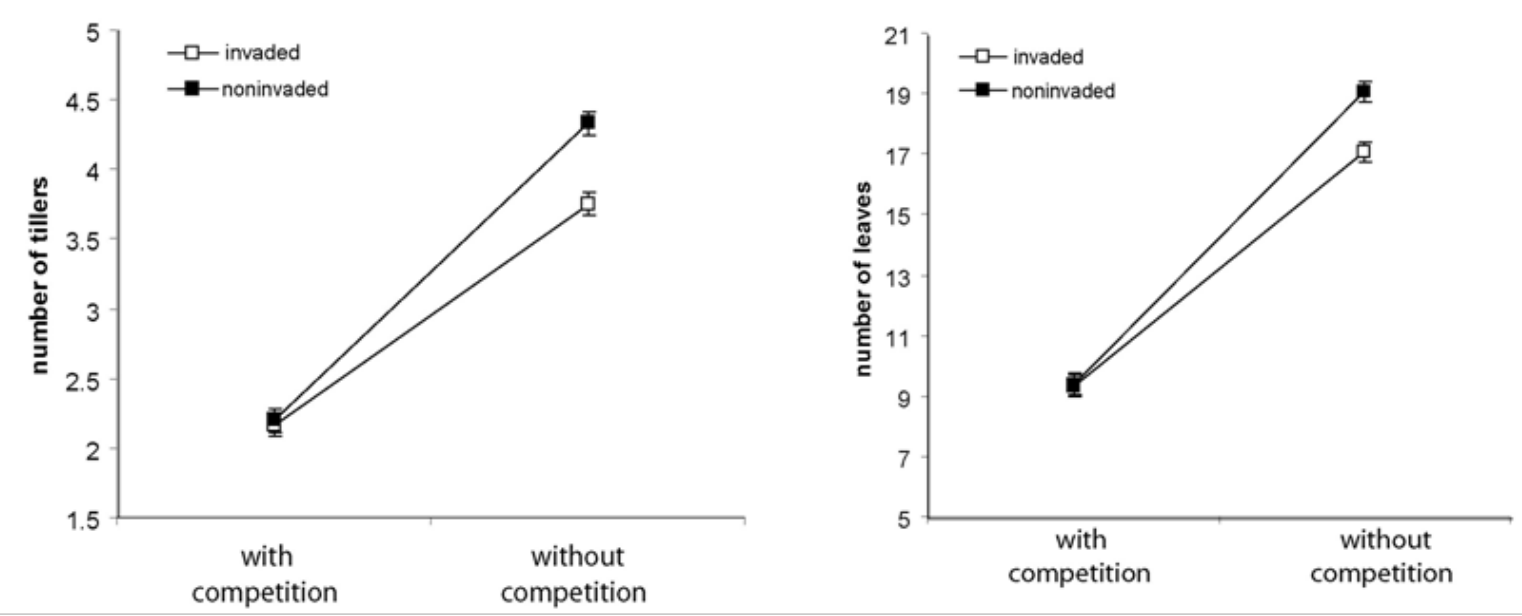

Figure 6. Number of tillers and number of leaves produced by Sporobolus airoides seedlings from communities invaded by Rhaponticum repens and non-invaded communities grown with and without $R$. repens competition in a greenhouse experiment. Values are least squares means and SE. 
Individual maternal genotypes differed greatly in their response to competitors and demonstrated a broad range of competitive responses (Figure 8). Rhaponticum repens biomass, height, number of shoots, number of leaves, and canopy width showed no differences among neighbor treatments genotypes ( $\mathrm{p}>0.05)$. However, $S$. airoides maternal genotypes differentially influenced aboveground biomass $\left(\mathrm{F}_{24,25}=2.24, \mathrm{p}=0.026\right)$ and number of leaves $\left(\mathrm{F}_{24,25}=1.99, \mathrm{p}=0.047\right)$ of $R$. repens (Figure 8$)$. The response of $R$. repens to presence of $S$. airoides was similarly varied. In general, more invaded grass genotypes reduced the growth of $R$. repens than did non-invaded grass genotypes (reduction of $R$. repens relative to $R$. repens grown alone, black column). Also, the highest competitive response values were of maternal genotypes from invaded communities.

Success of exotic invaders has been explained in some cases by the "novel weapons hypothesis" (Callaway and Aschehoug 2000), (Bais et al. 2003), (Callaway and Ridenour 2004). This hypothesis proposes that, in some cases, invasive plants perform better in a new environment because they bring specific biochemical impacts that are novel to native plants in the new environment. Grass tolerance to $R$. repens invasion have been explained as tolerance to allelopathic compounds (Callaway et al. 2005). The fact that the "experienced" genotypes in this study are more competitive than "inexperienced" with a new invader whose allelopathic potential has not been described as the cause for its success in North America, indicates that this study's observed apparent competitive advantage cannot be explained via tolerance to allelopathy. Apparently, experienced grass genotypes must have different patterns of allocation than inexperienced populations, and this provides a competitive advantage. In any case, additional future studies on the mechanisms of greater competitive response of experienced natives against $C$. arvense or other comparable NIPS are necessary to discern these patterns more clearly (see also Sections 3.2 [p 19] and Section 3.3 [p 20]). 


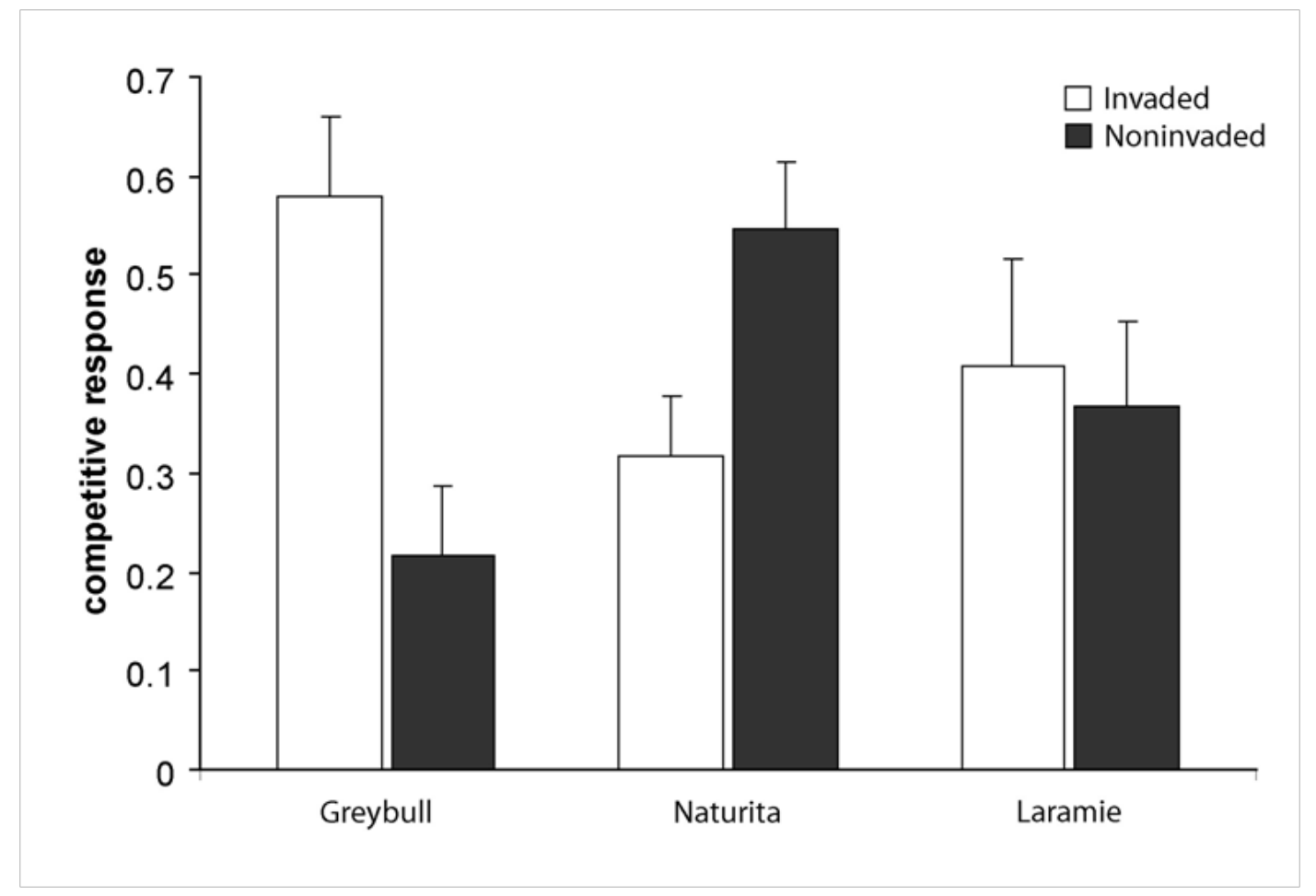

Figure 7. Competitive response of Sporobolus airoides from three different locations and two communities when grown with Rhaponticum repens under greenhouse conditions. Values represent means $\pm 1 \mathrm{SE}$.

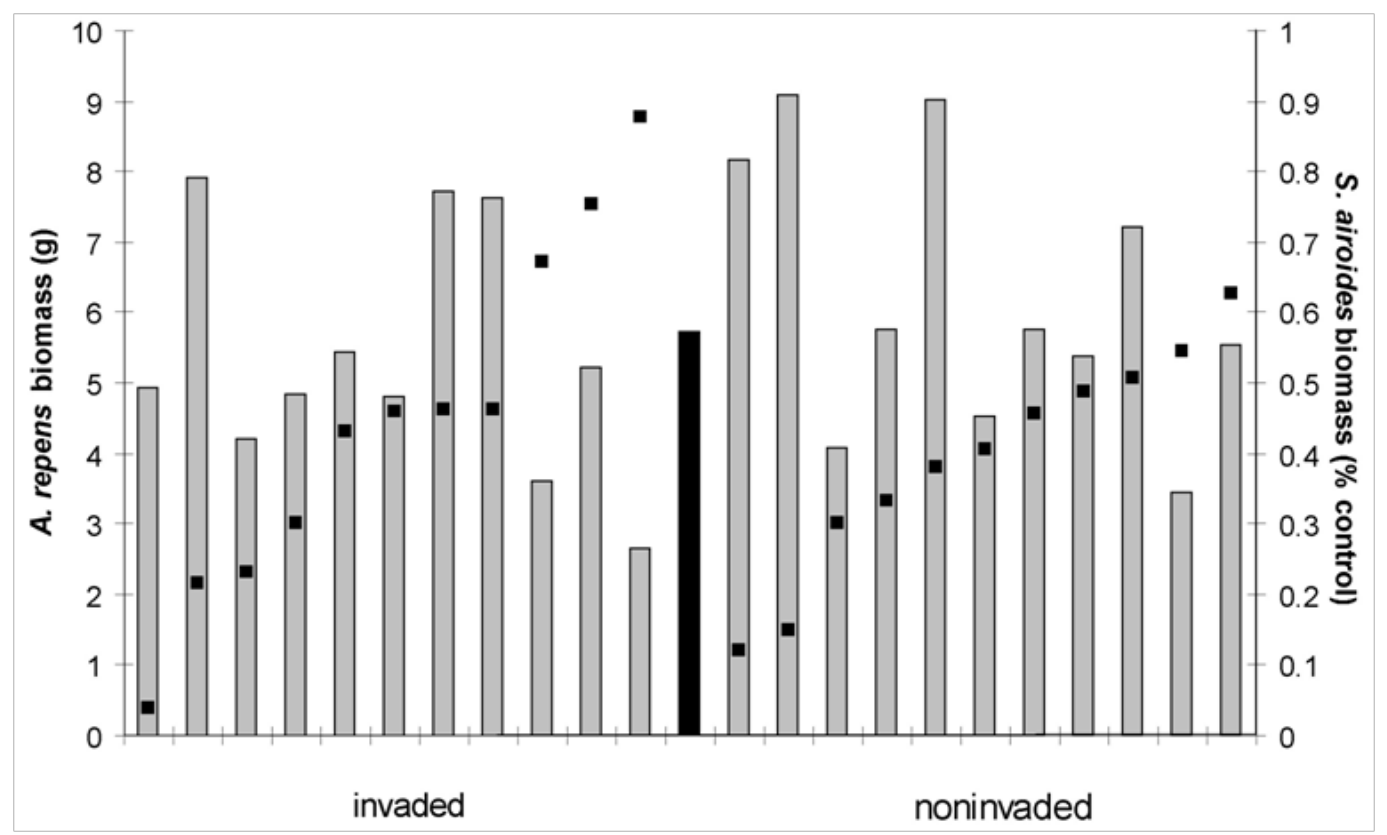

Figure 8. Sporobolus airoides maternal genotype - Rhaponticum repens biomass production. Dark squares represent average production of $S$. airoides biomass relative to control plants (grown alone) of the same maternal genotype. Filled columns represent average biomass production of $R$. repens grown with the corresponding $S$. airoides maternal genotype. Black column is mean biomass of $R$. repens grown alone. 


\subsubsection{Results of testing of native collections and seedlings for phenotypic and competitive traits response in response to Canada thistle}

In general, growth of both of the grasses were reduced by competition with C. arvense plants (Figures 5 and 6). Sporobolus airoides tillering decreased in the presence of $C$. arvense (Figure 9a; $P=0.0002$ ). By week 14, tillers of experienced $S$. airoides competing with $C$. arvense was not different from tillering of inexperienced $S$. airoides grown alone. Hesperostipa comata tiller numbers did not differ among treatments on any sampling date (Figure $9 \mathrm{~b} ; P=0.9882$ ).

Not surprisingly, grasses grown alone accumulated greater biomass than when grown with $C$. arvense (Figure 9). When grown alone, experienced and inexperienced $S$. airoides genets did not differ in size. When competing with $C$. arvense, experienced genets of $S$. airoides were larger than inexperienced conspecifics (Figure 9; $S$. airoides $P=0.0002$ ). Biomass of experienced $H$. comata did not differ from inexperienced genets when grown alone (Figure 10). When grown with $C$. arvense, inexperienced $H$. comata were smaller than $H$. comata grown alone whereas experienced $H$. comata did not differ from $H$. comata genets grown alone. Cirsium arvense biomass was reduced in the presence of $S$. airoides neighbors, both experienced and inexperienced (Figure 10; $C$. arvense $P=0.0017$ ), and $C$. arvense biomass was least with experienced neighbors. Cirsium arvense biomass did not differ when grown with either experienced or inexperienced $H$. comata neighbors.

\subsubsection{Results of testing for native grass competition with Canada thistle using the Relative Neighbor Effect (RNE) index}

In both grasses, RNE values for inexperienced genets were quite high (approaching 0.8) demonstrating the negative impact of the C. arvense neighbors (Figure 11). Experienced grasses had smaller RNE values (mean $\mathrm{RNE}=0.33$ ) when grown with $C$. arvense than did inexperienced grasses (mean RNE $=0.75$ ) suggesting that for both grass species, experienced genets were less affected by thistle neighbors (Figure 11; $P=0.0102$ ). Conversely, $C$. arvense were least impacted by $H$. comata neighbors. Cirsium arvense was most affected by competition from experienced $S$. airoides neighbors; $S$. airoides inexperienced neighbors had an intermediate impact not statistically different from $H$. comata neighbors. 
Military land managers and restoration ecologists are interested in creating native communities that will better resist the entrance of exotics. The results of this work suggest that native species exposed to long term invasions have undergone selection towards greater tolerance for the presence of some exotic plant species. These results support previous genetic studies showing genetic differentiation in natives exposed to long term $R$. repens invasions (Mealor and Hild 2006) and extend results to tolerance for another exotic species, $C$. arvense.

\subsubsection{Results of testing for nutrient content of Canada thistle}

Carbon content of $C$. arvense did not differ when grown with $S$. airoides neighbors $(P=0.4879$; Table 10). Nitrogen content in leaves of $C$. arvense grown alone was greater than when $C$. arvense was grown with experienced $S$. airoides neighbors $(P=0.0238)$. Nitrogen content of $C$. arvense when grown with inexperienced $S$. airoides was intermediate and did not differ from other treatments. Carbon to nitrogen ratios of $C$. arvense were also greater in plants competing with experienced $S$. airoides $(P=0.0156)$. Nitrogen content of $C$. arvense in injected pots did not differ among treatments $(\mathrm{P}=0.38)$.

Because leaf nitrogen content is directly related to photosynthetic activity (Sage and Pearcy 1987, Poorter et al. 1990, Poorter and Bergkotte 1992) and can impact species dominance (Tilman 1987), our tissue analyses indirectly indicate that experienced grass neighbors are more stressful to the exotic. Cirsium arvense is known to increase photosynthesis and production with greater nitrogen availability (Hamdoun 1970, Nadeau and Vanden Born 1990, Ziska 2003). In our study reduced leaf nitrogen content and $\mathrm{C}: \mathrm{N}$ ratios of $C$. arvense associated with experienced native grasses corroborates increased stress placed on $C$. arvense by experienced neighbors. If experienced native populations truly limit nitrogen accumulation by invaders, nutrient cycling processes can be targeted to enhance future restoration efforts. 

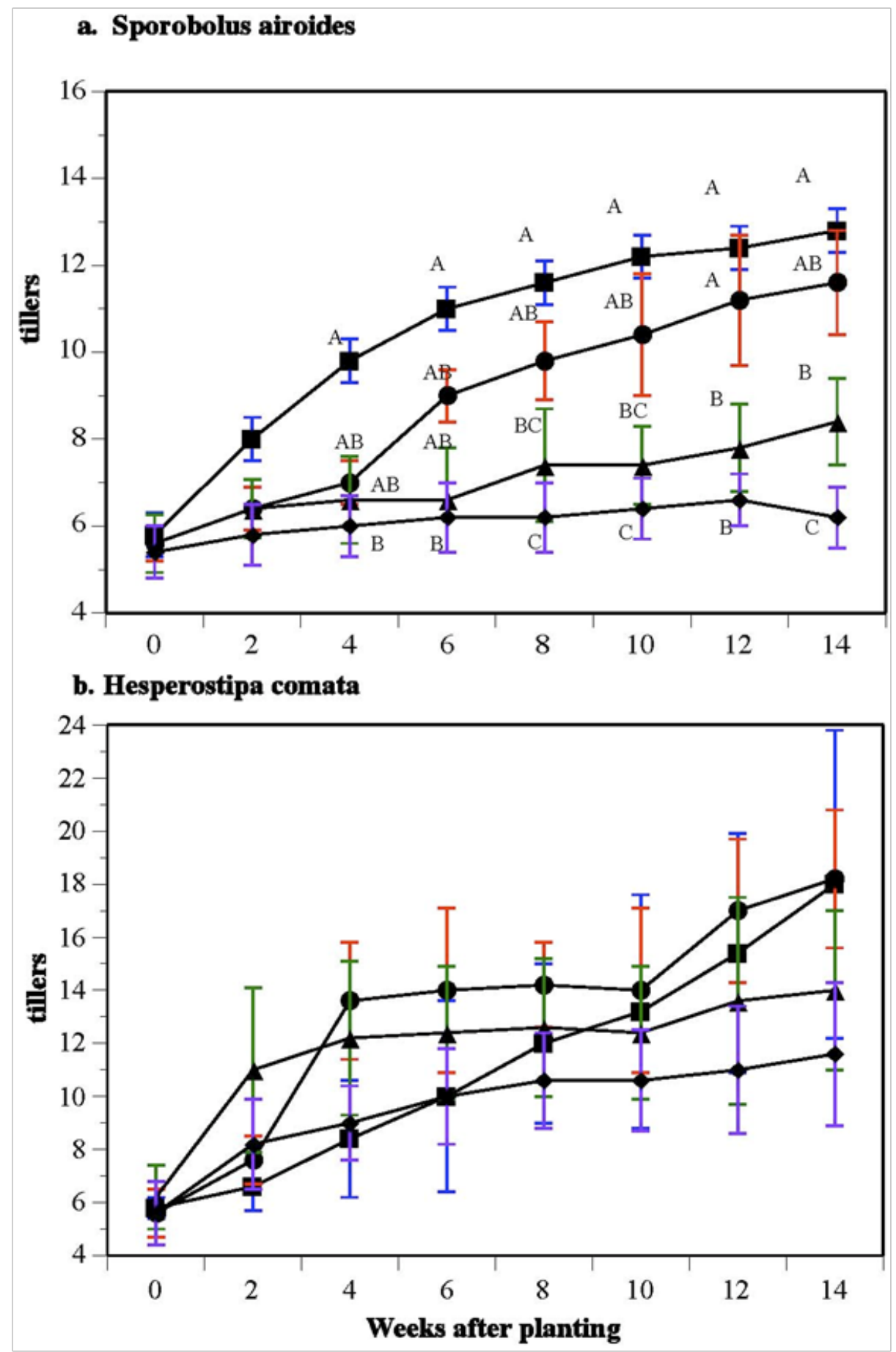

Figure 9. Growth (tiller number) of experienced and inexperienced grasses (Sporobolus airoides [a] and Hesperostipa comata [b]) with and without Cirsium arvense neighbors on eight sampling dates. Treatments are: experienced genets alone (squares), inexperienced genets alone (circles), experienced genets $+C$. arvense (triangles) and inexperienced genets $+C$. arvense (diamonds). Within a date, treatments with the same letter do not differ ( $p<$ 0.05). 
a. Sporobolus

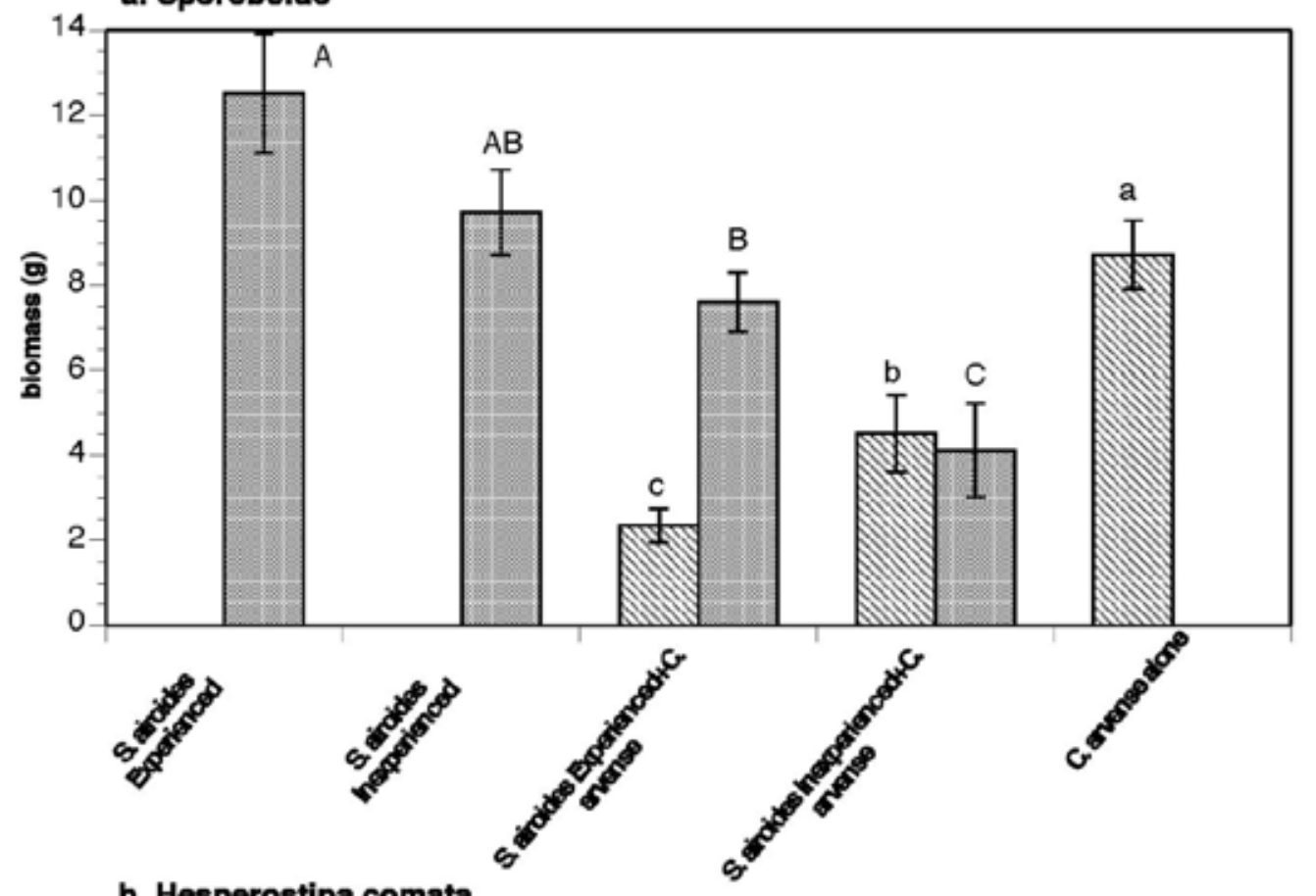

b. Hesperostipa comata

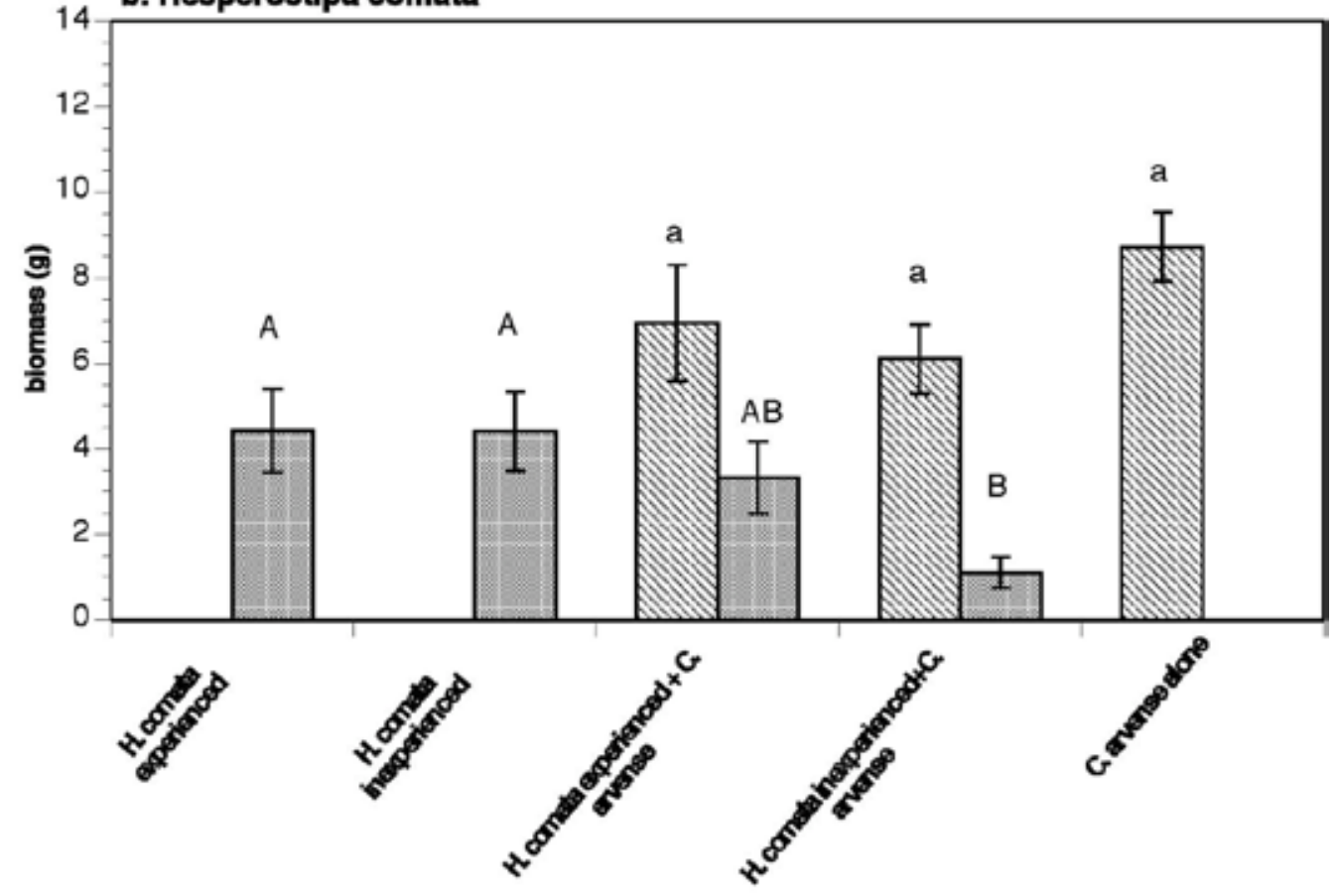

Figure 10. Biomass of experienced and inexperienced Sporobolus airoides (a) and Hesperostipa comata (b) grass genets grown alone and with Cirsium arvense. Columns in the figures are grass biomass (solid columns) and biomass of $C$. arvense (hatched columns). Means without the same letter differ (a. S. airoides $P=0.0002$; b. H. comata $P=0.0161$; and C. arvense $P=0.0017$ ). 


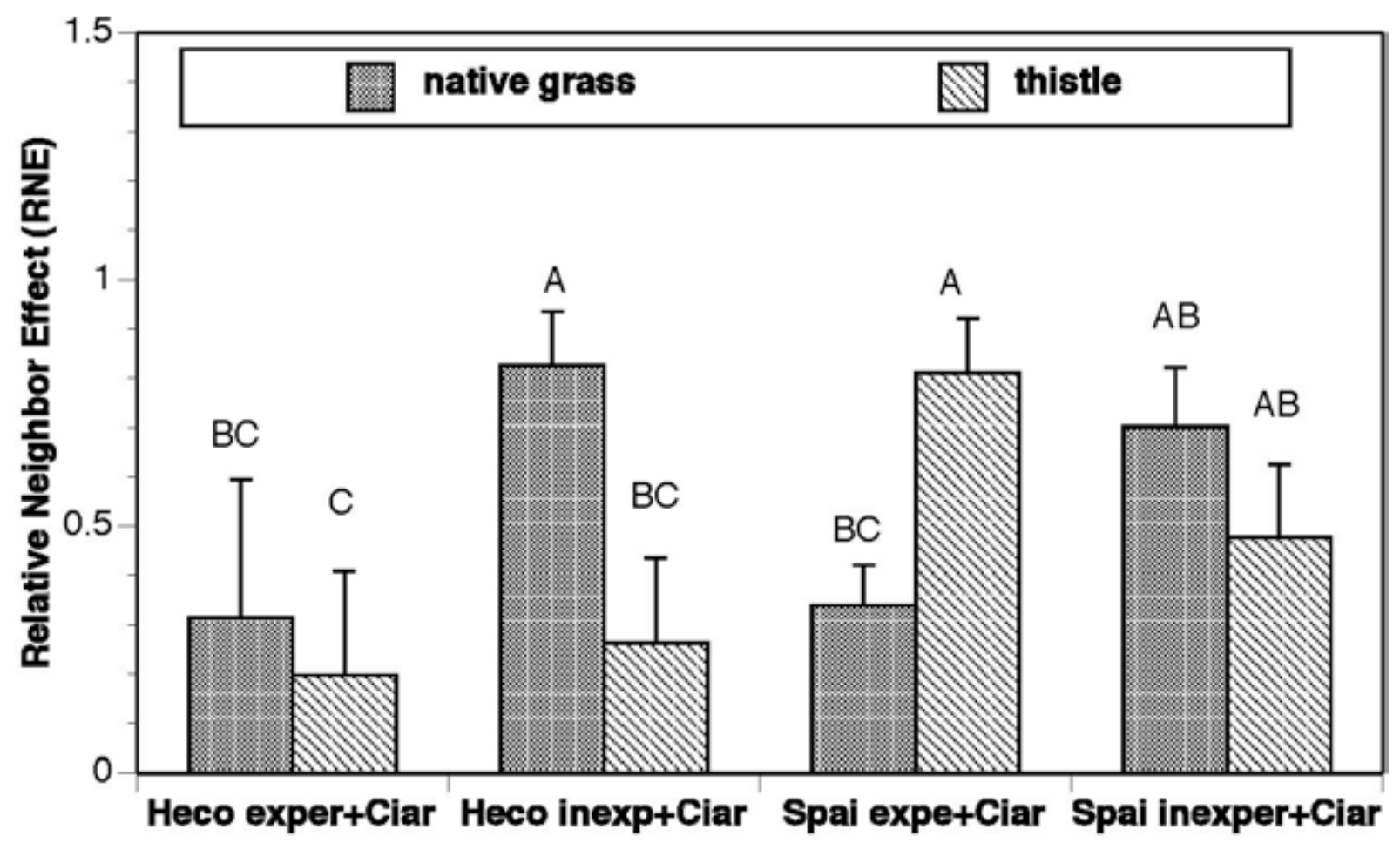

Figure 11. Relative Neighbor Effect (RNE) for interactions of Cirsium arvense (Ciar) with experienced (exp) and inexperienced (inexper) native grasses (Heco = Hesperostipa comata, Spai $=$ Sporobolus airoides). Larger RNE values suggest greater impact of neighbors. Across all RNE values, means with the same letter do not differ $(P=0.03)$.

Table 10. Nitrogen and carbon content ( $\mathrm{mg} / \mathrm{mg}$ tissue) in Cirsium arvense grown alone and with grass competitors (Sporobolus airoides) from populations exposed to Russian knapweed invasions (experienced) and from outside the invasion (inexperienced). Mean separation was completed using Tukey's HSD.

\begin{tabular}{|l|c|c|c|}
\hline Treatment & $\begin{array}{c}\text { Carbon (\%) } \\
(\mathrm{P}=\mathbf{0 . 4 8 7 9 )}\end{array}$ & $\begin{array}{c}\text { Nitrogen (\%) } \\
(\mathrm{P}=0.0355)\end{array}$ & $\begin{array}{c}\text { C:N Ratio } \\
(\mathrm{P}=0.0156)\end{array}$ \\
\hline C. arvense (Ciar) alone & 38.9 & $64.4 \mathrm{a}$ & $64.2 \mathrm{~b}$ \\
\hline Ciar + Experienced Spai & 38.0 & $40.6 \mathrm{~b}$ & $94.0 \mathrm{a}$ \\
\hline Ciar + Inexperienced Spai & 39.4 & $50.6 \mathrm{ab}$ & $82.6 \mathrm{ab}$ \\
\hline Mean & 38.8 & 50.8 & 80.3 \\
\hline
\end{tabular}

\subsubsection{Results of testing for competition with Canada Thistle under} herbivory by stem-mining weevils

None of the treatments significantly reduced shoot size (aboveground biomass) of $C$. arvense. However, root biomass was reduced by several of the treatment combinations (Figure 12). Sporobolus airoides alone, and both grasses combined, significantly suppressed root growth (55.4 and 84.0 percent respectively), but competition from $H$. comata alone did not. Reduced thistle root growth may be attributed to competition from warmseason grasses later in the growing period. 


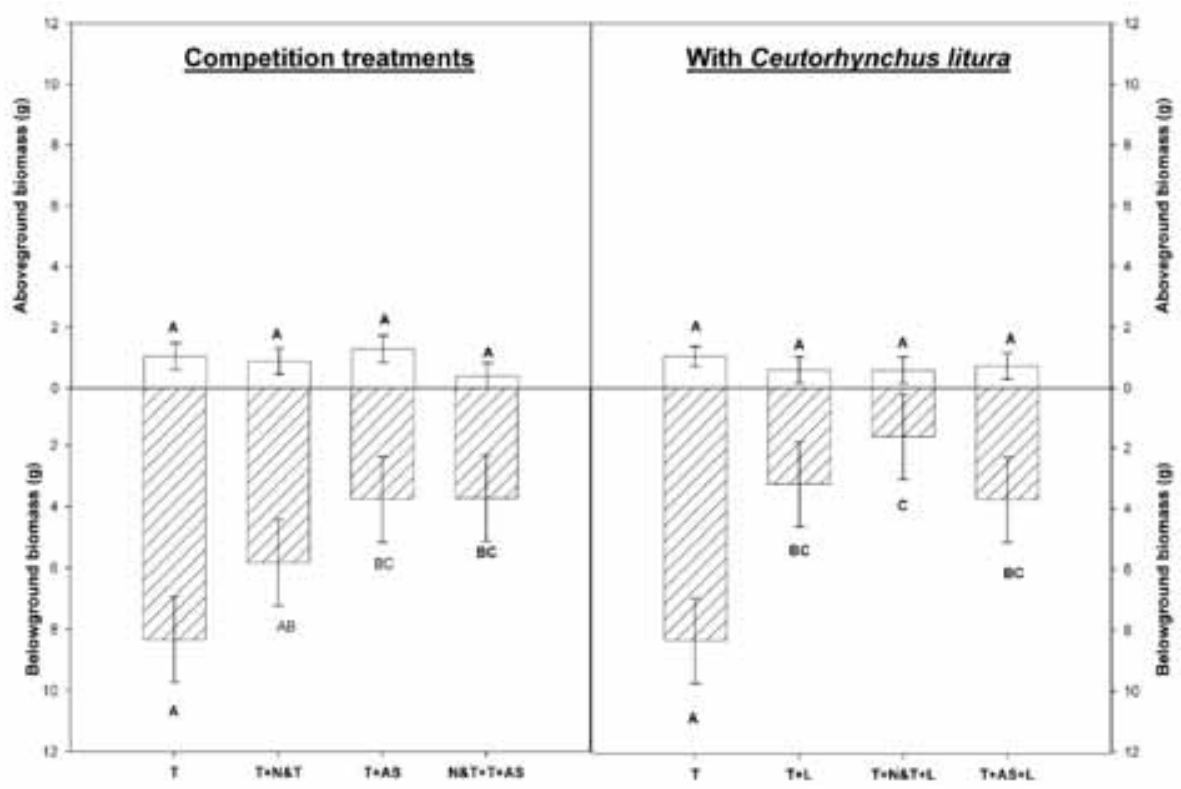

Figure 12. Aboveground and belowground biomass of Cirsium arvense. $(p<0.01$; $d f=6)$ in competition and weevil herbivory treatments $(T=$ Canada thistle, $N \& T=$ Needle-and-thread grass, AS=Alkali sacaton (Sporobolus airoides) grass, L = the weevil, Hadroplontus litura (syn. Ceutorhynchus litura).

When $H$. litura was present, either alone or in combination with the grasses, $C$. arvense roots were significantly smaller. It is interesting to note that, while competition from needle-and-thread grass alone did not reduce root growth, thistle roots were reduced 80.6 percent when the weevil was added in combination with the cool-season grass.

The significant reduction in root biomass relative to controls, or to coolseason competition alone, suggests that the combined effect of $H$. litura and needle-and-thread has increased effectiveness. The synergistic effect on $C$. arvense thistle root biomass may occur because the timing of weevil effects coincides with competitive stress from the cool-season grass. Thistle mortality was significantly greater (Chi square analysis) when weevil herbivory and competitive grasses were combined. Mortality of thistle with the insect alone was 10 percent, whereas when needle-and-thread grass and the weevil were combined, thistle mortality was 40 percent.

Sporobolus airoides growth takes place after C. arvense (cool-season) has completed its period of active growth and depleted root reserves. Thistle at this time is more vulnerable to competitive effects (McAllister and Haderlie 1985). Since $C$. arvense allocates most of its biomass belowground, root growth may be critical in accounting for the effect of competition on C. arvense growth. Studying aboveground biomass alone does not give a com- 
plete understanding of underlying competitive mechanisms that makes some species better competitors than others (Nadeau and Vandenborn 1989, Nadeau and Vandenborn 2011).

The importance of belowground competition is widely recognized (Casper and Jackson 1997), but the effect of aboveground stress has been a subject of discussion (Ang 1994). Ang (1994) suggested that aboveground stress has great impact on C. arvense biomass. Herbivory caused by Cassida rubiginosa (Coleoptera: Chrysomelidae; an introduced defoliating beetle used for thistle control) has a stronger effect on aboveground biomass of C. arvense than on its roots (Bacher and Schwab 2000). After being stressed by $H$. litura, $C$. arvense aboveground shoot biomass decreased, but shoots recovered by the end of the study. C. arvense may recover from aboveground stress by reallocating resources from the roots to make up for the loss of photosynthetic tissue. Overall, this work concludes that the effect of the insect alone reduced $C$. arvense biomass and increases mortality, especially when combined with grass competition.

It seems that the synchronization of competition from the cool-season native grass and $H$. litura enhanced the impact of herbivory and competition on root biomass, while the use of consecutive stresses (combination of cool and warm season impacts) in time did not. The combination of both warm- and cool-season grasses at the same time did not differ from either cool- or warm-season competition alone on $C$. arvense belowground biomass. Therefore, a combination of cool- and warm-season competition did not improve control of $C$. arvense. However, this work did not test the impact of both grasses combined with weevil herbivory, which may have provided synergism.

Contrary to previous studies (Zwölfer and Harris 1966, Peschken and Wilkinson 1981, Peschken and Derby 1992, Hein and Wilson 2004), H. litura alone provides effective control of $C$. arvense in the greenhouse. But a more important question is whether the insect's impacts increases or declines when combined with competition from already established native grasses. In this study, native grass competition had additive effects that enhance the impacts of $H$. litura. Although cool-season competition was not synergistic, its combined use with weevil would provide a good strategy for control of $C$. arvense since the combined effect is significantly greater than the effect of competition alone. 
Weevil herbivory reduced root, but not shoot, biomass of Canada thistle. Competition from $H$. comata did not reduce biomass of thistles, but combinations of the weevil and $H$. comata greatly reduced thistle root biomass. Sporobolus airoides suppressed $C$. arvense root biomass independent of weevils. Weevils had a positive indirect effect on the cool-season grass $H$. comata, presumably by reducing the competitive ability of thistles, but had no effect on biomass of the warm-season grass, $S$. airoides. Benefits of weevil presence as an augmentation of grass competition appear to depend on appropriate timing, and weevils provided the most benefit to the cool-season competitor. These results suggest that restoration efforts can be complemented with insect biocontrol agents, although the timing of impact will depend on the particular weed species, grass competitors, and biocontrol insect agents involved. The combination of S. airoides with $H$. litura did not increase the detrimental impact of $S$. airoides competition on $C$. arvense. This study concludes that the combination of $H$. litura and warm-season competitors may not improve effectiveness of control of $C$. arvense. Relative measures of competitive response suggest that $S$. airoides had a significant impact on biomass, and since mortality is increased, should be considered good competitors for revegetation efforts.

Military land managers and restoration ecologists are interested in creating native communities that will better resist the entrance of exotics. The results of this work suggest that native species exposed to long term invasions have undergone selection towards greater tolerance for the presence of some exotic plant species. These results support previous genetic studies showing genetic differentiation in natives exposed to long term $R$. repens invasions (Mealor and Hild 2006) and extend results to tolerance for another exotic species, $C$. arvense.

Success of exotic invaders has been explained in some cases by the "novel weapons hypothesis" (Callaway and Aschehoug 2000), (Bais et al. 2003), (Callaway and Ridenour 2004). This hypothesis proposes that, in some cases, invasive plants perform better in a new environment because they bring specific biochemical impacts that are novel to native plants in the new environment. Grass tolerance to $R$. repens invasion have been explained as tolerance to allelopathic compounds (Callaway et al. 2005). The fact that the "experienced" genotypes in this study are more competitive than "inexperienced" with a new invader whose allelopathic potential has not been described as the cause for its success in North America, indicates that this study's observed apparent competitive advantage cannot be explained via tolerance to allelopathy. Apparently, experienced grass genotypes must have 
different patterns of allocation than inexperienced populations, and this provides a competitive advantage. In any case, future studies on the mechanisms of greater competitive response of experienced natives against $C$. arvense are necessary to discern these patterns more clearly.

\subsubsection{Testing for phenotype of first and second generation seedlings - plant traits in response to long-term exposure to Rhaponticum repens}

This research examined the impacts of greenhouse production by addressing two questions: (1) whether seedlings of invaded $S$. airoides populations are phenotypically similar to non-invaded populations, and

(2) whether the phenotypic traits remain stable or change from the production of multiple generations within a greenhouse environment. As a legacy of the competitive invaded environment, this work hypothesized that remnant native populations with a history of invasion should display greater aboveground vegetative growth than the non-invaded population. Increased vegetative growth would assist plants in competition for space and nutrients in a densely populated environment. As a trade-off for allocating more resources to vegetative or clonal growth, this work hypothesized seed production to be reduced in the invaded population compared to the non-invaded population. Understanding the phenotypic expression of remnant natives in production and the prevalence of inadvertent selection for specific phenotypes within lineages is important for the potential use of remnant native grass populations in native plant production and restoration efforts (Gustafson et al. 2002).

\subsubsection{Vegetative growth traits of maternal lineages after greenhouse increase}

Tiller production of S. airoides (Figure 13a) differed between the two populations (IN or OUT) depending on generation ( $\mathrm{G} 1$ or G2; population by generation interaction $p<0.001$ ). Within the IN population, IN G1 produced 39.9 percent more tillers than ING2; tiller production in OUT G1 and OUT G2 did not differ. When averaged across generations, the IN population produced 13.9 percent more tillers than the OUT population $(p=0.003)$.

Plant height (Figure 13b) differed between the two populations (IN or OUT) depending on generation (G1 or G2; population by generation interaction $p=0.011$ ). Within populations, IN G1 seedlings were 24.3 percent taller than ING2 seedlings and OUT G1 seedlings were 12.2 percent taller than OUT G2 seedlings. 
Basal diameter (Figure 13c) of IN seedlings differed between generations (interaction $p=0.008$ ). IN G2 basal diameter was 15.8 percent wider than ING1; basal diameter of OUT G1 and OUT G2 did not differ. Irrespective of generation, basal diameter of the IN population was 8.6 percent greater than the OUT population $(p=0.002)$.

There was no interaction between population and generation for leaf length ( $p=0.538$ ) or leaf width (interaction $p=0.652$ ). IN and OUT populations had similar leaf elongation rates. Second generation seedlings of both populations had greater leaf growth than the first generation ( $p<0.001$ ). IN G2 had 26 percent longer leaves than IN G1 and OUT G2 having 21 percent longer leaves than OUT G1. The OUT population seedlings had 17 percent wider leaves than the IN population $(p<0.001)$. The rate at which populations achieved the study mean for each trait was not statistically different among populations, but IN G1 achieved study mean growth for all traits in 7 weeks whereas other populations took an additional 1 to 6 weeks to attain the same growth.

The cultivar population did not differ in tiller production $(p=0.230)$ or leaf width ( $p=0.051$; Table 11) from the native populations. Native seedlings were 26 percent taller $(p<0.001)$ and had 27 percent greater leaf elongation $(p=0.003)$ than the cultivar population. Cultivar basal diameter was 35 percent larger $(p<0.001)$ than the native populations.

\subsubsection{Sexual reproductive traits of maternal lineages after greenhouse increase}

Based on earlier reports, expected germination for each lineage was 82 percent (Hyder and Yasmin 1972); observed germination was much lower than expected for all populations under greenhouse conditions $\left(\chi^{2}, p\right.$ $<0.001$ ). Germination (Figure 14; Table 12) differed between the two populations (IN or OUT) depending on generation (G1 or G2; population by generation interaction $p<0.001$ ). Within populations, germination of IN G1 (45 percent) was greater than IN G2 (18 percent; $p<0.001$ ). Germination of OUT generations did not differ. Regardless of generation, the IN population germination (32 percent) was twice that of the OUT population (15 percent; $p<0.001$ ). Cultivar germination was quite low, 1.0 percent, and less than the wild population $(22.5$ percent; Table $13(p<0.001)$. 


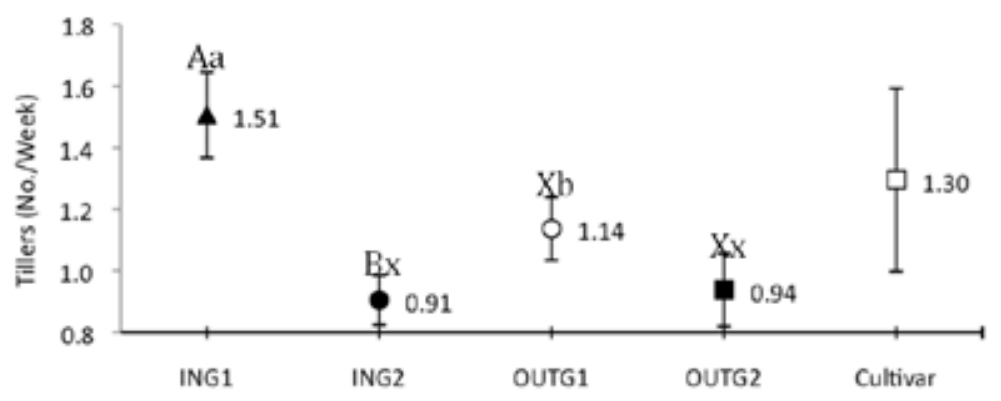

a. Tiller No., interaction $\mathrm{p}<0.001$

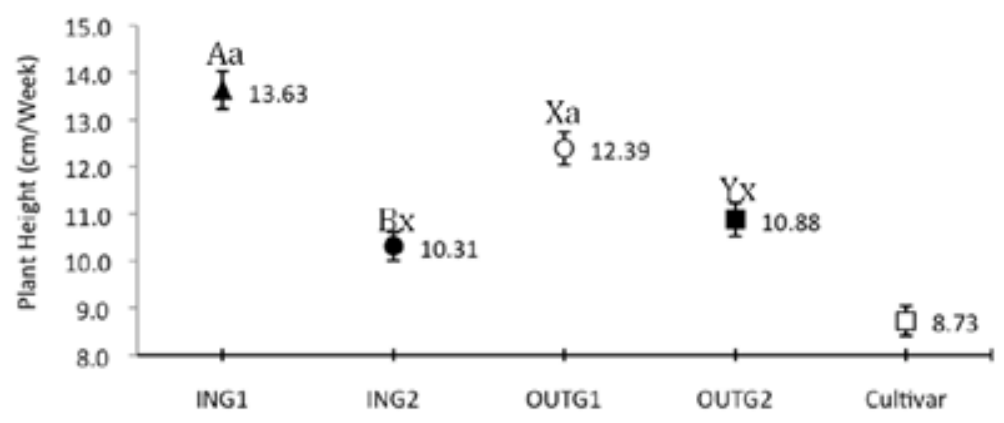

b. Plant Height, interaction $p=0.011$

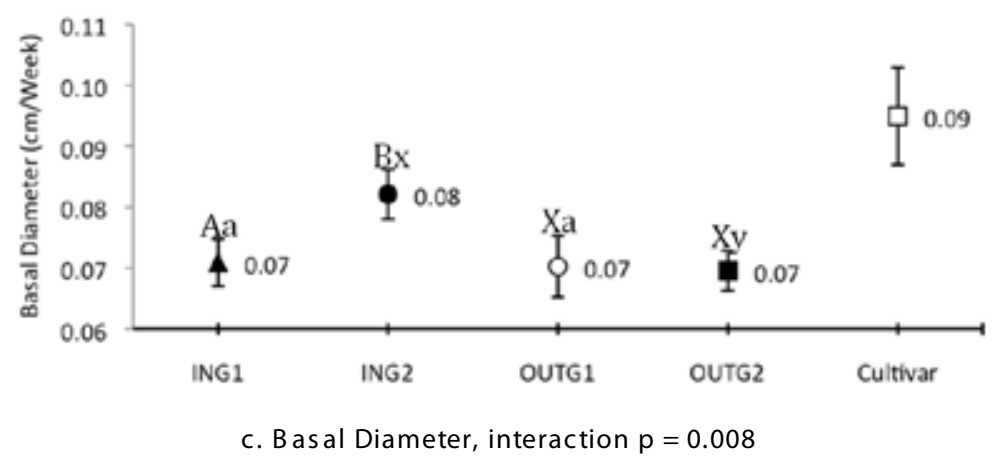

Figure 13. Relative growth per week (mean $\pm \mathrm{SE}$ ) for first (G1) and second (G2) generations of Sporobolus airoides populations from invaded (IN) and non-invaded (OUT) Rhaponticum repens areas. Probabilities (Proc GLM) for interactions (population* generation) are reported for each trait. Cultivar means provided for visual comparison (not included in GLM analysis). Within a population (IN or OUT), generation means with the same upper case letter do not differ. Within a generation (G1 or G2), population means with the same lower case letter do not differ.

Table 11. Mean ( \pm SE) values of phenotypic traits for cultivar and native Sporobolus airoides populations.

\begin{tabular}{|l|l|c|c|c|c|c|c|}
\hline Source & $\mathrm{n}$ & $\begin{array}{c}\text { Tiller Production } \\
(\text { No. })\end{array}$ & $\begin{array}{c}\text { Plant Height } \\
(\mathbf{c m})\end{array}$ & $\begin{array}{c}\text { Basal Diameter } \\
(\mathbf{c m})\end{array}$ & $\begin{array}{c}\text { Leaf Length } \\
(\mathbf{c m})\end{array}$ & $\begin{array}{c}\text { Leaf Width } \\
(\mathrm{mm})\end{array}$ & $\begin{array}{c}\text { Germination } \\
(\text { No. })\end{array}$ \\
\hline Cultivar & 20 & $1.30 \pm 0.14$ & $8.73 \pm 0.31$ & $0.095 \pm 0.004^{* * *}$ & $1.53 \pm 0.18$ & $0.146 \pm 0.005$ & $0.050 \pm 0.05$ \\
\hline Natives & 673 & $1.12 \pm 0.03$ & $11.79 \pm 0.18^{* * *}$ & $0.073 \pm 0.001$ & $2.10 \pm 0.51^{* *}$ & $0.161 \pm 0.006$ & $1.130 \pm 0.05^{* * *}$ \\
\hline$* \quad p<$ value $<0.05 ;{ }^{* *} p<$ value $<0.01 ;{ }^{* * *} p<$ value $<0.001$ \\
\hline
\end{tabular}




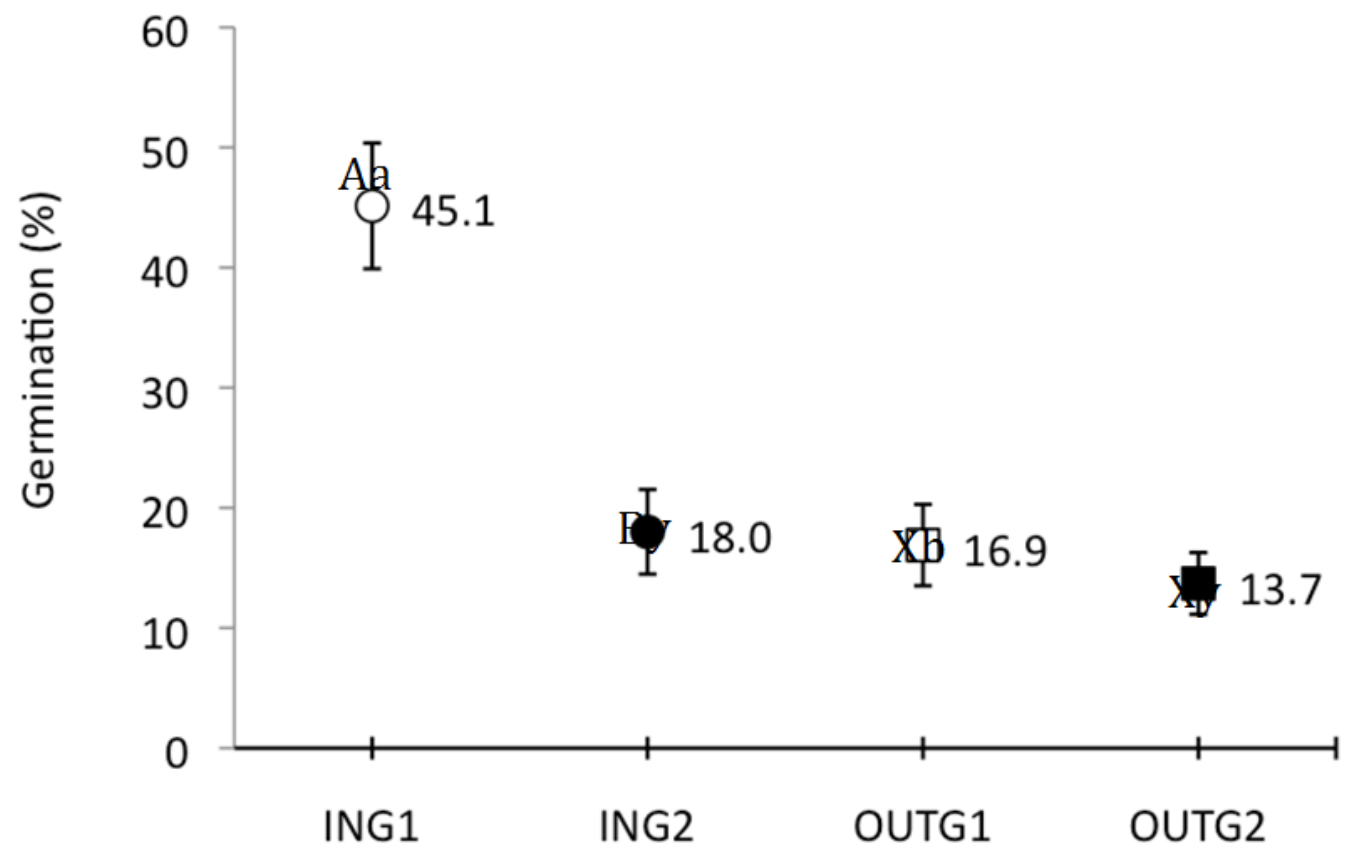

a. Germination No., interaction $p=0.008$

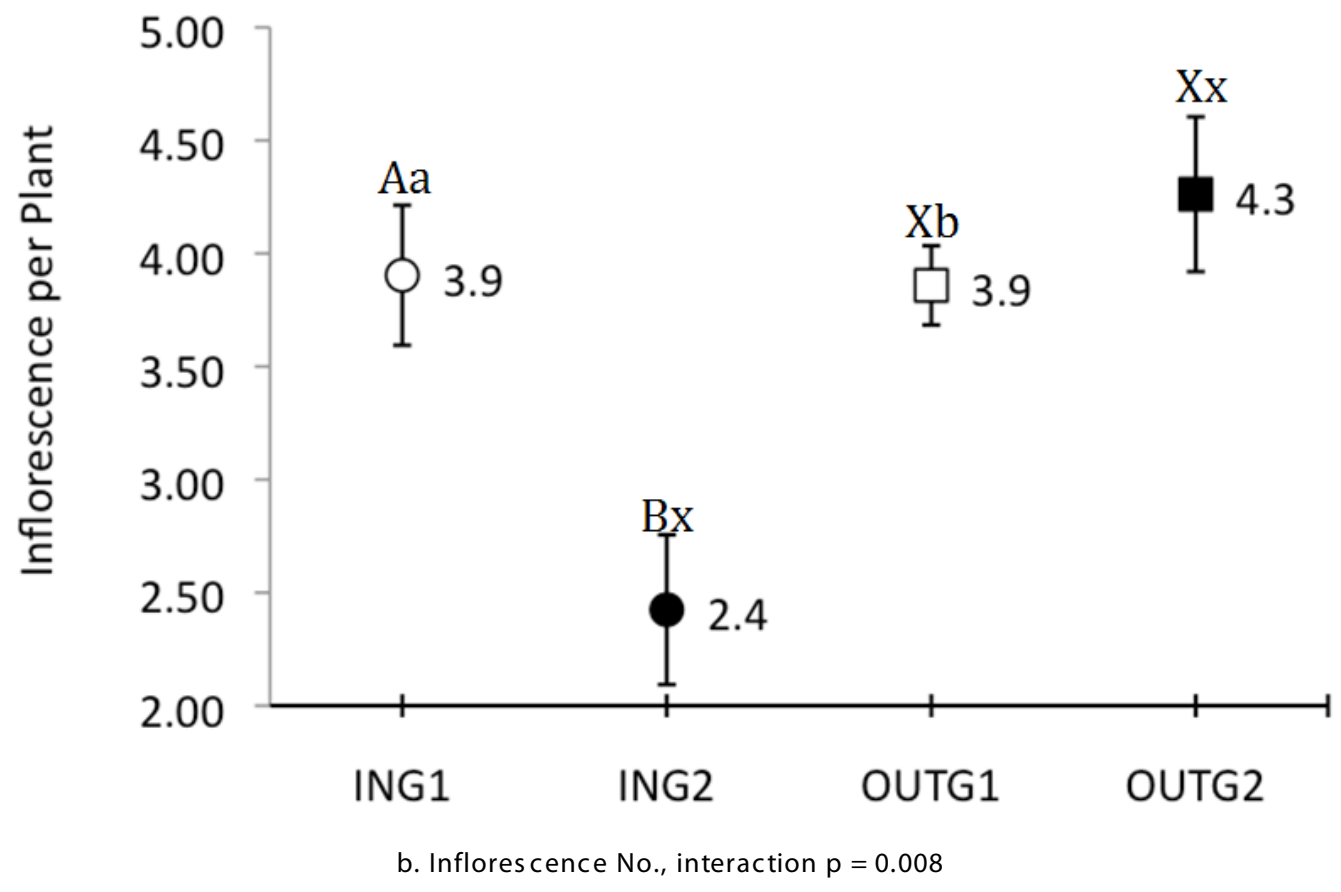

Figure 14. Reproductive means ( $\pm \mathrm{SE}$ ) for first (G1) and second (G2) generations of Sporobolus airoides populations from invaded (IN) and non-invaded (OUT) Rhaponticum repens areas. Probabilities (Proc GLM) for interactions (population*generation) are reported for each trait. Germination rate is out of five seeds planted per pot. Within a population (IN or OUT), generation means with the same upper case letter do not differ. Within a generation (G1 or G2), population means with the same lower case letter do not differ. 
Table 12. Summary of total Sporobolus airoides seedlings used in the study and reproductive outputs. Original maternal plants were collected from invaded (IN) and non-invaded (OUT) areas of long-term Rhaponticum repens invasion (Mealor and Hild 2006). Each population consisted of maternal lineages that were increased for two generations (G1 and G2) in the greenhouse.

\begin{tabular}{|l|c|c|c|c|c|c|c|}
\hline Population & $\begin{array}{c}\text { Lineages } \\
\text { (No.) }\end{array}$ & $\begin{array}{c}\text { Seeds } \\
\text { Planted (No.) }\end{array}$ & $\begin{array}{c}\text { Seeds } \\
\text { Germinated (No.) }\end{array}$ & $\begin{array}{c}\text { Plants } \\
\text { Observed (No.) }\end{array}$ & $\begin{array}{c}\text { Plants } \\
\text { Harvested (No.) }\end{array}$ & $\begin{array}{c}\text { Seed } \\
\text { (No.) }\end{array}$ & $\begin{array}{c}\text { Inflorescence } \\
\text { (No.) }\end{array}$ \\
\hline IN & - & 1600 & 506 & 320 & 126 & 56413 & 443 \\
\hline G1 & 16 & 800 & 362 & 180 & 93 & 46999 & 363 \\
\hline G2 & 16 & 800 & 144 & 140 & 33 & 9414 & 80 \\
\hline OUT & - & 2000 & 306 & 253 & 127 & 71447 & 505 \\
\hline G1 & 20 & 1000 & 169 & 187 & 85 & 45298 & 328 \\
\hline G2 & 20 & 1000 & 137 & 66 & 42 & 26149 & 177 \\
\hline
\end{tabular}

Table 13. S. airoides growth production Analysis of Variance F-test probabilities for data collected in Environmental Simulation Laboratory.

\begin{tabular}{|l|c|c|c|c|c|}
\hline Source & DF & $\begin{array}{c}\text { Longest Leaf } \\
(\mathbf{c m})\end{array}$ & $\begin{array}{c}\text { Tillers } \\
\text { (No.) }\end{array}$ & $\begin{array}{c}\text { Basal } \\
\text { Circumference } \\
(\mathbf{c m})\end{array}$ & $\begin{array}{c}\text { Flower } \\
\text { (No.) }\end{array}$ \\
\hline Weed & 1 & 0.8684 & 0.4485 & 0.8317 & 0.2146 \\
\hline Rep (weed) & 8 & & & & - \\
\hline History & 1 & 0.2478 & 0.1935 & 0.3866 & 0.4621 \\
\hline Weed*history & 1 & 0.6222 & 0.2095 & 0.0661 & 0.4270 \\
\hline Rep*history(weed) & 8 & & & & \\
\hline Date & 13 & $<0.0001$ & $<0.0001$ & $<0.0001$ & 0.0094 \\
\hline Weed*date & 13 & 0.0004 & 0.6152 & 1.0000 & 0.0192 \\
\hline Date*history & 13 & $<0.0001$ & 0.0506 & 0.6091 & 0.8931 \\
\hline Weed*date*history & 13 & 0.9774 & 0.3103 & 0.1327 & 0.8280 \\
\hline Residual error & 208 & - & - & - & - \\
\hline
\end{tabular}

Cultivar plants did not produce any inflorescences and was excluded from the sexual reproductive traits analysis. Plants averaged 85 days from planting to anthesis in the IN and OUT populations $(p=0.978)$. The first generation (G1) took 4 days fewer than the second generation (G2) to reach anthesis $(p=0.069)$. Days to anthesis was less variable in the IN population (range of 19 days) than the OUT population (range of 23 days). IN G2 and OUT G2 had a range of 24 days to reach anthesis whereas the first generation of both populations had a shorter range (IN G1 range 13 days and OUT G1 range 20 days).

IN plants produced 9 percent taller inflorescences than OUT plants ( $p=$ o.026), but inflorescence height did not differ between generations within populations. Inflorescence production differed between the two populations (IN or OUT) depending on generation (G1 or G2; population by generation interaction $p=0.010$ ). OUT plants produced 29.4 percent more 
inflorescences than the IN population $(p<0.001)$. Within a population, IN G1 produced 37.4 percent more inflorescences than IN G2 $(p=0.009)$; generations within the OUT population did not differ. Seed production in the OUT population was twice the seed production of the IN population (Table 13; $p<0.001$ ). The OUT population produced 37 percent heavier seed than the IN population $(p<0.001)$ and had 51 percent more seeds per inflorescence than the IN population $(p=0.013)$ (see also Table 25). Seed production, weight per 100 seed, and seed number per inflorescence did not differ between generations of either population.

\subsubsection{Traits discussion (after greenhouse increase) - general}

The IN population accumulated more vegetative growth than the OUT population, especially the first generation of the IN population. The IN population demonstrated more vegetative growth before allocating resources for seed production or sexual reproductive growth than the OUT population. Increased tiller production, or clonal spread, and leaf canopy expansion in the IN population may represent a competitive asexual reproductive tactic. Increased seedling germination and initial growth in the IN populations may be a useful response in the presence of exotic encroachment (Galloway 2005); (Lavergne and Molofsky 2007). This study's results agree with prior findings that invaded remnant $S$. airoides populations express increased tillering and larger basal growth than non-invaded populations when under competition with an exotic invader (R. repens) at a novel field site (Mealor and Hild 2007).

Greater tiller numbers increases leaf area and photosynthetic potential and enhances the likelihood to shade an invasive competitor's persistent seed bank. Larger basal crowns may enhance stability and dominance to compete with quick spreading invasive species in a resource limited environment where horizontal spread or tillering would be more adventitious than vertical growth (Bazzaz et al. 1987). A life cycle of faster vegetative growth is important for native perennial grasses to establish rapidly and maintain high survival rates when under the stress of reduced moisture, nutrient, and light conditions such as when exotic invaders are present (Lesica and Allendorf 1999, Seabloom et al. 2003). Fitness and phenotypic adaptations ensure persistence against disturbances, but trade-offs between reproduction and vegetative growth most likely will occur (Herms and Mattson 1992). The IN population may allocate more resources to vegetative growth rather than producing a large amount of seed as a competition strategy. Competitive traits may be demonstrated by increasing ve- 
getative growth or reproduction depending on which trait is most important for success in a new environment (Blossey and Notzold 1995). Longlived native plants, such as $S$. airoides, may have persisted through exotic invasion via phenotypes that allocate resources to vegetative growth.

Although variable among species, trade-offs between resource allocation to sexual reproduction and asexual reproduction are well documented (Bazzaz et al. 1987). For example, new generations from clonal growth will be limited to the close proximity of their maternal plants rather than the outward dispersal from seed spread (Seabloom et al. 2003). However, tiller production transfers competitive genetic material to clonal offspring (Lavergne and Molofsky 2007). Offspring exposed to the same environment as the maternal plant promotes selection for adaptive maternal effects (Galloway 2005). Competitive traits such as clonal reproduction and increased vegetative growth could indicate selection of this phenology (Lavergne and Molofsky 2007).

The tradeoff for the IN population's competitive vegetative traits may translate to decreased seed production. When a plant delays or limits their sexual reproduction, fitness might be compromised by the production of smaller and fewer amounts of seed. In a limiting or high plant density environment, tiller recruitment offers sustained productivity and a greater probability of establishment than do seedlings (Herms and Mattson 1992, Piquot et al. 1998). Even in favorable environments, such as the greenhouse setting, where nutrients were readily available for allocation to seed reserves, sexual reproduction does not appear to have taken precedence over vegetative growth in the IN population. Even though sexual reproductive traits seem to be a priority for the OUT population rather than the IN population, the average time from planting to pollen shed was the same for both populations (indicating that sexual development of IN plants was not delayed).

The OUT population was expected to differ in phenotypic expression from the first generation to the second generation, however the IN population demonstrated more differences in phenotypic expression between generations. Reduced growth in the second generation may demonstrate the influence of a controlled environment, even over a short period of time. Because these plants were not stressed, this study probably does not document a full expression of competitive phenology. 


\subsubsection{Germination of 2006 and 2007 Sporobolus airoides seed from In and Out maternal plants after field increase}

When averaged across maternal lineages, the effect of position (IN vs. OUT) on germination (\%) of the 2006 seed depended on sample day (Wilk's $\Lambda=0.540, F_{(3,14)}=3.971 ; \mathrm{P}=0.031$, Figure 15 ) over the first 4 sample days. Using standard protocol for $\mathrm{P}$ values close to this study's specified alpha (0.05), the data were also subjected to univariate ANOVA as a more conservative test and results suggests that an interaction was not present between IN and OUT positions for germination $(\%)(F(3,48)=$ $0.775 ; \mathrm{P}=0.514)$.

As expected, germination differed among sample days (simple effect of time) $\left(F_{(3,14)}=1220.287 ; \mathrm{p}<0.001\right)$ and in general, decreased after day two. Germination did not differ between positions $\left(F_{(1,16)}=2.465 ; \mathrm{P}=\right.$ 0.136).

When averaged across 2007 maternal lineages, the effect of position (IN vs. OUT) on germination (\%) depended on sample day (Wilk's $\Lambda=0.421, F$ $(3,20)=9.165 ; \mathrm{P}=0.001$, Figure 15) over the first 4 sample days. Germination of IN maternal lineages increased from day two to day four, and then rapidly decreased from day four too day six and ceased by day eight (Wilk's $\Lambda=0.012, F_{(3,9)}=251.104 ; \mathrm{p}<0.001$ ). Germination of OUT maternal lineages was initially rapid on sample day two and steadily decreased on sample days four, six, and eight (Wilk's $\Lambda=0.070, F_{(3,9)}=39.604 ; \mathrm{p}<$ o.001). IN maternal lineages behaved as a $3^{\text {rd }}$ order (cubic) polynomial $(F$ $(1,11)=48.003 ; \mathrm{p}<0.001)$, and OUT maternal lineages behaved as a $2^{\text {nd }}$ order (quadratic) polynomial $\left(F_{(1,11)}=9.706 ; \mathrm{P}=0.010\right)$. IN germination $(\%)$ differed from OUT germination (\%) on specific sample days two (Bonferonni $t(66)=4.43 ; \mathrm{p}<0.001$ ), and day four (Bonferonni $t(66)=4.70$; $\mathrm{p}<0.001)\left(\alpha^{\prime}=0.0125\right)$.

Even though an interaction is not present in the 2006 seed source year between IN and OUT maternal lineages, an interaction is present among the IN and OUT maternal lineages for germination (\%) in 2007. The germination of 2007 IN maternal lineages nearly doubles from day two to day four. IN maternal lineages have experienced invasions of $R$. repens and germination trends seem to be affected by this with 2007 seed. The seed sources (years) could differ via altered environmental conditions between years or because of a shorter after-ripening period for 2007 seed. 
Of the 43 maternal lineages germinated, 16 produced seed in both 2006 and 2007 (IN=bgvin 1, 3, 6, 8 and 9; gbin 6; monoin 7; OUT=bgvout 1, 7, 10; gbout 3 and 7; monoout 1, 2, 7 and 8). When the same maternal lineages were compared, germination was similar between IN and OUT maternal lineages. Earlier analysis of the 2006 seed germination by sample day revealed no position differences, but when comparing identical maternal lineages across years, effects of position (IN and OUT) on germination depended on sample day for both 2006 seed (Wilk's $\Lambda=0.464, F_{(3,12)}=$ 4.624; $\mathrm{P}=0.023$ ) and 2007 seed (Wilk's $\Lambda=0.346, F_{(3,12)}=7.570 ; \mathrm{P}=$ 0.004, Figure 16).
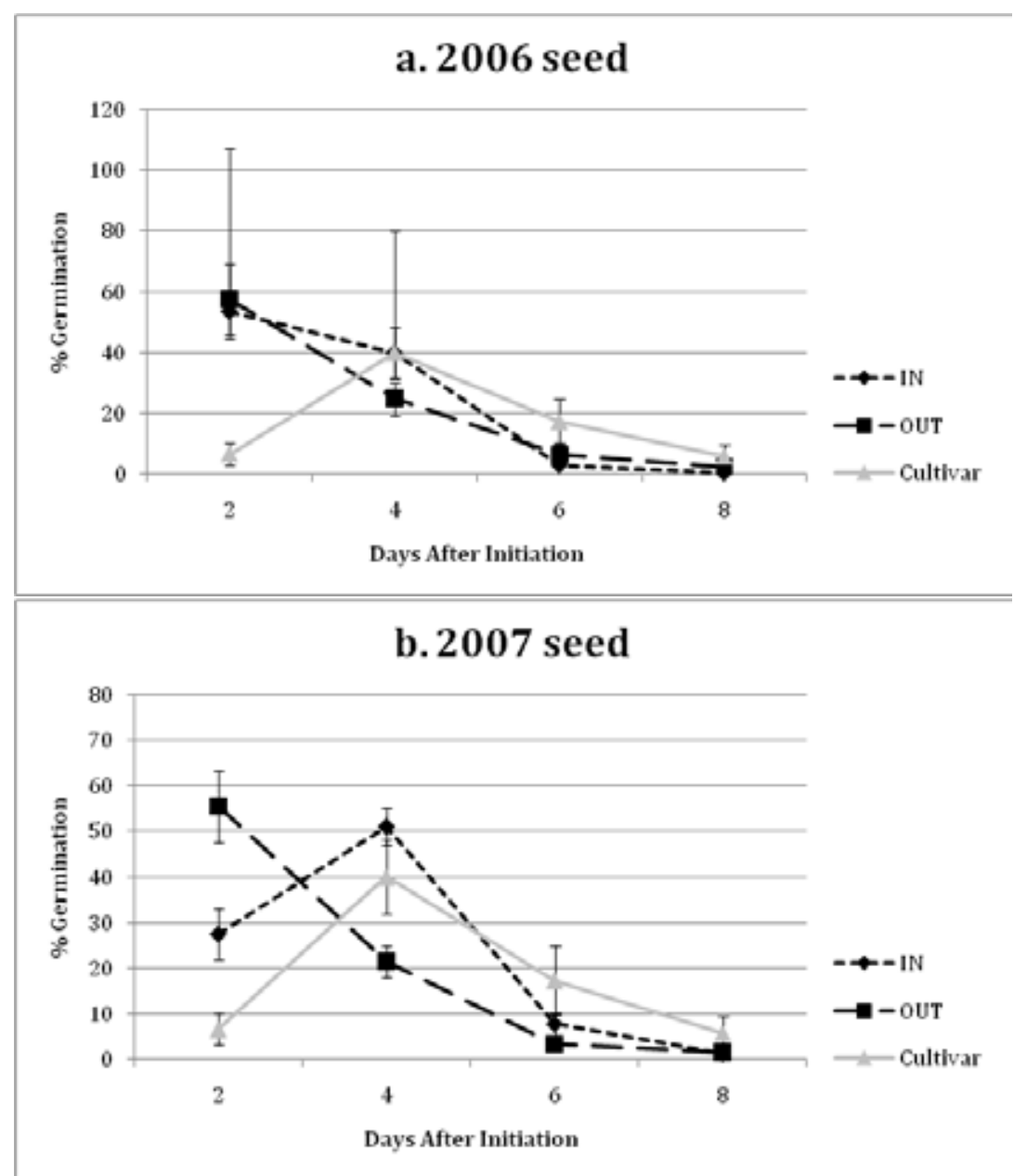

Figure 15. Germination (\%) of Sporobolus airoides by sample day profile plot for a) $2006(P=$ $0.514)$ and b) $2007(p<0.001)$ seed. Significant differences exist on sample days two (Bonferonni $t_{(66)}=4.43, \mathrm{p}<0.001$ ), and four (Bonferonni $t_{(66)}=4.70, \mathrm{p}<0.001$ ). Solid line represents the commercial cultivar (included for comparison). Error bars represent \pm 1 standard error. 


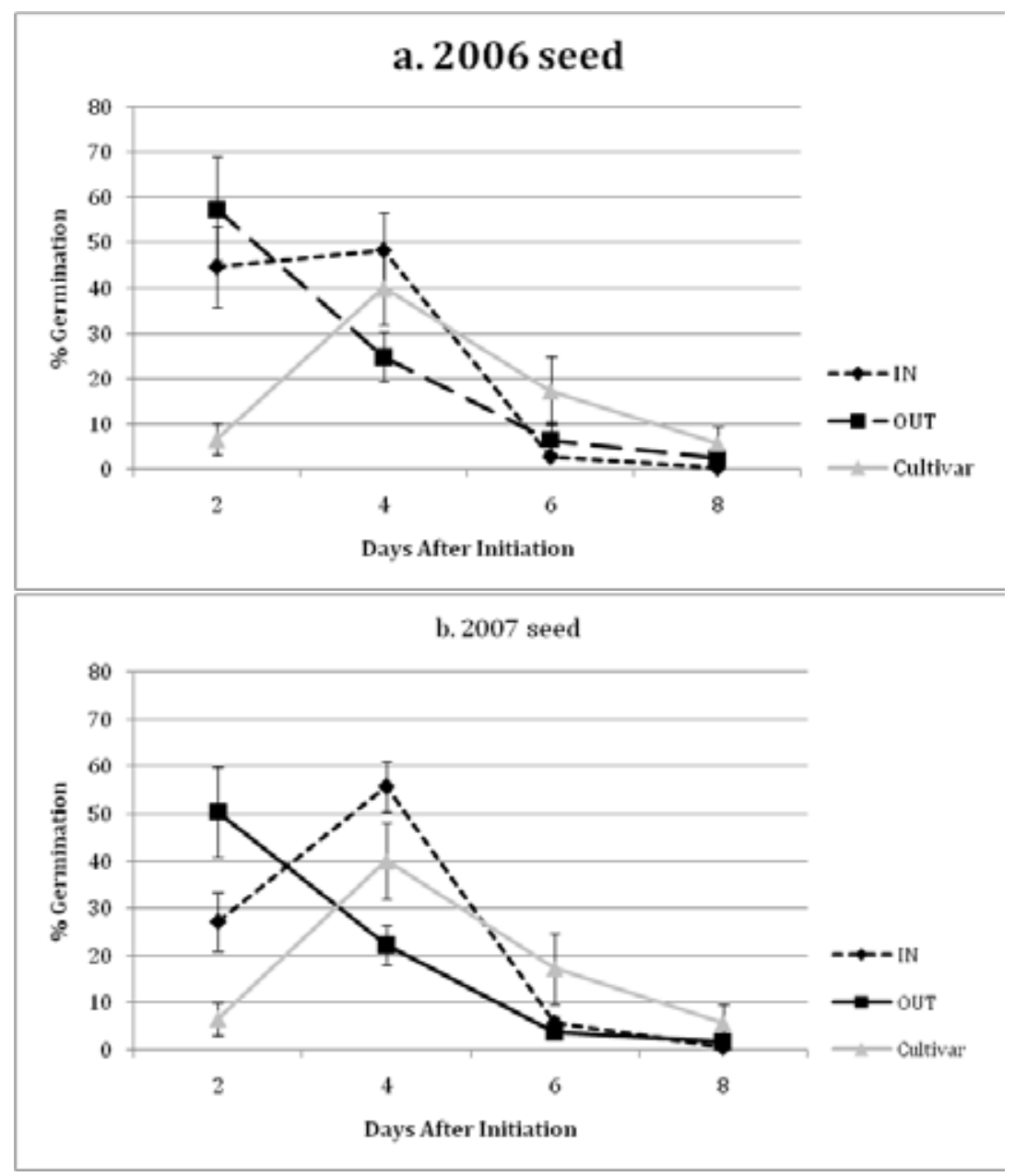

Figure 16. IN and OUT Sporobolus airoides maternal lineage overlap between: (a) 2006 ( $p=$ $0.023)$ and (b) $2007(P=0.004)$ seed source years. Solid line represents the commercial cultivar (included for comparison). Error bars represent \pm 1 standard error.

IN maternal lineages from 2006 displayed nearly the same germination on day two and four and little germination by day six and eight (Wilk's $\Lambda=$ $\left.0.001, F_{(3,4)}=1659.637 ; \mathrm{p}<0.001\right)$, and behaved as a $3^{\text {rd }}$ order polynomial $\left(F_{(1,6)}=8.047 ; \mathrm{P}=0.030\right)$. OUT maternal lineages from 2006 displayed rapid germination on day two with steadily decreasing germination on day's four, six, and eight (Wilk's $\Lambda=0.004, F_{(3,6)}=554.871 ; \mathrm{p}<0.001$ ), and behaved linearly $\left(F_{(1,8)}=23.620 ; \mathrm{P}=0.001\right)$. IN maternal lineages from 2007 displayed nearly double the germination on day four as day two and little germination on days six and eight (Wilk's $\Lambda=0.002, F_{(3,4)}=834.776$; $\mathrm{p}<0.001)$, and behaved as a $3^{\text {rd }}$ order polynomial $\left(F_{(1,6)}=40.575 ; \mathrm{P}=\right.$ o.001). OUT maternal lineages from 2007 displayed rapid germination on day two, with steadily decreasing germination on day's four, six, and eight (Wilk's $\left.\Lambda=0.091, F_{(3,6)}=20.060 ; \mathrm{P}=0.002\right)$, and behaved linearly $\left(F_{(1,8)}=\right.$ 28.920; $\mathrm{P}=0.001)$. For the 2007 seed, IN and OUT positions differed in 
germination on days two (Bonferonni $t_{(42)}=3.018 ; \mathrm{P}=0.002$ ) and day four (Bonferonni $\left.t_{(42)}=4.383 ; \mathrm{p}<0.001\right)\left(\alpha^{\prime}=0.0125\right)$.

\subsubsection{Germination with additional after-ripening}

The results indicate that the $2006 \mathrm{IN}$ and OUT maternal lineages (with 26 months of after-ripening) exhibit nearly identical germination patterns as the same 2006 maternal lineages with only 18 months of after-ripening Figure 17). Interestingly, the 2007 IN maternal lineages (with 14 months of after-ripening) displayed different germination traits than the same 2007 IN maternal lineages with only 6 months of after-ripening (Figure 18).

\subsubsection{Cumulative seedling root growth of 2006 and 2007 Sporobolus airoides seed from In and Out maternal plants after field increase}

Seedling root growth for both 2006 and 2007 seed sources began on day two and, in general, root length increases continually through the culmination of the experiment. Additionally, for both seed sources, roots grew rapidly on days three and four (Figure 19). When averaged across 2006 maternal lineages, the effect of cumulative root growth on position (IN and OUT) did not depend on sample day (Wilk's $\Lambda=0.407, F_{(8,9)}=1.641 ; \mathrm{P}=$ 0.238 , Figure 17) over 9 sample days. As expected, root growth of seedlings increased over 9 sample days (Wilk's $\Lambda=0.215, F_{(8,9)}=4.101 ; \mathrm{P}=$ $0.025)$. The IN position behaved as a $7^{\text {th }}$ order polynomial $\left(F_{(1,8)}=6.684\right.$; $\mathrm{P}=0.032$ ), and the OUT maternal lineages behaved as a $4^{\text {th }}$ order polynomial $\left(F_{(1,8)}=19.460 ; \mathrm{P}=0.002\right)$. Root growth did not differ between positions $\left(F_{(1,16)}=0.307 ; \mathrm{P}=0.587\right)$.

(IN and OUT) did not depend on sample day (Wilk's $\Lambda=0.617, F_{(8,15)}=$ 1.164; $\mathrm{P}=0.380$, Figure 17) over 9 sample days. As expected, root growth increased over 9 sample days (Wilk's $\left.\Lambda=0.258, F_{(8,15)}=5.406 ; \mathrm{P}=0.002\right)$. Both the IN $\left(F_{(1,11)}=5.194 ; \mathrm{P}=0.044\right)$ and $\operatorname{OUT}\left(F_{(1,11)}=18.368 ; \mathrm{P}=0.001\right)$ maternal lineages behaved (quintically) as $5^{\text {th }}$ order polynomials. Root growth did not differ between positions $\left(F_{(1,22)}=2.550 ; \mathrm{P}=0.125\right)$.

Differences in timing of germination on the second sample day of the 2007 seeds could be the result of the IN maternal lineages having different dormancy or seed-coat traits via the influence of $R$. repens, which could derive from natural selection of certain $S$. airoides maternal lineages (Mealor and Hild 2006) that exhibit delayed onset of germination. 


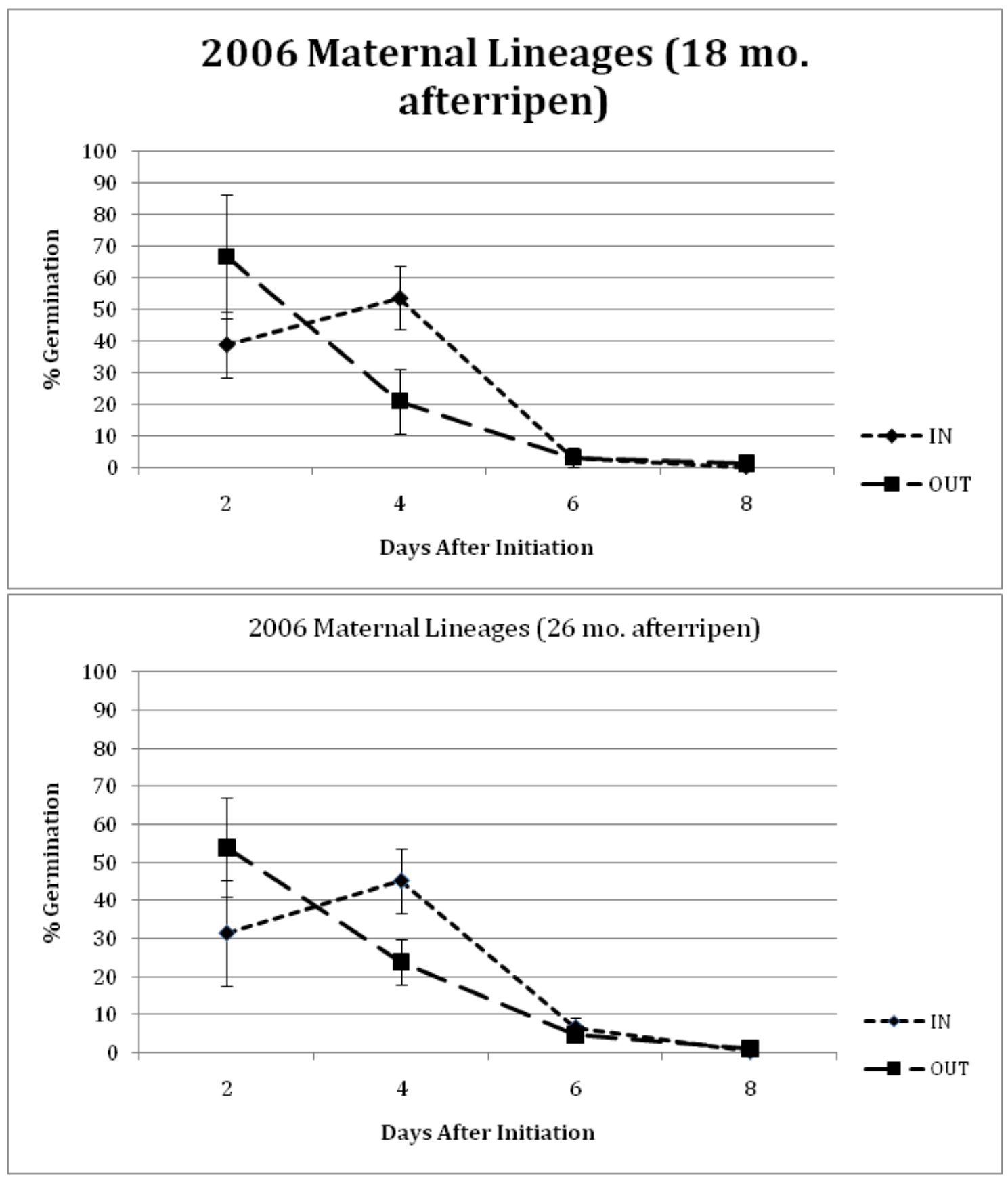

Figure 17. Germination (\%) of Sporobolus airoides by sample day profile plot for a) 2006 seed with 18 months of after-ripening and b) 2006 seed with 26 months of after-ripening. Error bars represent \pm 1 standard error. 


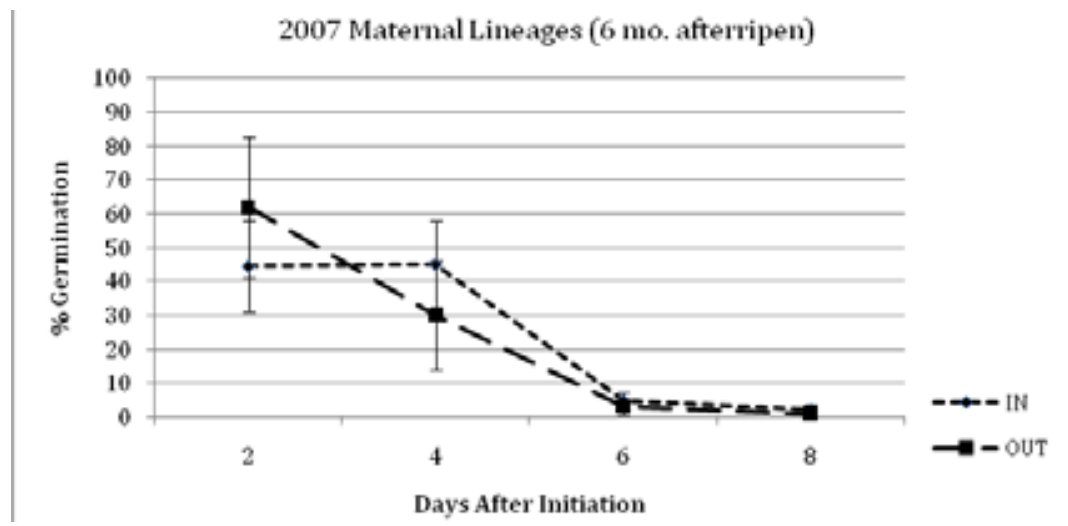

Figure 18. Germination (\%) of Sporobolus airoides by sample day profile plot for a) 2007 seed with 6 months of after-ripening and b) 2007 seed with 14 months of after-ripening. Error bars represent \pm 1 standard error.

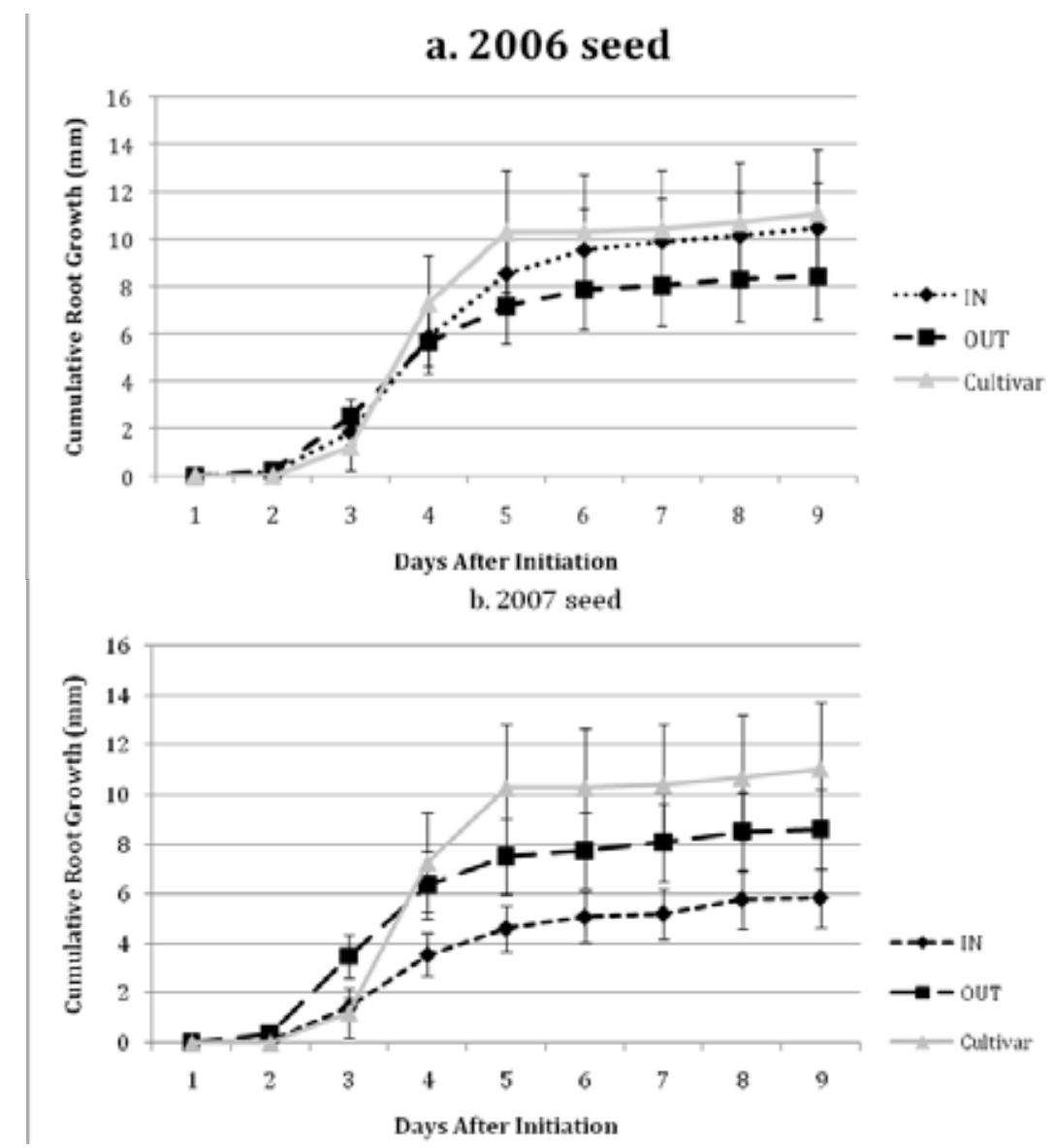

Figure 19. Profile plot for cumulative Sporobolus airoides root growth by IN and OUT positions for a) $2006(P=0.238)$ and b) 2007 seed $(P=0.380)$. Solid green line represents the commercial cultivar (included for comparison). Error bars represent \pm 1 standard error. 


\subsubsection{General Discussion - testing for phenotype of first and second generation seedlings - plant traits in response to long-term exposure to Rhaponicum repens}

Competitive ability of particular maternal lineages that are fully grown may substantially differ from their ability to establish as seedlings. Both traits (competitive ability at maturity and successful seedling establishment) are needed to maintain populations. This study assessed competitive ability in S. airoides maternal lineages collected from within (IN) and outside of (OUT) $R$. repens invaded sites. Seedling establishment depends particularly on germination, primary root growth following germination, and the ability to successfully garner nutrients to ensure growth and survival. Here, germination and primary root growth of $43 \mathrm{~S}$. airoides maternal lineages were examined as a measure of establishment traits.

The maternal plant environment at the time of seed maturation and the genetic makeup of individuals are two very important factors influencing seed germination (Baskin and Baskin 2001) and plant phenotype (Roach and Wulff 1987). Since genetics and maternal plant environment at the time of seed maturity do not operate independently, difficulty can arise when trying to determine the contribution of each to the overall differences in seed germination among the same species (Baskin and Baskin 2001). IN and OUT maternal lineages of $S$. airoides were examined for potential differences in seed germination and primary root growth due to genetic differences as indicators of their ability to establish.

Invasive species can also alter the genetic makeup of native plant populations (Leger 2008) and has been documented in $S$. airoides populations (Mealor and Hild 2006). Seed germination, root growth, and establishment of propagules may be quite different among maternal lineages originating from IN versus OUT positions.

Seed germination and primary root growth among maternal lineages of $S$. airoides seeds produced by maternal plants originating from invaded and non-invaded environments were tested to examine the selective pressures of $R$. repens on seedling establishment traits. It was hypothesized that the selective pressures of $R$. repens on $S$. airoides will influence germination and seedling establishment of $S$. airoides. Specifically, this work hypothesized that seeds will either exhibit rapid initial germination or delayed germination. Both displays of seed germination would also be coupled with rapid initial seedling root growth following germination. This work 
also documented germination and root growth characteristics of IN and OUT $S$. airoides maternal lineages from 2 seed collection years (2006, 2007).

Primary root (radicle) growth is considered to be one of the most important stages in a plant's life (Mueller and Weaver 1942), especially in arid environments where water is limited (Sheley et al.1993, Simanton and Jordan 1986). On western rangelands, rapid seedling growth and competitive ability are important for perennial grass competitiveness with annual grasses (Aguirre and Johnson 1991). In arid grasslands, water is a key limiting resource. Species with early and rapid root growth are better able to provide moisture to the above-ground portion of the plant (Mueller and Weaver 1942) aiding plant establishment and growth in arid environments (Harris 1967, Sheley et al. 1993).

Germination of seed from maternal plants is influenced by differing history of exposure to $R$. repens. Apparently, seed germination is altered among IN maternal lineages, so that, when optimum conditions are present for germination, IN $S$. airoides maternal lineages have either: (1) equal or lower germination than OUT maternal lineages early on, or (2) greater germination later (sample day four). That is, IN maternal lineages seem to delay germination relative to conspecifics (OUT maternal lineages) even though optimum germination conditions are present. Delayed germination during optimum conditions may disperse in time and thus ensure greater survivability of seedlings. Optimum seed germination conditions may only be present for a few days during peak $S$. airoides seed germination periods (July). If the majority of seeds germinate during optimum conditions (OUT maternal lineages), a single detrimental event could prove fatal to the majority of newly established seedlings. If, however, only half of the seed bank germinates during optimum conditions, and then seedlings die due to an unforeseen climatic event (frost, flood, drought), half of the seed bank still remains, waiting for later optimum conditions to arrive for seed germination. Later optimum conditions may not arrive until the following growing season. When seeds of a certain maternal lineage have delayed germination that is spread out over a number of years, the probability of seedling die-off before seedlings can mature and reproduce is decreased (Clauss and Venable 2000). Delayed germination may be a bet-hedging strategy if it reduces temporal variance in reproductive success of a maternal lineage (Clauss and Venable 2000). Reducing the variance (temporally) of reproductive success simply means that the chances may be greater 
for more seedlings to survive and reach a reproductive stage during highly variable conditions. The pressures of $R$. repens may be selecting for maternal lineages that demonstrate a delayed germination or bet-hedging strategy.

Another explanation of differences between IN and OUT seed germination may derive from seed coat permeability to water (Kilen and Hartwig 1978). IN maternal lineages seed coats may be less permeable to water, and thus slower to imbibe than OUT maternal lineages. If IN maternal lineage seeds take longer to imbibe water, seed germination and subsequent seedling establishment may be delayed. However, one must also consider that other factors could be at play that may influence $S$. airoides maternal plants and subsequent seed germination of their offspring.

Differences between seed source years $(2006,2007)$ may derive from differing environmental conditions from year to year during seed ripening. The National Climatic Data Center (NCDC) (Laramie 2 station) recorded average monthly temperatures for 2006 that were slightly cooler (July, August, September) than average monthly temperatures for the same months in 2007. Average monthly precipitation totals were also slightly higher for the same months in 2006 than in 2007. In certain instances, wetter, cooler conditions could enhance seed dormancy (Fenner 2000) and thus be a reason for germination differences between seed source years. Differences between seed source years $(2006,2007)$ may not be solely due to differing after-ripening periods. Earlier in this work, it was determined that the 2006 seed had 18 months of after-ripening and 2007 seed had 6 months of after-ripening. The 2007 maternal lineages (with an additional 8 months of after-ripening) appear to have lost their delay in germination and instead behave similar to the 2007 OUT maternal lineages regardless of after-ripening. Results of after-ripening for an additional 8 months suggest that after-ripening differences among seed source years may not be the only factor in explaining differences between seed source years.

Root growth among the maternal lineages seems to be more tied to individual plant characteristics than it is inherent in any particular IN or OUT maternal lineage. On average, IN maternal lineages from 2006 seed had greater overall root growth than OUT maternal lineages, and the opposite was true for the 2007 seed. 


\subsection{Environmental Simulation Laboratory}

\subsubsection{Above-ground production of Sporobolus airoides in the ESL}

Longest leaf growth and inflorescence production of S. airoides differed among weed and history treatments depending on date (Table 13). S. airoides initially had longer leaves when grown without $R$. repens, but $S$. airoides grown with $R$. repens had longer leaves after 8 July 2010 (Figure 20). Though initially different from 21 January - 27 May 2010, invaded lineages of $S$. airoides did not differ from non-invaded lineages after that time (Figure 21). Sporobolus airoides in the presence of $R$. repens produced more inflorescences than when grown without $R$. repens (Figure 22).

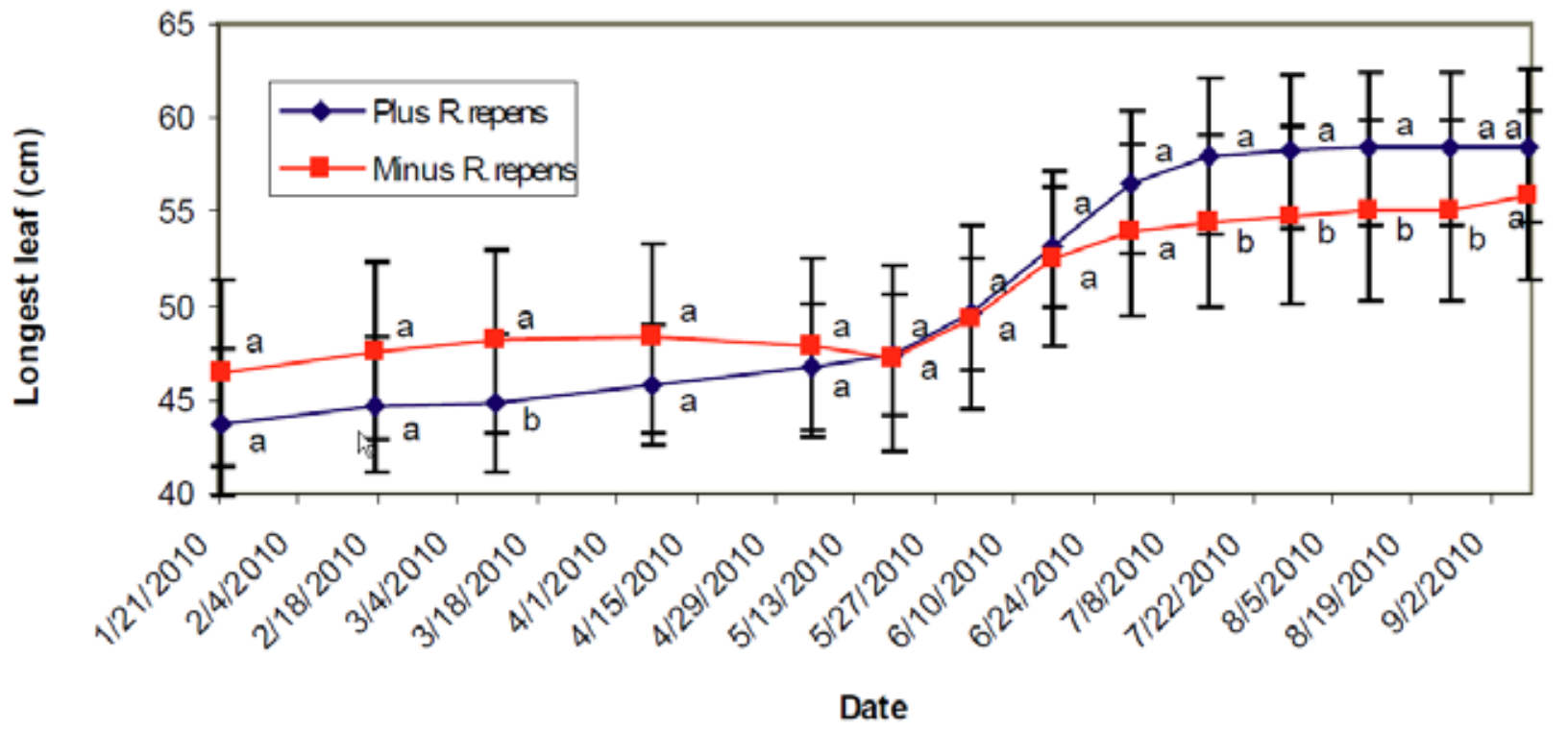

Figure 20. Length of longest leaf for Sporobolus airoides $(\mathrm{cm})$ within two weed treatments $(+,-)$ on 14 sampling dates grown within a controlled environment (University of Wyoming Environmental Simulation Laboratory). Means with the same letters do not differ, FLSD, 0.05. 


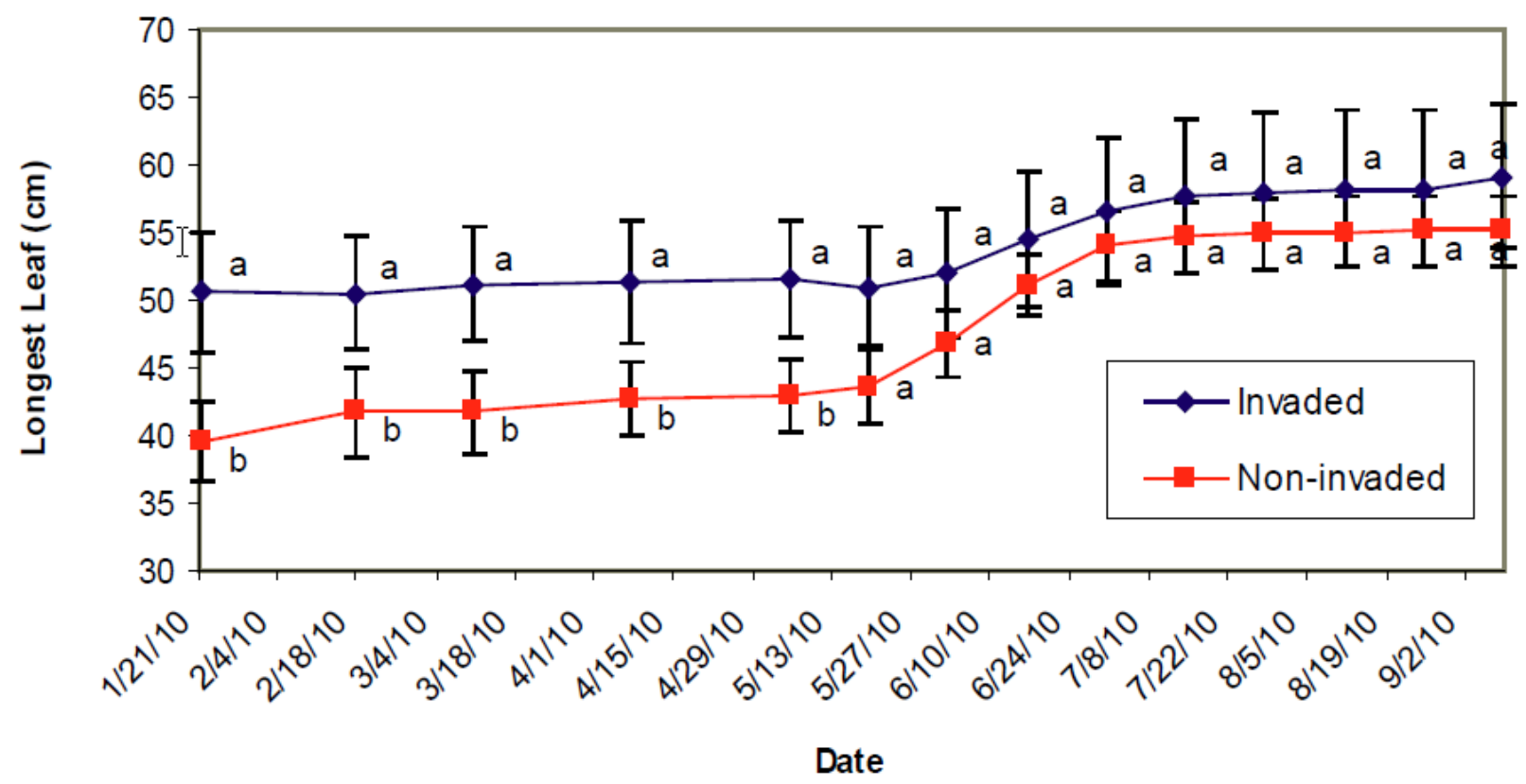

Figure 21. Length of longest leaf for Sporobolus airoides $(\mathrm{cm})$ invaded and non-invaded lineages on 14 sampling dates grown within a controlled environment (University of Wyoming Environmental Simulation Laboratory). Means with the same letters do not differ, FLSD, 0.05.

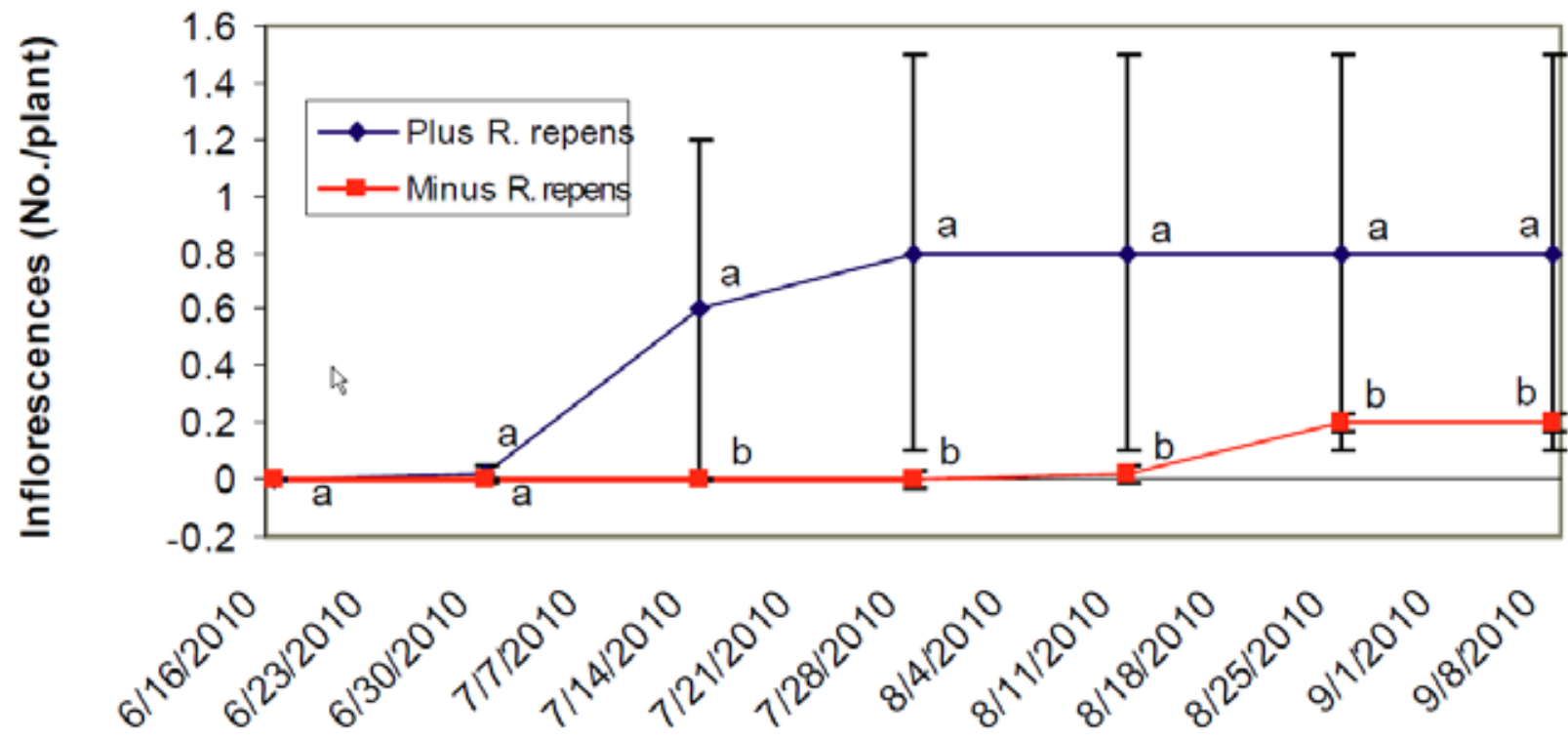

\section{Date}

Figure 22. Inflorescence production of Sporobolus airoides with and without the presence of Raponticum repens competitors (+, -) on 14 sampling dates grown within a controlled environment (University of Wyoming Environmental Simulation Laboratory). Means with the same lowercase letters do not differ, FLSD, 0.05. Measurements between the dates of 21 January 2010 and 2 June 2010 are zero. 


\subsubsection{Germination and seedling establishment of Sporobolus airoides in the ESL}

After four collection periods, cumulative germination differed between all treatments (combined interaction of date, weed, and history $\mathrm{p}=0.0142$, Table 14). Germination of non-invaded $S$. airoides seed (cumulative \%) in general did not differ between $R$. repens treatments (Figure 23a). Germination (cumulative \%) of $S$. airoides seed from invaded lineages was greater when competing with $R$. repens than without $R$. repens (Figure 23b). Seedling establishment of $S$. airoides in seeded grids was minimal during the study: invaded lineages (110 established seedlings total for $10,123 \mathrm{~cm}^{2} \mathrm{gr}-$ ids) and non-invaded (100 established seedlings total for $10,123 \mathrm{~cm}^{2}$ grids). Recruitment of new $R$. repens stems over the course of the study differed between invasion history of neighbors ( $\mathrm{p}=0.0284$, Table 15). Rhaponticum repens encroachment for invaded lineage plots was less (2.81 stems per 1.0 $\mathrm{m}^{2}$ ) compared to non-invaded plots (3.15 stems per 1.0 m2) (Table 16).

Table 14. Seedling germination Analysis of Variance F-test probabilities (Environmental Simulation Laboratory).

\begin{tabular}{|l|c|c|}
\hline Source & DF & $\begin{array}{c}\text { Germination } \\
\text { (Cumulative \%) }\end{array}$ \\
\hline Weed & 1 & 0.3259 \\
\hline Rep(weed) & 8 & - \\
\hline History & 1 & 0.9301 \\
\hline Weed*history & 1 & 0.0830 \\
\hline Rep*history(weed) & 8 & - \\
\hline Date & 3 & $<0.0001$ \\
\hline Weed*date & 3 & 0.2073 \\
\hline Date*history & 3 & 0.4410 \\
\hline Weed*date*history & 3 & 0.0142 \\
\hline Residual error & 48 & - \\
\hline
\end{tabular}


a) Non-invaded Lineages

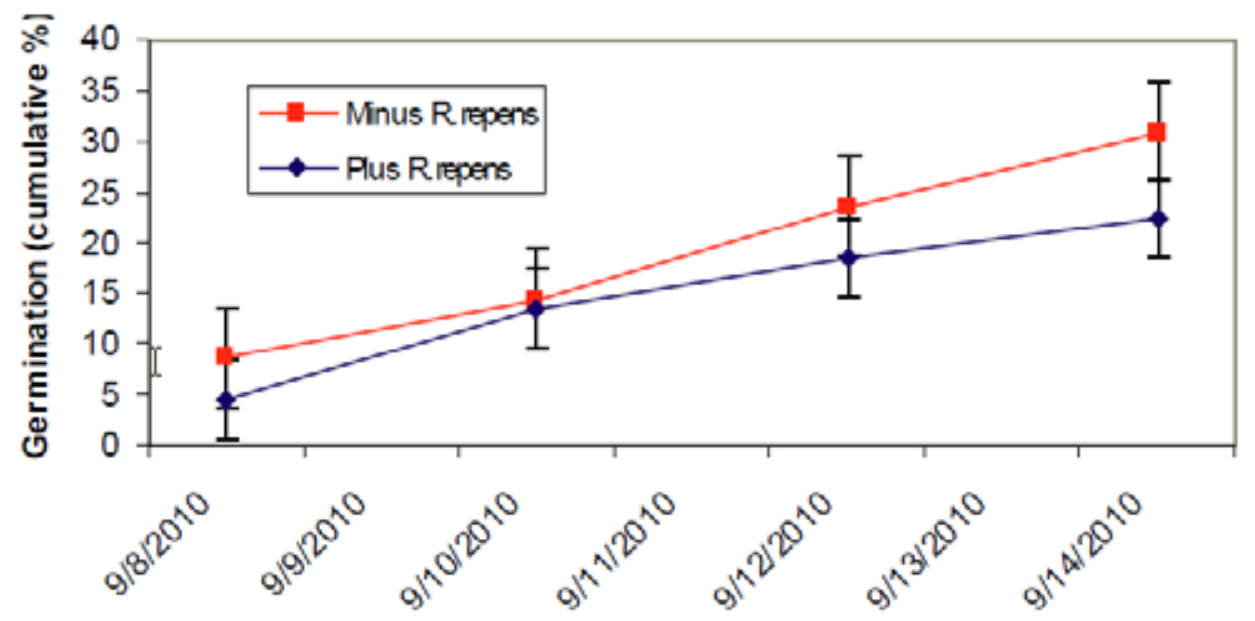

Time of Observation

b) Invaded Lineages

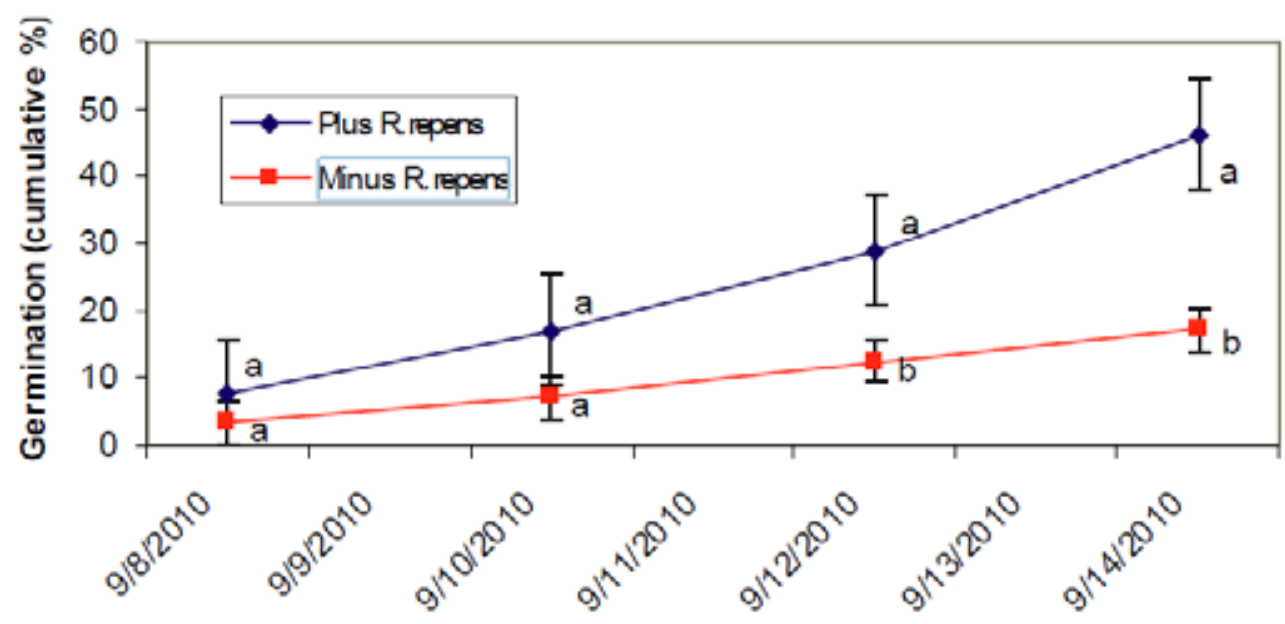

Time of Observation

Figure 23. Sporobolus airoides germination (cumulative \%) from a) non-invaded lineage history and b) invaded lineage history grown with and without competition from Rhaponticum repens in controlled environment (University of Wyoming Environmental Simulation Laboratory). Three way interaction of weed $x$ history $x$ date $(p=0.0142)$. Within a date and lineage history, means with the same lowercase letters do not differ, FLSD, 0.05. Germination of non-invaded lines did not differ between weed treatments (part a, weed treatment $\mathrm{p}=0.2847$ ). 
Table 15. Invasive encroachment Analysis of Variance F-test probabilities for Environmental Simulation Laboratory study. Source DF R. repens.

\begin{tabular}{|l|c|c|}
\hline Source & DF & $\begin{array}{c}\text { R. repens } \\
\text { Encroachment }\end{array}$ \\
\hline Date & 13 & $<0.0001$ \\
\hline History & 1 & 0.0284 \\
\hline Date*history & 13 & 0.9811 \\
\hline Residual error & 112 & - \\
\hline
\end{tabular}

Table 16. Invasive species encroachment (stems per $1.0 \mathrm{~m}^{2}$ ) within plots at FEWAFB and Crowheart, WY. Invaded, non-invaded, disturbed, and undisturbed means with the same letter do not differ for a location ( $p>0.05$, LSD).

\begin{tabular}{|l|c|c|c|c|}
\hline Location & Invaded & Non-invaded & Disturbed & Undisturbed \\
\hline FEWAFB $($ C. arvense) & $46.4 \pm 0.9 \mathrm{a}$ & $46.1 \pm 0.9 \mathrm{a}$ & $34.8 \pm 1.2 \mathrm{~b}$ & $31.0 \pm 0.9 \mathrm{~b}$ \\
\hline Crowheart $(R$. repens) & $12.8 \pm 0.4 \mathrm{~b}$ & $14.3 \pm 0.6 \mathrm{a}$ & $12.5 \pm 0.4 \mathrm{~b}$ & $11.6 \pm 0.4 \mathrm{~b}$ \\
\hline
\end{tabular}

\subsubsection{ESL results general discussion}

Above-ground production in the ESL differed from the field results, perhaps because light levels were less intense in the ESL. Our ESL results seem to reflect a response to the increased light availability we provided at the midpoint of our study. Increased light intensity allowed non-invaded lineages to catch up to the invaded clones. We speculate that invaded lineages were increasing their growth rate and were able to expand leaves to capture more light and be more competitive in low light conditions, a trait that non-invaded lineages do not seem to share. Sporobolus airoides is suggested by Brackie and Anderson (2007) to be shade intolerant. Increased competitive ability in low light may be an advantageous competitive trait in the presence of invaders capable of producing dense canopies. The amount of light available and competition from other plant species may also influence field results. Foliar cover of associated vegetation was high at both field sites in our experiment (Table 17).

Table 17. Total plant cover (\%) within plots at FEWAFB and Crowheart, WY.

\begin{tabular}{|l|c|c|c|c|}
\hline Location & Invaded & $\begin{array}{c}\text { Non- } \\
\text { invaded }\end{array}$ & Disturbed & Undisturbed \\
\hline FEWAFB (C. arvense) & 65 & 57 & 81 & 92 \\
\hline Crowheart (R. repens) & 85 & 85 & 89 & 95 \\
\hline
\end{tabular}


ESL results for this study may be limited by the relatively short study duration. The time that $R$. repens and $S$. airoides were allowed to compete and interact in the ESL (9 months) is a much less than the amount of time $R$. repens and $C$. arvense have been established and competing at the two field sites. Because $R$. repens was planted from root cuttings, perhaps plants in the ESL did not have enough time to be truly competitive with each other. In the field sites $R$. repens and $C$. arvense had established roots below the transplanted clones at the beginning of each field study which provided a more competitive environment for field planted $S$. airoides than for plants in the ESL.

\subsection{Field plantings - plant traits in response to long-term exposure to $R$ haponticum repens}

\subsubsection{Community of origin assessment}

Growth and survival differences of collections from invaded and noninvaded source communities depended on transplant site and species, but there were consistent differences between communities of origin. For both species, non-invaded individuals were larger than invaded individuals at the onset of the experiment. These absolute differences in size decreased throughout the experiment for $H$. comata, but remained for $S$. airoides (Mealor 2006). Because of the initial size differences, this study focused on growth relative to initial size to indicate potential for biomass production under invaded conditions.

Fewer $H$. comata from invaded populations survived for the duration of the experiment when transplanted into $R$. repens than $H$. comata from non-invaded populations $\left(\mathrm{F}_{1,32}=8.91 ; \mathrm{P}=0.005\right)$. Survival and growth of H. comata were less at Fort Steele than at Laramie $\left(\mathrm{F}_{1,3_{2}}=50.0 ; \mathrm{p}<\right.$ o.0001). Collections from non-invaded communities had greater survival than those from invaded communities $\left(\mathrm{F}_{1,32}=8.91 ; \mathrm{P}=0.0054\right)$. Relative tiller production $\left(\mathrm{F}_{1,32}=10.3 ; \mathrm{P}=0.003\right)$ and basal area change $\left(\mathrm{F}_{1,32}=\right.$ 4.92; $\mathrm{P}=0.035$ ) were greater for invaded populations than for noninvaded populations at Laramie (Figure 24). Total performance of $H$. comata was greater at Laramie than Fort Steele, but did not differ among collection locations or community of origin. Twenty seven percent of established $H$. comata transplants from invaded communities produced seed whereas 49 percent of transplants derived from non-invaded communities produced seed. 
a)

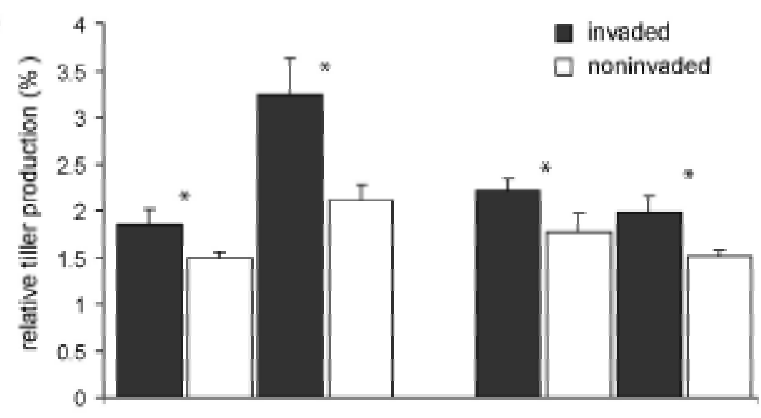

b)

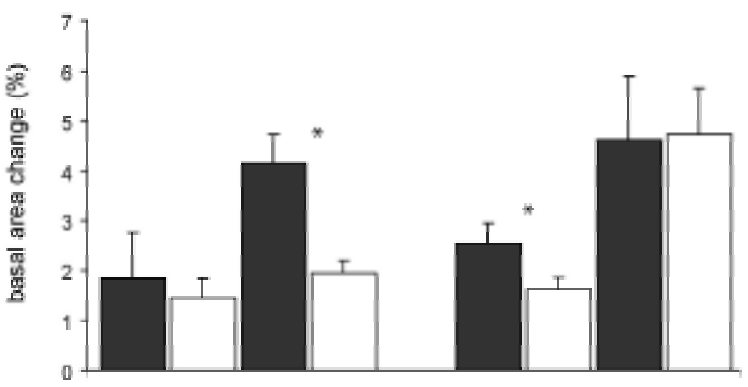

c)

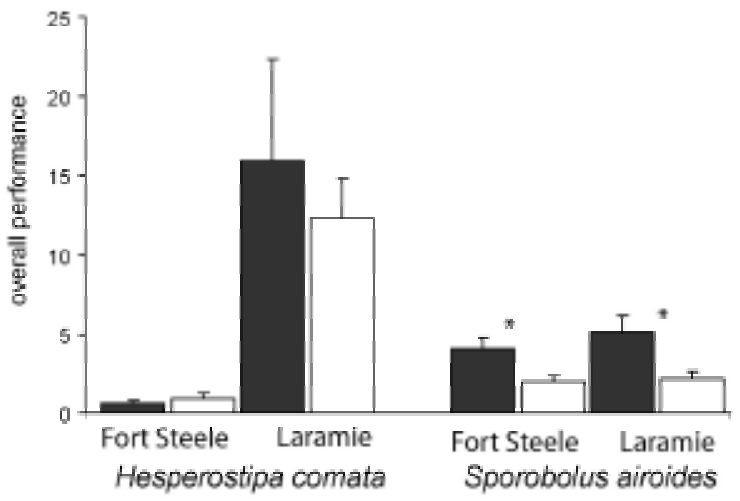

Figure 24. Relative tiller production (a), change in basal area (b), and overall performance (c) of Hesperostipa comata and Sporobolus airoides populations from communities invaded by Rhaponticum repens and non-invaded communities when transplanted into two infestations of $R$. repens. Solid bars represent populations from invaded communities, open bars are populations from non-invaded communities. Asterisks denote significant differences $(p<$ 0.01 ) between communities within a field site.

Growth and survival differences of collections from invaded and noninvaded source communities depended on transplant site and species, but there were consistent differences between communities of origin. For both species, non-invaded individuals were larger than invaded individuals at the onset of the experiment. These absolute differences in size decreased throughout the experiment for $H$. comata, but remained for $S$. airoides (Mealor 2006). Because of the initial size differences, this study focused on growth relative to initial size to indicate potential for biomass production under invaded conditions. 
Populations of $S$. airoides from invaded communities produced more tillers $\left(\mathrm{F}_{1,47}=9.07 ; \mathrm{P}=0.004\right)$, increased basal area $\left(\mathrm{F}_{1,47}=6.60 ; \mathrm{P}=\right.$ $0.0031)$ and had higher performance $\left(\mathrm{F}_{1,47}=12.59\right.$; $\left.\mathrm{P}<0.0001\right)$ than noninvaded populations (Figure 25). Sporobolus airoides survival as not different between invaded and noninvaded communities of origin. Two $S$. airoides transplants from invaded communities produced seed during the monitoring period, whereas transplants from noninvaded communities produced no seed.

Fewer $H$. comata from invaded populations survived for the duration of the experiment when transplanted into $R$. repens than $H$. comata from non-invaded populations $\left(\mathrm{F}_{1,32}=8.91 ; \mathrm{P}=0.005\right)$. Survival and growth of H. comata were less at Fort Steele than at Laramie $\left(\mathrm{F}_{1,3_{2}}=50.0 ; \mathrm{p}<\right.$ o.0001). Collections from non-invaded communities had greater survival than those from invaded communities $\left(\mathrm{F}_{1,32}=8.91 ; \mathrm{P}=0.0054\right)$. Relative tiller production $\left(\mathrm{F}_{1,3_{2}}=10.3 ; \mathrm{P}=0.003\right)$ and basal area change $\left(\mathrm{F}_{1,3_{2}}=\right.$ 4.92; $\mathrm{P}=0.035)$ were greater for invaded populations than for noninvaded populations at Laramie (Figure 24). Total performance of $H$. comata was greater at Laramie than Fort Steele, but did not differ among collection locations or community of origin. Twenty seven percent of established $H$. comata transplants from invaded communities produced seed whereas 49 percent of transplants derived from non-invaded communities produced seed.

\subsubsection{Tiller production - genets}

Tiller production of individual $H$. comata did not differ among genets at the Fort Steele site, but did differ at the Laramie site $\left(\mathrm{F}_{19,80}=2.83 ; \mathrm{P}=\right.$ o.006) (Figure 25). At the Laramie site genets from invaded communities grew more tillers relative to initial tiller number. Individual genets of $S$. airoides differed in tiller production $\left(\mathrm{F}_{29,120}=1.71 ; \mathrm{P}=0.024\right)$ at Fort Steele. Sporobolus airoides tillering $\left(\mathrm{F}_{29,120}=1.58 ; \mathrm{P}=0.045\right)$ and change in basal area $\left(\mathrm{F}_{29,120}=1.87 ; \mathrm{P}=0.014\right)$ also differed among genotypes at Laramie (Figure 25). Genets with the largest tiller increase were from invaded communities. Sporobolus airoides basal area showed a similar pattern (data not shown). 
a) Hesperostipa comata

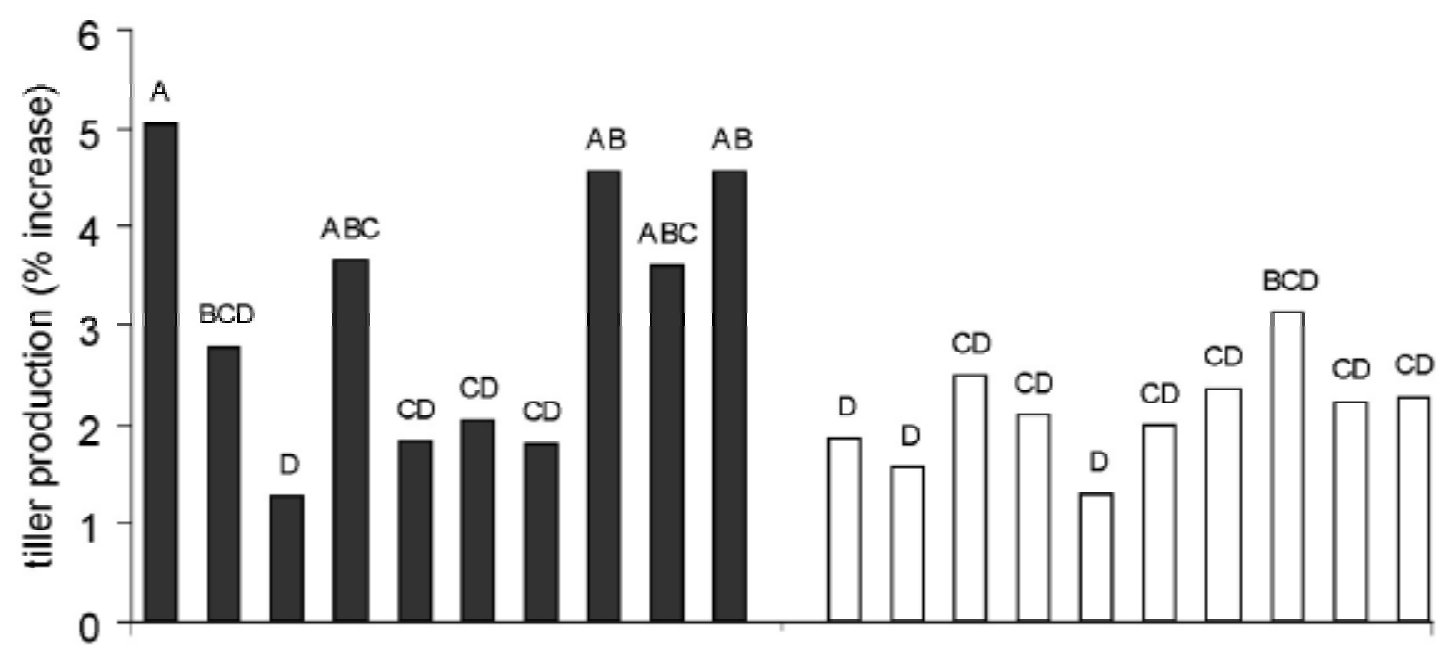

b) Sporobolus airoides

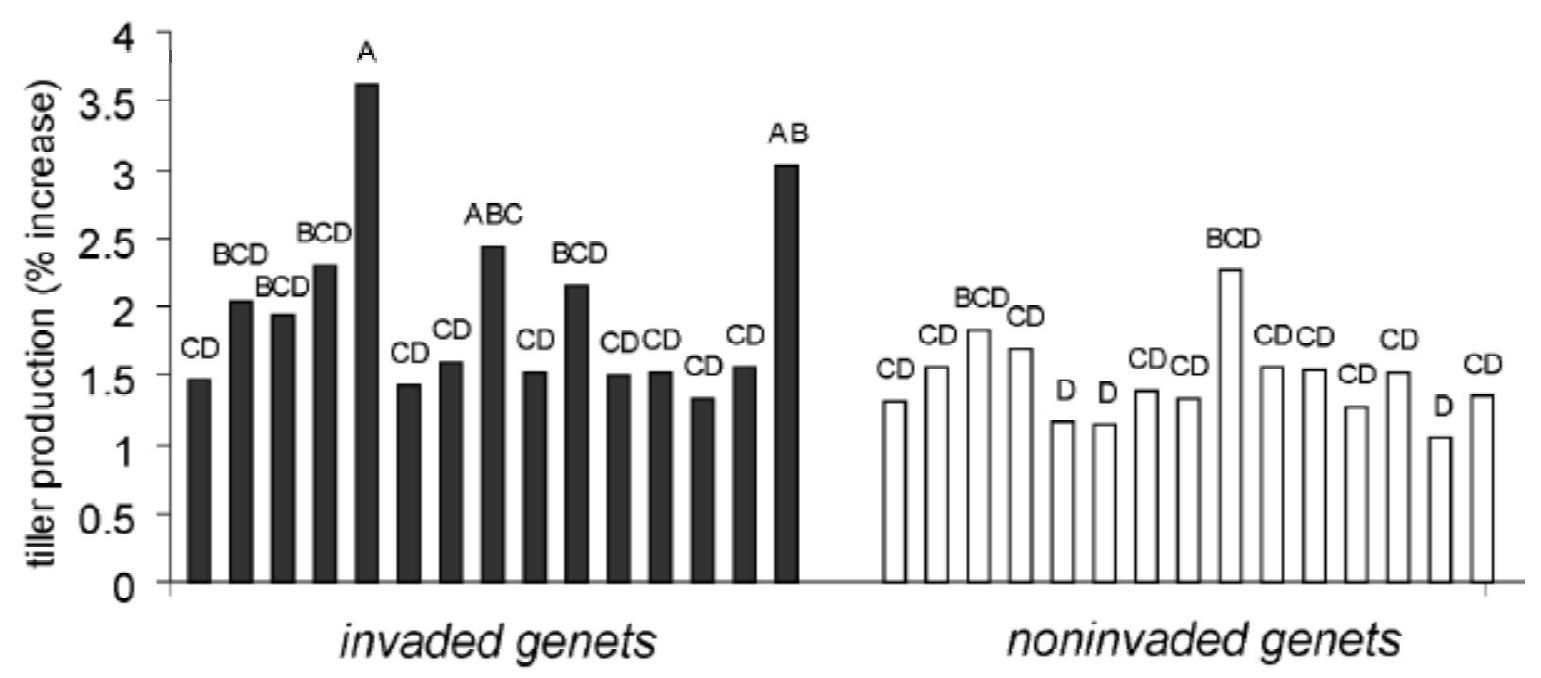

Figure 25. Relative tiller production at the Laramie field site for 20 Hesperostipa comata (a), and 30 Sporobolus airoides genotypes (b). Within a species, values with different letters are significantly different $(p<0.05$, LSD).

Cumulative differences between collections from invaded and non-invaded communities were species-specific. Sporobolus airoides displayed a consistent positive response to long-term coexistence with $R$. repens, whereas the performance of $H$. comata originating from invaded communities was not different from $H$. comata collected from non-invaded communities. In general, genets from invaded communities had fewer tillers than did genets from non-invaded communities, but their relative tiller production (percent increase) was greater for genets from invaded communities at both field transplant sites for both grass species. Basal area increase and overall performance of collections from invaded and non-invaded com- 
munities of origin depended on transplant site and grass species. The results of this portion of the work continue to suggest that native species have the potential for adaptation to coexist with exotic invasives, although that potential may differ among species.

\subsubsection{Results of testing the effect of long-term exposure to Rhaponticum repens on native populations - general discussion}

This experiment further tested the hypothesis that native plant populations can adapt to invasion and new neighbors. More specifically, it addressed the question: "Do native plants from communities long-invaded by $R$. repens exhibit greater growth than those from non-invaded communities when transplanted into existing $R$. repens invasions?” Multiple populations of two native grass species, $H$. comata and $S$. airoides (collected from invaded and non-invaded areas) were planted into common gardens in two R. repens infestations in Wyoming. Hesperostipa comata is a cool season and $S$. airoides is a warm season grass (see Section 1.3.2 [p 8] for a description), and these species with differences in periods of active growth were selected to examine stress caused by $R$. repens throughout the year. A 2-year field based experiment was used to assess the influence of plant species, community of origin, location of collection, and individual genotype on the ability of native grasses to survive and grow in dense $R$. repens invasions. By tracking the performance of individual genotypes, it was possible to assess whether genotypic variation for tolerance of $R$. repens invaded conditions existed in natural populations of native grasses.

\subsection{Field plantings - resistance and resilience}

We compared growth, seedling germination and establishment, and invasive encroachment of $S$. airoides lines to test resistance and resilience, given their invasion history. In this study we tested resistance through aboveground growth of transplanted clones and the ability to limit invasive species encroachment. We tested resilience through seedling germination and establishment when competing with invaders.

\subsubsection{Growth of Sporobolus airoides in field experiments}

At the Crowheart site, invaded lineages had longer leaves, greater tillering, and greater basal circumference than non-invaded lineages (Table 18 , Figure 26). Sporobolus airoides leaf production differed among dates, 
whereas tillering, basal circumference, and inflorescence production did not (Table 19). Date did not interact with origin history treatments (Table 19) Mortality of clones was negligible after the first growing season, while $20 \%$ mortality (10\% of each history) occurred during the second growing season (via burrowing of small mammals), causing the loss of two invaded and two non-invaded plots at Crowheart.

At FEWAFB invaded lineages had longer leaves, greater tillering, and greater basal circumference than non-invaded lineages (Table 20, Figure 27). Inflorescence production of non-invaded $S$. airoides differed from invaded $S$. airoides on some dates (Table 19). Inflorescence production was much greater for invaded grass clones in the second summer (Figure 28 ). At FEWAFB, mortality was 16\% (4 invaded, 12 non-invaded) by the end of the second field season. No plots were totally lost for either history.

\subsubsection{Establishment of Sporobolus airoides and invasive species in field experiments}

At Crowheart, cumulative germination was greater for invaded lineages than non-invaded lineages $(\mathrm{p}=0.0076$, Table 18 Seedling establishment did not differ by invasion history (Table 18). Rhaponticum repens encroachment was greatest for non-invaded lineage plots and undisturbed (reference plots) had the lowest number of $R$. repens encroachment (Table 16).

Table 18. Growth and reproduction of Soporobolus airoides at Crowheart, WY when transplanted into Rhaponticum repens invasion. Within a growth trait (i.e., longest leaf), invaded and non-invaded means with the same letter do not differ ( $p>0.05, L S D)$. Inflorescence production is not presented because of insufficient results.

\begin{tabular}{|l|c|c|c|c|c|}
\hline $\begin{array}{l}\text { Crowheart } \\
\text { WY }\end{array}$ & $\begin{array}{c}\text { Longest Leaf } \\
(\mathbf{c m})\end{array}$ & $\begin{array}{c}\text { Basal Circ. } \\
(\mathbf{c m})\end{array}$ & $\begin{array}{c}\text { Tiller } \\
(\text { No. })\end{array}$ & $\begin{array}{c}\text { Cumulative } \\
\text { Germination } \\
(\%)\end{array}$ & $\begin{array}{c}\text { Establishment } \\
(\text { No. })\end{array}$ \\
\hline Invaded & $31.8 \pm 0.8 \mathrm{a}$ & $9.7 \pm 0.2 \mathrm{a}$ & $6.2 \pm 0.2 \mathrm{a}$ & $26.2 \pm 3.0 \mathrm{a}$ & $0.4 \pm 0.1 \mathrm{a}$ \\
\hline Non-invaded & $24.7 \pm 0.8 \mathrm{~b}$ & $6.0 \pm 0.2 \mathrm{~b}$ & $3.0 \pm 0.2 \mathrm{~b}$ & $14.5 \pm 3.0 \mathrm{~b}$ & $0.2 \pm 0.1 \mathrm{a}$ \\
\hline
\end{tabular}


a) Longest leaf Production

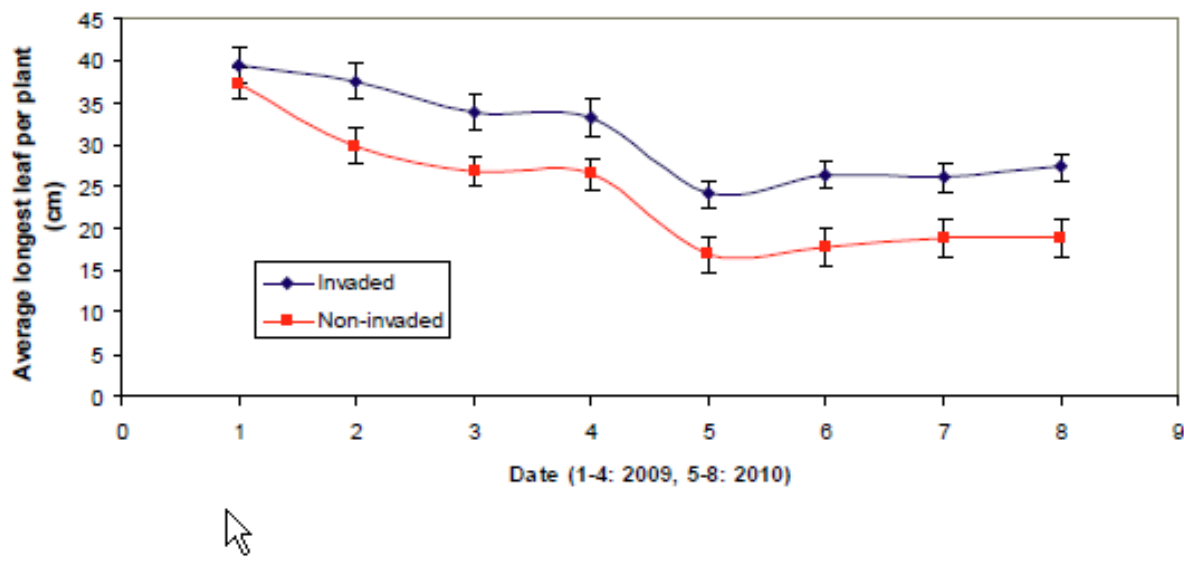

b) Tiller Production

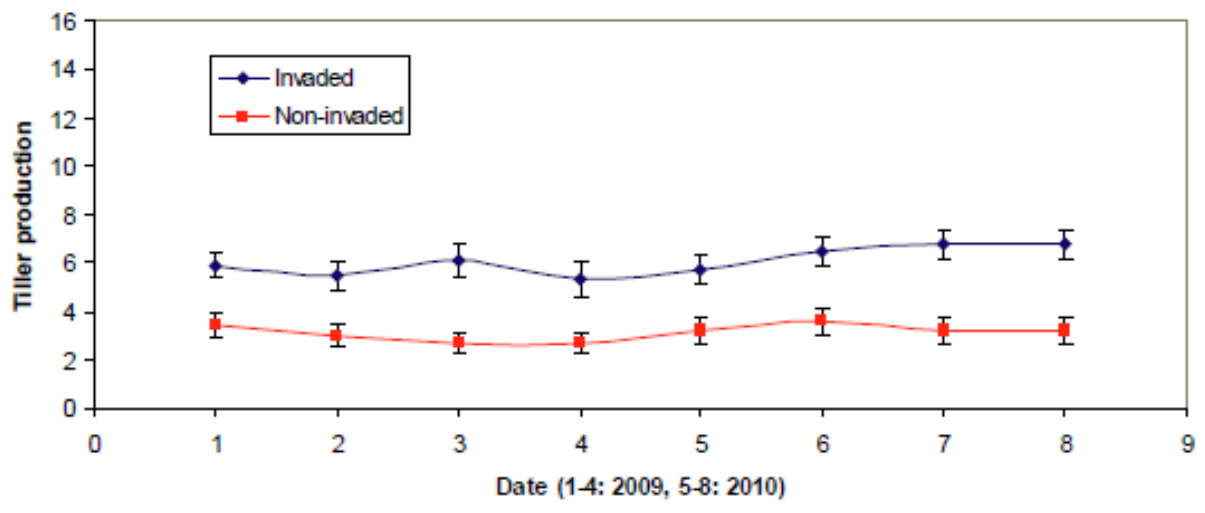

c) Basal Circumference

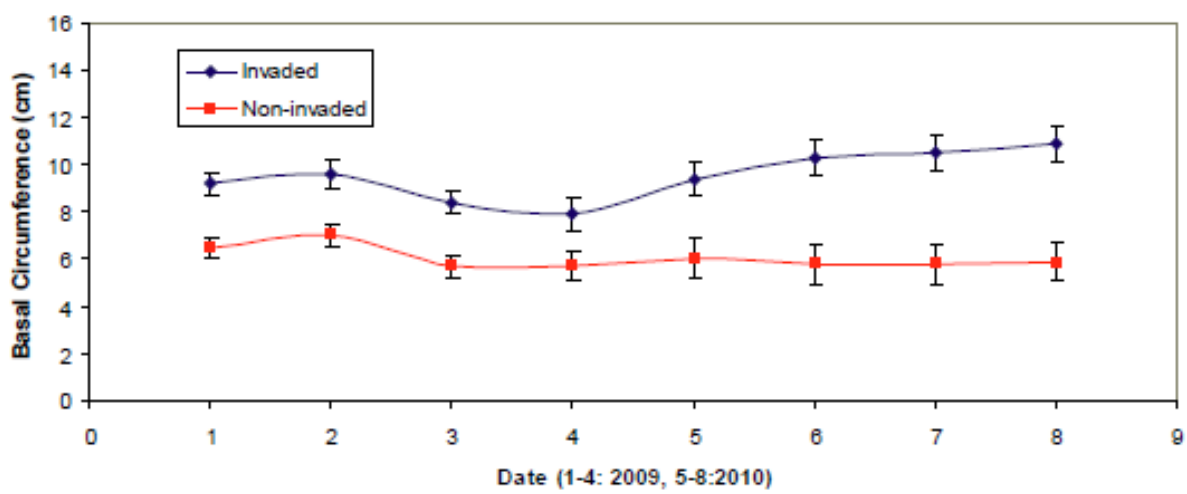

Figure 26. Sporobolus airoides growth production at Crowheart, WY for two growing seasons

(eight sampling dates); (a) longest leaf production, (b) tiller production, (c) basal circumference. In no case $(a, b$, or $c)$ was interaction of history by date significant (a. $p=$ 0.1866, b. $p=0.8124, c . p=0.3912$ ). 
Table 19. Sporobolus airoides growth trait Analysis of Variance F-test probabilities for data collected at Crowheart and FEWAFB, WY transplant field sites.

\begin{tabular}{|c|c|c|c|c|c|}
\hline Source & DF & $\begin{array}{l}\text { Longest } \\
\text { Leaf }\end{array}$ & $\begin{array}{c}\text { Basal } \\
\text { Circumference }\end{array}$ & Tiller & Flower \\
\hline Crowheart & - & - & - & - & - \\
\hline Date & 7 & $<0.0001$ & $<0.0001$ & $<0.0001$ & $<0.0001$ \\
\hline History & 1 & $<0.0001$ & $<0.0001$ & $<0.0001$ & $<0.0001$ \\
\hline History*Date & 7 & 0.1866 & 0.3912 & 0.8124 & $<0.0001$ \\
\hline Error C & 144 & - & - & - & - \\
\hline FEWAFB & - & - & - & - & - \\
\hline Date & 7 & $<0.0001$ & 0.3237 & 0.9599 & 0.6406 \\
\hline History & 1 & $<0.0001$ & $<0.0001$ & $<0.0001$ & 0.0819 \\
\hline History*Date & 7 & 0.9230 & 0.4499 & 0.9879 & 0.6409 \\
\hline Error C & 127 & - & - & - & - \\
\hline
\end{tabular}

Table 20. Growth and reproduction of Sporobolus airoides at FEWAFB, WY when transplanted into Cirsium arvense invasion. Within a growth trait (i.e., longest leaf), invaded and noninvaded means with the same letter do not differ ( $p>0.05$, LSD). Inflorescence production is not presented because of insufficient results.

\begin{tabular}{|l|c|c|c|c|c|}
\hline $\begin{array}{l}\text { FEWAFB, } \\
\text { Wyoming }\end{array}$ & $\begin{array}{c}\text { Longest Leaf } \\
(\mathbf{c m})\end{array}$ & $\begin{array}{c}\text { Basal } \\
\text { Circumference } \\
(\mathbf{c m})\end{array}$ & $\begin{array}{c}\text { Tiller } \\
(\text { No. })\end{array}$ & $\begin{array}{c}\text { Cumulative } \\
\text { Germination } \\
(\%)\end{array}$ & $\begin{array}{c}\text { Establishment } \\
\text { (No.) }\end{array}$ \\
\hline Invaded & $31.9 \pm 0.6 \mathrm{a}$ & $10.7 \pm 0.2 \mathrm{a}$ & $8.2 \pm 0.2 \mathrm{a}$ & $15.1 \pm 2.3 \mathrm{a}$ & $1.4 \pm 0.3 \mathrm{a}$ \\
\hline Non- invaded & $24.0 \pm 0.7 \mathrm{~b}$ & $7.0 \pm 0.2 \mathrm{~b}$ & $4.4 \pm 0.2 \mathrm{~b}$ & $10.5 \pm 2.3 \mathrm{a}$ & $1.3 \pm 0.3 \mathrm{a}$ \\
\hline
\end{tabular}


a) Longest Leaf Production

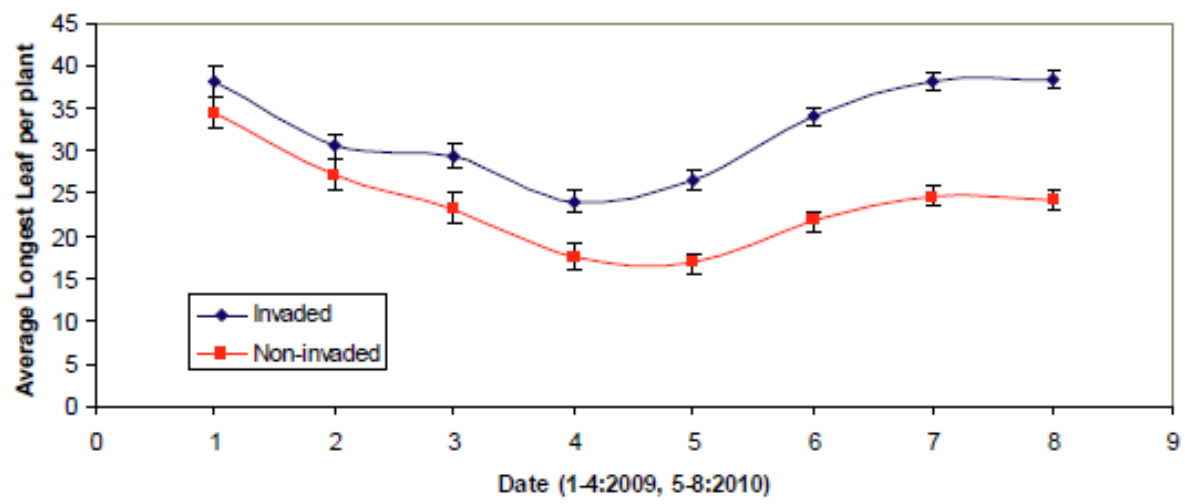

b) Tiller Production

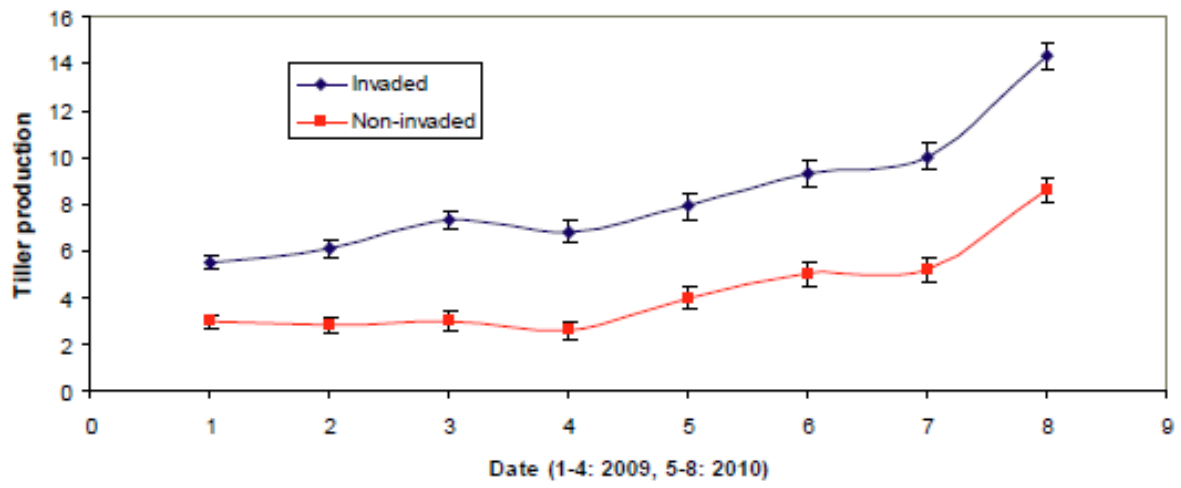

c) Basal Circumference

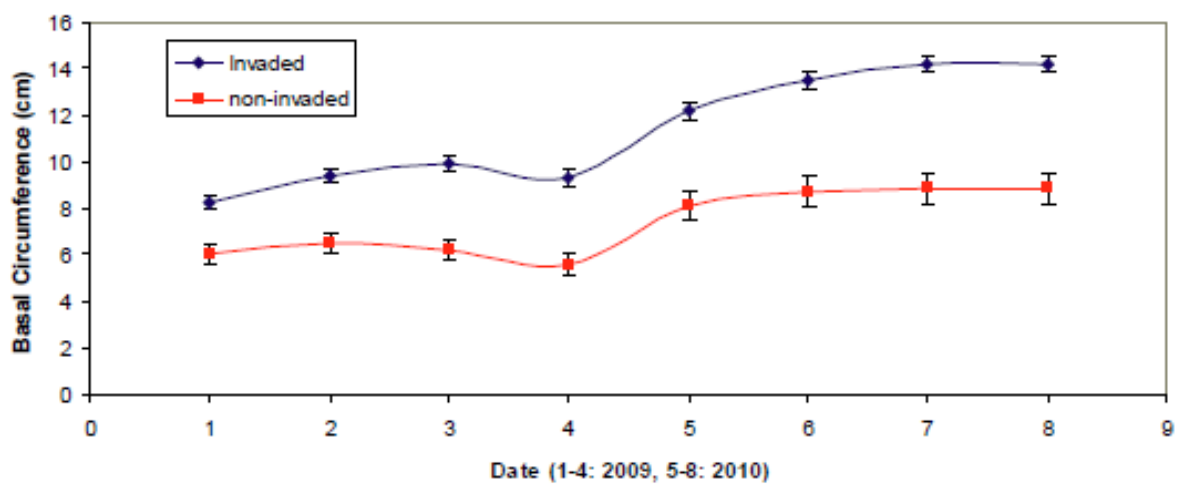

Figure 27. Sporobolus airoides growth production at FEWAFB, WY for two growing seasons (eight sampling dates); (a) longest leaf production, (b) tiller production, (c) basal circumference. In no case $(a, b$, or $c)$ was interaction of history by date significant ( $a . p=$ 0.9230, b. $p=0.9879$, c. $p=0.499$ ). 


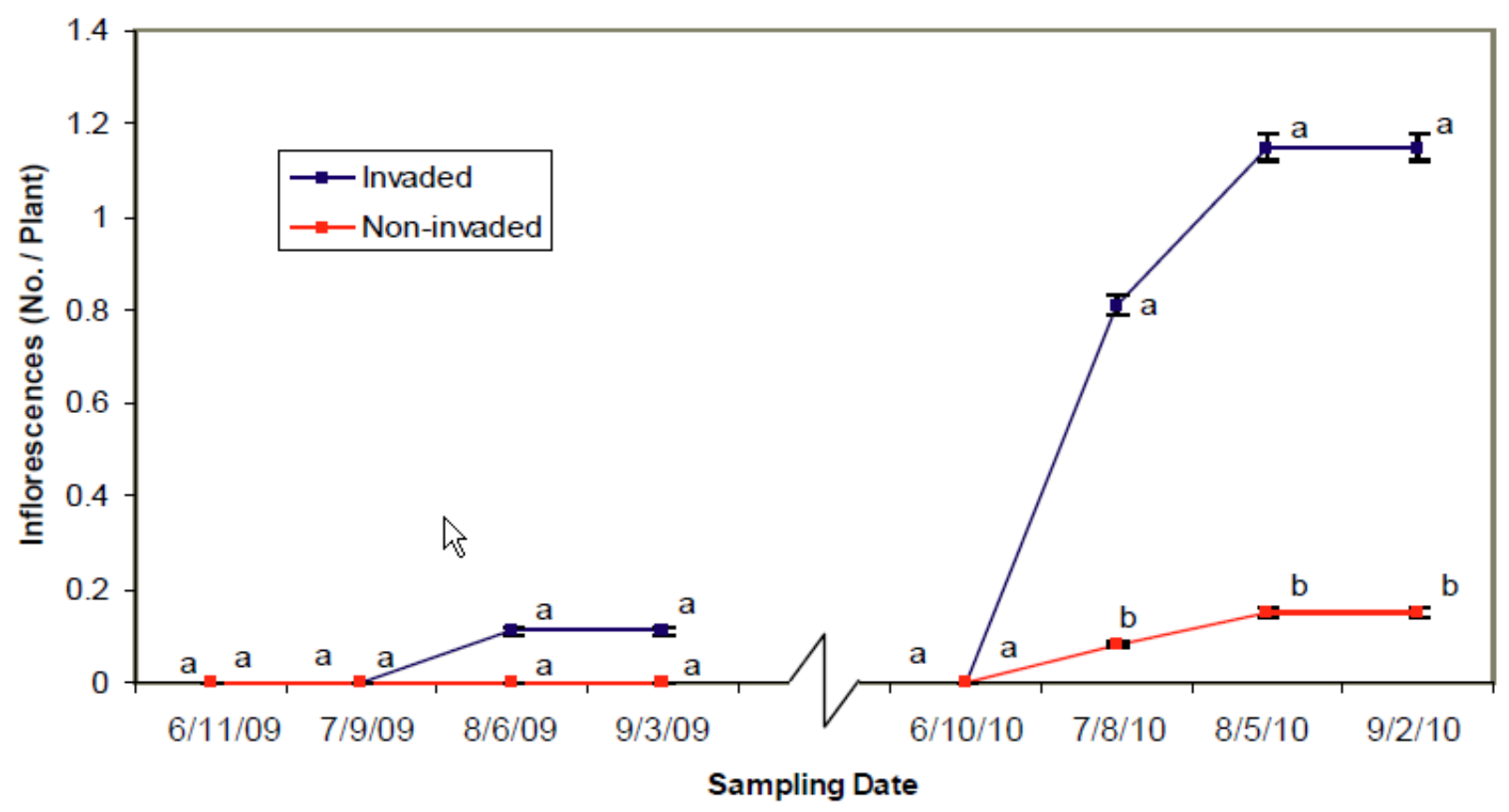

Figure 28. Mean inflorescence production per plant at FEWAFB, WY. Means with the same lowercase letters do not differ, FLSD, 0.05 .

At FEWAFB, germination (cumulative \%) and establishment of $S$. airoides seedlings differed across all dates ( $\mathrm{p}<0.0001$, Tables 21 and 22), but did not differ between lineage history. Cirsium arvense encroachment was greatest for invaded lineage plots and lowest for undisturbed plots. Rhaponticum repens encroachment was greatest for non-invaded lineage plots, while undisturbed plots had lowest encroachment (Table 16 ). Invasive encroachment was different for all dates for both sites ( $p<0.0001$, Table 23).

Table 21. Sporobolus airoides seedling germination Analysis of Variance F-test probabilities at Crowheart and FEWAFB, WY.

\begin{tabular}{|l|c|c|c|}
\hline Source & DF & $\begin{array}{c}\text { Germination } \\
\text { at FEWAFB }\end{array}$ & $\begin{array}{c}\text { Germination } \\
\text { at Crowheart }\end{array}$ \\
\hline Date & 3 & $<0.0001$ & $<0.0001$ \\
\hline Position & 1 & 0.1660 & 0.0076 \\
\hline Position*date & 3 & 0.9706 & 0.2241 \\
\hline Error residual & 72 & - & - \\
\hline
\end{tabular}


Table 22. Sporobolus airoides seedling establishment Analysis of Variance F-test probabilities at Crowheart and FEWAFB, WY.

\begin{tabular}{|l|c|c|c|}
\hline Source & DF & $\begin{array}{c}\text { Seedling Establishment } \\
\text { at FEWAFB }\end{array}$ & $\begin{array}{c}\text { Seedling Establishment } \\
\text { at Crowheart }\end{array}$ \\
\hline Date & 7 & 0.0004 & $<0.0001$ \\
\hline History & 1 & 0.7940 & 0.1488 \\
\hline History*date & 7 & 0.6893 & 0.9972 \\
\hline Error residual & 144 & - & - \\
\hline
\end{tabular}

Table 23. Invasive species encroachment within plots Analysis of Variance F-test probabilities at Crowheart and FEWAFB, WY.

\begin{tabular}{|l|c|c|c|}
\hline Source & DF & $\begin{array}{c}\text { Invasive encroachment } \\
\text { FEWAFB }\end{array}$ & $\begin{array}{c}\text { Invasive encroachment } \\
\text { Crowheart }\end{array}$ \\
\hline Date & 7 & $<0.0001$ & 0.0110 \\
\hline History & 3 & $<0.0001$ & 0.0002 \\
\hline History*date & 21 & 0.0545 & 0.3114 \\
\hline Error residual & 288 & - & - \\
\hline
\end{tabular}

6.6.3 Field planting and ESL resistance and resilience results -- general discussion

This research tested the ability of $S$. airoides to tolerate and reproduce in the presence of NIPS (R. repens and C. arvense), in studies conducted at two field sites and within a controlled growth chamber (ESL). Potential resilience was documented via grass seedling germination and establishment within invasions, whereas resistance was recorded as growth of $S$. airoides and its ability to limit encroachment of the invader. Species that exhibit resilience should be able to persist in the presence of invaders and continue to recruit cohorts that can establish and reach sexual maturity. Growth of transplanted grass clones was measured using longest leaf, basal circumference, tillers, and flowering to examine competitiveness of mature grass lineages to the re-entry of the exotics (resistance). S. airoides used in this study was derived from maternal lineages collected from distinct invasive histories. The lineages were separated into two populations, invaded (maternal lineages with a past history of living among exotics invasions ranging from 25 to 75 years) and non-invaded (maternal lineages having no past history of exposure to exotics).

We hypothesize that invaded lineages should produce greater above-ground growth, higher germination, and have greater establishment in the presence of invaders than non-invaded lineages. Implications from this research are useful for understanding impacts of invaders on native grass resistance and 
resilience. Our field transplant studies test grasses in competition with two invasives to complement earlier work by Mealor et al. (2004), Mealor and Hild (2006), Mealor and Hild (2007), Ferrero-Serrano et al. (2008, 2009), Bartlett (2009), and Bergum et al. (2010). This study relates to reclamation reseeding practices by documenting if there is potential benefit to using seed derived from grass populations surviving in the presence of invasive species. Seeds and plants with high establishment, germination, aboveground growth, and decreased invasive encroachment are advantageous for sites exposed and that have the potential to invasive pressure.

This study was designed to test competitive abilities of $S$. airoides populations differing in invasion history (invaded and non-invaded). Other studies suggest that the two populations with different histories of invasion differ genetically and phenotypically (Mealor et al. 2004, Mealor and Hild 2006, Bergum et al. 2010). We observed differences in growth and reproduction characteristics between the lineages differing in history of exposure to invasion. Our results suggest that invaded and non-invaded lineages differ in their ability to grow, germinate, and prevent encroachment when competing with $R$. repens and $C$. arvense. Invaded lines had longer leaves, greater basal circumference, greater tillers, and more inflorescence production than non-invaded lineages at both field locations. Initial size of clones for the field experiments also varied and we did not test for differences between clones depending on the two histories on the initial planting date. If initial size differences occurred, they may affect our interpretations of the results (Figures 26 and 27). This trend was not as strongly demonstrated in the ESL (only leaf length was greater for invaded lines). In addition, invaded lineages were more resistant to re-invasion when competing with $R$. repens. The lack of differences in the ESL may be partially related to relative light duration during the study.

The differences we observe in clone production (e.g., greater relative increase in tillering of invaded lineages than non-invaded lineages when planted with $R$. repens and $C$. arvense) parallel previous research under this overall study effort (Mealor and Hild 2007, Ferrero-Serrano et al. 2009). At both field locations, above-ground growth of the individual grasses was larger with either NIPS. Selection for greater aboveground production may allow the coexistence of our invaded lineages with invasive species. 
Invasive encroachment may be an important measure of resistance. Ferrero-Serrano et al. (2008), using pot experimentation, suggest that $S$. airoides invaded lineages produced greater root biomass than non-invaded lineages, which one might expect to limit invasion encroachment. Our field results substantiated such expectations: at Crowheart the $R$. repens invasion and the ESL invaded plots had less encroachment than non-invaded lineages, yet not at FEWAFB in C. arvense invasion. However, $R$. repens was not slowed by invaded grasses. We did not remove any plants or find any roots using the Minirhizotron observation tubes in the ESL study to detect any differences in root biomass. Continued field and controlled environment studies that measure below ground biomass are needed. Differences in invasive species densities may have also influenced these result with Crowheart at $18 \mathrm{~A}$. repens stems/ $1.0 \mathrm{~m}^{2}$ compared to FEWAFB at 61 C. arvense stems/ $1.0 \mathrm{~m}^{2}$. Different densities may have also influenced other above-ground production results by increased competition for nutrients light, and water needed for growth.

Sporobolus airoides seedling germination and establishment were used in our study to reflect resilience. Our results differ from controlled growth chamber experiments in petri dishes (this report (Section 6.3.6.4, p 73, [Bartlett 2009]) that noted slightly delayed germination of invaded seedling lineages. We could not monitor daily, but our cumulative field germination was greater for invaded lineages planted in $R$. repens at Crowheart and in the ESL, but not as great when planted with the novel invader, $C$. arvense. It is possible that particular soil characteristics may trigger greater germination of invaded seedling lineages than non-invaded seedling lineages in the presence of $R$. repens, (the invader with which the lineages had historic exposure). In the ESL, litter cover was low and initially the same in both pits, but increases in litter associated with $R$. repens growth may have facilitated germination for invaded seedling exposed to $R$. repens. Small amounts of litter in the $R$. repens pit may have increased water infiltration and soil moisture. Grant et al. (2003) suggest that native seed germination is decreased with exposure to R. repens. However, whether this potential is related to allelochemical production is undetermined (Stermitz 2003, 2009). We did not document litter in our study and allelochemicals do not appear to have been present in the ESL.

Above-ground production can be measured more easily in two field seasons and one growth period than seedling germination and establishment, which may take longer time to measure for seedlings reach maturity. Our germina- 
tion and establishment results are not compelling because we lacked high rates of seedling emergence and survival. Seedling germination and establishment are more influenced by fluctuations in yearly climate factors because of close proximity to the soil surface compared clone roots occupying deeper soil. Climatic differences may have influenced results.

Our results indicate that invaded lineages demonstrate some traits that may favor resistance and resilience when competing with $R$. repens. Coevolution of invaders and native species is a difficult area of study requiring future research and testing (Aarssen et al. 1983, Strauss et al. 2006). Using the ESL to impose a variety of climatic conditions and $R$. repens densities, may help tease out other competitive traits that were not easily detected thus far. Results from this study have real world application to restoration settings. Revegetation of disturbed areas with competitive native plant species instead of non-native species is important to maintain the longevity of biodiversity of desirable plants (Linhart 1995, Mangold et al. 2007). Planting native species with invasive history may augment biodiversity and in turn, increase native ecosystem resistance and resilience to invasion (Kennedy et al. 2002).

\subsection{How to select candidate genotypes from the invaded and non- invaded sub-populations.}

Selecting successful competitors in native grasses is important to reclamation where invasive species are likely to enter the site. Within a native grass species, some individuals may have the ability to survive and reproduce while competing with invasives for resources. We identified promising genotypes of $S$. airoides by unifying past competition experiments with $R$. repens and C. arvense. We developed a Biological Screening Process (BSP) that identifies promising genotypes collected from within (IN) and outside of (OUT) areas invaded by A. repens. Using past experiments conducted by Ferrero-Serrano et al. (2006, 2008), Mealor and Hild (2004, 2006, and 2007), and unpublished germination and root growth experiments using IN and OUT genotypes of $S$. airoides, the BSP is a process to select $S$. airoides genotypes that may possess enhanced competitive ability against $R$. repens or $C$. arvense. Our BSP is essentially a discrimination tool that evaluates and categorizes genotypes for their competitive ability against $C$. arvense or $R$. repens from past experiments.

The development of a Biological Screening Process for genotypes depends on the statistical results from a large number of studies, pooled for an 
overall assessment. However, there is no known statistical test to include the results of a variety of datasets, and experimental outcomes. Thus, the problem was approached as a decision tool schematic to incorporate all experimental outcomes. Because "competitive success" is a hotly discussed topic in plant ecology, there is no one measure that can be clearly tied to competitive ability. Thus, in extreme environments, competitive superior genotypes may have greater vegetative growth below ground, or in nutrient rich environments, superior competitive ability may be conferred with the ability to attain great height and shade out neighbors. This study's screening process evaluates outcomes from all experiments to determine prevalence of favorable outcomes together. This is not statistically tested, although statistical tests from all experiments are reported here. Additional consideration should be given to the notion that "superior" competitive ability is only demonstrated in comparison with non-invaded or "inferior" competitors of the same species. For this reason, a variety of genotypes were used, both promising and less promising ones, to provide clear contrasts. Thus, both types of genotypes were included in subsequent study. Had only promising genotypes been used, this work would not have had a comparator set of genotypes.

\subsubsection{BSP competitor categories}

The BSP places the 50 maternal lineages into three (strong, moderate, or unlikely) competitor categories based on their growth or performance in the experiments (Figure 29; Table 11). Starting with the first series of experiments (immediately to the right of the starting point located on the left side of the BSP), specific competition questions were asked of the $S$. airoides maternal lineages, which include $S$. airoides competitive response in the presence of $R$. repens in a field experiment and $S$. airoides competitive effect while in the presence of $R$. repens and $C$. arvense in greenhouse experiments. Maternal lineages that possessed the ability to compete with $R$. repens or $C$. arvense ended up in a resulting box located immediately below the corresponding question box, and were successful maternal lineages in that portion of the BSP.

Maternal lineages that did not possess the ability to compete with $R$. repens or $C$. arvense (unsuccessful maternal lineages) were not placed in any boxes. After moving through the first series of experiment questions regarding competition, additional questions regarding competition were asked of the original pool of 50 maternal lineages (STEP 2). These questions were based on above- and below-ground productivity in the presence 
of $C$. arvense and a stem-mining weevil. Root growth and germination experiment questions were then asked of the pool of 50 maternal lineages (STEP 3), and finally, an exceptional (fully developed or larger) seed weight question was asked, again of the original pool of 50 maternal lineages (STEP 4).

A competitor code was then established for each maternal lineage based on its performance in the BSP (Table 24). For example, a competitor code of "ccrgs" represents a maternal lineage that was successful in two competition experiments (designated by two letter "c's"), the root growth experiment (designated by the letter " $r$ "), the germination experiment (designated by the letter "g"), and the seed weight experiment (designated by the letter "s"). A competitor code of "cg" represents a maternal lineage that was successful in only one competition experiment and the germination experiment. More of the letter "c's" equates to maternal lineages that were successful in multiple competition experiments.

This study's selections of strong competitor maternal lineages demonstrated competitive success in at least two of the experiments involving competitive response, competitive effect, and increased above- or belowground growth in past competition experiments with $R$. repens or C. arvense. Maternal lineages that were placed in the moderate competitor category were only successful in one of the competition experiments. Maternal lineages in the unlikely competitor category were either unsuccessful in any of the competition experiments or were not included in as many experiments and therefore, may not actually be unlikely competitors.

Once BSP competitive categories were determined for competition, this study used seed germination and root growth results to examine seedling competitive potential and compared it to BSP competitive categories. Competitive potential here represents seedlings with high germination percentages and rapid initial root growth. The resulting competitive categories in the BSP classify maternal lineages for sorting purposes, and correspond to $S$. airoides maternal lineages that reflect strong, moderate, or little promise in competitive ability against $R$. repens or $C$. arvense. 


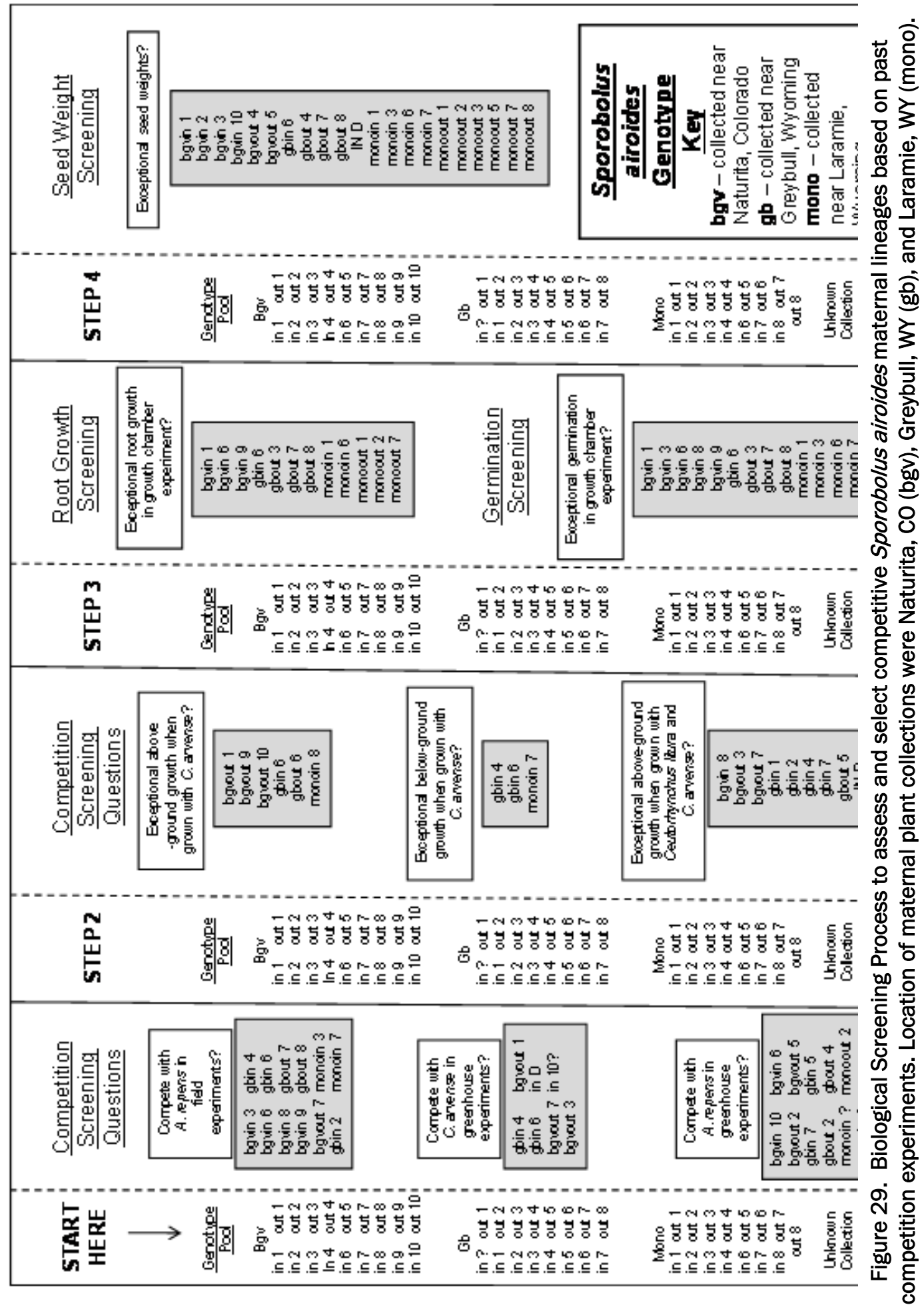


Table 24. Maternal lineages corresponding with the BSP, their code, and their final competitor category ranking.

\begin{tabular}{|c|c|c|c|c|c|}
\hline \begin{tabular}{|l|} 
Maternal \\
lineage
\end{tabular} & Code & $\begin{array}{c}\text { Competitor } \\
\text { Category }\end{array}$ & $\begin{array}{l}\text { Maternal } \\
\text { lineage }\end{array}$ & Code & $\begin{array}{c}\text { Competitor } \\
\text { Category }\end{array}$ \\
\hline Bgv in 6 & ccgr & strong & $G b$ in 5 & c & moderate \\
\hline Bgv out 1 & CC & strong & Gb out 4 & CS & moderate \\
\hline Bgv out 7 & $\operatorname{ccc}$ & strong & Gb out 7 & csgr & moderate \\
\hline Gb in 4 & $\operatorname{cccc}$ & strong & Gb out 8 & csgr & moderate \\
\hline Gb in 6 & ccccsgr & strong & Mono out 2 & csgr & moderate \\
\hline IN D & $\operatorname{ccs}$ & strong & Gb out 1 & N/A & unlikely \\
\hline Mono in 3 & $\operatorname{ccsg}$ & strong & Mono in 4 & N/A & unlikely \\
\hline Bgv in 8 & $\operatorname{ccg}$ & strong & Mono out 3 & s & unlikely \\
\hline Bgvout 3 & $\mathrm{cc}$ & strong & Mono out 4 & N/A & unlikely \\
\hline$G b$ in 2 & Cc & strong & Mono out 6 & N/A & unlikely \\
\hline Gb in 7 & CC & strong & Mono out 8 & s & unlikely \\
\hline Mono in 7 & $\operatorname{ccsg}$ & strong & Mono out 5 & s & unlikely \\
\hline Bgv out 10 & c & moderate & Bgv in 1 & sgr & unlikely \\
\hline Ggv out 2 & c & moderate & Gb out 3 & $g r$ & unlikely \\
\hline Ggv out 9 & c & moderate & Mono in 1 & sgr & unlikely \\
\hline Gb out 2 & c & moderate & Mono in 6 & sgr & unlikely \\
\hline Gb out 5 & c & moderate & Mono out 1 & sgr & unlikely \\
\hline Gb out 6 & c & moderate & Mono out 7 & sgr & unlikely \\
\hline Mono in 2 & c & moderate & Bgv in 2 & s & unlikely \\
\hline Mono in 8 & c & moderate & Bgv in 4 & N/A & unlikely \\
\hline Bg vin 10 & cs & moderate & Bgv in 7 & N/A & unlikely \\
\hline Bg vin 3 & csg & moderate & Bgv out 4 & s & unlikely \\
\hline Bgv in 9 & cgr & moderate & Bgv out 8 & N/A & unlikely \\
\hline Bgv out 5 & cs & moderate & $\mathrm{Gb}$ in? & N/A & unlikely \\
\hline$G b$ in 1 & c & moderate & $G b$ in 3 & N/A & unlikely \\
\hline
\end{tabular}

Of the $50 S$. airoides maternal lineages screened, 12 were categorized as showing strong promise as competitors, 24 were categorized as moderate competitors, and 14 were categorized as unlikely competitors (Table 24). Maternal lineages ranked in the strong competitor category were successful in at least two competition experiments against $C$. arvense or $R$. repens. Some of the strong competitors were also successful in the germination or root growth experiments and had heavy seed weights (Table 25). Maternal lineages ranked in the moderate competitor category were successful in at least one competition experiment against $C$. arvense or $R$. repens, but may not have been successful in the germination or root growth experiments or had heavy seed weights. Maternal lineages ranked in the unlikely competitor category did not rank in any of the competition experiments. 
More maternal lineages in the strong competitor category were IN maternal lineages ( 9 of 50 or 18 percent) than OUT maternal lineages ( 3 of 50 or 6 percent). In the moderate competitor category, IN maternal lineages ( 7 of 50 or 14 percent) were outnumbered by OUT maternal lineages (11 of 50 or 22 percent). Fewer unlikely competitors were IN maternal lineages (9 of 50 or 18 percent) than OUT maternal lineages (11 of 50 or 22 percent). Differences between IN and OUT competitive ability are most apparent in the Greybull (gb) population (Table 26). However, these results are not statistically significant.

Table 25. Maternal lineages, their associated seed weights (per seed in grams) and the rank the maternal lineage received (based on 45 maternal lineages examined).

\begin{tabular}{|c|c|c|c|c|c|}
\hline Maternal lineage & Weight/Seed & Rank & Maternal lineage & Weight/Seed & Rank \\
\hline Bgv in 1 & 0.0002502 & 12 & Gb in 7 & 0.0001973 & 29 \\
\hline Bgv in 10 & 0.0002412 & 15 & Gb out 2 & 0.0002056 & 26 \\
\hline Bgv in 2 & 0.0002471 & 14 & Gb out 3 & 0.0002164 & 23 \\
\hline Bgv in 3 & 0.0002498 & 13 & Gb out 4 & 0.0002954 & 5 \\
\hline Bgv in 4 & 0.0001435 & 40 & Gb out 6 & 0.0001579 & 38 \\
\hline Bgv in 5 & 0.0002020 & 27 & Gb out 7 & 0.0003261 & 2 \\
\hline Bgv in 6 & 0.0001808 & 32 & Gb out 8 & 0.0002369 & 16 \\
\hline Bgv in 7 & 0.0001692 & 36 & IN D & 0.0002241 & 21 \\
\hline Bgv in 8 & 0.0001146 & 42 & IN? & 0.0002332 & 18 \\
\hline Bgv in 9 & 0.0002109 & 24 & Mono in 1 & 0.0002837 & 8 \\
\hline Bgv out 1 & 0.0001897 & 31 & Mono in 2 & 0.0000000 & 45 \\
\hline Bgv out 10 & 0.0001260 & 41 & Mono in 3 & 0.0002942 & 6 \\
\hline Bgv out 2 & 0.0001737 & 35 & Mono in 6 & 0.0002554 & 10 \\
\hline Bgv out 4 & 0.0002238 & 22 & Mono in 7 & 0.0004702 & 1 \\
\hline Bgv out 5 & 0.0002247 & 20 & Mono in 8 & 0.0001772 & 33 \\
\hline Bgv out 6 & 0.0001760 & 34 & Mono out 1 & 0.0002955 & 4 \\
\hline Bgv out 7 & 0.0000507 & 43 & Mono out 2 & 0.0002590 & 9 \\
\hline Bgv out 8 & 0.0001506 & 39 & Mono out 3 & 0.0002541 & 11 \\
\hline Bgv out 9 & 0.0001585 & 37 & Mono out 5 & 0.0002256 & 19 \\
\hline Gb in? & 0.0001910 & 30 & Mono out 6 & 0.0002000 & 28 \\
\hline$G b$ in 2 & 0.0000486 & 44 & Mono out 7 & 0.0003227 & 3 \\
\hline Gb in 5 & 0.0002107 & 25 & Mono out 8 & 0.0002333 & 17 \\
\hline Gb in 6 & 0.0002933 & 7 & & & \\
\hline
\end{tabular}


Table 26. Number of Sporobolus airoides maternal lineages falling into three competitive categories as determined by the BSP.

\begin{tabular}{|l|c|c|c|c|}
\hline Maternal lineage & & & Competitor Category & \\
\hline Location & Position & Strong & Moderate & Unlikely \\
\hline \multirow{2}{*}{ Naturita, CO (Bgv) } & IN & 2 & 4 & 3 \\
\cline { 2 - 5 } & OUT & 3 & 4 & 2 \\
\hline \multirow{2}{*}{ Greybull, WY (Gb) } & IN & 4 & 2 & 2 \\
\cline { 2 - 5 } & OUT & 0 & 7 & 1 \\
\hline \multirow{2}{*}{ Laramie, WY (Mono) } & IN & 2 & 4 & 5 \\
\cline { 2 - 5 } & OUT & 0 & 3 & 0 \\
\hline Unknown & IN & 1 & 0 & 1 \\
\hline
\end{tabular}

Table 27. Number of Sporobolus airoides maternal lineages falling into two competitive categories as determined by the BSP.

\begin{tabular}{|c|c|c|c|c|}
\hline Location & Position & Competitive & Non-Competitive & Samples \\
\hline Bgv & IN & 2 & 7 & 9 \\
\hline Bgv & OUT & 3 & 6 & 9 \\
\hline $\mathrm{Gb}$ & IN & 4 & 4 & 8 \\
\hline$G b$ & OUT & 0 & 8 & 8 \\
\hline Mono & IN & 2 & 5 & 7 \\
\hline Mono & OUT & 0 & 8 & 8 \\
\hline \multirow[t]{2}{*}{ TOTAL } & IN & 8 & 16 & 24 \\
\hline & OUT & 3 & 22 & 25 \\
\hline
\end{tabular}

Nonetheless, as an alternative analysis, the three competitor categories are collapsed into two categories (Table 27), "Competitive"="Strong" and "Non-Competitive"="Moderate" and "Unlikely." With the Location "Unknown" excluded, a generalized linear model approach based on a logistic regression can be used to analyze the binary competitor categories to answer the questions: (1) "In the Strong category, are the INs significantly more numerous that the OUTs?"; and (2) "and/or is the distribution of Strong INs and OUTs different from that that might be expected in that category (or across the board in all categories)?”

Although only moderately significant ( $\mathrm{p}=0.0842)$, there appears to be more INs than OUTs in the Competitive category, while in the NonCompetitive category, there are a significantly more OUTS than INs $(\mathrm{p}=0.0312)$. With logistic regression, the probabilities for the Competitive category can be predicted for the INs and OUTs positions (Figure 30). Clearly, in the Competitive category, the IN probability is higher than the 
OUT (Figure 30). Similar probabilities for the Competitive category can be predicted by Position and Location (Figure 31). In this instance, the predicted probabilities for the Competitive category tend to be higher for the INs versus OUTs for each location.

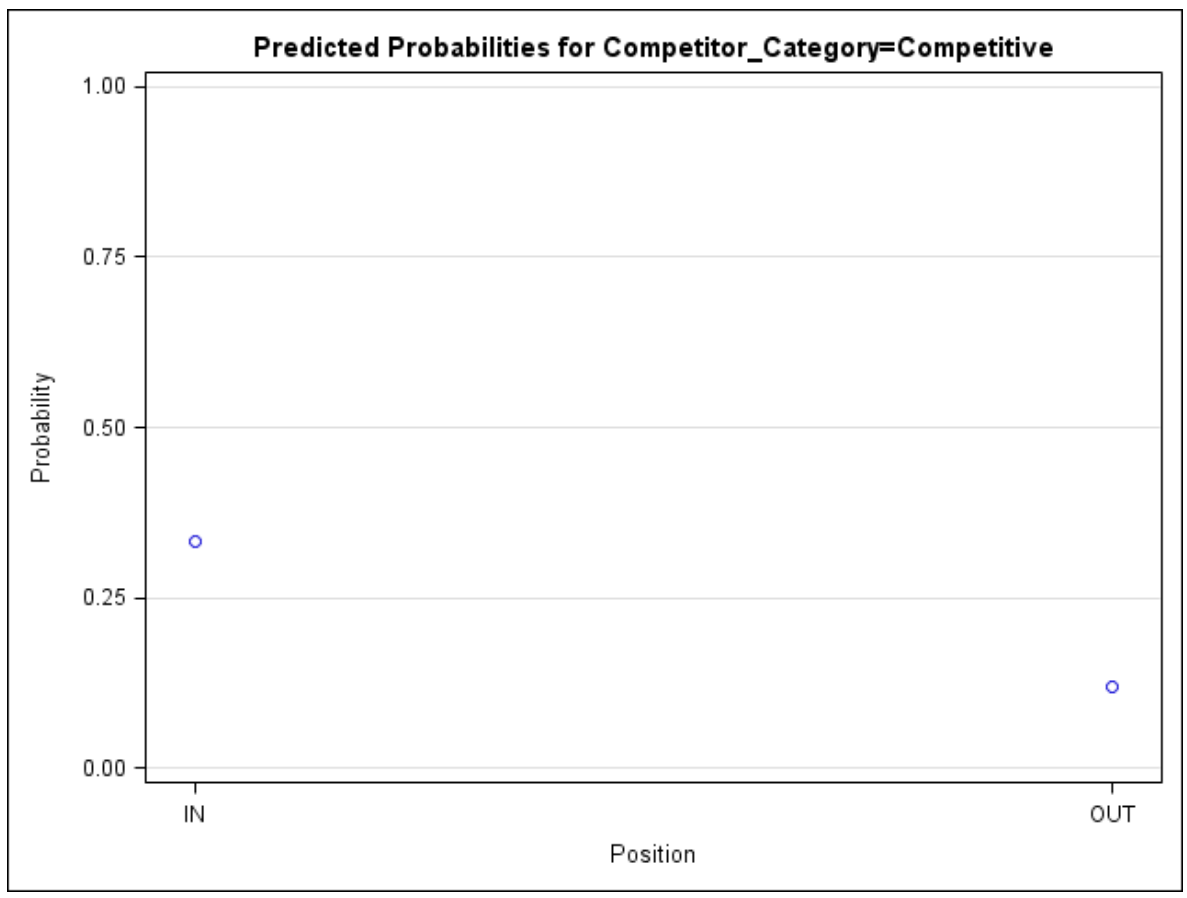

Figure 30. Predicted probabilities by position for Competitor Category = Competitive.

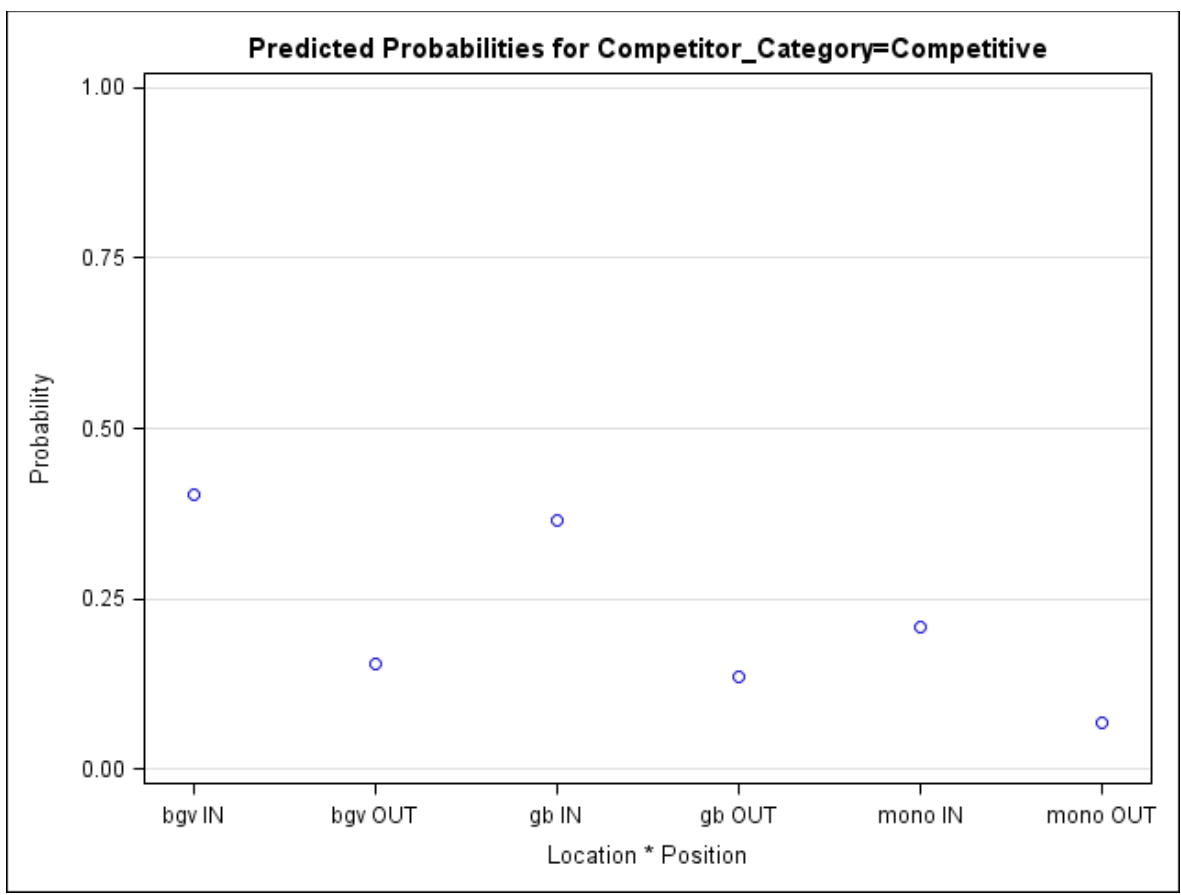

Figure 31. Predicted probabilities for Competitor category $=$ Competitive by position and location. 
There is a highly significant difference than what be expected by chance $(\mathrm{p}=0.0004)$ in the distribution of Competitive INs and OUTS versus the Non-Competitive INs and OUTS. This is clear when inspecting the totals on the bottom of Table 27.

Taken in total these results do offer some insight and support as to what Mealor and Hild (2007) suggested in that native species (S. airoides) may be adapting to coexist with $R$. repens. Furthermore, these results support the supposition that the results of BPS process used, accurately reflects the competitive and non-competitive categories and subsequently can be used to help predict response in further investigative research.

The resulting BSP competitor categories developed are also compared using the same maternal lineages in a germination and root growth experiments. Most of the experiments used in the BSP examined mature plants so germination and root growth experiments were designed to assess the BSP categories as indicators of seedling potential. Thus, the germination and root growth experiments add breadth to the competitive assessment of S. airoides maternal lineages by examining seedling potential.

This assessment compiles a series of experiments using S. airoides competitive response against $R$. repens; competitive effect against $R$. repens and $C$. arvense, and $S$. airoides maternal plant attributes to assess performance of individual maternal lineages from within and outside of invasions. This study developed a BSP to sort and select $S$. airoides maternal lineages that may have increased competitive ability in the face of competition from $R$. repens (competitive response), or that have the competitive ability to suppress $R$. repens or C. arvense (competitive effect). Competitive response in this sense is the ability of an individual (S. airoides) to continue to survive and grow in the presence of invasives ( $R$. repens or $C$. arvense). Competitive effect is the ability of an individual (S. airoides) to reduce growth of $R$. repens or C. arvense (Goldberg and Werner 1983, Miller 1987, Goldberg and Fleetwood 1987). Mealor and Hild (2007) and Leger (2008) have proposed that native species, when exposed to longterm invasions, can undergo natural selection to favor competitive maternal lineages. Individual native grass maternal lineages that are persistent in invaded $R$. repens sites may possess enhanced competitive ability as seedlings and as mature plants. These remnant maternal lineages may therefore be more capable of germination, initial nutrient garnishment, overall growth, and survival when used in revegetation of disturbed areas 
containing exotic populations. The selective pressures of $R$. repens on $S$. airoides should transfer to seed and influence germination and growth of $S$. airoides seedlings in maternal lineages derived from invasions (IN position maternal lineages).

The BSP developed provides a systematic approach to evaluate overall competitive attributes of native grass species and serves to help identify those that are potentially most effective in competing with $R$. repens and C. arvense. 


\section{Conclusions and Implications for Future Research and Implementation}

\subsection{Summary of this research on native plant responses to invasions}

Our research follows previous research that examines interactions of distinct native plant populations with exotic invaders. Mealor et al. (2004) first addressed genetic variability of native plants growing within and outside invasive plant populations. Invaded and non-invaded maternal plants were first collected from field sites by Mealor et al. (2004). Genetic variation of invaded and non-invaded $S$. airoides measured using inter-simple sequence repeat (ISSR) analysis demonstrated that invaded and noninvaded populations of $S$. airoides display genetic differences between the two sub-populations.

Amplified fragment length polymorphisms (AFLPs) were used to evaluate evidence for natural selection within native grass populations (Mealor and Hild 2006). Field experiments conducted following the genetic assays monitored competitive differences between the two sub-populations of $S$. airoides (Mealor and Hild 2007). Invaded S. airoides genets demonstrated higher growth rates than non-invaded genets, suggesting possible resilience of invaded S. airoides sub-populations (Mealor and Hild 2007).

Ferrero-Serrano et al. (2009) compared invaded and non-invaded S. airoides growth with $C$. arvense. This research was unique because it tested $S$. airoides plants collected from $R$. repens invasions against a novel (to the grass) exotic species, $C$. arvense. Invaded $S$. airoides plants showed greater negative impacts on growth of neighbor $C$. arvense, primarily as reduced root biomass (Ferrero-Serrano et al. 2009).

Phenotypic variability of the invaded and non-invaded $S$ airoides lineages has been documented via greenhouse and genetic experiments (Bergum 2009, Bergum et al. 2010). Sporobolus airoides phenology also differs between invasive histories (Bergum et al. 2010). Bartlett (2009) examined invaded and non-invaded seedlings to determine germination and shoot growth using laboratory experiments and noted delayed germination in invaded $S$. airoides seed. 
Sebade (2011) compared invaded and non-invaded $S$. airoides lineages for their ability to tolerate the presence and resist the encroachment of $R$. repens and $C$. arvense in field settings. This research is also unique to invasive species ecology because it targets the resilience of a native species as expressed in two distinct native plant population histories: one with a past exposure to an invasive species and the second lacking invasion history. Results indicate that invaded lineages with NIPS invasion history demonstrate some traits (e.g., less invasion of $R$. repens) that may favor resistance and resilience when competing with $R$ repens.

\subsection{Conclusions and research recommendations}

Non-indigenous invasive plant species can alter ecological functions of native plant communities. Hydraulic, nutrient cycling, and plant community composition are factors that can change from invasive species (Mack et al. 2000). Although individual native grasses can persist in areas where invasive species flourish, native population resistance and resilience may be limited (Mack et al. 2000, D’Antonio and Meyerson 2002). One important process for native species individuals is regeneration to produce subsequent populations that maintain the species.

The term resilience, introduced and used in ecology by Elton (1958) and Holling (1973), is defined as the amount of energy a system can absorb from a perturbation and still return to a stable state (Holling 1973, Gunderson 2000). Resistance is the ability for a population or ecosystem to remain in a similar state after a disturbance (Connell and Sousa 1983, Grandpré and Bergerson 1997, Levine et al. 2004). Grandpré and Bergerson (1997) suggest that resilience should be measured over a longer time period than resistance because resilience is often a measure of long term reproduction and reestablishment of species.

We use both terms in our studies, but applied in a different context than commonly described at the community and ecosystem level (Grimm and Wissel 1997, Gunderson 2000). We use the term resistance to describe the ability of mature individuals within the population to grow and limit the encroachment of invaders. We define resilience as the ability for a plant population to recruit new cohorts in the presence of invaders. Resistant and resilient terms for our study are applied at population rather than community or ecosystem levels. 
Much debate surrounds the appropriate definitions and measurements for resistance and resilience. Incorporating these terms into the context of ecology is important to ecosystem management (Grimm and Wissel 1997). We tested resistance and resilience in our studies in part through above-ground growth of transplanted clones and seed germination and the ability to limit invasive species encroachment and establish in the presence of invaders.

Resistance and resilience are often associated with ecosystem processes; this work examines resistance and resilience of native grass clone populations in the presence of two exotic invaders. Although similar, we deviate from use of these terms as first presented by Elton (1958) and Holling (1973), at the ecosystem and community level, in that we consider populations of a single grass species rather than whole community responses to invaders. We also focus on the concept that native plant populations with a history of competition from invasive species may differ in their resistance and resilience traits from grass populations lacking history of exposure to invaders. Native plant responses to exotic invasions have not been well documented until relatively recently (Grant et al. 2003, Mealor et al. 2004, Callaway 2005, Lau 2006, Strauss et al. 2006, Leger 2008; also this work including Mealor and Hild 2006, Mealor and Hild 2007, Ferrero-Serrano et al. 2006, Ferrero-Serrano et al. 2008, Ferrero-Serrano et al. 2009, Bartlett 2009, Bergum et al. 2010, Sebade et al. 2011). This overall study addresses population resistance and resilience of native grass populations in the context of their past exposure to invaders.

Contemporary evolution may explain the success of some exotic plant invasions. However, the evolutionary response of recipient native plant populations to exotic invasion has received relatively little attention. Because plant populations are genetically variable, contemporary evolution may also occur in native populations following entry of invasive species. Evolution in response to biotic factors (i.e., competition) can present a continuum "of playing the game" rather than "winning." Rhaponticum repens is a novel neighbor to native grass species, and does not share a long coevolutionary history. Thus, native plants persisting inside infestations are subject to different biotic interactions than are their conspecifics in noninvaded areas. It is reasonable to suggest that community transformation by an invasive species should affect the genetic composition of native populations, and that these changes in turn affect morphologic and phenotypic attributes. Rhaponticum repens and C. arvense are highly competitive, found in many western states, and can reproduce via root shoots from ex- 
tensive root systems (Watson 1986, Dock Gustavsson 1997, Mangold et al. 2007). They occur in range, pasture and agricultural areas, are difficult to control, and often increase with cultivation practices (Mangold et al. 2007, Dock Gustavsson 1997). Although R. repens and other NIPS stands in grasslands may appear to be monospecific, native plants persist in old invasions. Given the capacity of $R$. repens (and other NIPS) to alter site conditions, native plants growing within dense stands of $R$. repens are subject to different selective pressures than are conspecifics growing in areas free of the invader. In particular, edaphic factors are especially suited to select for microdifferentiation in plants.

This research hypothesized that native species in R. repens-invaded communities persisted since before invasion and that they have continued to persist for a reason, not simply by chance (Callaway et al. 2005). The genetic, morphological, and plant performance data collected provides an indication that these trait differences between community types relate to increased tolerance of conditions within $R$. repens invasions.

The results of this research provides multiple lines of evidence that maternal lineages of $S$. airoides, and to a lesser degree $H$. comata, collected from within (IN) invaded sites of $R$. repens, differ from maternal lineages collected outside of (OUT) invaded sites. Indications are that these differences translate into differences in competitive ability between IN and OUT populations. Portions of the research also provide evidence that differences in competitive ability toward the knapweed (i.e., $R$. repens) invader may also apply to other exotic invaders, in this instance $C$. arvense. This study also provides evidence of differences in competitive performance of differing IN and OUT genotypes.

This research also developed an effective way to comparatively evaluate the performance of differing and disparate genotypes and to select for the most promising genotypes for further and expanded study evaluation. Evolutionary forces should act on native species once a new environment has been constructed around them in the same way that invasives adapt to new environments. Plant invasions may affect the evolutionary trajectories of native plant populations in ways not previously investigated. More extensive research of native population response to invasions is needed to successfully address potential genetic changes caused by exotic invasion. 
This research documented molecular differences in native populations; portions of the research extended those studies to experimentally evaluate growth of native species in a representative field environment, and in subsequent generations under greenhouse conditions. The overall objective was to attempt to determine if three populations of two native grass species ( $H$. comata and $S$. airoides) demonstrate evidence of contemporary evolution in response to invasion by $R$. repens.

By comparing genetic similarity within and between community types, this study assessed whether observed divergence patterns could be attributed to crossing of community boundaries. Individuals were more similar to one another within community types (vs. between community types), which led to the tentative conclusion that alteration of site characteristics by $R$. repens invasion may be capable of driving divergence in native grass populations. Divergence in the face of significant amounts of gene flow is possible if selective pressure is great enough (see Antonovics and Bradshaw 1970, Al-Hiyaly et al. 1988 for examples). A portion of the overall research sampled mature adult plant material instead of seed, and by doing so, characterized those individuals that have been able to persist within old weed exotic invasions, but may not reflect current levels of gene flow between the sampled communities. Additionally, it must be assumed that the non-invaded communities sampled represent pre-invasion pools of genetic information because it was not possible to sample these communities before invasion. The invasion and dominance of a community by $R$. repens is a rapid event, in evolutionary terms. Thirty five to 70 years is a short time for a grass population to have diverged into two genetically distinct populations even when converted to an invasive plant dominated community. A more direct test of this study's hypothesis would be to sample pre- and post-invasion communities, but logistic restraints (a 70-year waiting period) make such study difficult. However, this should not preclude the initiation and continuance of such long-term studies.

The results of this research provide evidence that invasive species dominance induces selection in native grass populations, but that there may be potential for localized selection between these two communities. The results of this research suggest that native populations can respond to the selective pressure exerted by non-indigenous invasive species (Figure 32). The impacts of invading weeds on native plant populations and their potential use for restoration has not been well documented before this research and is currently poorly understood. 


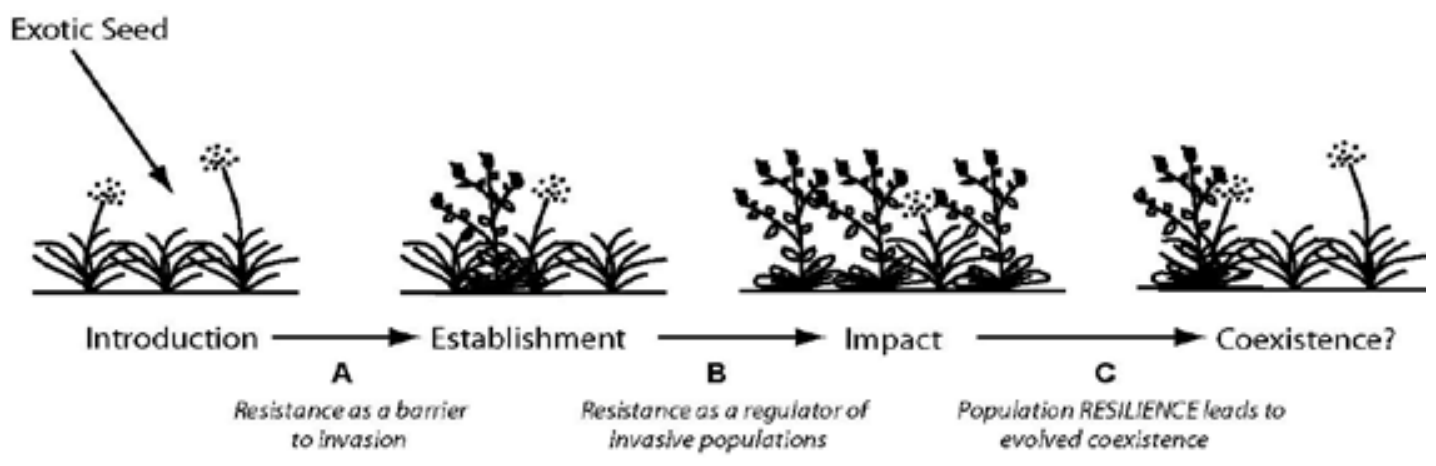

Figure 32. Conceptualized process of native plant response to exotic invasives.

However, native grasses that remain following long-term exposure to invading species seem to better tolerate weed presence than do naive natives. Such invasion "experienced" native plants can be more competitive with invaders, but are often excluded as restoration materials. Excluding native materials within weed-invaded sites may result in the loss of the competitive advantage such exposure elicits within native populations.

In other portions of this research we propagated $S$. airoides for two generations in a greenhouse setting to evaluate gene flow and phenotypic traits while growing in a production environment. Phenotypic expression differed from the first generation to the second generation, predominately in the IN population, which is not favored in native seed production. AFLP methods were used to estimate genetic variation within and among populations, locations, and generations.

Also, seedlings were found to be better response competitors than adult plants (Howard and Goldberg 2001). Thus, future monitoring of initial above- or below-ground growth of experienced (IN) and inexperienced (OUT) maternal lineages (as seedlings) may be an important next step in identifying maternal lineages with strong competitive ability. Knowing how experienced and inexperienced maternal lineages recruit as seedlings when exposed to $R$. repens and $C$. arvense in a field setting would extend the current knowledge of recruitment ability as a competitive trait.

In other portions of this research, invasive species recruitment, and grass seedling germination and establishment were also studied in field environments. In summary, when competing with $R$. repens, and $C$. arvense growth (longest leaf, basal circumference, and tillers) of invaded S. air- 
oides were greater than growth of the non-invaded plants. Future research should examine root growth among $S$. airoides in realistic settings whereby seeds are exposed to gradual temperature changes from day to night as is the case in seed germination and root growth substrate. Future research should also further monitor competition in a field setting between $S$. airoides maternal lineages and C. arvense. It is known that IN maternal lineages studied here showed a consistent positive response when exposed to $R$. repens in field settings (Mealor and Hild 2007), and that $S$. airoides reduces $C$. arvense root biomass when examined in a greenhouse setting (Ferrero-Serrano et al. 2006, Ferrero-Serrano et al. 2008).

Our studies demonstrate that there is differential growth, competitive ability, and genotypic variation in native plants derived from long-established exotic invasions. We now know that native individuals remain within even very dense stands of exotics and that abundance of some native species is reduced inside invasions. Remnant native species that remain within invasions display reduced genotypic variability relative to native populations outside invasions. These "experienced" native plants also grow larger in competition with the invasives than do non-experienced native plants of the same species. Our results give strong suggestion that native species have the resilience to co-evolve alongside exotic invaders over the long-term. Portions of this research were constrained by inherent greenhouse growth conditions. We need to be aware that plant and seed collection of native grass populations will be affected by greenhouse production, so we can avoid restoration failures from incompatible genetic variation and phenotypic traits.

Subsequent research should further examine the behavior of the two populations (IN and OUT) in restoration field settings. Because production environments in greenhouse laboratory settings are optimal, conditions and agronomic techniques could inadvertently select for the phenotypes documented here. It is important to know if traits are genetically linked, or if they are the result of maternal effects or plasticity (Lavergne and Molofsky 2007). Future studies should specifically test the remnant native's plasticity in natural environments under varying conditions (temperature, soil conditions, precipitation, and nutrient availability).

Because the cool season competitor (H. comata) was not as competitive with $C$. arvense, these results agree with the suggestions that, with other factors remaining constant, warm-season plants (e.g., S. airoides) have a competitive advantage over cool season species, which have lower growth 
rates (Black et al.1969). This difference may help explain aspects of structure and function of plant communities and the implications of revegetation with cool- and warm-season species (Waller and Lewis 1979). This evidence should be explored along with investigation of other cool-season grasses such as western wheatgrass (Pascopyrum smithii (Rydb.); syn. Agropyron smithii), intermediate wheatgrass (Thinopyrum intermedium (Host) Barkworth and D.R. Dewey; syn. Agropyron intermedium), Russian wild rye (Psathyrostachys juncea (Fisch.) Nevski; syn. Elymus junceus), or tall fescue (Schedonorus phoenix (Scop.) Holub.; syn. Festuca arundinacea) which is known to be competitive with thistles or other cool season species, the competitive effects of which have been proven against exotics (Wilson and Kachman 1999, Rose et al. 2001). Since H. comata and $S$. airoides are commonly used in restoration, these results present the opportunity to use selected populations to increase native grass resistance to $R$. repens and $C$. arvense. Future research should integrate the notion of selected genotypes into restoration strategies. In general, it seems that the use of experienced warm season grasses would be a strategy that may provide a sound revegetation strategy for control of knapweed and thistle invasions. Future studies should assess the effectiveness of this strategy under field conditions. The conservation of native species populations and the support of native ecosystem processes can combine to serve as a tool to retain important native genetic material.

Revegetation is critical to successfully control of NIPS (Benz et al. 1999, Shaw and Roundy 1997, Whitson 1999). Reseeding with competitive herbaceous species has been effective in limiting the return of $R$. repens, leafy spurge (Euphorbia esula L.), and other invasive species after herbicide treatment (Benz et al. 1999). Yet concern for maintaining native aspect and genetic integrity of native plant communities in grassland ecosystems has limited the species available for replanting after invasive species removal. Additionally, some advocates of native species argue that even use of the same native species from distant sites can be considered detrimental pollution of local gene pools (Jones and Johnson 1998). Ideal revegetation efforts should include local native species that are known to successfully grow and regenerate while limiting the advance of NIPS. Although some isolated individuals of native plants do successfully emerge and establish within weedy populations, these individuals are not often included in wildland seed collections. Collectors commonly focus upon dense stands and avoid isolated natives because they fear inclusion of weed seed contaminants, and because they realize poor returns from collections in scattered 
populations. The ability of isolated native plants to grow in the presence of an exotic species may invoke superior competitive ability, attributed to native individuals' exposure to selective forces associated with the invasive exotic species. The invasive exotic then, may serve as a screening agent in long-invaded sites by retaining remnant natives that are able to grow and reproduce under invaded conditions. Therefore, it is reasonable to suggest that areas of NIPS invasions can be the source of native species genotypes that are vegetatively and reproductively successful in association with the exotic. Thus, the native genotypic pool within remnant individuals maybe more NIPS resilient than are native gene pools in non-invaded sites.

Co-evolution of NIPS and native species is a difficult area of study and requires additional future research and testing (Aarssen et al. 1983, Strauss et al. 2006). Results from this research have real world application to restoration settings. Revegetation of disturbed areas with competitive native plant species instead of non-native species and potentially noncompetitive native genotypes is important to maintain the longevity of biodiversity of desirable plants (Linhart 1995, Mangold et al. 2007). Planting native species with invasive history may augment biodiversity and in turn, increase native ecosystem resistance and resilience to invasion (Kennedy et al. 2002). Outcomes of this research should help us understand the potential benefits derived from use of invaded grass lineages in reclamation plantings.

Ideally, making use of invaded native sub-populations via seed collection will allow development of a more resilient seed source for revegetation of disturbed lands. It is recommended that future investigations include a survey of long-term weed invasions in western military lands to determine the presence of native species remaining within invasions. A massive collection effort of these native remnants should be examined for their success in reseeding efforts following actions to control non-indigenous invasive species. Based on the differences we note here, we conclude that experienced native grass individuals may retain a competitive advantage against their new neighbors. If we work to integrate this facet of native community response to invaders into our understanding of resilience, we may begin to more clearly describe the mechanisms that enhance resilience in native populations. Such mechanisms may be applicable in restoration settings and strengthen our strategies to limit invasion. Additionally, we might consider means for retaining resilient native gene pools and better understand the dynamic nature of native population responses to 
exotics. However, currently, invaded native populations are avoided in restoration for obvious reasons. Seed collections with even a small portion of invasive weed seed contamination is much less marketable, and seed collection within weedy areas enhances the spread of exotic invasive species by providing human and mechanical vectors. Seed from species in the $A s-$ teracea family (both $R$. repens and $C$. arvense) are especially problematic because of their very small seed size. Additionally the history of exotic invasion is seldom documented on wildlands where native seed collections take place making the longevity of weed tolerance by the community unclear. For these reasons, native seed collectors and commercial propagation techniques are unlikely to use invaded populations as sources. Enlisting a dynamic process approach to invasion resistance (e.g., shifting competitive interactions, nutrient cycling, gene flow, and recruitment patterns) could prove to be potentially powerful additions to restoration ecology, although these ideas challenge common perceptions of native populations.

\subsection{Implications for practice}

- Native sources of plant materials are often most desired for restoration but continued disturbance and invasive exotics limit their availability.

- The impacts of invading weeds on native plant populations and their potential use for restoration is poorly understood. However, native grasses that remain following long-term exposure to invading species may better tolerate weed presence than nonexposed natives.

- Such invasion "experienced" native plants can be more competitive with invaders but are often excluded as restoration materials. By excluding native materials within weed-invaded sites, we may lose the competitive advantage such exposure elicits within native populations.

- Native seed collection may be enhanced by including invasionexperienced native plant populations if an accurate invasion history can be documented and the resulting seed collections are carefully cleaned to omit invasive species impurities.

- The native seed production industry can use this research to develop wild seed collection protocols to included remnant native populations (from long-term exotic invasions) and production techniques that ensure competitive traits are not being lost from native accessions. Remnant native plants used to restore degraded areas may also reduce the chances of future exotic invasion. 


\section{Literature Cited}

Aguirre, L., and D. A. Johnson. 1991. Influence of temperature and cheatgrass competition on seedling development of two bunchgrasses. Journal of Range Management 44(4):347-54.

Aldon, E. F. 1981. Long-term plant survival and density data from reclaimed southwestern coal mine spoils. Great Basin Naturalist 41:271-3.

Ang, B. N. 1994. Canada thistle (Cirsium arvense) response to simulated insect defoliation and plant competition. Weed Science 42:403-10.

Applied Biosystems. 2007. AFLP plant mapping protocol. Foster City, CA: PE Corporation.

Aarssen, L. W. 1983. Ecological combining ability and competitive combing ability in plants: Toward a general evolutionary theory of coexistence in systems of competition. The American Naturalist. 122:707-731.

Bacher, S., and F. Schwab. 200o. Effect of herbivore density, timing of attack and plant community on performance of creeping thistle Cirsium arvense (L.) scop. (Asteraceae). Biocontrol Science and Technology 10(3):343-52.

Bais, H. P., R. Vepachedu, S. Gilroy, R. M. Callaway, and J. M. Vivanco. 2003. Allelopathy and exotic plant invasion: From molecules and genes to species interactions Science 301(5638):1377-80.

Bartlett, F. 2009. Selection of alkali sacaton maternal lineages as competitors with Russian knapweed and Canada thistle. Thesis. Laramie, WY: University of Wyoming.

Baskin, C. C., and J. M. Baskin. 2001. Seeds: Ecology, biogeography, and evolution of dormancy and germination. San Diego, CA: Academic Press.

Bazzaz, F. A., N. R. Chiariello, P. D. Coley, and L. F. Pitelka. 1987. Allocating resources to reproduction and defense. Bioscience 37(1):58-67.

Beaumont, M. A., and D. J. Balding. 2004. Identifying adaptive genetic divergence among populations from genome scans. Molecular Ecology 13(4):969-80.

Beaumont, M. A., and R. A. Nichols. 1996. Evaluating loci for use in the genetic analysis of population structure. Proceedings: Biological Sciences 263(1377):1619-26.

Belcher, J. W., P. A. Keddy, and L. Twolan-Strutt. 1995. Root and shoot competition intensity along a soil depth gradient. Journal of Ecology 83(4):673-82.

Belnap, J., R. Reynolds, R. D. Evans, R. Sanford, S. L. Phillips, B. Webb, and M. Reheis. 2004. Exotic annual grasses in western rangelands: Predicting resistance and resilience of native ecosystems to invasion. SERDP Final Technical Report DRAFT CS-1144, http://www.dtic.mil/cgi-bin/GetTRDoc?AD=ADA436874\&Location=U2\&doc=GetTRDoc.pdf 
Benham, J., J. U. Jeung, M. Jasieniuk, V. Kanazin, and T. Blake. 1999. Genographer: A graphical tool for automated fluorescent AFLP and microsatellite analysis. Journal of Agricultural Genomics 4:399.

Benz, L., J. G. Beck, T. D. Whitson, and D. W. Koch. 1999. Reclaiming Russian knapweed infested rangeland. Journal of Range Management. 52:351-356.

Bergum, Karin. 2009. Genetic variation and phenotypic traits of Sporobolus airoides from exotic-invaded and non-invaded areas after two generations of seed increase. MS Thesis. Laramie, WY: University of Wyoming.

Bergum, K. E., A. L. Hild, and B. A. Mealor. 2010. Phenotypes of two generations of Sporobolus airoides seedlings derived from Acroptilon repens invaded and noninvaded grass populations. Restoration Ecology. DOI 10.1111/j.1526100X.2010.00754.x.

Black, C. C., T. M. Chen, and R. H. Brown. 1969. Biochemical basis for plant competition. Weed Science 17(3):338-44.

Blair, A. C., and L. M. Wolfe. 2004. The evolution of an invasive plant: An experimental study with Silene latifolia. Ecology 85(11):3035-42.

Blossey, B., and R. Notzold. 1995. Evolution of increased competitive ability in invasive nonindigenous plants: A hypothesis. Journal of Ecology 83(5):887-9.

Bottoms, R. M., and T. D. Whitson. 1998. A systems approach for the management of Russian knapweed (Centaurea repens). Weed Technology. 12:363-366.

Bowcock, A. M., J. R. Kidd, J. L. Mountain, J. M. Hebert, L. Carotenuto, K. K. Kidd, and L. L. Cavalli-Sforza. 1991. Drift, admixture, and selection in human evolution: A study with DNA polymorphisms. Proceedings of the National Academy of Sciences of the United States of America 88 (3): 839-43.

Boyd, G. W., and D. L. Corkins. 1940. Wyoming weeds and their control. Yoder, WY: Wyoming Extension Service.

Brackie, M., and M. K. Anderson. 2007. Alkali Sacaton plant fact sheet. Contributed by: USDA-NRCS East Plant Materials Center. 2 p. Callaway, R. M., and E. T. Aschehoug. 2000. Invasive plants versus their new and old neighbors: A mechanism for exotic invasion. Science 290(5491):521.

Callaway, R. M., and E. T. Aschehoug. 2000. Invasive plants versus their new and old neighbors: a mechanism for exotic invasion. Science 290:521-523.

Callaway, R. M., and W. M. Ridenour. 2004. Novel weapons: Invasive success and the evolution of increased competitive ability. Frontiers in Ecology and the Environment 2(8):436-43.

Callaway, R. M., W. M. Ridenour, T. Laboski, T. Weir, and J. M. Vivanco. 2005. Natural selection for resistance to the allelopathic effects of invasive plants. Journal of Ecology 93(3):576-83.

Campbell, D., and L. Bernatchez. 2004. Generic scan using AFLP markers as a means to assess the role of directional selection in the divergence of sympatric whitefish ecotypes. Molecular Biology and Evolution 21(5):945-56. 
Casper, B. B., and R. B. Jackson. 1997. Plant competition underground. Annual Review of Ecology and Systematics 28:545-70.

Clauss, M. J., and D. L. Venable. 2000. Seed germination in desert annuals: An empirical test of adaptive bet hedging. American Naturalist 155(2):168-86.

Connell, J. H., and W. P. Sousa. 1983. On the evidence needed to judge ecological stability or persistence. The American Naturalist. 121:789-824

D'Antonio, C. D., and L. A. Meyerson. 2002. Exotic plant species as problems and solutions in ecological restoration: A synthesis. Restoration Ecology, 10:703-713.

DeHaan, L. R., N. J. Ehlke, C. C. Sheaffer, G. J. Muehlbauer, and D. L. Wyse 2003. Illinois bundleflower genetic diversity determined by AFLP analysis. Crop Science 43(4):402-408.

Díaz, O., B. Salomon, and R. V. Bothmer. 1999. Genetic diversity and structure in populations of Elymus caninus (L.) L.(poaceae). Hereditas 131(1):63-74.

Dock Gustavsson, A. M. 1997. Growth and regenerative capacity of plants of Cirsium arvense. Weed Research. 37:229-236.

Doyle, J. J., and J. L. Doyle. 1987. A rapid DNA isolation procedure for small quantities of fresh leaf tissue. Phytochemical Bulletin 19(1):11-5.

Elton, C. S. 1958. The ecology of Invasions by Animals and Plants. London, UK: Methuen.

Excoffier, L., G. Laval, and S. Schneider. 2005. Arlequin (ver. 3.0): An integrated software package for population genetics data analysis. Evolutionary Bioinformatics Online 1:47-50.

Felsenstein, J. 1989. PHYLIP-phylogeny inference package (version 3.2). Cladistics 5(1):164-6.

Fenner, M. 2000. Seeds: The ecology of regeneration in plant communities. $2 \mathrm{~d}$ ed. Wallingford, Oxfordshire, UK: CABI.

Ferdinandez, Y. S. N., B. E. Coulman, and B. E. Fu. 2005. Detecting genetic changes over two generations of seed increase in an awned slender wheatgrass population using AFLP markers. Crop Science 45(3):1064-8.

Ferrero-Serrano, A., T. R. Collier, B. A. Mealor, T. Smith, and A. L. Hild. 2006. Combination of stem-boring weevil and native grasses reduces root biomass of Canada thistle in greenhouse experiment (Wyoming). Ecological Restoration 24(3):201-2. accessed 01/19/2011, http://er.uwpress.org/cgi/reprint/24/3/190.pdf

Ferrero-Serrano, Á., T. R. Collier, A. L. Hild, B. A. Mealor, and T. Smith. 2008. Combined impacts of native grass competition and introduced weevil herbivory on Canada thistle (Cirsium arvense). Rangeland Ecology and Management 61(5):529-34.

Ferrero-Serrano, A., A. L. Hild, and B. A. Mealor. 2009. Can invasive species enhance competitive ability and restoration potential in native grass populations? Restoration Ecology. 18: 1-7 DOI:10.1111/j.1526-100X.2009.00611.x. 
Freeman, C. D., and J. M. Emlen. 1995. Assessment of interspecific interactions in plant communities: An illustration from the cold desert saltbush grasslands of North America. Journal of Arid Environments 31(2):179-98.

Fryxell, P. A. 1957. Mode of reproduction of higher plants. The Botanical Review 23(3):135-233.

Fu, Y. B. F., Y. S. N. Phan, A. T. Coulman, B. Richards, and W. Ken. 2004. AFLP variation in four blue grama seed sources. Crop Science 44(1):283-8.

Galloway, L. F. 2005. Maternal effects provide phenotypic adaptation to local environmental conditions. New Phytologist 166(1):93-100.

Gavrilets, S. 1997. Hybrid zones with Dobzhansky-type epistatic selection. Evolution 51(4):1027-35.

Goldberg, D. E., and L. Fleetwood. 1987. Competitive effect and response in four annual plants. The Journal of Ecology 75(4):1131-43.

Goldberg, D. E., T. Rajaniemi, J. Gurevitch, and A. Stewart-Oaten. 1999. Empirical approaches to quantifying interaction intensity: Competition and facilitation along productivity gradients. Ecology 8o(4):1118-31.

Goldberg, D. E., and P. A. Werner. 1983. Equivalence of competitors in plant communities: A null hypothesis and a field experimental approach. American Journal of Botany 70(7):1098-104.

Goodwin, J. R., P. S. Doescher, I. E. Eddleman, and D. R. Zobel. 1999. Persistence of Idaho fescue on degraded sagebrush-steppe. Journal of Range Management 52:187-198.

Grabe, D. F. 200o. Tetrazolium testing handbook for agricultural seeds. Lincoln, NE: Association of Official Seed Analysts (AOSA), http://openlibrary.org/books/OL16304422M/Tetrazolium testing handbook for agricultural seeds

Grant, V. 1971. Plant speciation. 2d ed. New York: Columbia University Press.

Grant D. W., D. P. C. Peters, G. K. Beck, and H. D. Fraleigh. 2003. Influence of an exotic species, Acroptilon repens (L.) DC. on seedling emergence and growth of native grasses. Plant Ecology. 166: 157-166.Grimm, V., and C. Wissel. 1997. Babel, or the ecological stability discussions: An inventory and analysis of terminology and a guide for avoiding confusion. Oecologia. 109:323-334.

Grandpré, L. D., and Y. Bergeron. 1997. Diversity and stability of understory communities following disturbance in the southern boreal forest. Journal of Ecology. 85:777784 .

Gunderson, L. H. 2000. Ecological resilience - in theory and application. Annual Review of Ecological Systems. 31:425-439.

Gustafson, D. J. 1999. Random amplified polymorphic DNA variation among remnant big bluestem (Andropogon gerardii vitman) populations from Arkansas' grand prairie. Molecular Ecology 8(10):1693-701. 
Gustafson, D. J., D. J. Gibson, and D. L. Nickrent. 2002. Genetic diversity and competitive abilities of Dalea purpurea (Fabaceae) from remnant and restored grasslands. International Journal of Plant Sciences 163(6):979-90.

Hanfling, B., and J. Kollmann. 2002. An evolutionary perspective of biological invasions. Trends in Ecology and Evolution 117:545-546.

Hamdoun, A. 1970. The effects of different levels of nitrogen upon Cirsium arvense (L.) Scop. plants grown from seeds and root fragments. Weed Research 10:121-125.

Hamrick, J. L., and M. J. W. Godt. 1996. Effects of life history traits on genetic diversity in plant species. Philosophical Transactions: Biological Sciences 351(1345):12918.

Harris, G. A. 1967. Some competitive relationships between Agropyron spicatum and Bromus tectorum. Ecological Monographs 37(2):89-111.

Hein, G. L., and R. G. Wilson. 2004. Impact of Ceutorhynchus litura feeding on root carbohydrate levels in Canada thistle (Cirsium arvense). Weed Science 52(4):628-33.

Herms, D. A., and W. J. Mattson. 1992. The dilemma of plants: To grow or defend. Quarterly Review of Biology 67(3):283-335.

Holling, C. S. 1973. Resilience and stability of ecological systems. Annual Review of Ecology and Systematics. 4:1-23.

Howard, T. G., and D. E. Goldberg. 2001. Competitive response hierarchies for germination, growth, and survival and their influence on abundance. Ecology 82(4):979-90.

Huckle, J. M., J. A. Potter, and R. H. Marrs. 2000. Influence of environmental factors on the growth and interactions between salt marsh plants: Effects of salinity, sediment and waterlogging. Journal of Ecology 88(3):492-505.

Hyder, S. Z., and S. Yasmin. 1972. Salt tolerance and cation interaction in alkali sacaton at germination. Journal of Range Management 25(5):390-2.

Johnson, K. A. 2000 . Sporobolus airoides, in "Fire effects information system" (online). in US Department of Agriculture, Forest Service [database online]. Rocky Mountain Research Station, Fire Sciences Laboratory. Accessed 01/15/2011, http://www.fs.fed.us/database/feis/

Jones, T. A., and D. A. Johnson. 1998. Integrating genetic concepts into planning rangeland seedings. Journal of Range Management 51:594-606.

Kennedy, T. A., S. Naeem, K. M. Howe, J. M. H. Knops, D. Tilman, and P. Reich. 2002. Biodiversity as a barrier to ecological invasion. Nature. 417:636-638.

Kilen, T. C., and E. E. Hartwig. 1978. An inheritance study of impermeable seed in soybeans. Field Crops Research 1:65-70.

Knapp, E. E., and K. J. Rice. 1994. Starting from seed: Genetic issues in using native grasses for restoration. Restoration and Management Notes (USA) 12:40-5. 
Knipe, O. D. 1970. Large seeds produce more, better alkali sacaton plants. Journal of Range Management 23(5):369-71.

---. 1967. Influence of temperature on the germination of some range grasses. Journal of Range Management 20(5):298-9.

Lalonde, R. G., and B. D. Roitberg. 1994. Mating system, life-history, and reproduction in Canada thistle (Cirsium arvense; Asteraceae). American Journal of Botany. 81:21-28.

Larson, S. R., E. Cartier, C. L. McCracken, and D. Dyer. 2001a. Mode of reproduction and amplified fragment length polymorphism variation in purple needlegrass (Nassella pulchra): Utilization of natural germplasm sources. Molecular Ecology 10(5):1165-77.

Larson, S. R., B. L. Waldron, S. B. Monsen, L. St. John, A. J. Palazzo, C. L. Mccracken, and R. D. Harrison 2001b. AFLP variation in agamospermous and dioecious bluegrasses of Western North America. Crop Science 41(4):1300-1305.

Larson, S. R., T. A. Jones, and K. B. Jensen. 2004. Population structure in Pseudoroegneria spicata (Poaceae: Triticeae) modeled by bayesian clustering of AFLP genotypes. American Journal of Botany 91(11):1789-801.

Lau, J.A. 2006. Evolutionary responses of native plants to novel community members. Evolution. 60:56-63.

Lavergne, S., and J. Molofsky. 2007. Increased genetic variation and evolutionary potential drive the success of an invasive grass. Proceedings of the National Academy of Sciences 104(10):3883-8.

Leger, E. A. 2008. The adaptive value of remnant native plants in invaded communities: An example from the great basin. Ecological Applications 18(5):1226-35.

Lesica, P., and F. W. Allendorf. 1999. Ecological genetics and the restoration of plant communities: Mix or match? Restoration Ecology 7(1):42-50.

Levine, J. M. 2000. Species diversity and biological invasions: relating local process to community pattern. Science. 288 : 852-854.

Levine, J. M., P. B. Adler, and S. G. Yelenik. 2004. A meta-analysis of biotic resistance to exotic plant invasions. Ecology Letters. 7:975-989.

Linhart, Y. B. 1995. Restoration, revegetation, and the importance of genetic and evolutionary perspective. pp. 271-287 in B. A. Roundy, E.D. McArthur, J.S. Haley, and D.K. Mann (eds.), Proceedings of the Wildland Shrub and Air Restoration Symposium, October 19-21, 1993, Las Vegas, Nevada. General Technical Report INT-GTR-315. Ogden, Utah; USDA Forest Service.

Linhart, Y. B., and M. C. Grant. 1996. Evolutionary significance of local genetic differentiation in plants. Annual Review of Ecology and Systematics 27:237-77.

Lynch, M., and B. G. Milligan. 1994. Analysis of population genetic structure with RAPD markers. Molecular Ecology 3(2):91-9.

MacDougall, A. S., and R. Turkington. 2005. Are invasive species the drivers or passengers of change in degraded systems? Ecology. 86(1):42-55. 
Mack, R. N. 1985. Invading plants: their potential contribution to conservation biology. Studies on Plant Demography: A Festschrift for John L. Harper. New York: Academic Press, pp. 127-142.

Mack, R. N., D. Simberloff, M. W. Lonsdale, H. Evans, M. Clout, and F. A. Bazzaz. 2000. Biotic invasions: causes, epidemiology, global consequences, and control. Ecological Applications. 10. 689-710.

Mangold, J. M., C. L. Poulsen, and M. F. Carpinelli. 2007. Revegetating Russian knapweed (Acroptilon repens) infestations using morphologically diverse species and seedbed preparation. Rangeland Ecology and Management. 60:378-385.

Markham, J. H., and C. P. Chanway. 1996. Measuring plant neighbour effects. Functional Ecology 10(4):548.

McAllister, R. S., and L. C. Haderlie. 1985. Seasonal variations in Canada thistle (Cirsium arvense) root bud growth and root carbohydrate reserves. Weed Science 33(1):44-9.

Mcfarland, M. L., D. N. Ueckert, and S. Hartmann. 1987. Revegetation of oil well reserve pits in west Texas. Journal of Range Management. 40:122-127.

McKane, R. B., D. F. Grigal, and M. P. Russelle. 1990. Spatiotemporal differences in $15 \mathrm{~N}$ uptake and the organization of an old-field plant community. Ecology 71(3):112632.

Mealor, B. A. 2006. Native plant population resilience to exotic invasion. $\mathrm{PhD}$ dissertation. University of Wyoming, Laramie, WY.

Mealor, B. A., and A. L. Hild. 2006. Potential selection in native grass populations by exotic invasion. Molecular Ecology 15(8):2291-300.

- - .2007. Post-invasion evolution of native plant populations: A test of biological resilience. Oikos 116(9):1493-500.

Mealor, B. A., A. L. Hild, and N. L. Shaw. 2004. Native plant community composition and genetic diversity associated with long-term weed invasions. Western North American Naturalist 64(4):503-13.

Melgoza, G., and R. S. Nowak. 1991. Competition between cheatgrass and two native species after fire: Implications from observations and measurements of root distribution. Journal of Range Management 44(1):27-33.

Messing, R. H. and M. G. Wright. 2006. Biological control of invasive species: solution or pollution? Frontiers in Ecology and the Environment. 4: 132-140.

Miller, T. E., and P. A. Werner. 1987. Competitive effects and responses between plant species in a first-year old-field community. Ecology 68(5):1201-10.

Mitich, L. W., B. L. Bohmont, H. P., Alley, and N. E. Harrington. 1962. Bulletin 394: Wyoming's primary noxious weeds. Bulletin 394 .Wyoming Agricultural Experiment Station, Laramie, WY. 
Montagu, K. D., K. Düttmer, C. V. M. Barton, and A. L. Cowie. 2005. Developing general allometric relationships for regional estimates of carbon sequestration--an example using Eucalyptus pilularis from seven contrasting sites. Forest Ecology and Management 204(1):115-29.

Mooney, H. A., and E. E. Cleland. 2001. The evolutionary impact if invasive species. Proceedings of the National Academy of Science 98:5446-5451.

Mueller, I. M., and J. E. Weaver. 1942. Relative drought resistance of seedlings of dominant prairie grasses. Ecology 23(4):387-98.

Mueller, U. G., and L. L. R. Wolfenbarger. 1999. AFLP genotyping and fingerprinting. Trends in Ecology and Evolution 14(10):389-94.

Nadeau, L. B., and W. Vandenborn 1989. The root system of Canada thistle. Canadian Journal of Plant Science 69(4):1199-206. 1990. The effects of supplemental nitrogen on shoot production and root bud dormancy of Canada thistle (Cirsium arvense) under field conditions. Weed Science 38:379-384.

National climatic data center annual climate database (Laramie 2 station) in National Oceanic and Atmospheric Administration (NOAA) [database online]. 2011.Washington, DC: NOAA. Accessed 01/19/2011, http://www4.ncdc.noaa.gov/cgi-win/wwcgi.dll?wwevent storms

Nei, M. 1987. Molecular evolutionary genetics. New York, NY: Columbia Univ Pr.

-- - 1978. Estimation of average heterozygosity and genetic distance from a small number of individuals. Genetics 89(3):583-90.

---. 1973. Analysis of gene diversity in subdivided populations. Proceedings of the National Academy of Sciences of the United States of America 70(12):3321-3.

Novoplansky, A., and D. E. Goldberg. 2001. Effects of water pulsing on individual performance and competitive hierarchies in plants. Journal of Vegetation Science 12(2):199-208.

Odat, N., G. Jetschke, and F. H. Hellwig. 2004. Genetic diversity of Ranunculus acris ( $L$. Ranunculaceae) populations in relation to species diversity and habitat type in grassland communities. Molecular Ecology 13(5):1251-7.

Oksanen, L., M. Sammul, and M. Mägi. 2006. On the indices of plant-plant competition and their pitfalls. Oikos 112(1):149-55.

Page, H. N., and E. W. Bork. 2005. Effect of planting season, bunchgrass species, and neighbor control on the success of transplants for grassland restoration. Restoration Ecology 13(4):651-8.

Peschken, D. P., and J. L. Derby. 1992. Effect of Urophora cardui (L.) (Diptera:Tephritidae) and Ceutorhynchus litura (F.) (Coleopteran: Curculionidae) on the weed Canada thistle, Cirsium arvense (L.) scop. The Canadian Entomologist 124(1):145-50.

Peschken, D. P., and A. T. S. Wilkinson. 1981. Biocontrol of Canada thistle (Cirsium arvense): Releases and effectiveness of Ceutorhynchus litura (Coleoptera: Curculionidae) in Canada. Canadian Entomologist 113(9):777-85. 
Piquot, Y., D. Petit, M. Valero, J. Cuguen, P. de Laguerie, and P. Vernet. 1998. Variation in sexual and asexual reproduction among young and old populations of the perennial macrophyte Sparganium erectum. Oikos 82(1):139-48.

Poorter, H., C. Remkes, and H. Lambers. 1990. Carbon and nitrogen economy of 24 wild species differing in relative growth rate. Plant Physiology 94:621-627.

Poorter, H., and M. Bergkotte. 1992. Chemical composition of 24 wild species differing in relative growth rate. Plant, Cell and Environment 15:221-229.Promega Corp. 2007. Maxwell 16 DNA purification kits. Madison, WI: Promega Corporation.

Retana, J., D. R. Parker, C. Amrhein, and A. L. Page. 1993. Growth and trace element concentrations of five plant species grown in a highly saline soil. Journal of Environmental Quality 22(4):805-11.

Reynolds, J., B. S. Weir, and C. C. Cockerham. 1983. Estimation of the coancestry coefficient: Basis for a short-term genetic distance. Genetics 105(3):767-79.

Roach, D. A., and R. D. Wulff. 1987. Maternal effects in plants. Annual Review of Ecology and Systematics 18:209-35.

Rogers, C. F. 1928. Canada thistle and Russian knapweed and their control. Bulletin 348 ed. Colorado Agricultural College, Colorado Experiment Station.

Rose, K. K., A. L. Hild, T. D. Whitson, D. W. Koch, and L. Van Tassell. 2001. Competitive effects of cool-season grasses on re-establishment of three weed species. Weed Technology 15(4):885-91.

Sabin, D. R. 1935. Wyoming weeds and their control (Circular. no. 33). Wyoming Extension Service.

Sage, R., and R. Pearcy. 1987. The nitrogen use efficiency of C3 and C4 plants: III. Leaf nitrogen effects on the activity of carboxylating enzymes in Chenopodium album (L.) and Amaranthus retroflexus (L.). Plant Physiology 85:355-359.

Sanders, T. B., and J. L. Hamrick. 1980. Variation in the breeding system of elymus canadensis. Evolution 34(1):117-22.

Scott, S. J., and R. A. Williams. 1984. Review of data analysis methods for seed germination. Crop Science 24(6):1192-9.

Seabloom, E. W., W. S. Harpole, O. J. Reichman, and D. Tilman. 2003. Invasion, competitive dominance, and resource use by exotic and native California grassland species. Proceedings of the National Academy of Sciences of the United States of America 100(23):13384-9.

Sebade, B., A. L. Hild, and B. A. Mealor. 2011. Resistance and resilience of Sporobolus airoides from invaded and non-invaded histories transplanted into Acroptilon repens and Cirsium arvense invasion. In prep.

Segura, M., and M. Kanninen. 2005. Allometric models for tree volume and total aboveground biomass in a tropical humid forest in Costa Rica. Biotropica $37(1): 2-8$. 
Shaw, N. L., and B. A. Roundy (comps.). 1997. Proceedings: Using seeds of native species on rangelands. Gen. Tech. Rep. INT-GTR-372. Ogden, UT: US Department of Agriculture, Forest Service, Intermountain Research Station.

Sheley, R. L., L. L. Larson, and D. E. Johnson. 1993. Germination and root dynamics of range weeds and forage species. Weed Technology 7(1):234-7.

Simanton, J. R., and G. L. Jordan. 1986. Early root and shoot elongation of selected warm-season perennial grasses. Journal of Range Management 39(1):63-7.

Skinner, K., L. Smith, and P. Rice. 2000. Using noxious weed lists to prioritize targets for developing weed management strategies. Weed Science. 48:640-644.

Smith, S. E. 1998. Variation in response to defoliation between populations of Bouteloua curtipendula var. caespitosa (Poaceae) with different livestock grazing histories. American Journal of Botany 85(9):1266-79.

Strauss, S. Y., J. A. Lau, and S. P. Carroll. 2006. Evolutionary responses of natives to introduced species: What do introductions tell us about natural communities? Ecology Letters. 9:357-374.

Stermitz, F. R., H. P. Bais, T. A. Foderaro, and J. M. Vivanco. 2003. 7,8-Benzoflavone: a phytotoxin from root exudates of invasive Russian knapweed. Phytochemistry. 64(2):493-497.

Stermitz, F. R., H. P. Bais, T. A. Foderaro, and J. M. Vivanco. 2009. Retraction notice to 7,8-Benzoflavone: a phytotoxin from root exudates of invasive Russian knapweed. Phytochemistry. 70(1):209.

Thompson, K., J. G. Hodgson, and T. O. G. Rich. 1995. Native and alien invasive plants: More of the same? Ecography 18:390-402.

Tilman, D. 1987. Secondary succession and the pattern of plant dominance along experimental nitrogen gradients. Ecological Monographs 57:189-214.

US Department of Agriculture (USDA). 2011. National invasive species information center, www.invasivespeciesinfo.gov/plants/main/shtml

Vekemans, X. 2002. AFLP-surv version 1.o. Distributed by the author. Université Libre de Bruxelles, Belgium: Laboratoire de Génétique et Ecologie Végétale.

Vos, P., R. Hogers, M. Bleeker, M. Reijans, T. Lee, M. Hornes, A. Friters, J. Pot, J. Paleman, and M. Kuiper. 1995. AFLP: A new technique for DNA fingerprinting. Nucleic Acids Research 23(21):4407-14.

Waller, S. S., and J. K. Lewis. 1979. Occurrence of $\mathrm{C}_{3}$ and $\mathrm{C}_{4}$ photosynthetic pathways in North American grasses. Journal of Range Management 32(1):12-28.

Watson, A. K. 1986. Biology of Subanguina picridis, a potential biological control agent of Russian knapweed. Journal of Nematology. 18:149-154.

Weigelt, A., and P. Jolliffe. 2003. Indices of plant competition. Journal of Ecology 91(5):707-20. 
Whitson, T. D., L. C. Burrill, S. A. Dewey, D. W. Cudney, B. E. Nelson, R. D. Lee, and R. Parker. 1992. Weeds of the west. Jackson, WY: Western Society Weed Science. . 1999. Russian knapweed. In R. L. Sheley and J .K. Petroff, eds. Biology and Management of Noxious Rangeland Weeds. Corvallis, OR: Oregon State University Press.

Wilding, C. S., R. K. Butlin, and J. Grahame. 2001. Differential gene exchange between parapatric morphs of littorina saxatilis detected using AFLP markers. Journal of Evolutionary Biology 14(4):611-9.

Wilson, R. G., and S. D. Kachman. 1999. Effect of perennial grasses on Canada thistle (Cirsium arvense) control. Weed Technology 13:83-7.

Wright, S. 1943. Isolation by distance. Genetics 28(2):114.

Yan, X. B., Y. X. Guo, F. Y. Liu, C. Zhao, Q. L. Liu, and B. R. Lu. 2010. Population structure affected by excess gene flow in self-pollinating Elymus nutans and $E$. burchan-buddae (Triticeae: Poaceae). Population Ecology 52(1):233-41.

Yeh, F. C., R. C. Yang, T. B. J. Boyle, Z. H. Ye, and J. X. Mao. 1997. POPGENE, the userfriendly shareware for population genetic analysis. Molecular Biology and Biotechnology Centre. University of Alberta, Edmonton, Alberta, Canada.

Zhivotovsky, L. A. 1999. Estimating population structure in diploids with multilocus dominant DNA markers. Molecular Ecology 8(6):907-13.

Ziska, L. 2003. The impact of nitrogen supply on the potential response of a noxious, invasive weed, Canada thistle (Cirsium arvense) to recent increases in atmospheric carbon dioxide. Physiologia Plantarum 119:105-112.

Zlatnik, E. 1999. Hesperostipa comata. In Fire effects information system. Missoula. MT: US Department of Agriculture, Forest Service, Rocky Mountain Research Station, Fire Sciences Laboratory.

Zwölfer, H., and P. Harris. 1966. Ceutorhynchus litura (F.) (Col. Curculionidae), a potential insect for the biological control of thistle, Cirsium arvense (L.) scop., in Canada. Canadian Journal of Zoology 44(1):23-38. 


\section{Acronyms and Abbreviations}

\begin{tabular}{|c|c|}
\hline Term & Spellout \\
\hline AFLP & amplified fragment length polymorphism \\
\hline AMOVA & Analysis of molecular variance \\
\hline ANCOVA & analysis of covariance \\
\hline ANOVA & Analysis of Variance \\
\hline ANSI & American National Standards Institute \\
\hline AOSA & Association of Official Seed Analysts \\
\hline BSP & Biological Screening Process \\
\hline CERL & Construction Engineering Research Laboratory \\
\hline $\mathrm{Cl}$ & Confidence Interval \\
\hline $\mathrm{CR}$ & Competitive Response \\
\hline CRBD & Completely Randomized Block Design \\
\hline $\mathrm{CRCl}$ & Corrected Relative Competition Index \\
\hline DNA & deoxyribonucleic acid \\
\hline DoD & US Department of Defense \\
\hline $\mathrm{ER}$ & Engineer Regulation \\
\hline ERDC & Engineer Research and Development Center \\
\hline ERDC-CERL & $\begin{array}{l}\text { Engineer Research and Development Center, Construction Engineering Re- } \\
\text { search Laboratory }\end{array}$ \\
\hline ESL & Environmental Simulation Laboratory \\
\hline ESTCP & Environmental Security Technology Certification Program \\
\hline HSD & Honestly Significant Difference \\
\hline ISSR & Inter-Simple Sequence Repeat \\
\hline LSD & least significant difference \\
\hline MANOVA & ANOVA; time measured on an ordinal scale \\
\hline $\mathrm{N} / \mathrm{A}$ & not applicable \\
\hline $\mathrm{NCDC}$ & National Climatic Data Center \\
\hline NIPS & non-indigenous invasive plant species \\
\hline $\mathrm{NS}$ & loci not linked to genes under selection \\
\hline OMB & Office of Management and Budget \\
\hline PVC & polyvinyl chloride \\
\hline QTL & Quantitative Trait Locus \\
\hline $\mathrm{RCl}$ & Relative Competitive Intensity \\
\hline $\mathrm{RH}$ & relative humidity \\
\hline RNE & Relative Neighbor Effect \\
\hline ROX & rhodamine $X$ \\
\hline $\mathrm{RV}$ & Riverton \\
\hline SA & Supply Air \\
\hline
\end{tabular}




$\begin{array}{ll}\text { Term } & \text { Spellout } \\ \text { SAS } & \text { Statistical Analysis Software } \\ \text { SE } & \text { Standard Error } \\ \text { SERDP } & \text { Strategic Environmental Research and Development Program } \\ \text { SL } & \text { loci potentially linked to selection } \\ \text { SLA } & \text { Specific Leaf Area } \\ \text { SON } & \text { Statement of Need } \\ \text { SPSS } & \text { Statistical Package for the Social Sciences } \\ \text { SRM } & \text { Sustainment, Restoration, and Modernization } \\ \text { TDR } & \text { Time Domain Refractory } \\ \text { TR } & \text { Technical Report } \\ \text { TTC } & \text { 2, 3, 5-triphenyl tetrazolium chloride } \\ \text { TZ } & \text { Tetrazolium } \\ \text { UK } & \text { United Kingdom } \\ \text { USA } & \text { United States of America } \\ \text { USC } & \text { United States Code } \\ \text { USDA } & \text { US Department of Agriculture } \\ \text { UW } & \text { University of Wyoming }\end{array}$




\section{Appendix A: List of Scientific and Technical Publications}

\section{Articles in peer-reviewed journals}

Bergum, K. E., A. L. Hild, and B. A. Mealor. 2010. Phenotypes of two generations of Sporobolus airoides seedlings derived from Acroptilon repens invaded and noninvaded grass populations. Restoration Ecology. Doi 10.1111/j.1526100X.2010.00754.\%.

Ferrero-Serrano, A., T. R. Collier, B. A. Mealor, T. Smith, and A. L. Hild. 2006. Combination of stem-boring weevil and native grasses reduces root biomass of Canada thistle in greenhouse experiment. Ecological Restoration 24 (3):201-202. Invited.

Ferrero-Serrano, A., T. R. Collier, A. L. Hild, B. A. Mealor, and T. Smith. 2008. Combined impacts of native grass competition and introduced weevil herbivory on Canada thistle (Cirsium arvense). Rangeland Ecology and Management 61(5):529-534.

Ferrero-Serrano, A., A. L. Hild, and B. A Mealor. 2010. Can invasive species enhance competitive ability and restoration potential in native grass populations?

Restoration Ecology 18:1-7.

Mealor, B. A., and A. L. Hild. 2007. Post-invasion evolution of native plant populations: A test of biological resilience. Oikos 116 (9):1493-1500.

Tyrer, S., A. L. Hild, B. A. Mealor, and L. Munn. 2007. Properties of soils from Russian knapweed (Acroptilon repens) invasions and associated impacts on establishment of native species. Rangeland Ecology and Management 6o(6):604612.

\section{Conference and symposium proceedings}

Bergum, K. E., A. L. Hild, B. A. Mealor, and T. Smith. 2008. Genetic variation within genotypes of two native grass species after two generations of greenhouse seed source improvement. Joint meeting of the American Forage and Grassland Council and the Society for Range Management Annual Meeting, January 26-31, Lexington, KY. Poster.

Bergum, K. E., A. L. Hild, and B. A. Mealor. 2009. After invasion: Genetic and phenotypic variation of remnant natives in greenhouse production. International Meeting of the Society for Range Management. February 8-13, Albuquerque, NM. Paper.

Bartlett, F., A. L. Hild, B. A. Mealor, and T. Smith. 2008. Methods to select promising native grass genotypes as competitors with introduced invasive weed species. Joint meeting; American Forage and Grassland Council and the Society for Range Management Annual Meeting. January 26-31, Lexington, KY. Poster. 
Bartlett, F., A. L. Hild, B. A. Mealor, and T. Smith. 2008. Selection of Alkali sacaton genotypes as competitors with Russian knapweed and Canada thistle. SERDPESTCP Partners in Environmental Technology Technical Symposium \& Workshop. December 2-4, Washington, DC. Poster.

Bartlett, F. P., A. L. Hild, K. E. Bergum, B. A. Mealor, and T. Smith. 2009. Assessing competitiveness of Alkali sacaton genotypes exposed to invasive weeds. International Meeting of the Society for Range Management, February 8-13, Albuquerque, NM. Paper.

Bartlett, F., A. Hild, K. Bergum, B. Mealor, and T. Smith. 2009. Selecting promising native grass genotypes as competitors with invasive weeds. US Army Engineer Research and Development Center Science Conference. November 16 - 20, Memphis, TN. Poster.

Bartlett, F. A., A. L. Hild, K. E. Bergum, B. A. Mealor, and T. Smith. 2011. Selecting promising native grass species as competitors with non-indigenous invasive weeds. Sustainable Military Readiness Conference, July 25-29, Nashville, TN. Poster.

Ferrero-Serrano, A., A. L. Hild, T. Collier, S. Enloe, and S. Miller. 2005. Synergy of competitive native plants and a stem-boring weevil (Ceutorhynchus litura) for control of Canada thistle (Cirsium arvense), and invasive weed. UW Graduate Student Symposium, April 4-5, Laramie, WY. Paper.

Ferrero-Serrano, A., A. L. Hild, T. Smith, B. Mealor, T. Collier, S. Enloe, and S. Miller. 2005. Synergistic action of competitive native plants and a stem boring weevil (Ceutorhynchus litura) for control of Canada thistle (Cirsium arvense), an invasive weed. SERDP-ESTCP Partners in Environmental Technology Technical Symposium \& Workshop. November 29-December 1, Washington DC. Poster.

Ferrero-Serrano, A., A. L. Hild, B. Mealor, T. Collier, S. Enloe, S. Miller, and T. Smith. 2006. Synergistic action of competitive native plants and a stem-boring weevil for control of Canada thistle. Society for Range Management International Meeting, February 13-17, Vancouver, B.C. Poster.

Ferrero-Serrano, A., A. L. Hild, B. A. Mealor, T. R. Collier, S. F. Enloe, and S. D. Miller. 2006. Do combined actions of a stem-boring weevil and competition from native grasses form a synergistic weed control of Canada thistle? UW Graduate Student Symposium. April 3-4. Laramie, WY. Paper.

Ferraro-Serrano, A., T. Smith, B.A. Mealor, T. Collier, S. Enloe, S. Miller, and A.L. Hild. 2006. Combined action of a stem-boring weevil and native grass competition for control of Canada thistle (Cirsium arvense). NatureServe Leadership Conference Proceedings. April 24-26, Baltimore, MD. Poster.

Ferrero-Serrano, A., T. Smith, B. A. Mealor, T. Collier, S. Enloe, S.D. Miller, and A.L. Hild. 2007. Combined action of a stem-boring weevil and native grass competition for control of Canada thistle. Sustainable Military Readiness Conference, July 30-August 3, Orlando, FL. Poster. 
Ferrero-Serrano, A., T. R. Collier, B. A. Mealor, A. L. Hild, and T. Smith. 2007. Integrated application of biocontrol and native species for invasive plant control: Implications for restoration ecology. International Phytotechnologies Conference. Proceedings of the International Phytotechnology Society, September 24-26, Denver, CO. Paper.

Ferrero-Serrano, A., T. R. Collier, A. L. Hild, B. A. Mealor, and T. Smith. 2007. Potential control of Canada thistle through integrated use of biocontrol and native grass species. Proceedings of the American Society of Agronomy, November 4-9, New Orleans, LA. Paper.

Hild, A. L., F. Bartlett, K. Bergum, and T. Smith. 2007. Selecting promising native grass genotypes for competitive interactions with exotic species. SERDP -ESTCP Partners in Environmental Technology Technical Symposium \& Workshop. December 4-6, Washington, DC. Poster.

Hild, A., B. Sebade, B. Mealor, and T. Smith. 2009. Resistance and resilience of native grasses competing with exotic invaders. SERDP-ESTCP Partners in Environmental Technology Technical Symposium \& Workshop. December 1-3, Washington, DC. Poster.

Hild, A., K. Bergum, B. Mealor, and T. Smith. 2009. Genetic integrity of two generations of propagules from exotic-invaded and non-invaded plant populations. SERDPESTCP Partners in Environmental Technology Technical Symposium \& Workshop. December 1-3, Washington, DC. Poster.

Mealor, B., and A. L. Hild. 2006. There goes the neighborhood-or does it? International Meeting of the Society for Range Management. February 13-17, Vancouver, B.C. Society for Range Management National Graduate Student Competition, 2d place. Poster.

Mealor, B. A., and A. L. Hild. 2006. Native plant population resilience to exotic invasion. UW Graduate Student Symposium. April 3-4, Laramie, WY. Paper.

Sebade, B., and A. L. Hild. 2009. Resistance and resilience of native grasses competing with exotic invaders. UW Graduate Student Symposium April 6-7, Laramie, WY. Poster.

Sebade, B., A. Hild, B. Mealor, and T. Smith. 2010. Resistance of native grasses from invaded and non-invaded sites transplanted into weed invasions. Joint Meeting American Forage and Grassland Council and the Society for Range Management. 7-11 Feb, Denver, CO. Poster.

Sebade, B., A. Hild, B. Mealor, and T. Smith. 2011. Competition of native grasses from invasion transplanted into Russian knapweed and Canada Thistle., International Meeting of the Society for Range Management. February 6-10, Billings, MT. Paper.

Smith, T., B.A. Mealor, A. Ferraro-Serrano, A.L. Hild, and T.R. Collier. 2006. Evaluation of selected native plant populations for competition against exotic weeds. SERDP-ESTCP Partners in Environmental Technology Technical Symposium \& Workshop. Nov. 28-30, Washington, DC. Poster. 
Smith, T., B.A. Mealor, A. Ferraro-Serrano, A.L. Hild, and T.R. Collier. 2007. Selection of promising genotypes for restoration of military lands. SERDP-ESTCP Partners in Environmental Technology Technical Symposium \& Workshop. December. 4-6, Washington, DC. Poster.

Tyrer, S. J., A. L. Hild, L. C. Munn, and S. F. Enloe. 2005. Do soils from knapweed invasions limit germination of native forbs or shrubs? UW Graduate Student Symposium. April 4-5, Laramie, WY. Paper.

Tyrer, S. J., and A. L. Hild. 2005. Native forb and shrub seedling establishment in Russian knapweed (Acroptilon repens (L). D.C) dominated soils. International Meeting of the Society for Range Management. February 5-11, Fort Worth, TX. Paper.

Tyrer, S., A. L. Hild, L. Munn, B. Mealor, and S. Enloe. 2006. Soil chemical changes associated with Russian knapweed invasions. International Meeting of the Society for Range Management. February 13-17, Vancouver, B.C. Poster. 


\section{Appendix B: Other Supporting Materials: Patents, Protocols, Scientific Awards or Honors Graduate Students and Post-Doctoral Researchers Educated on this Project}

Bergum, Karin. M.S., Rangeland Ecology and Watershed Management. December 2009. Genetic variation and phenotypic traits of Sporobolus airoides from exoticinvaded and non-invaded areas after two generations of seed increase. Thesis. University of Wyoming, Laramie, WY.

Bartlett, Franklin. M S., Rangeland Ecology and Watershed Management. May 2009. Selection of alkalai sacaton genotypes as competitors with Russian knapweed and Canada thistle. Thesis. University of Wyoming, Laramie, WY.

Ferrero-Serrano, Angel. M.S. Rangeland Ecology and Watershed Management. August 2006. Use of native grass species and a stem boring weevil for control of Canada thistle. Thesis. University of Wyoming, Laramie, WY. Currently: Doctoral candidate, Population and Evolutionary Biology, University of Liverpool, Liverpool, UK.

Mealor, Brian A. Ph.D. August 2006. Native plant population resilience to exotic invasion. Dissertation. University of Wyoming, Laramie, WY.

Sebade, Brian. M.S. Rangeland Ecology and Watershed Management. December 2010. Sporobolus ariroides population resistance in competition with two exotic perennial herbs. Thesis. University of Wyoming, Laramie, WY. 


\section{Appendix C: Technology Transfer}

In addition to cooperation from public and private landowners In Wyoming, Idaho, and Colorado, the project involved demonstration plantings at F.E. Warren AFB, Cheyenne, WY and on lands owned by The Nature Conservancy near Lander, WY. The project results have been communicated via paper and poster presentations at more than 20 national and international professional meetings. Publications from the project continue to be developed, with three currently in prep, and six already published in peerreviewed scientific journals. The research has allowed training of five graduate students or post-doctoral research assistants. Results were also communicated at the National Invasive Species Awareness Week in Washington DC in January 2010; at the International Phytotechnology Conference in Denver, CO in September 2007; at the Meeting of the American Society of Agronomy, in New Orleans, LA, November 2007; at the International Meetings of the Society for Range Management in Ft. Worth, TX, Vancouver, BC, Lexington, KY, Albuquerque, NM, Denver, CO, and Billings, MT in January and February 2005. 2006, 2008, 2010, and 2011; at the Sustainable Military Readiness Conferences in Orlando, FL in August 2007, and in Nashville, TN in 2011, and at other scientific conferences. The final graduate student working on this project graduated in the last quarter of 2010.

The native seed production industry can use this research to develop wild seed collection protocols to included remnant native populations (from long-term exotic invasions) and production techniques that ensure competitive traits are not being lost from native accessions. Remnant native plants used to restore degraded areas may also reduce the chances of future exotic invasion. 